\title{
Streamlined Catalytic Enantioselective Synthesis of $\alpha$-Substituted $\beta, \gamma$-Unsaturated Ketones and Either of the Corresponding Tertiary Homoallylic Alcohol Diastereomers
}

\author{
Juan del Pozo, ${ }^{1}$ Shaochen Zhang, ${ }^{1}$ Filippo Romiti, ${ }^{1,2}$ Shibo Xu, ${ }^{1}$ Ryan P. Conger ${ }^{1}$ and Amir H. Hoveyda ${ }^{1,2}$ \\ ${ }^{1}$ Department of Chemistry, Merkert Chemistry Center, Boston College, Chestnut Hill, Massachusetts 02467, \\ USA \\ ${ }^{2}$ Supramolecular Science and Engineering Institute, University of Strasbourg, CNRS, 67000 Strasbourg, France \\ e-mail: amir.hoveyda@bc.edu or ahoveyda@unistra.fr
}

\section{SUPPORTING INFORMATION \\ PART TWO: NMr SPECTRA}

\section{Table of Content}

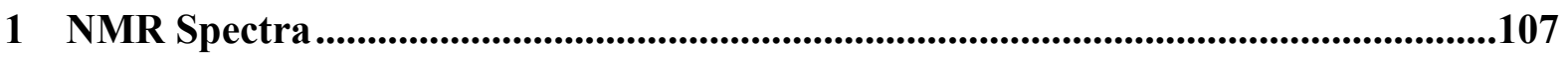

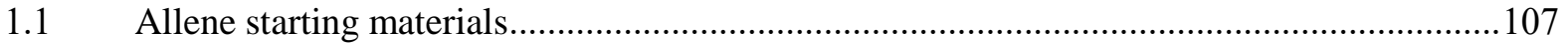

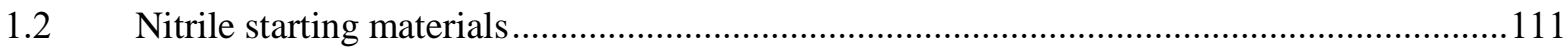

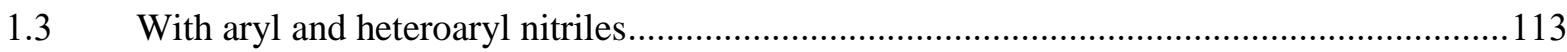

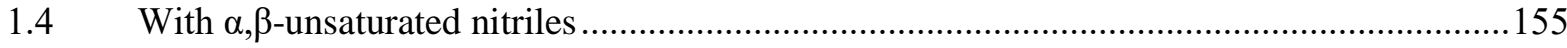

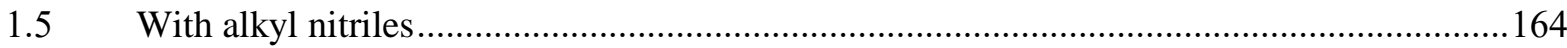

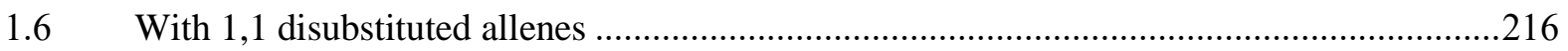

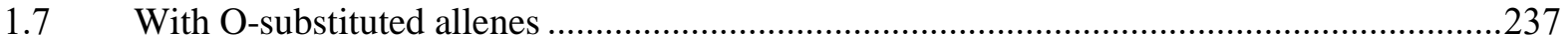

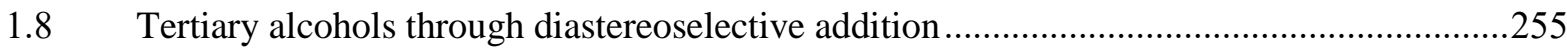

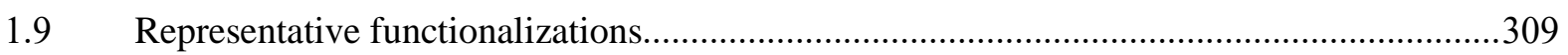

1.10 Synthesis of the Bicyclic Fragments of (+)-Rubriflordilactone A and B …...........................327

1.11 Synthesis of bicyclic fragment of 5-epi-rubriflordilactone A and B ...................................339

1.12 Determination of the absolute and relative configuration of products ..................................345 
Del Pozo, et al., Supplementary Materials; Page 107

$1 \quad$ NMR Spectra

1.1 Ilene starting materials

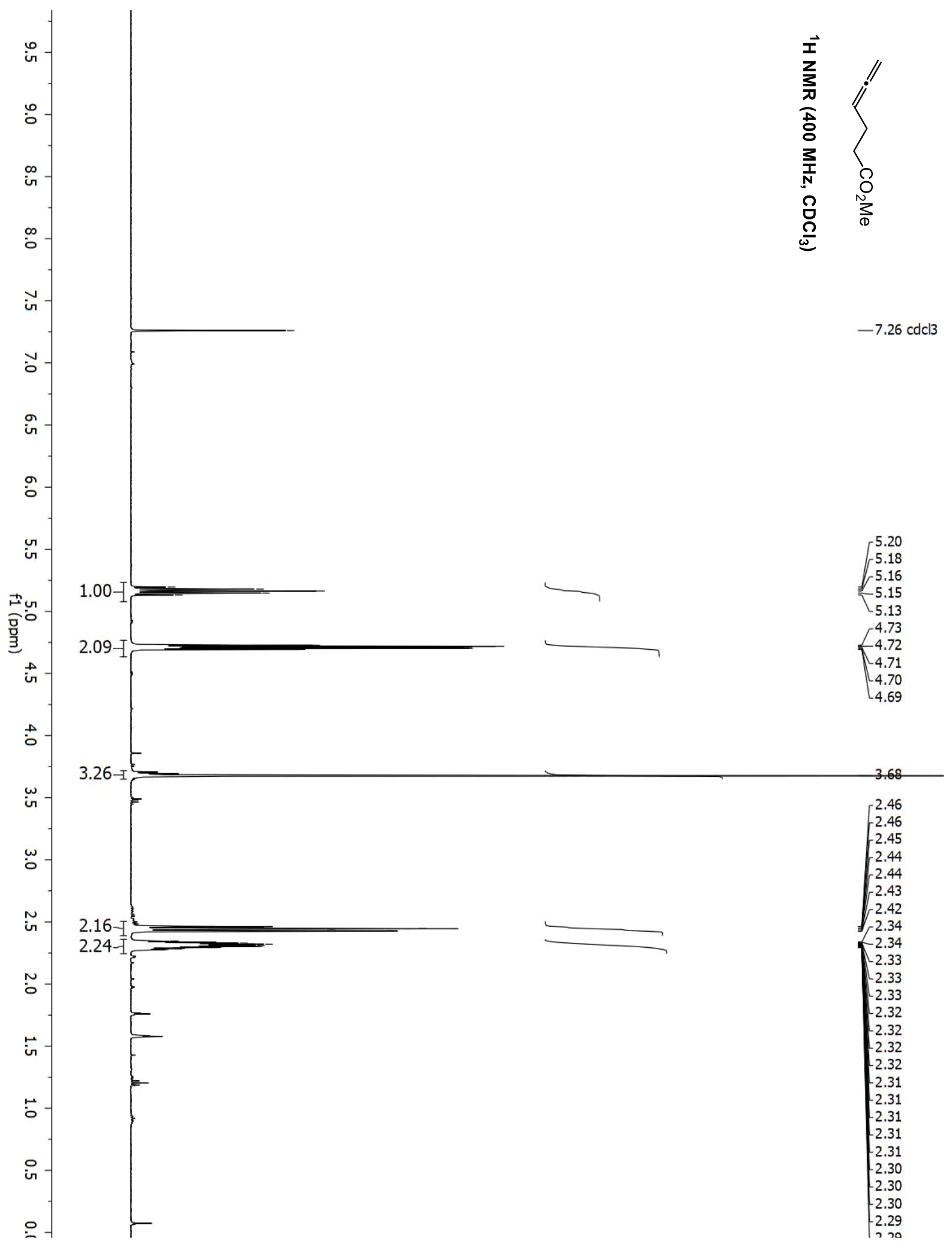




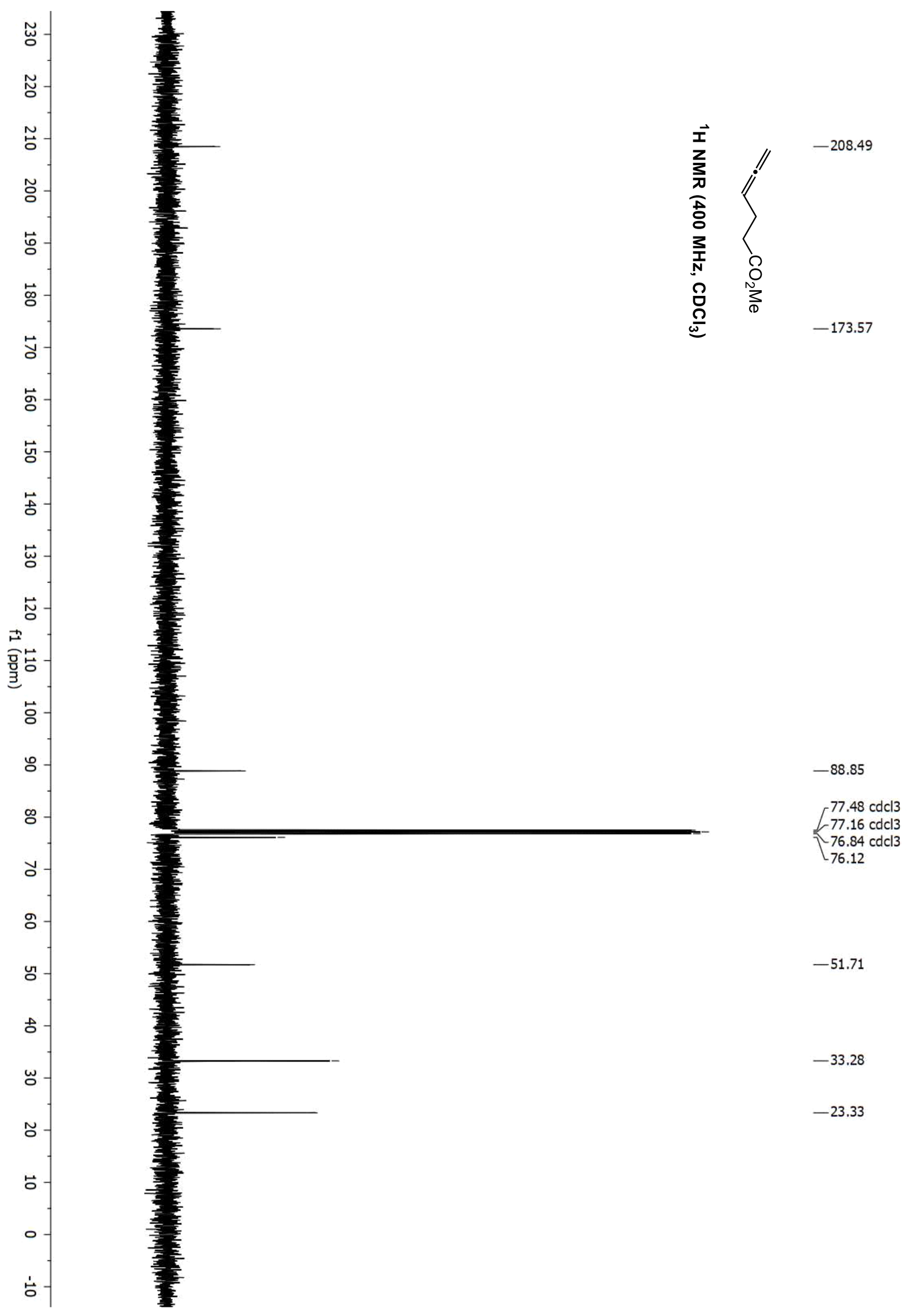




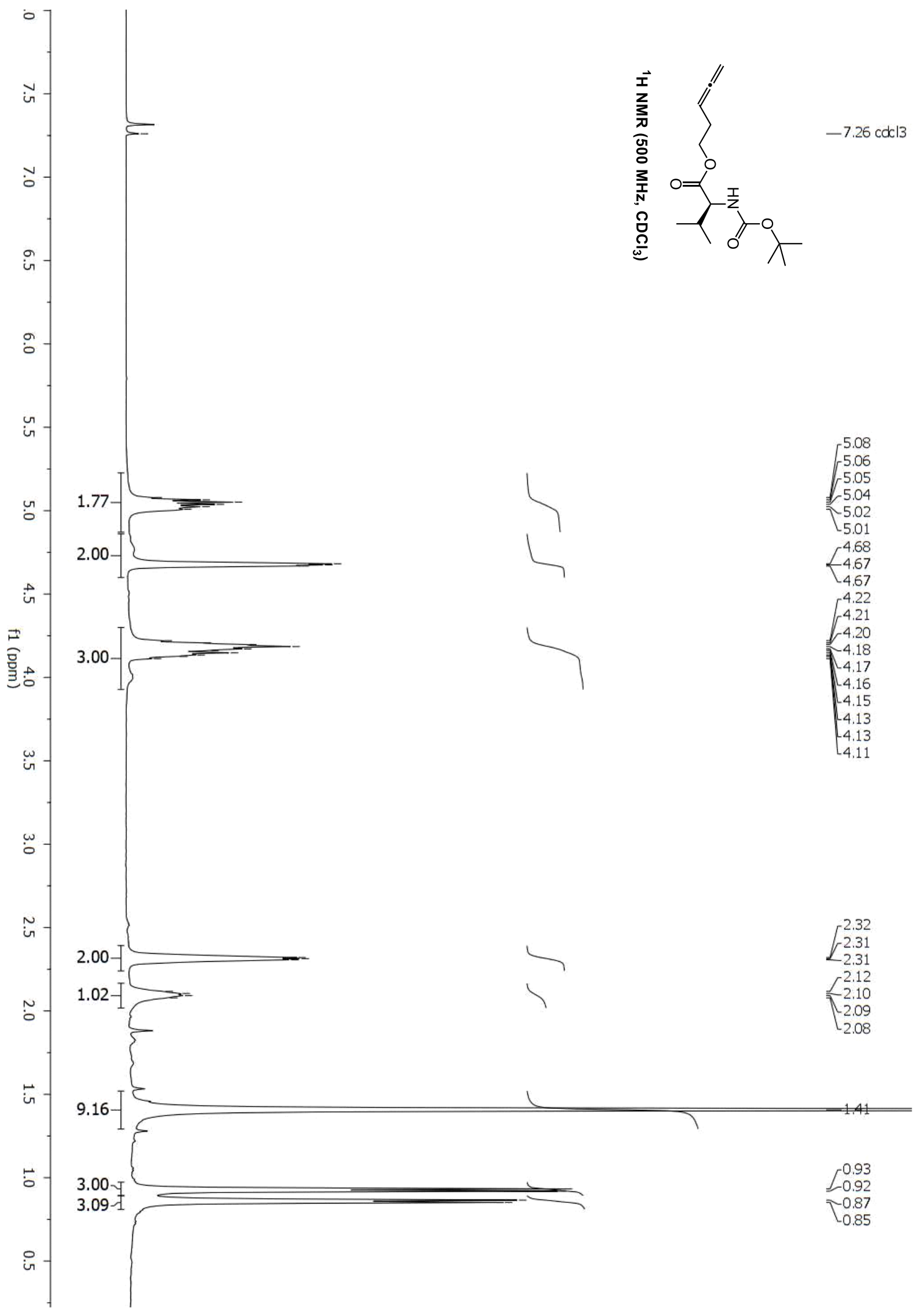




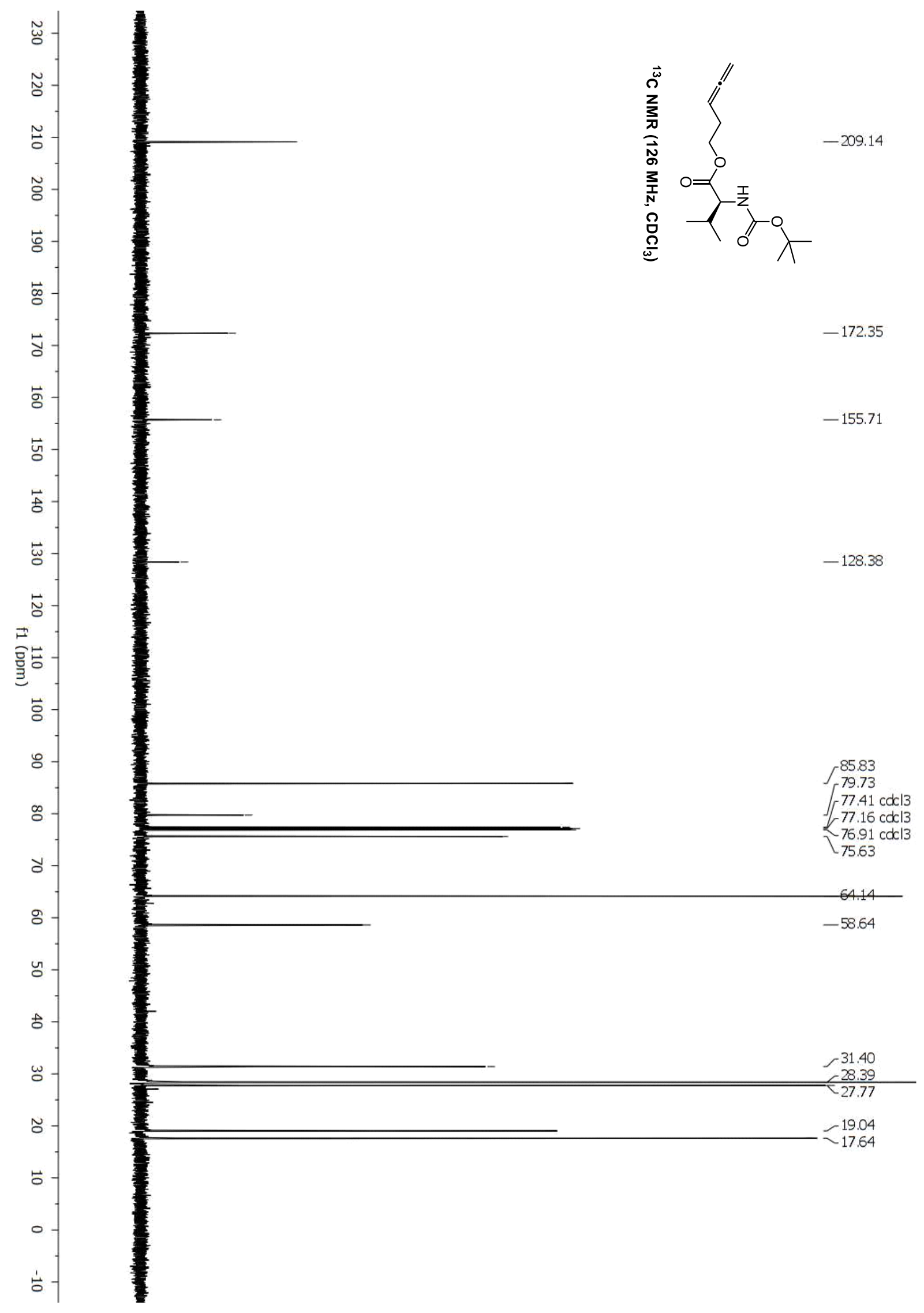




\subsection{Nitrile starting materials}

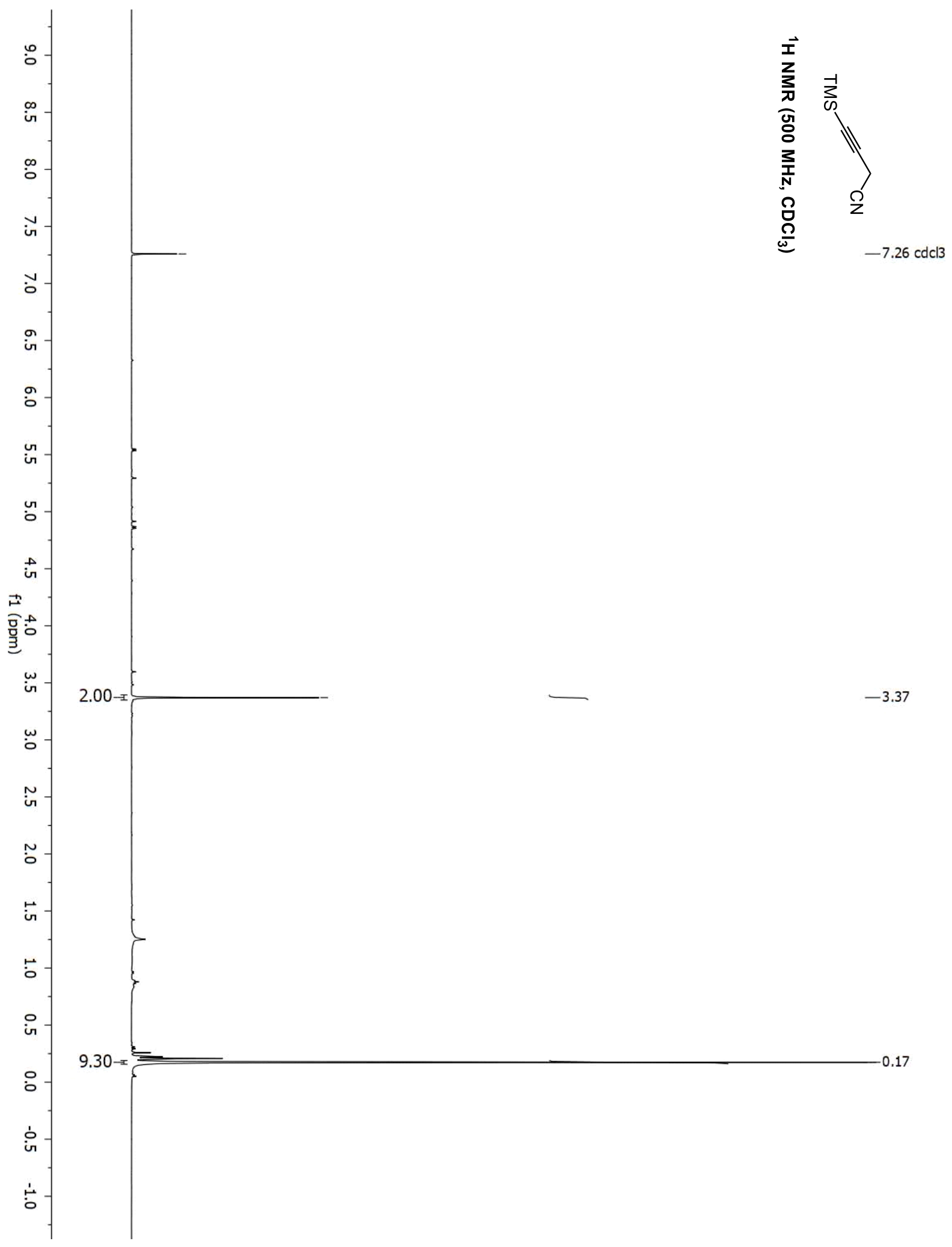




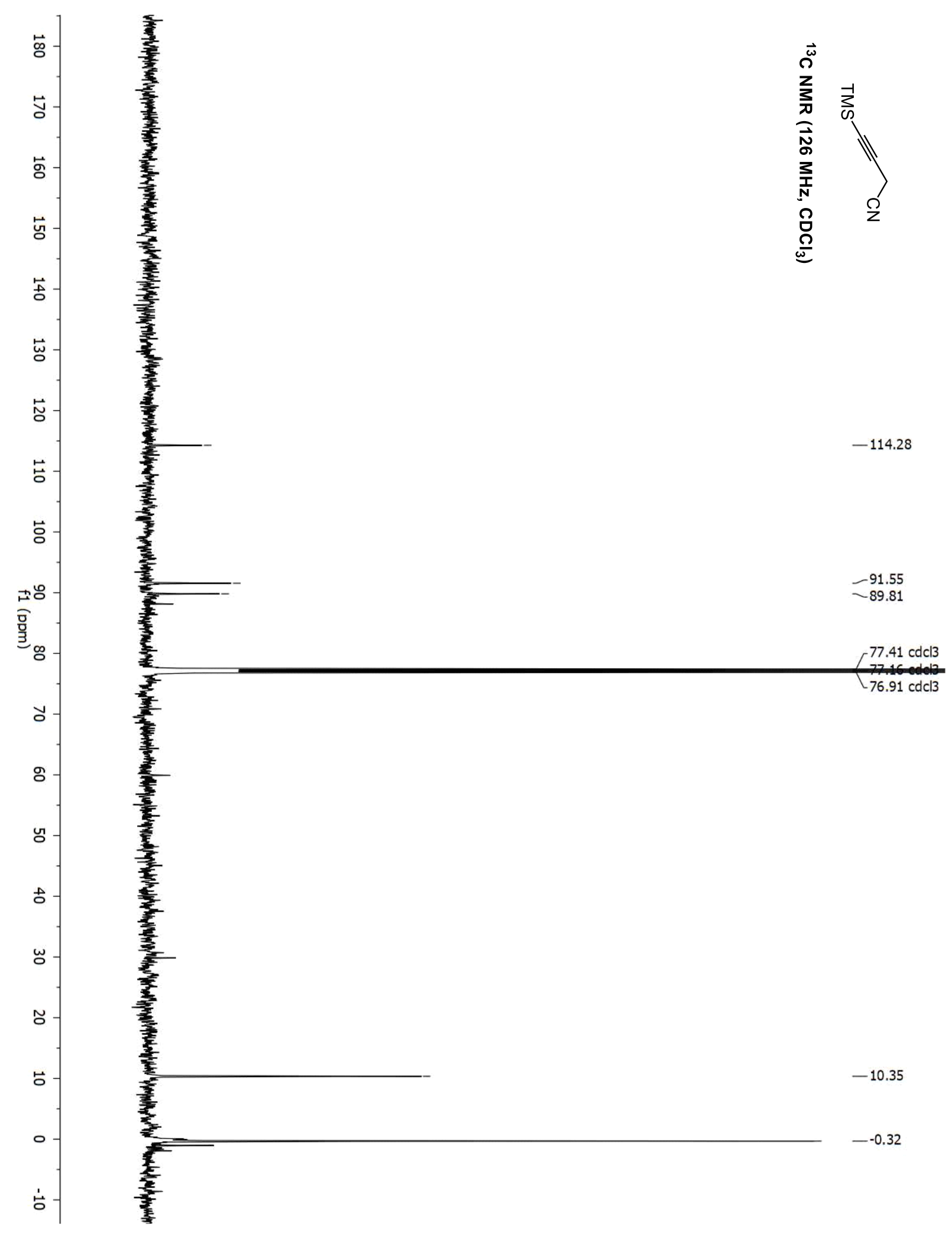




\subsection{With aryl and heteroaryl nitriles}

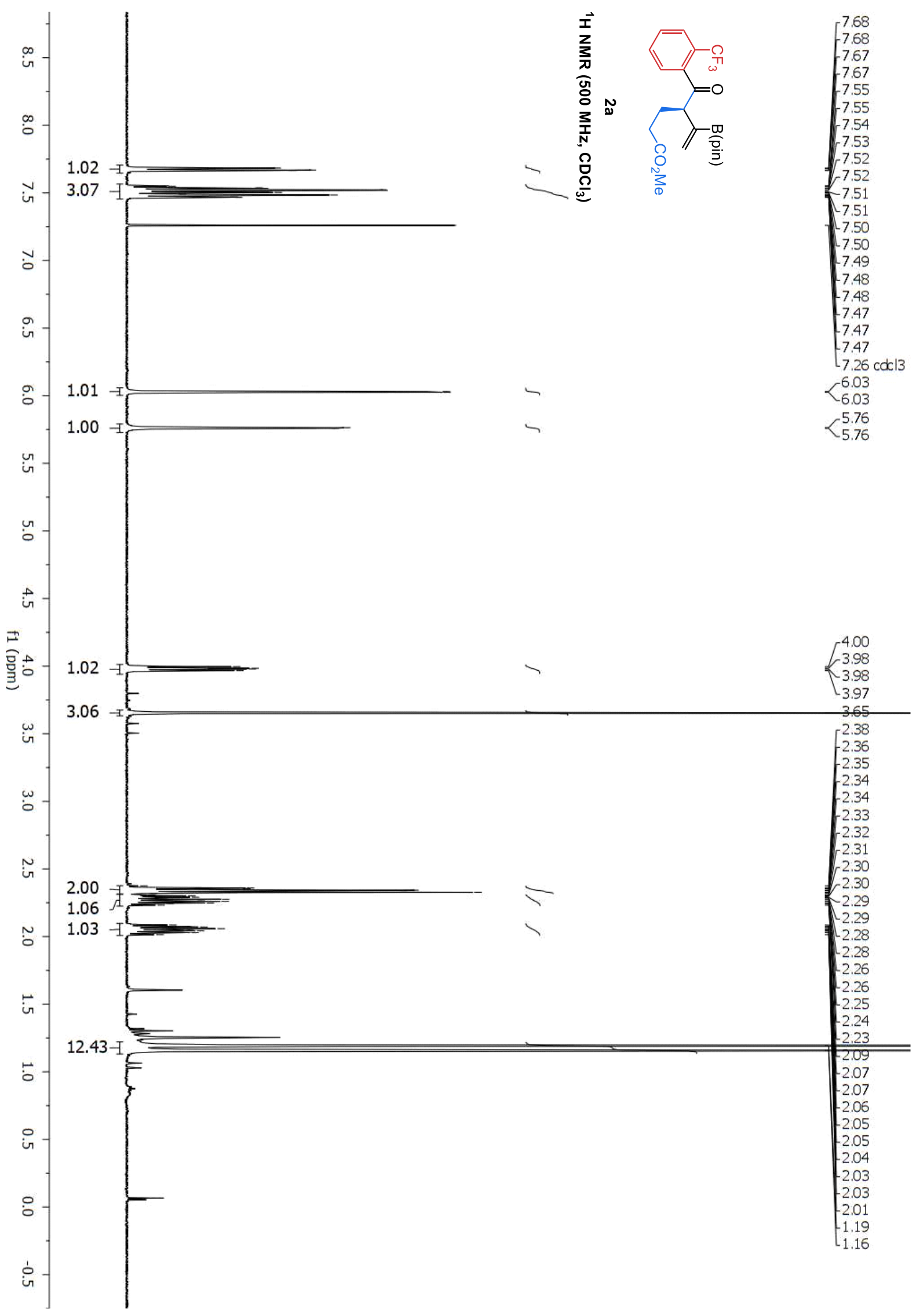




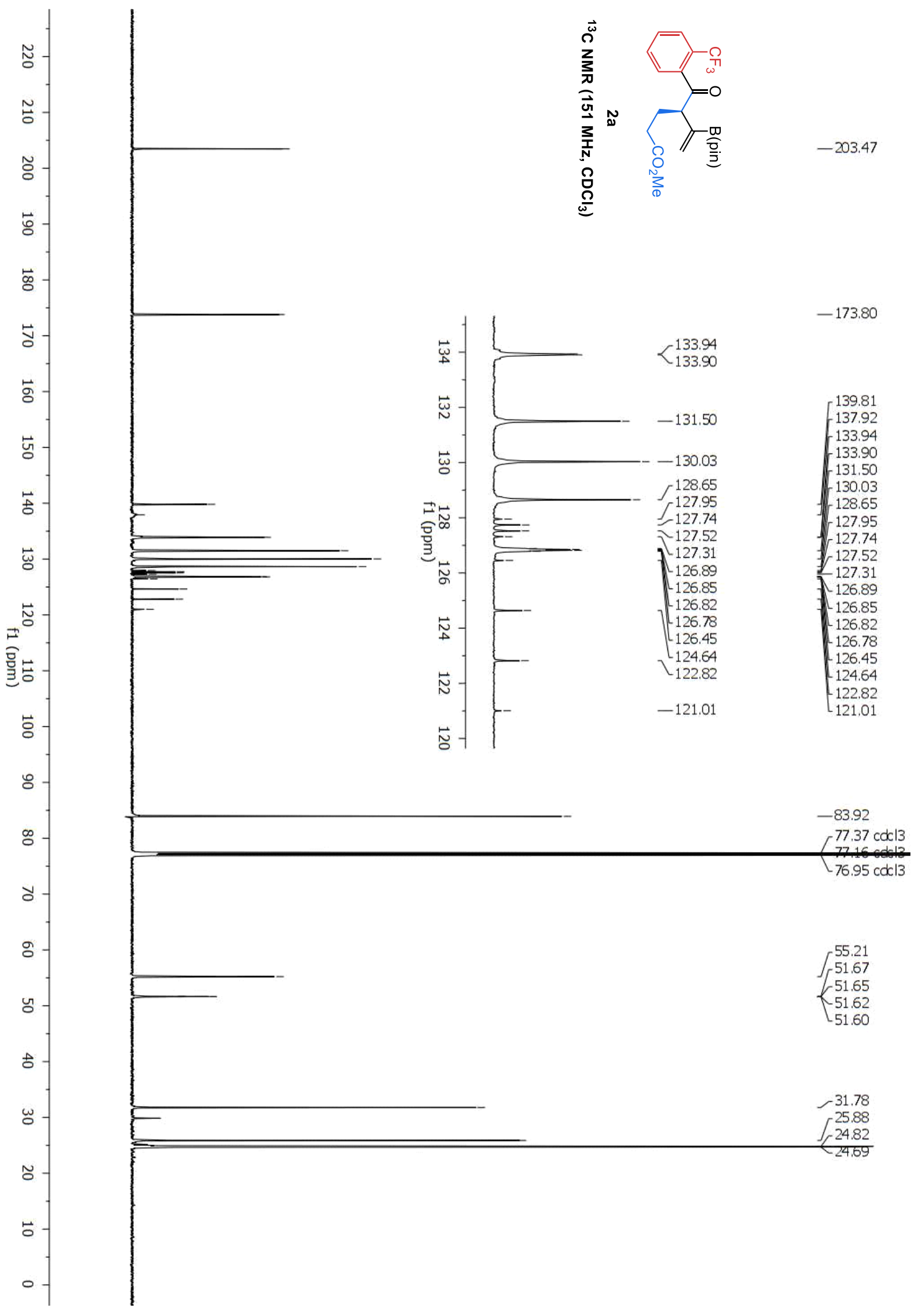


Del Pozo, et al., Supplementary Materials; Page 115

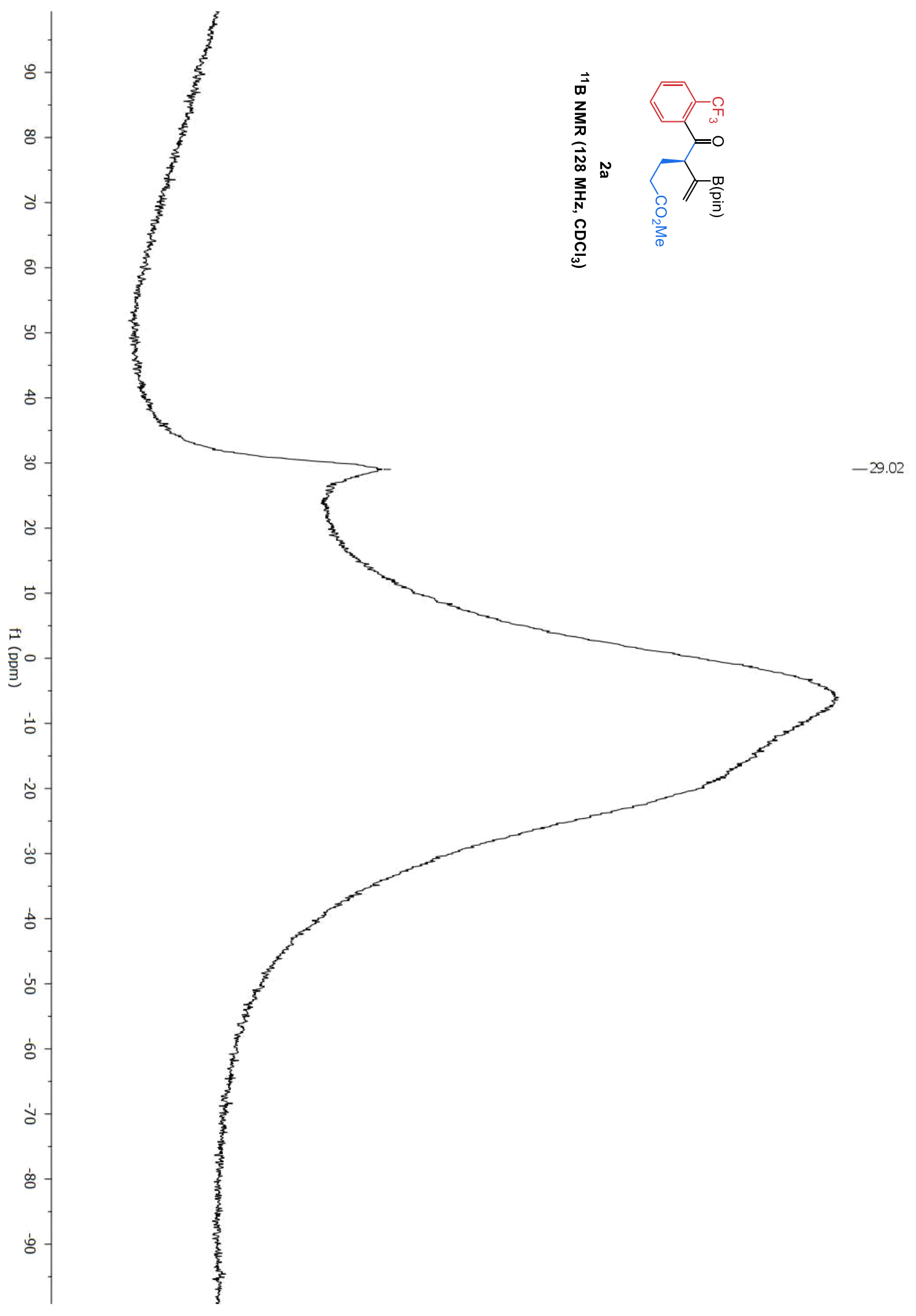




$$
\mid "
$$




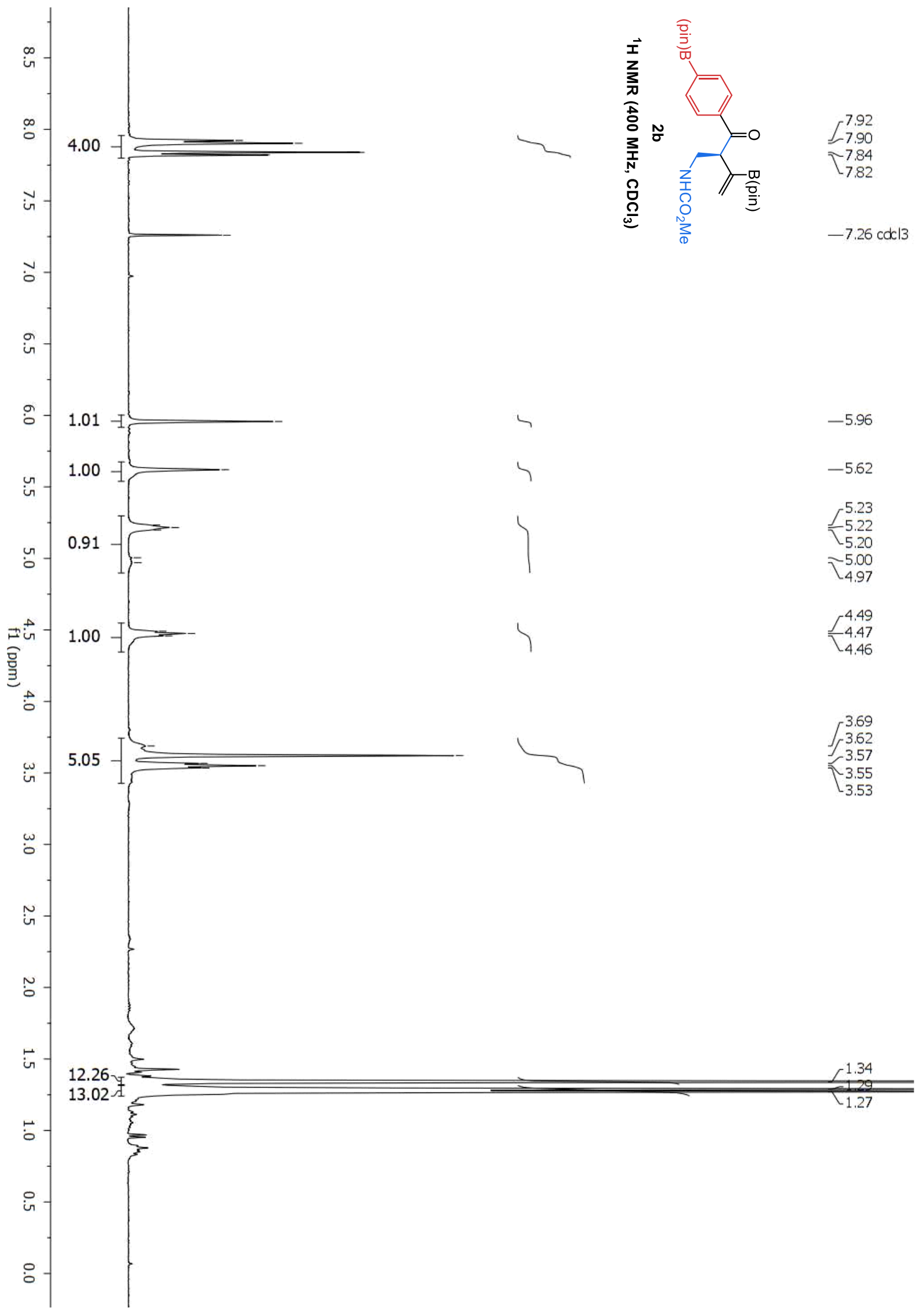




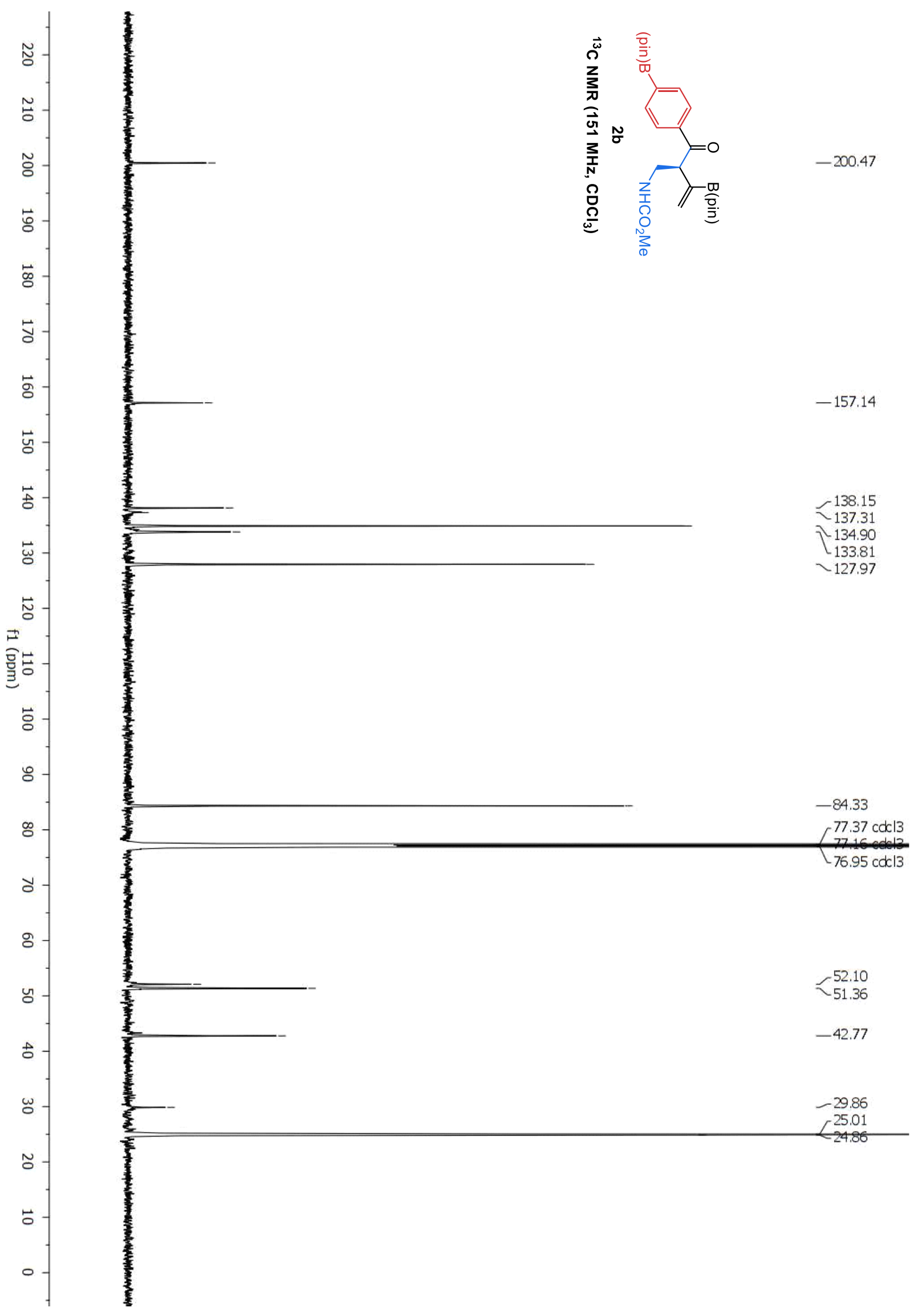




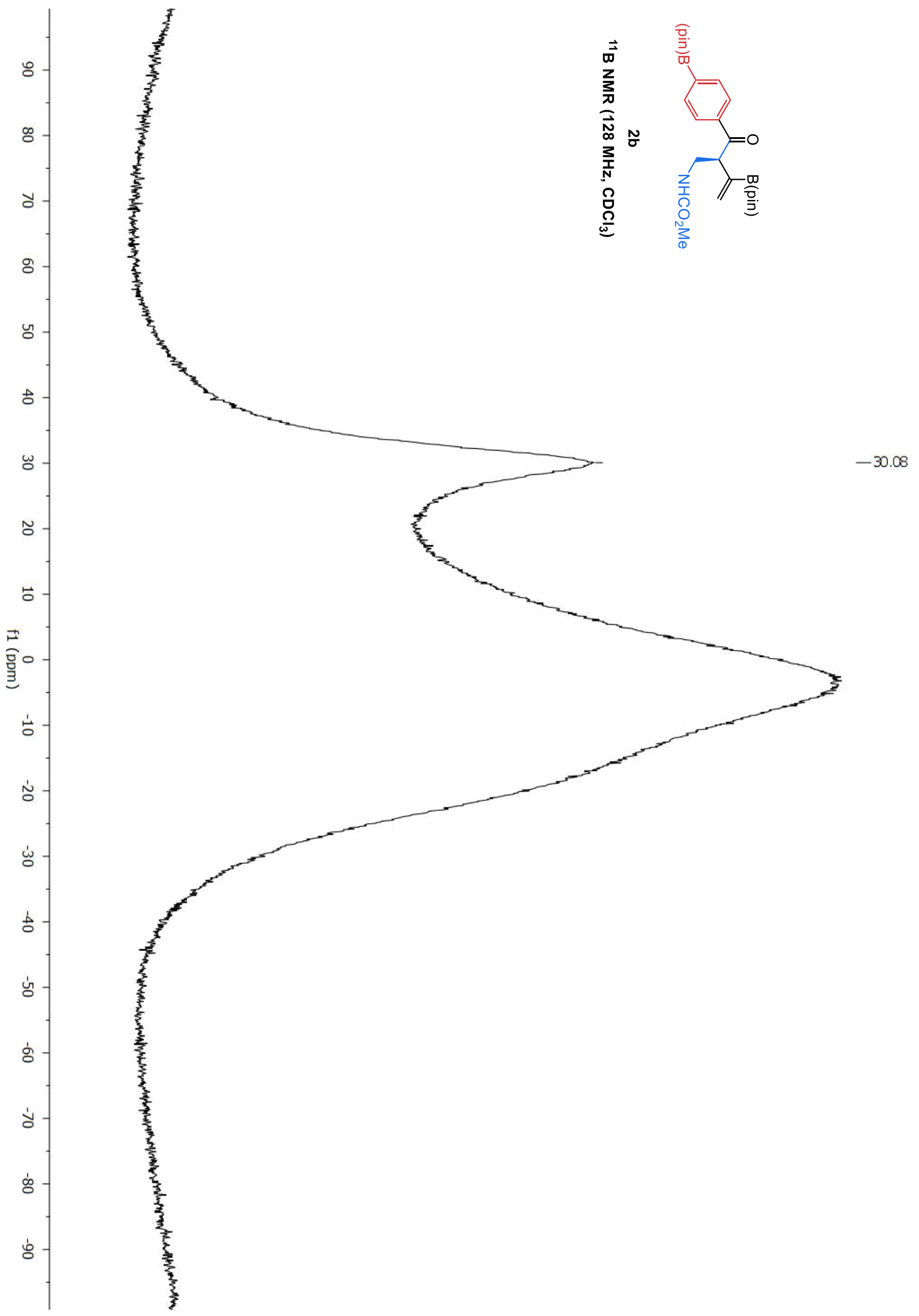




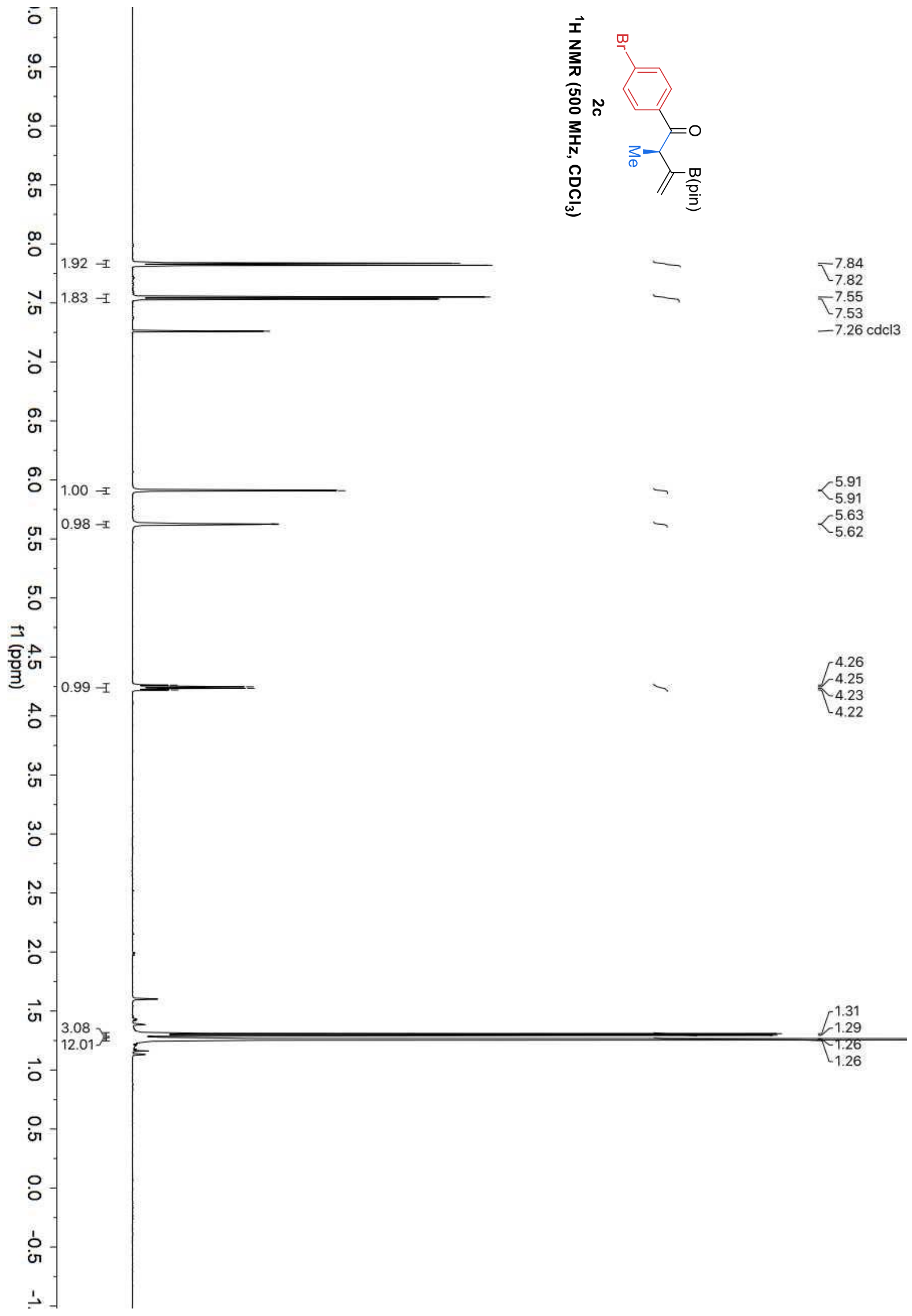




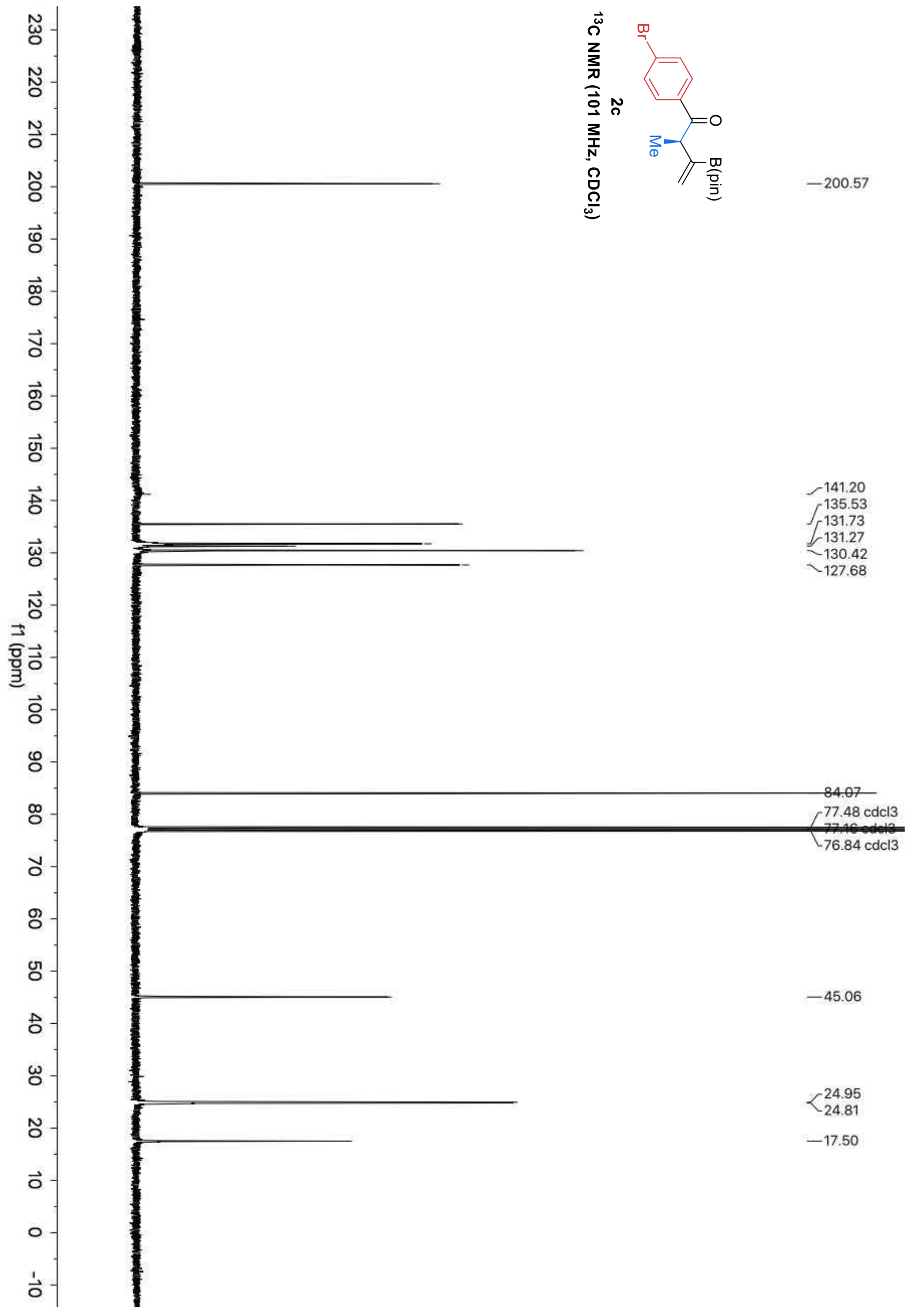


Del Pozo, et al., Supplementary Materials; Page 122

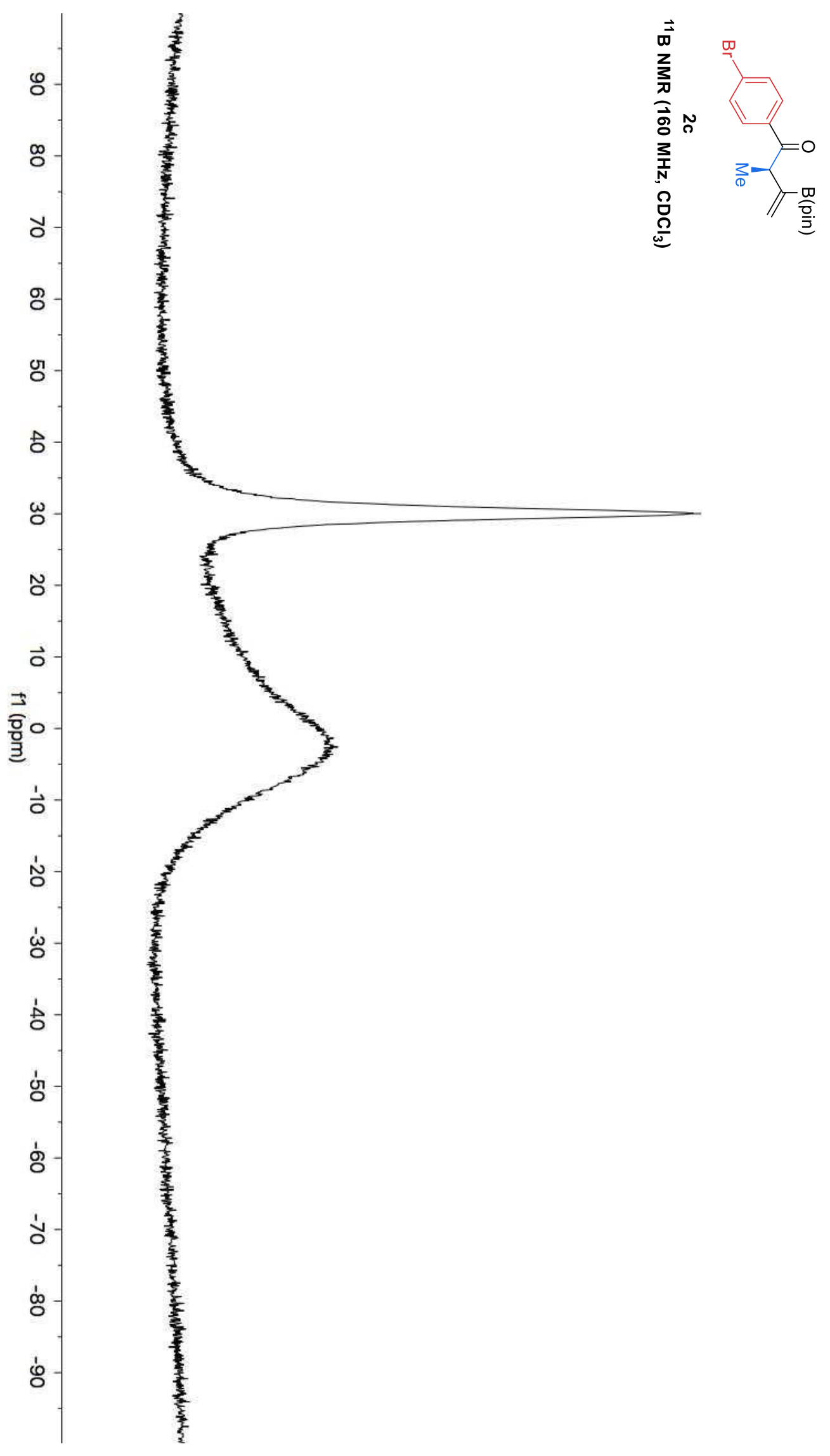

$-30.02$ 


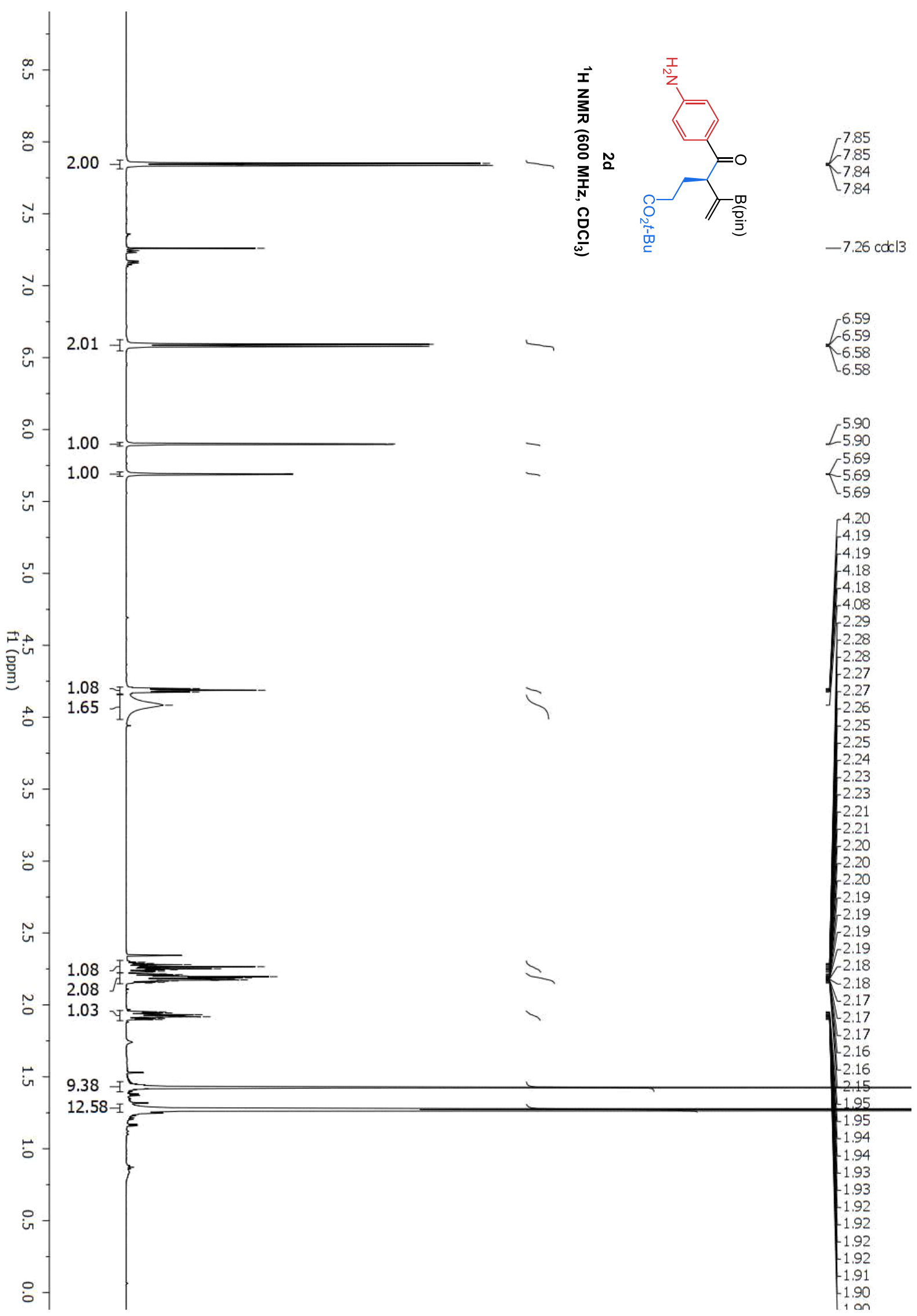




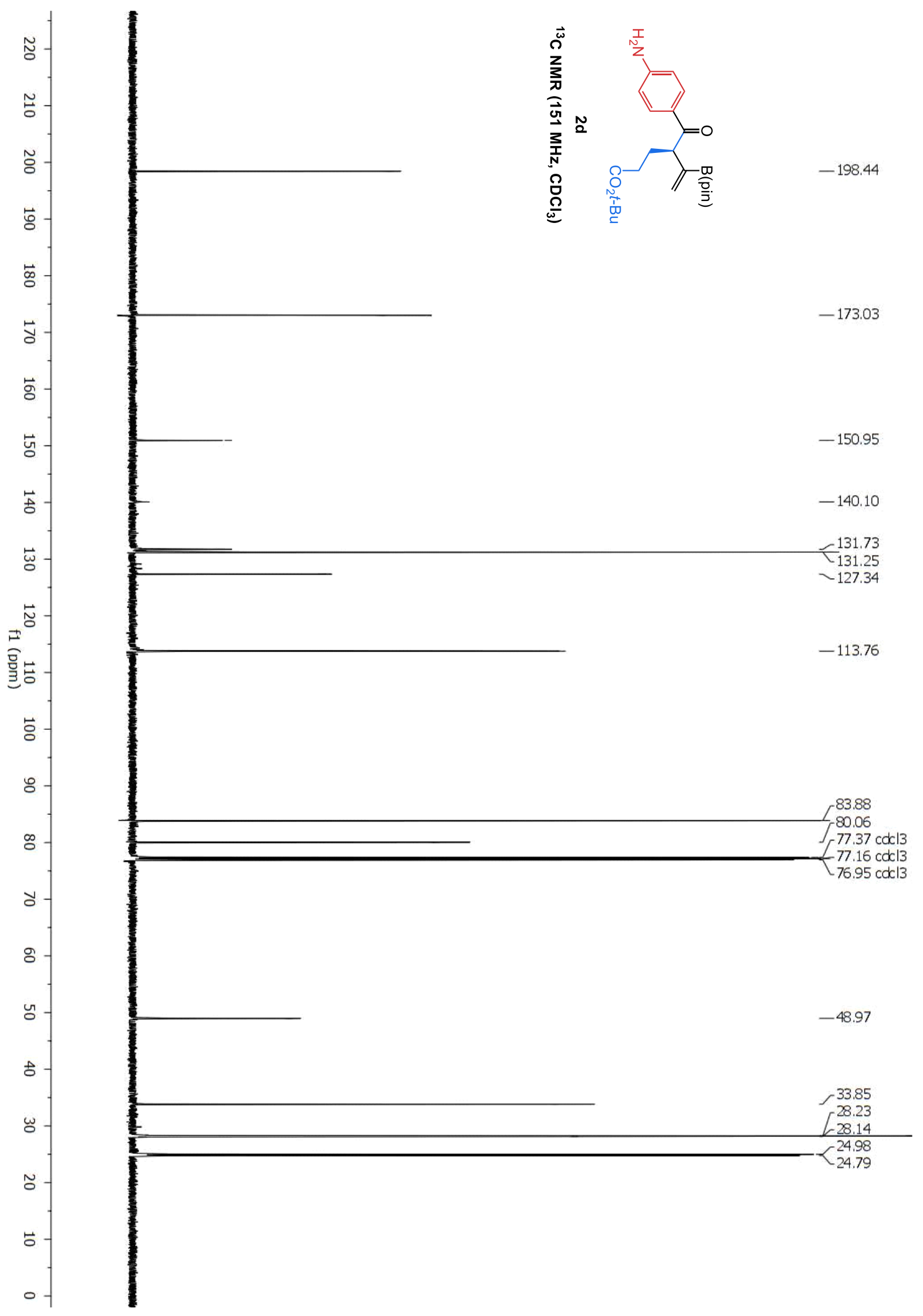


Del Pozo, et al., Supplementary Materials; Page 125

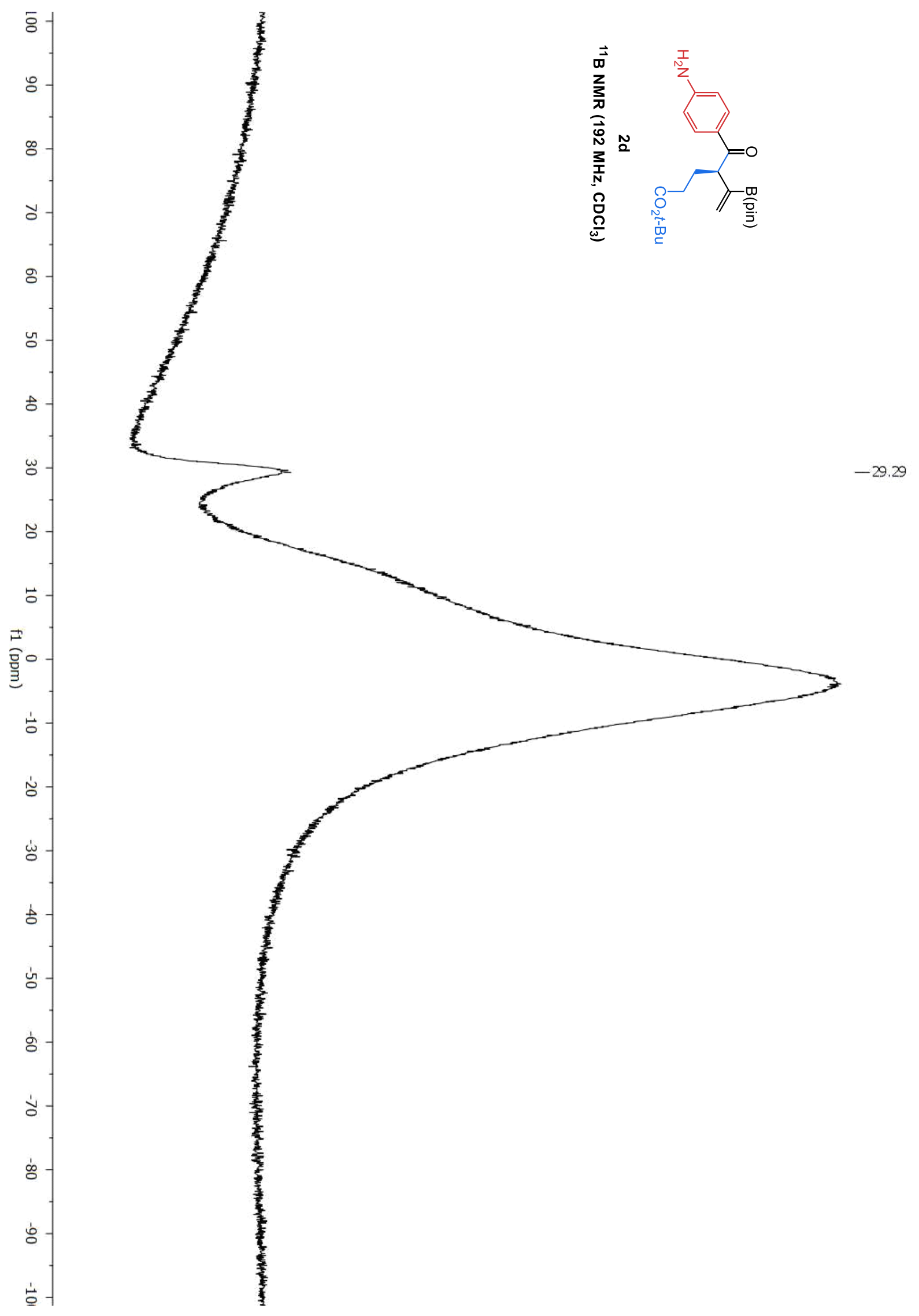




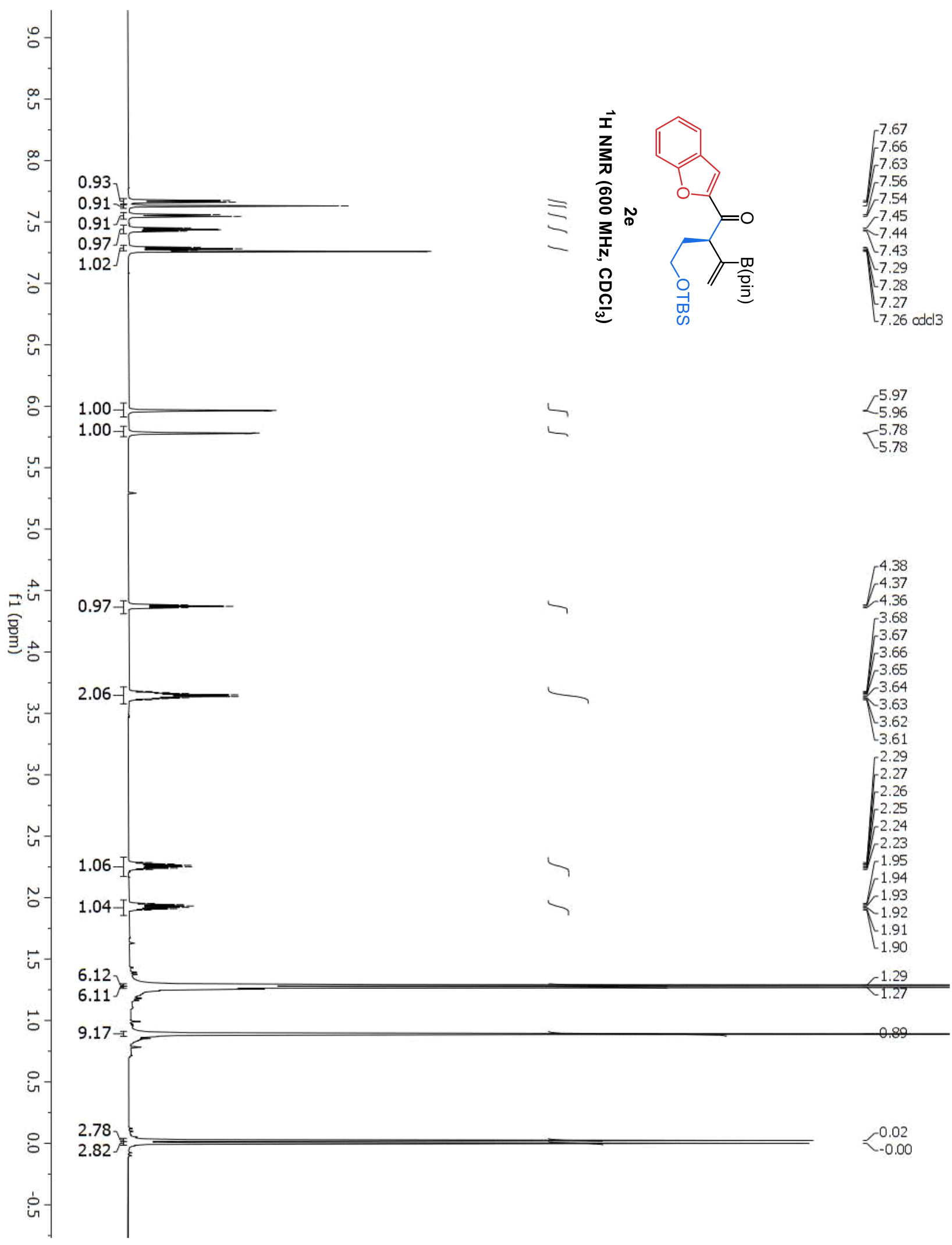




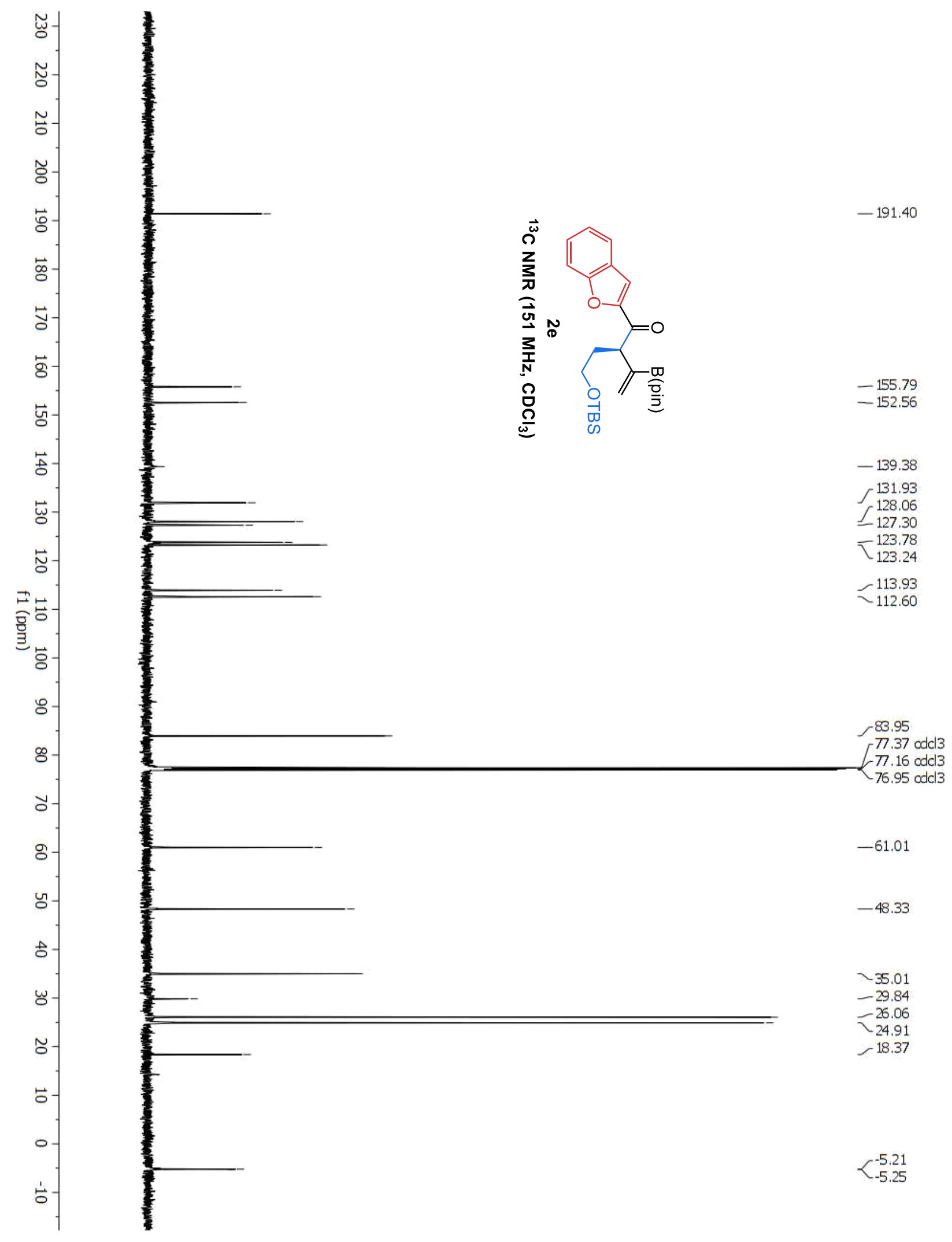


Del Pozo, et al., Supplementary Materials; Page 128

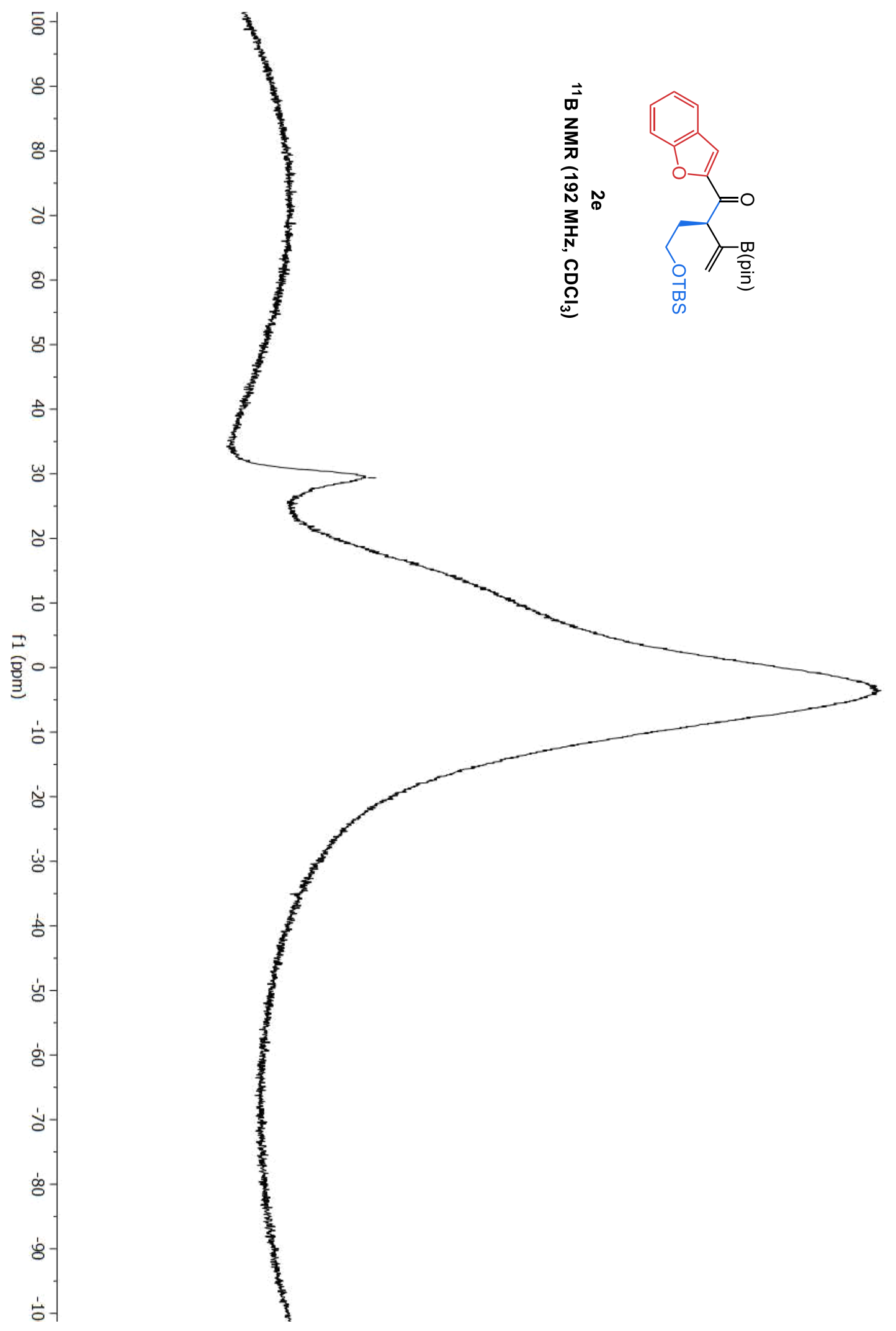

$-29.38$ 


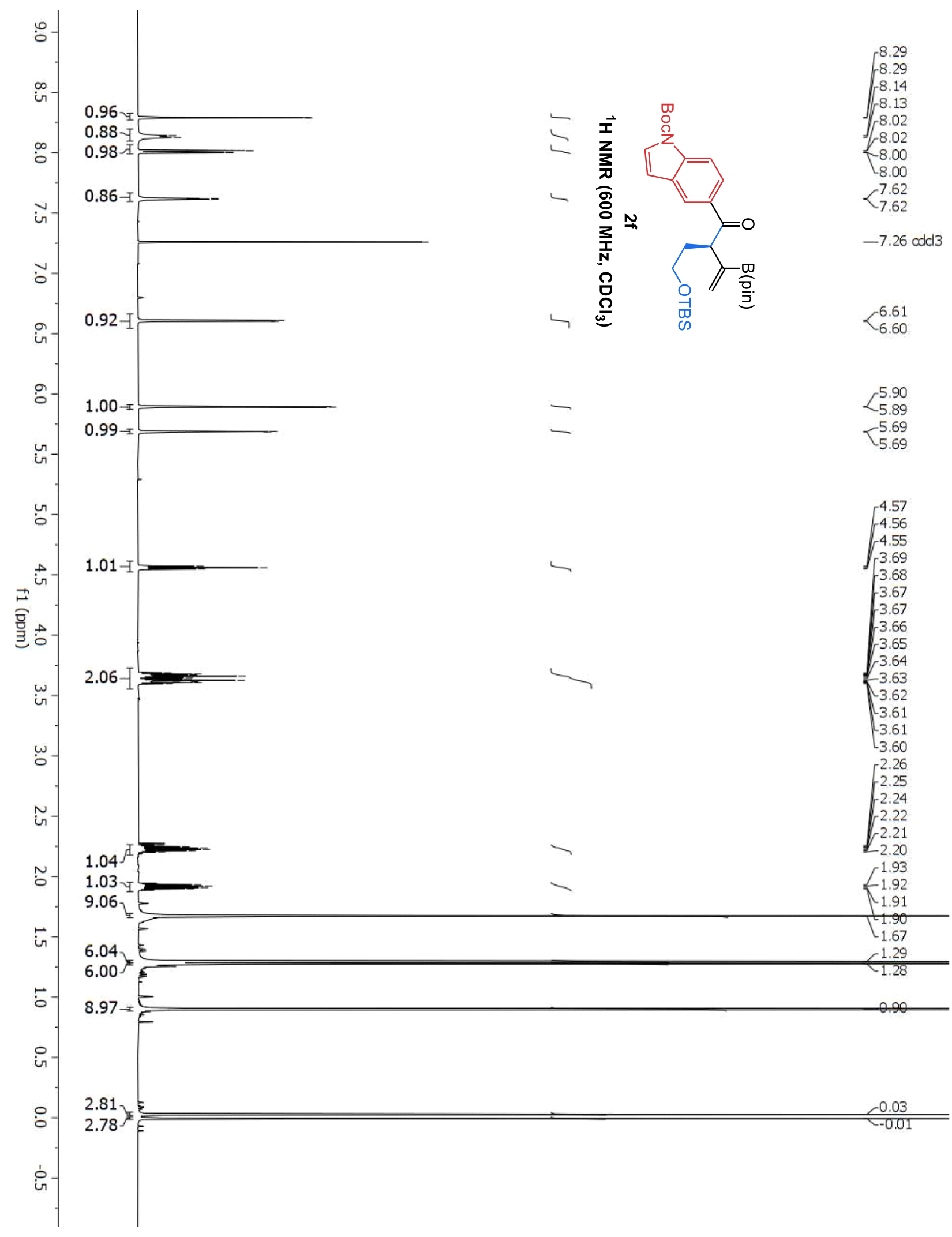


Del Pozo, et al., Supplementary Materials; Page 130

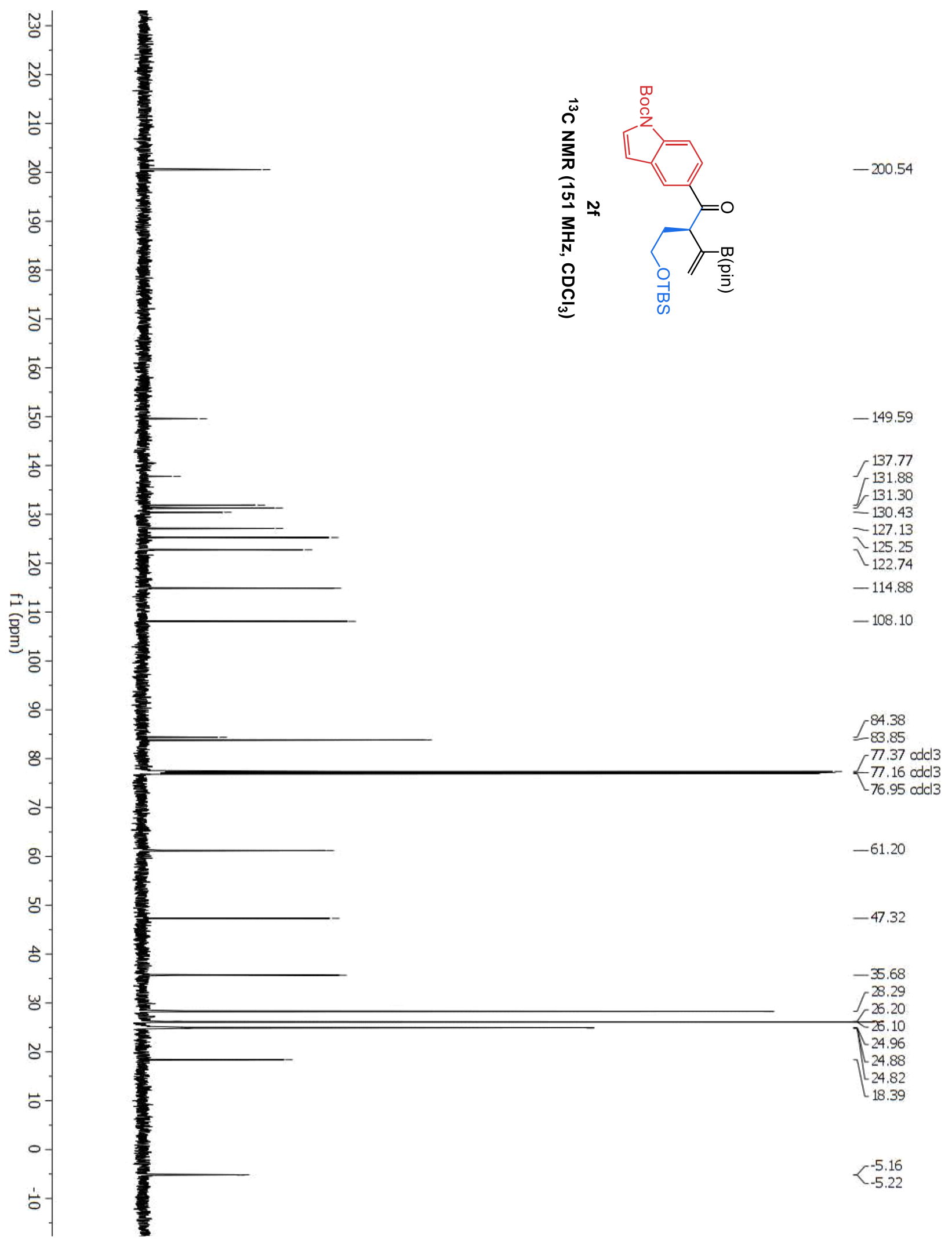


Del Pozo, et al., Supplementary Materials; Page 131

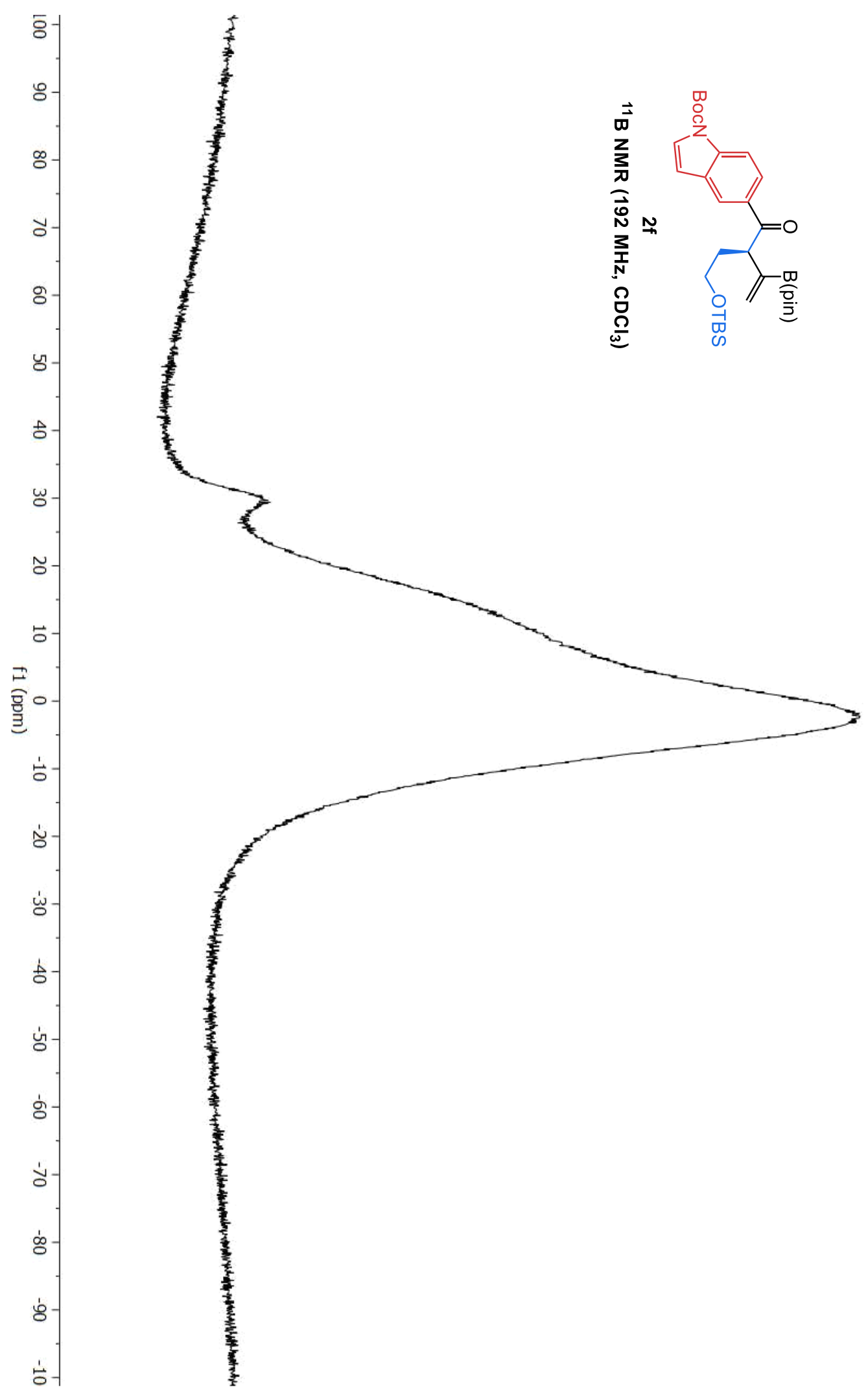




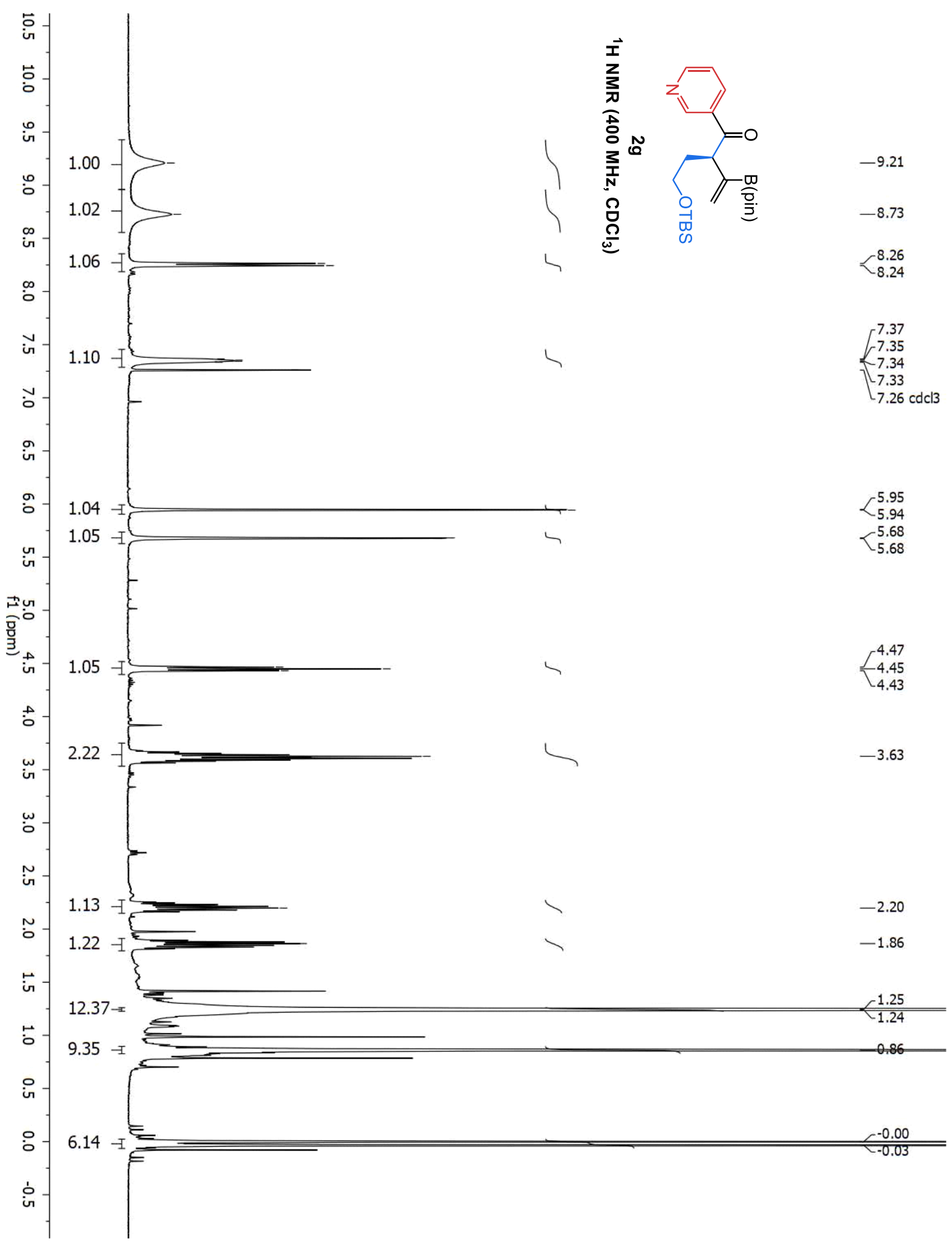




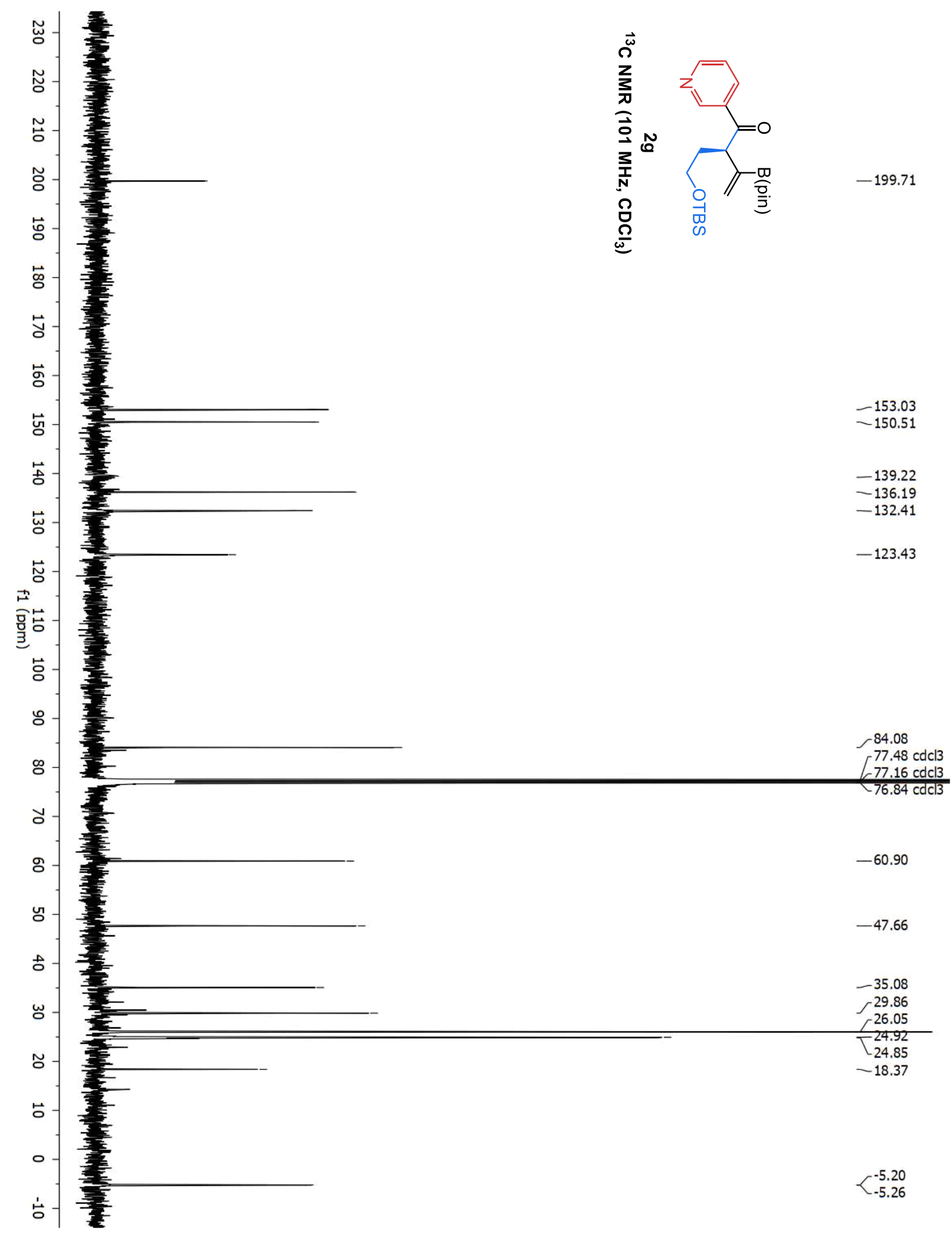


Del Pozo, et al., Supplementary Materials; Page 134
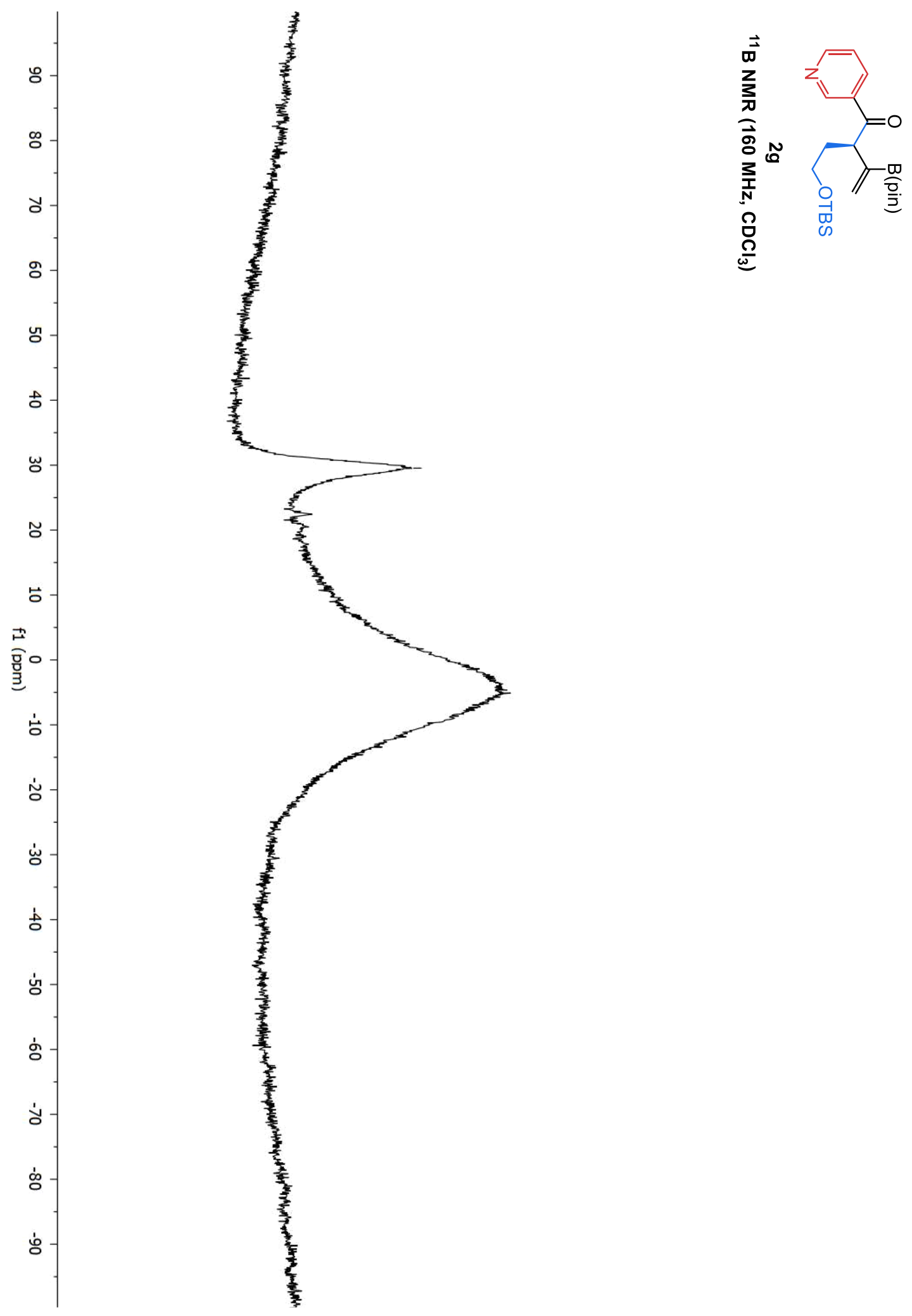

$-29.54$ 


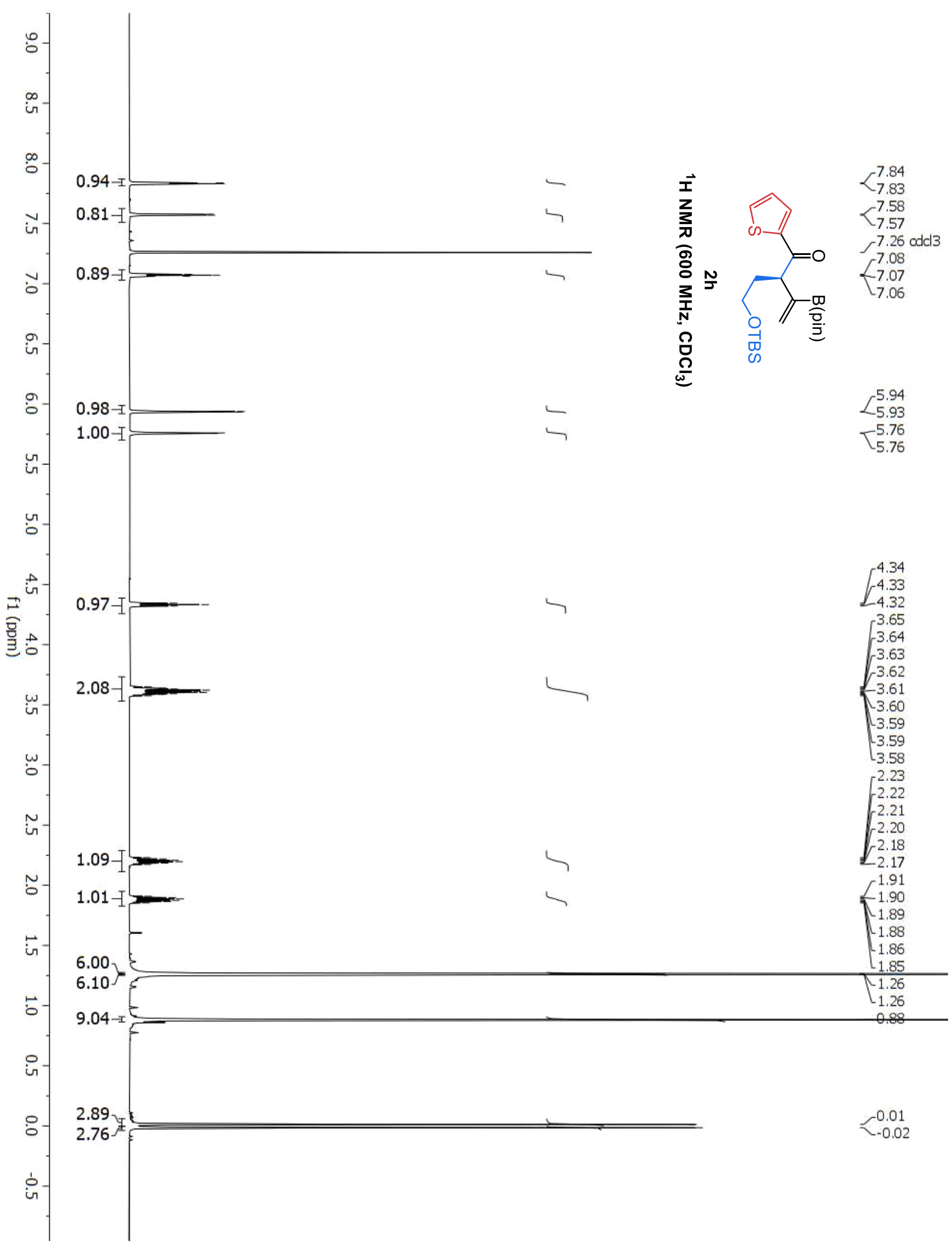




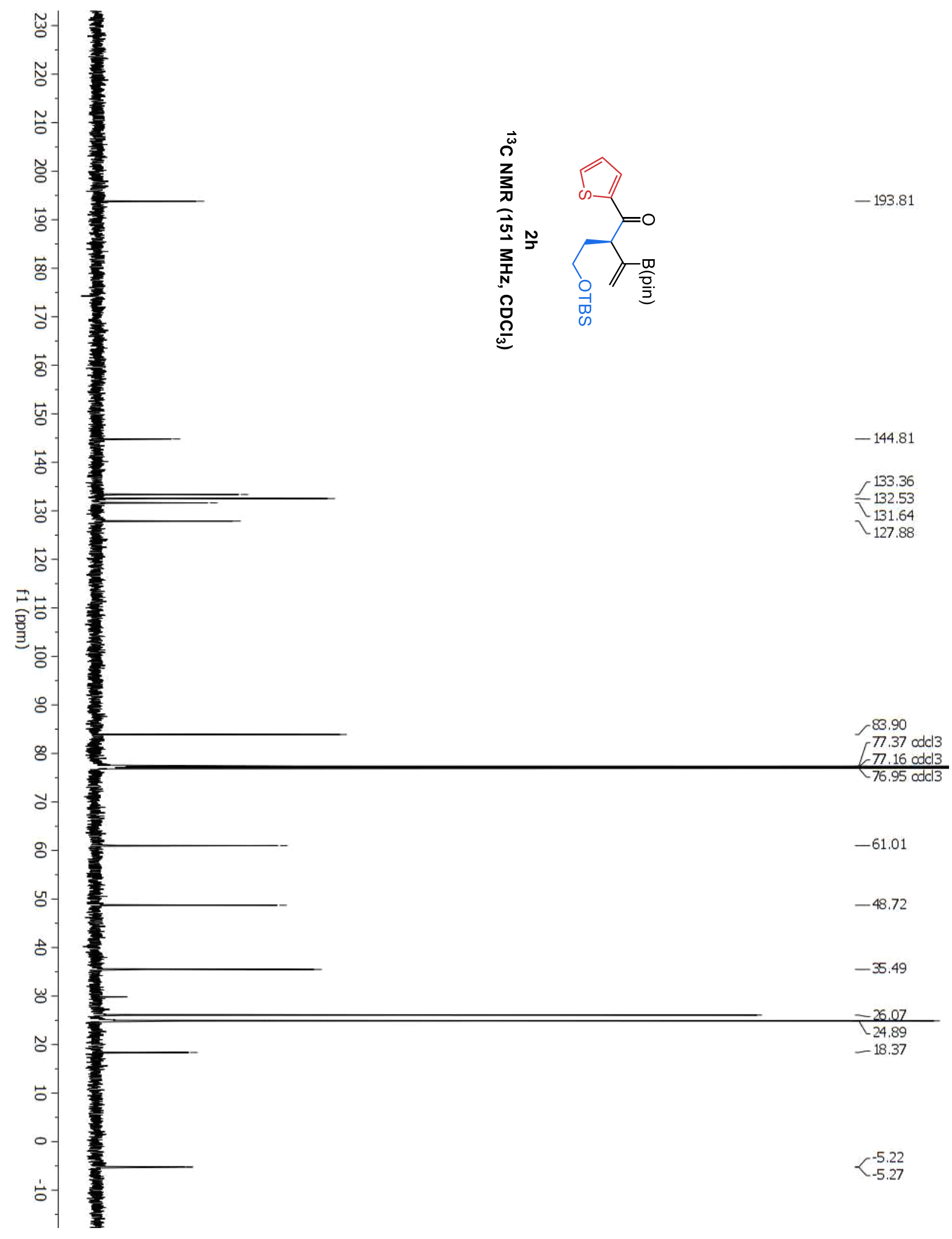


Del Pozo, et al., Supplementary Materials; Page 137

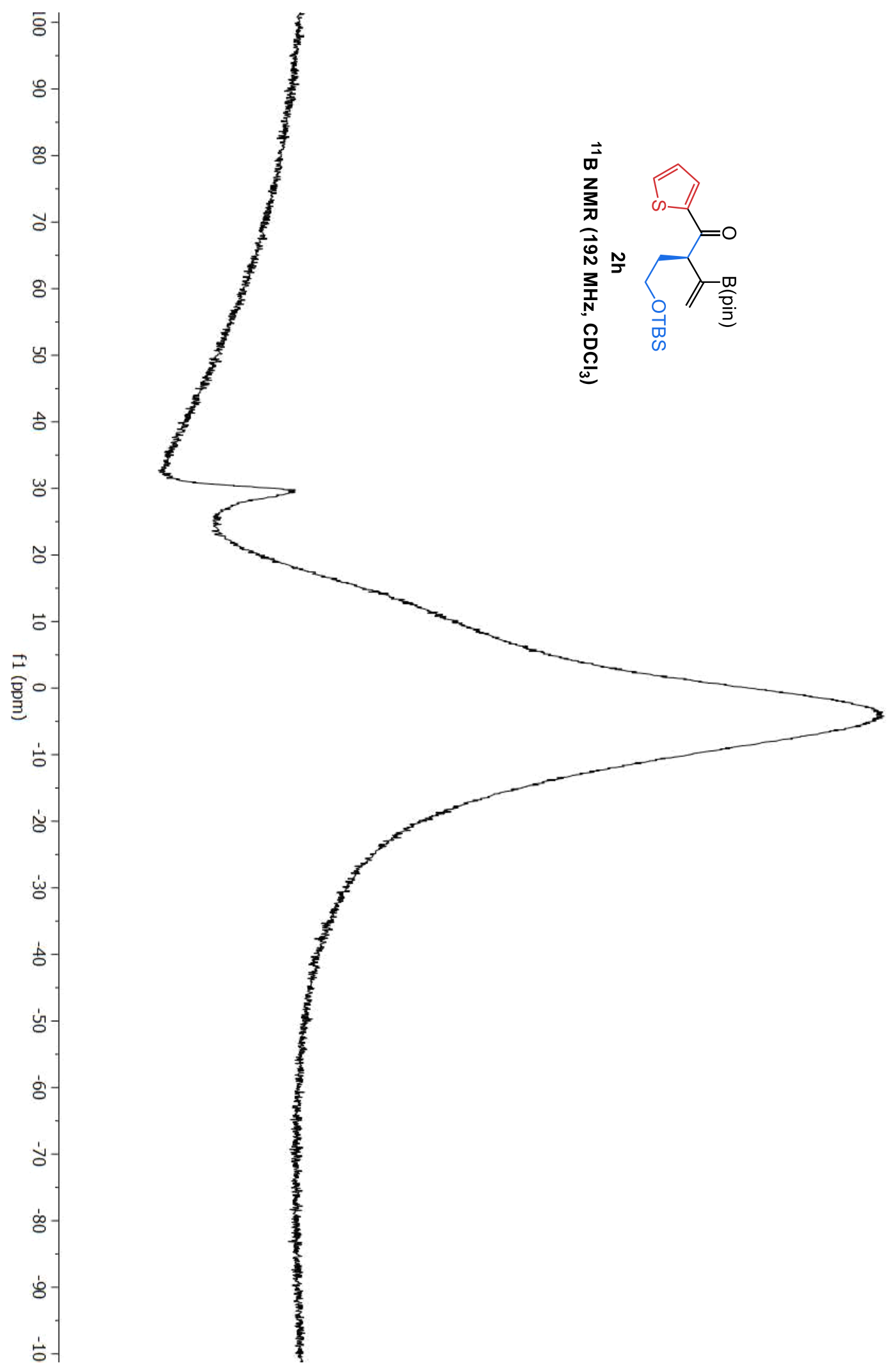

$-29.79$ 


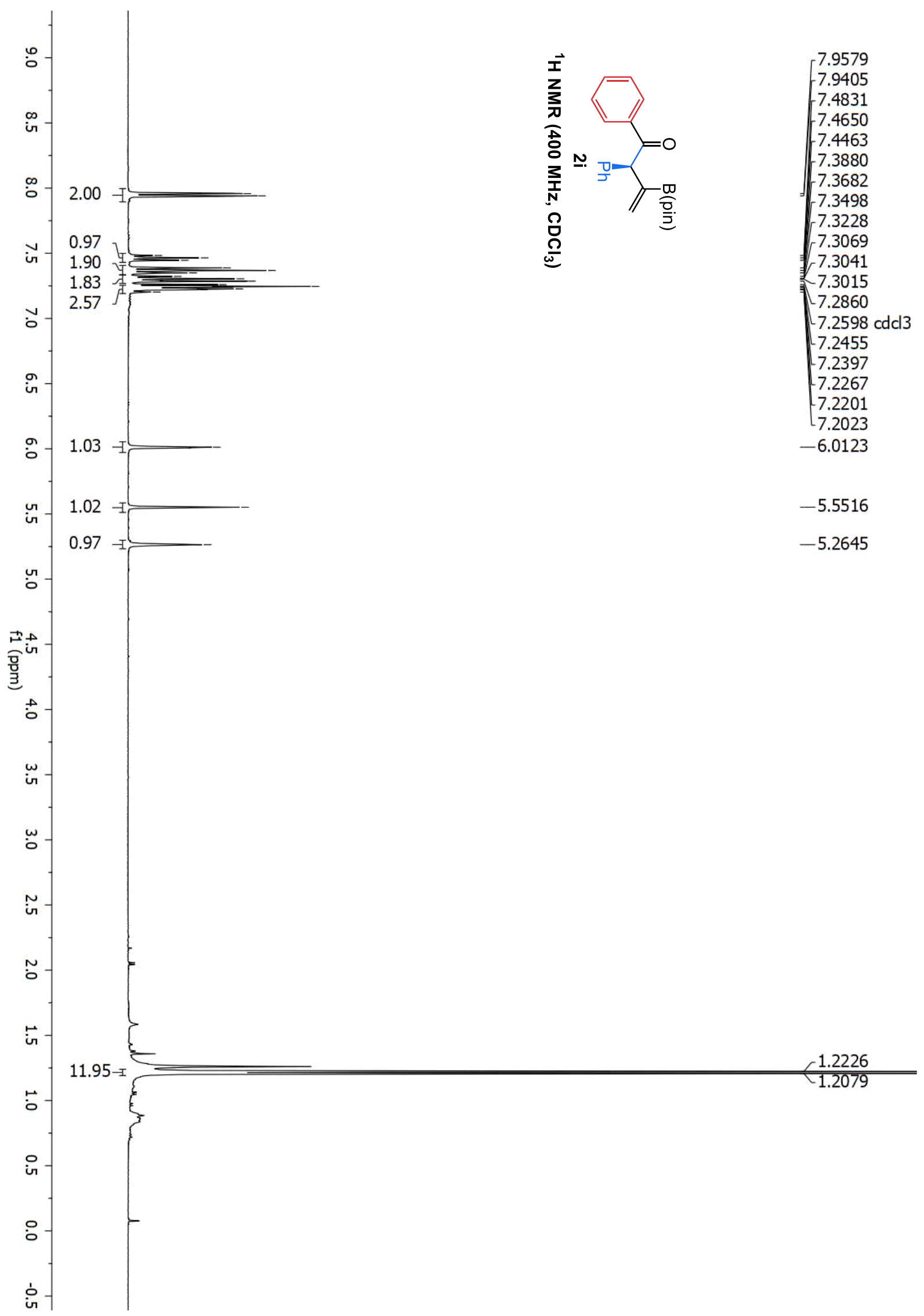




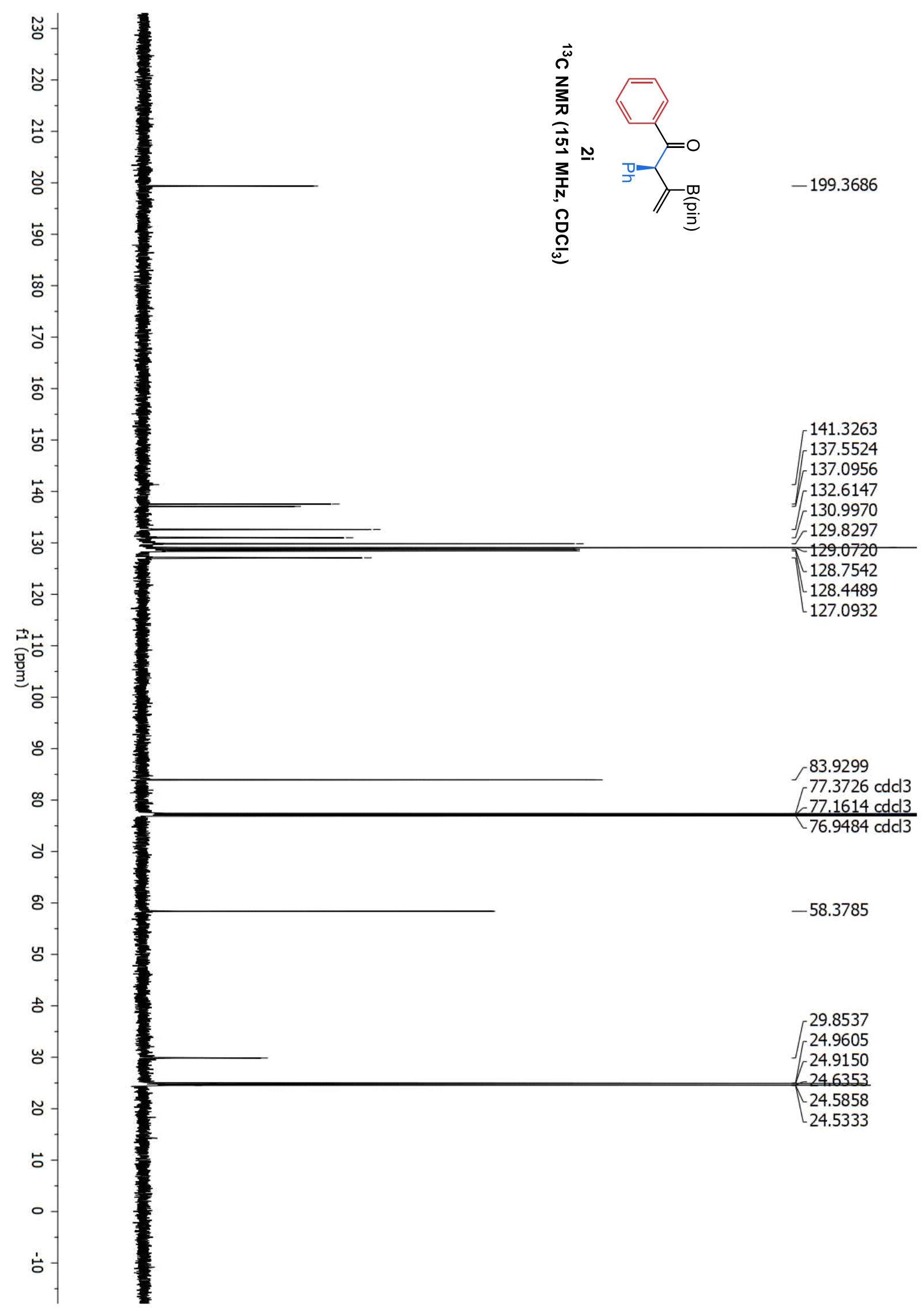


Del Pozo, et al., Supplementary Materials; Page 140
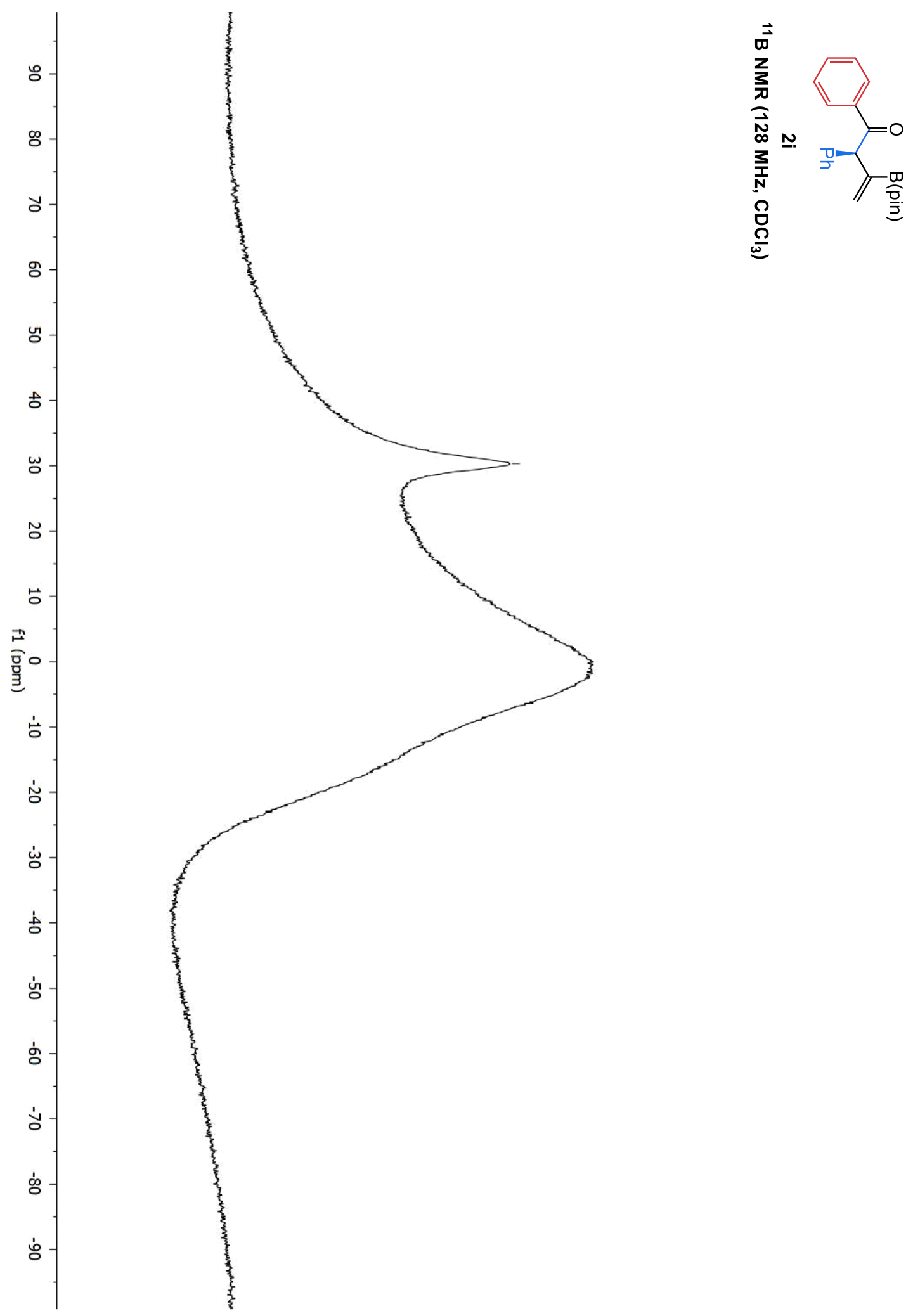

$-30.34$ 


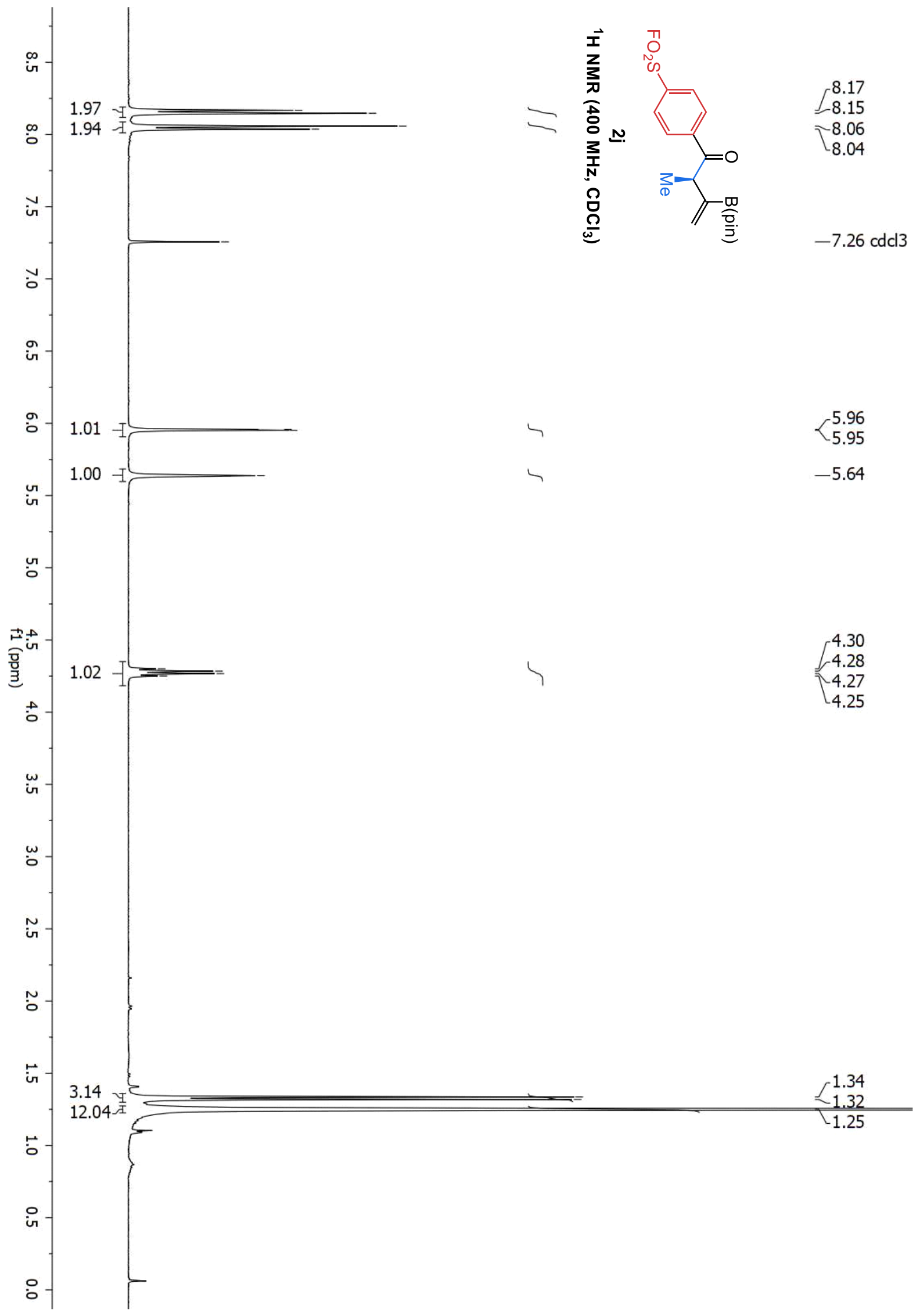




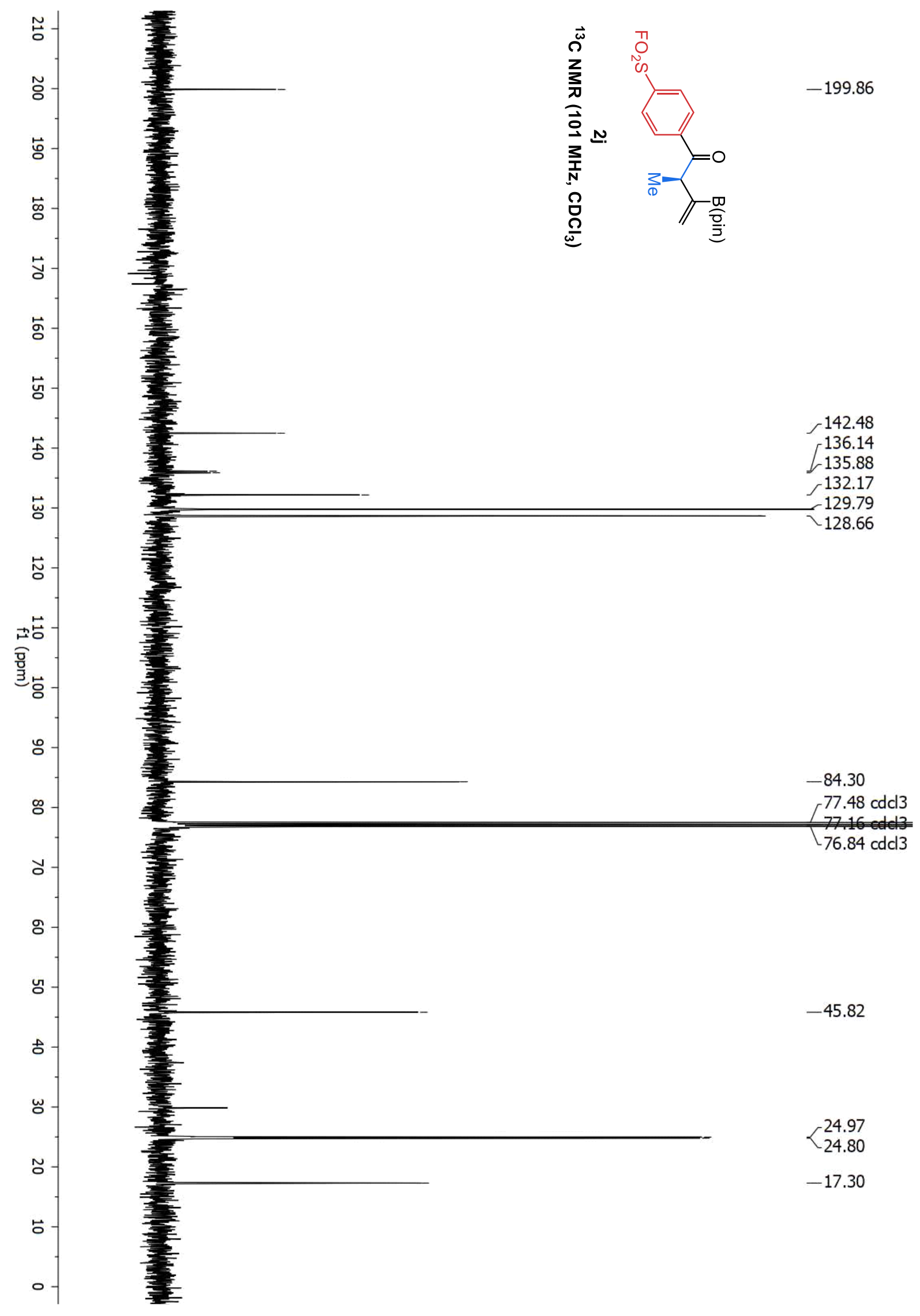




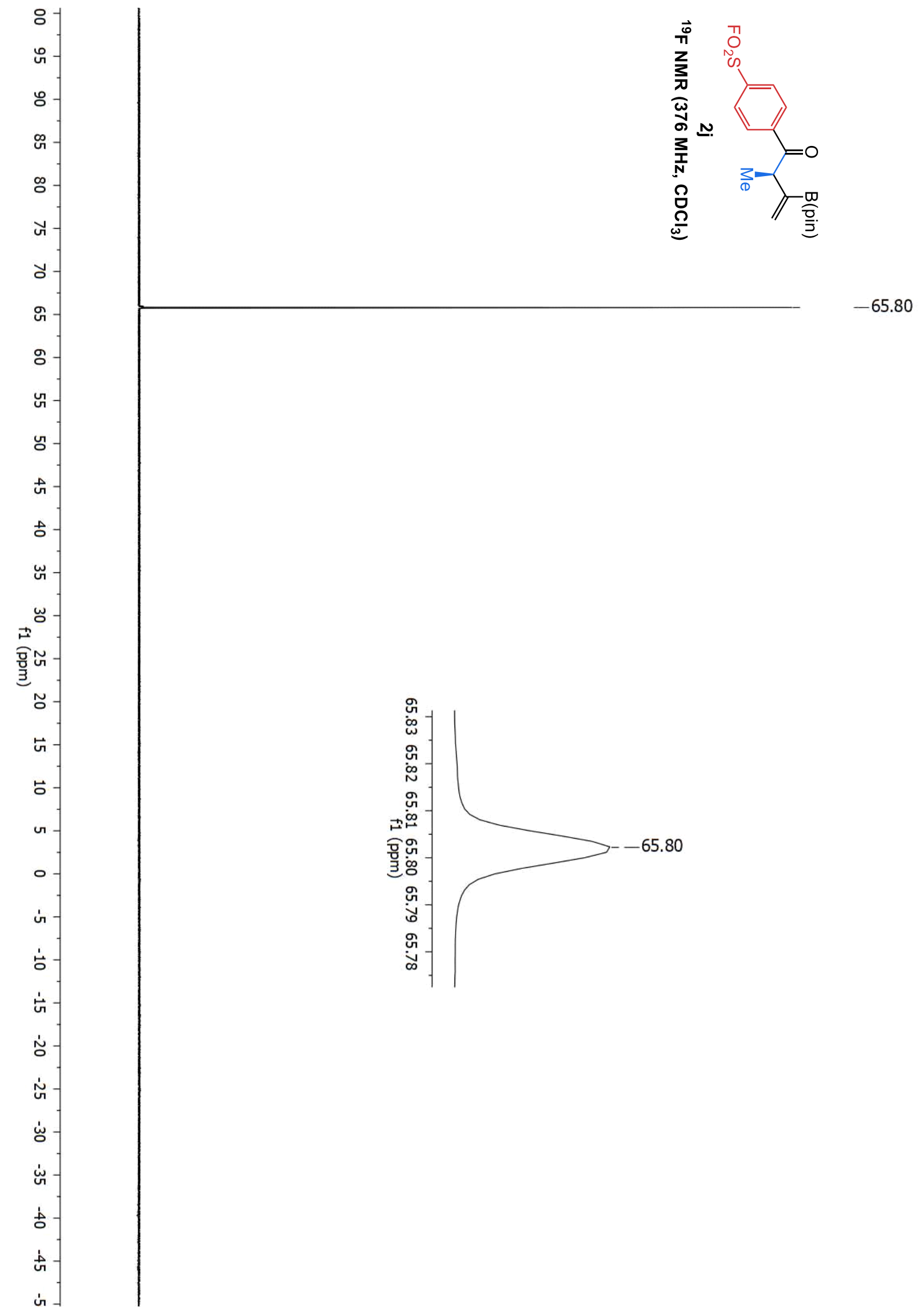



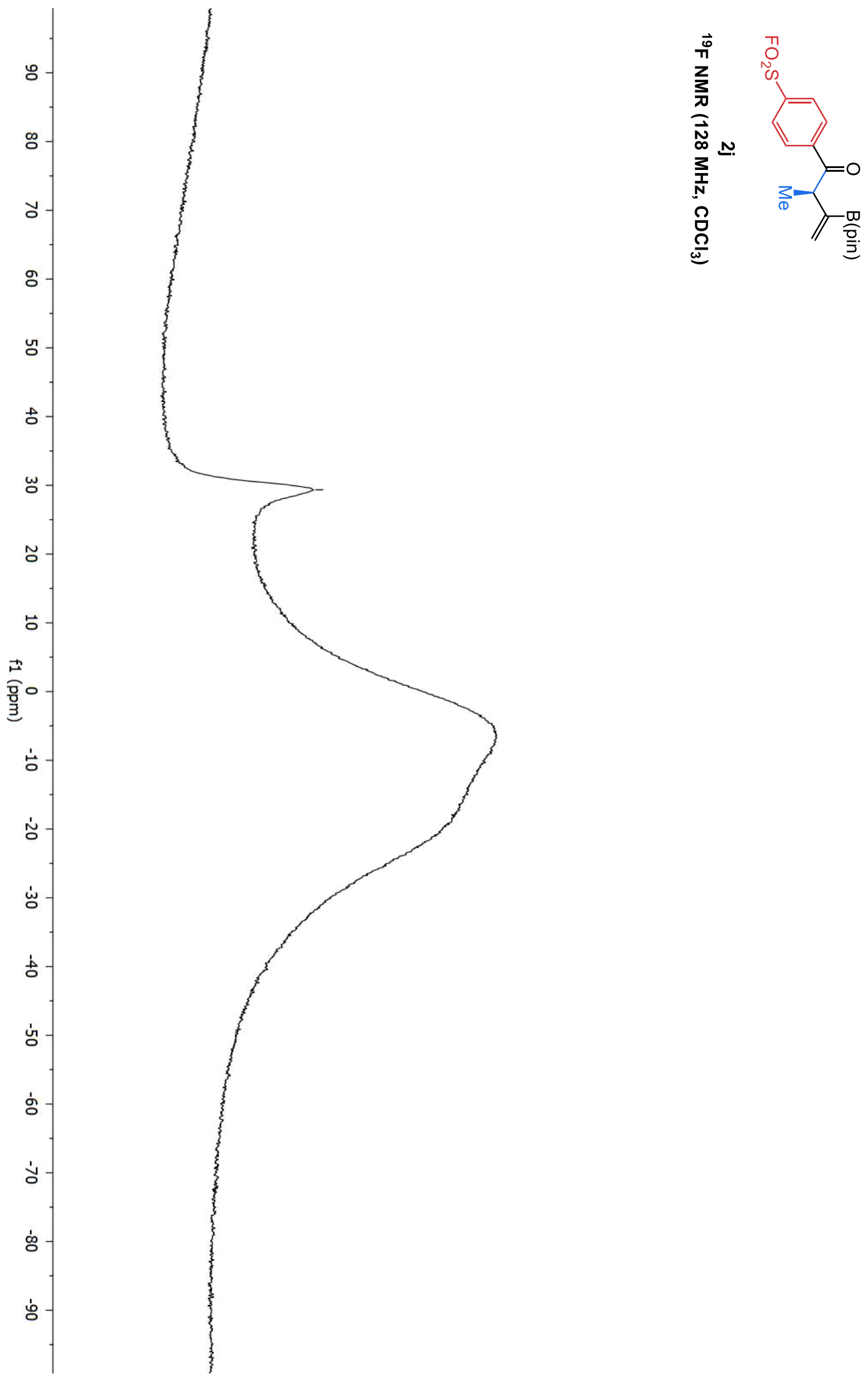


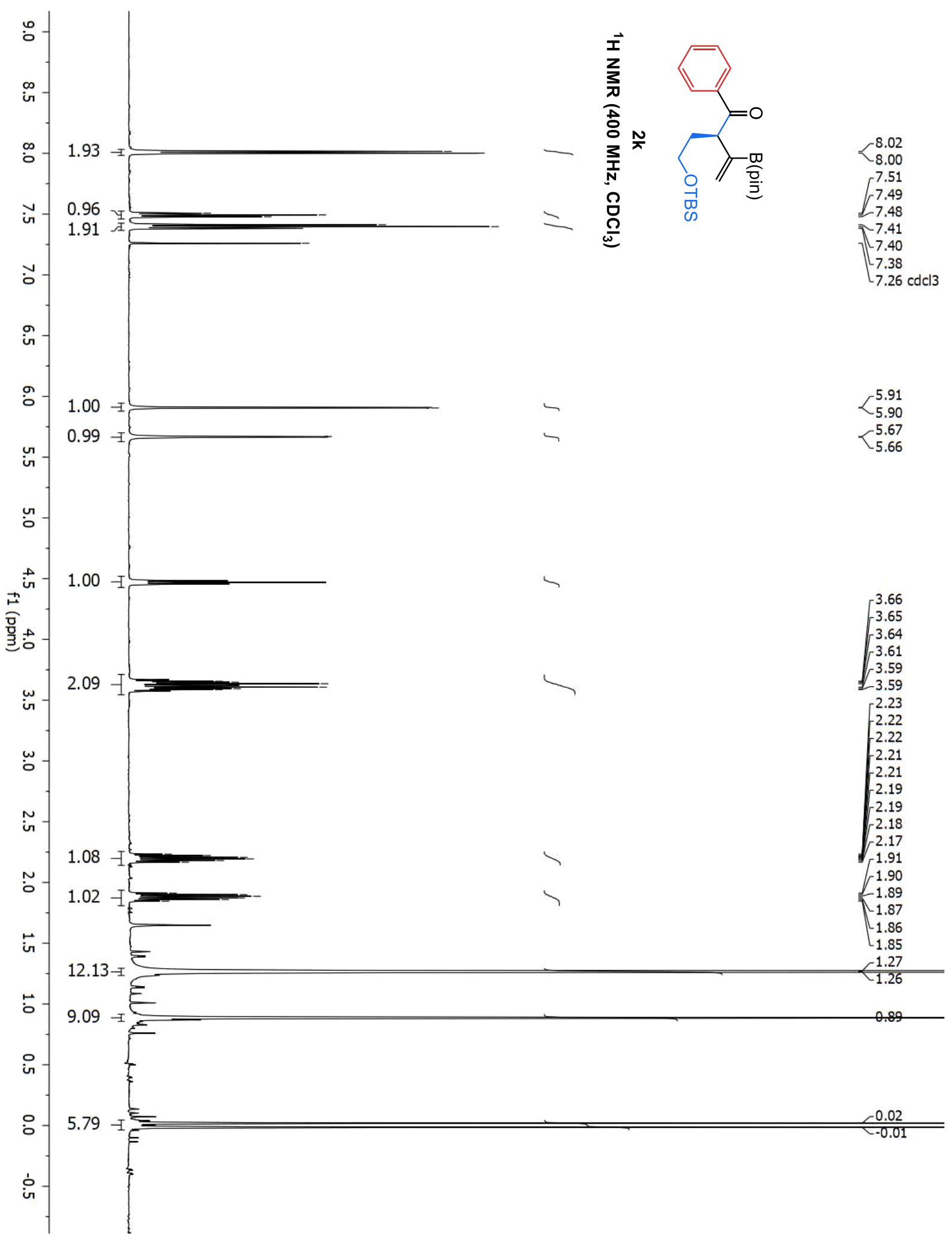




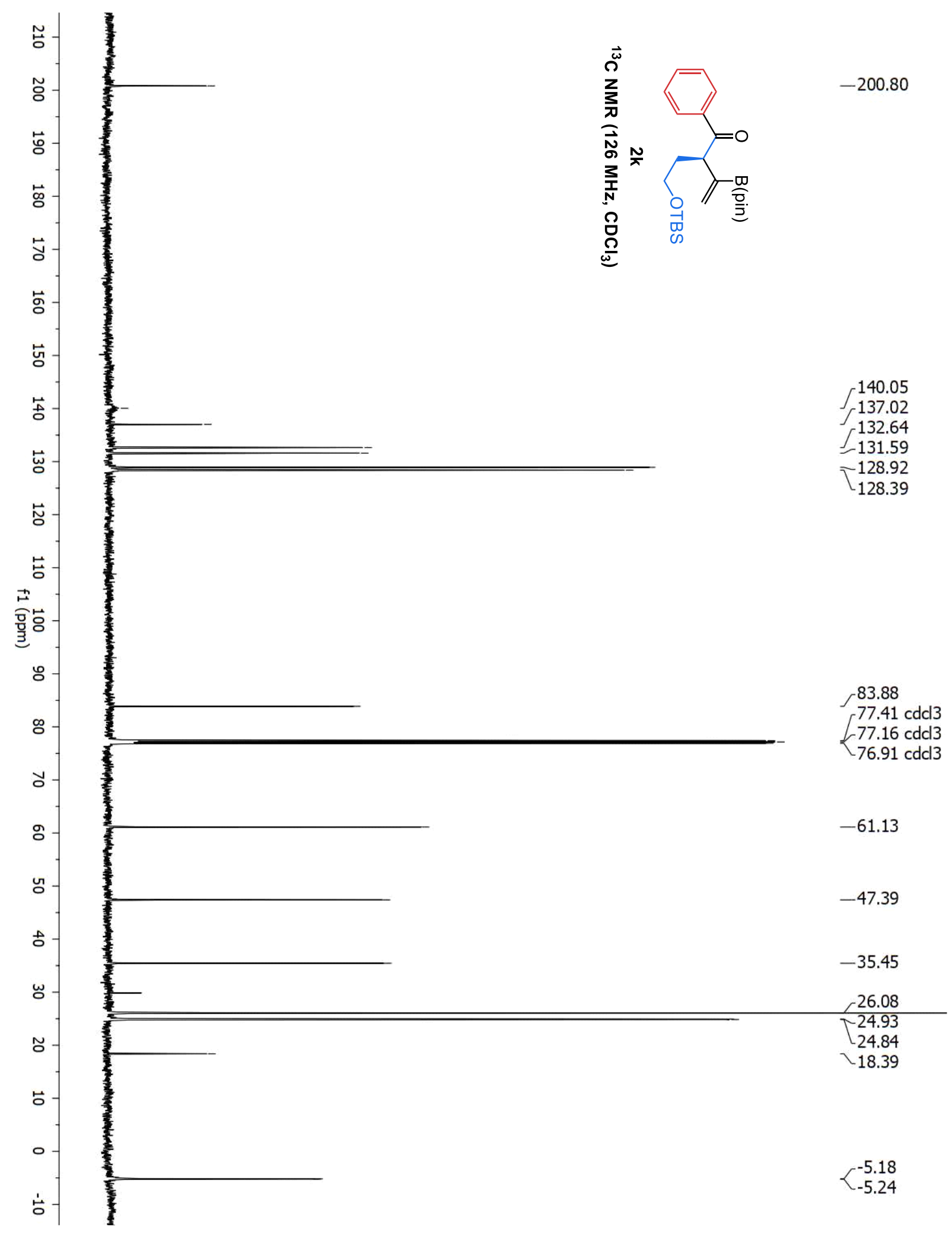


Del Pozo, et al., Supplementary Materials; Page 147

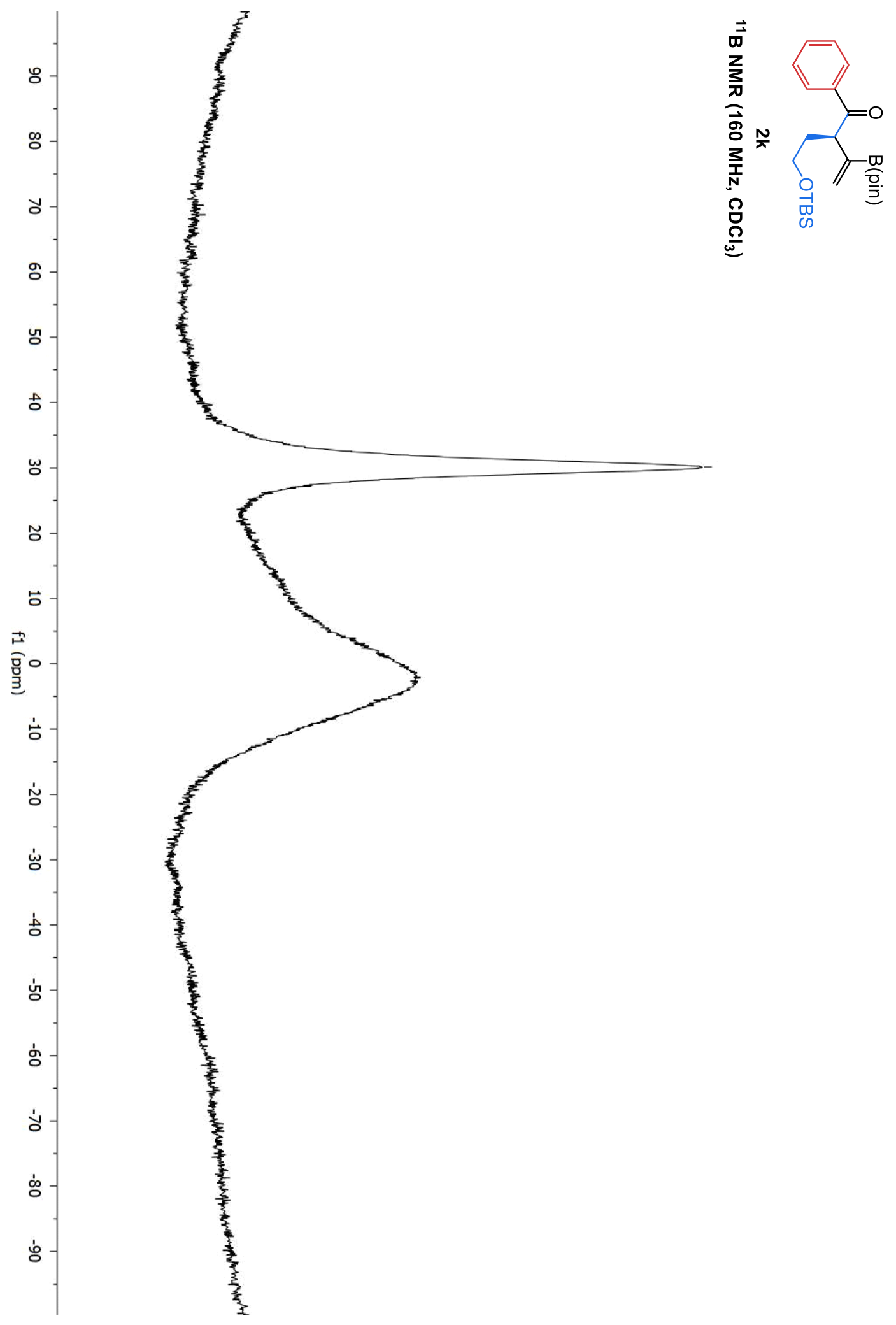

$-30.12$ 


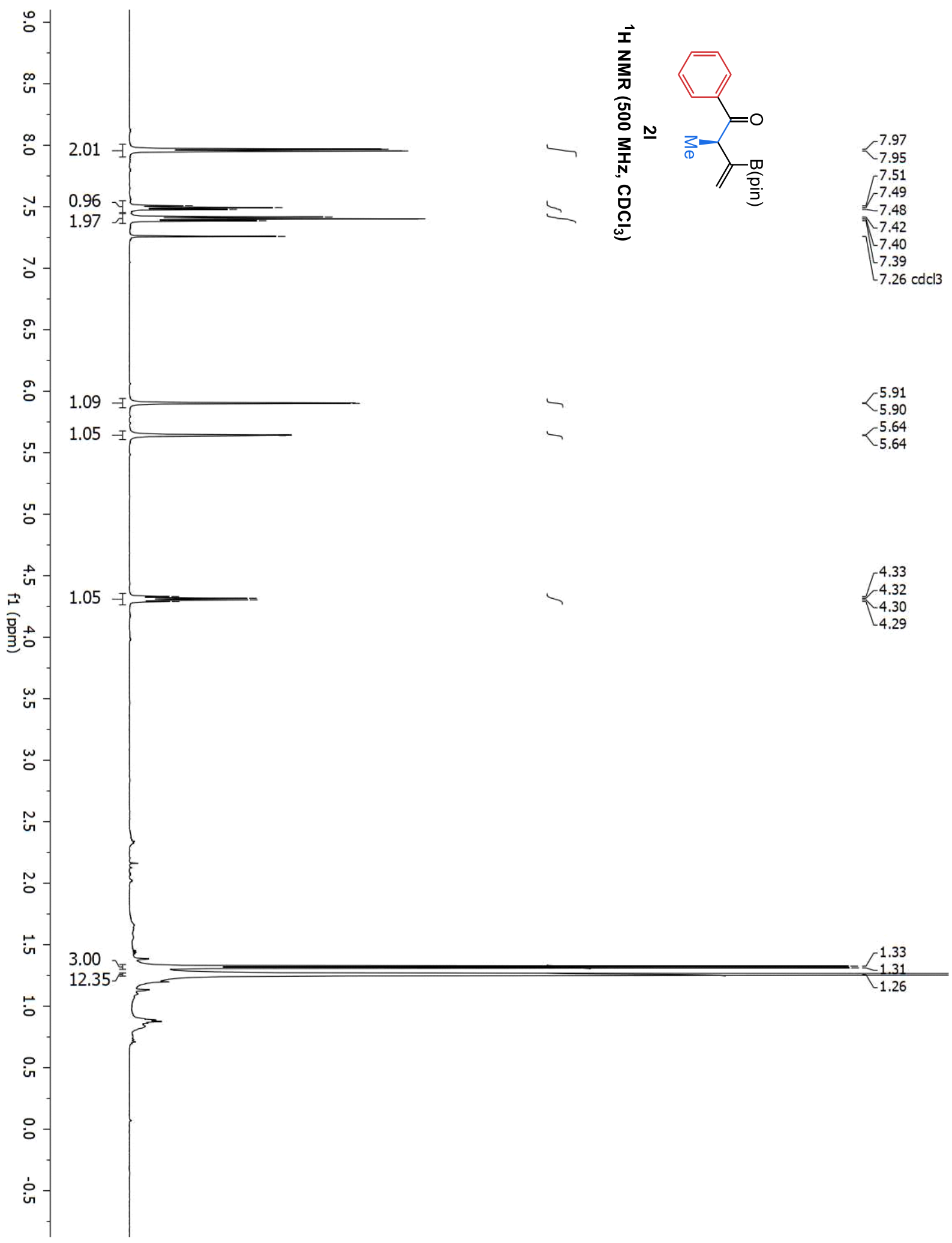




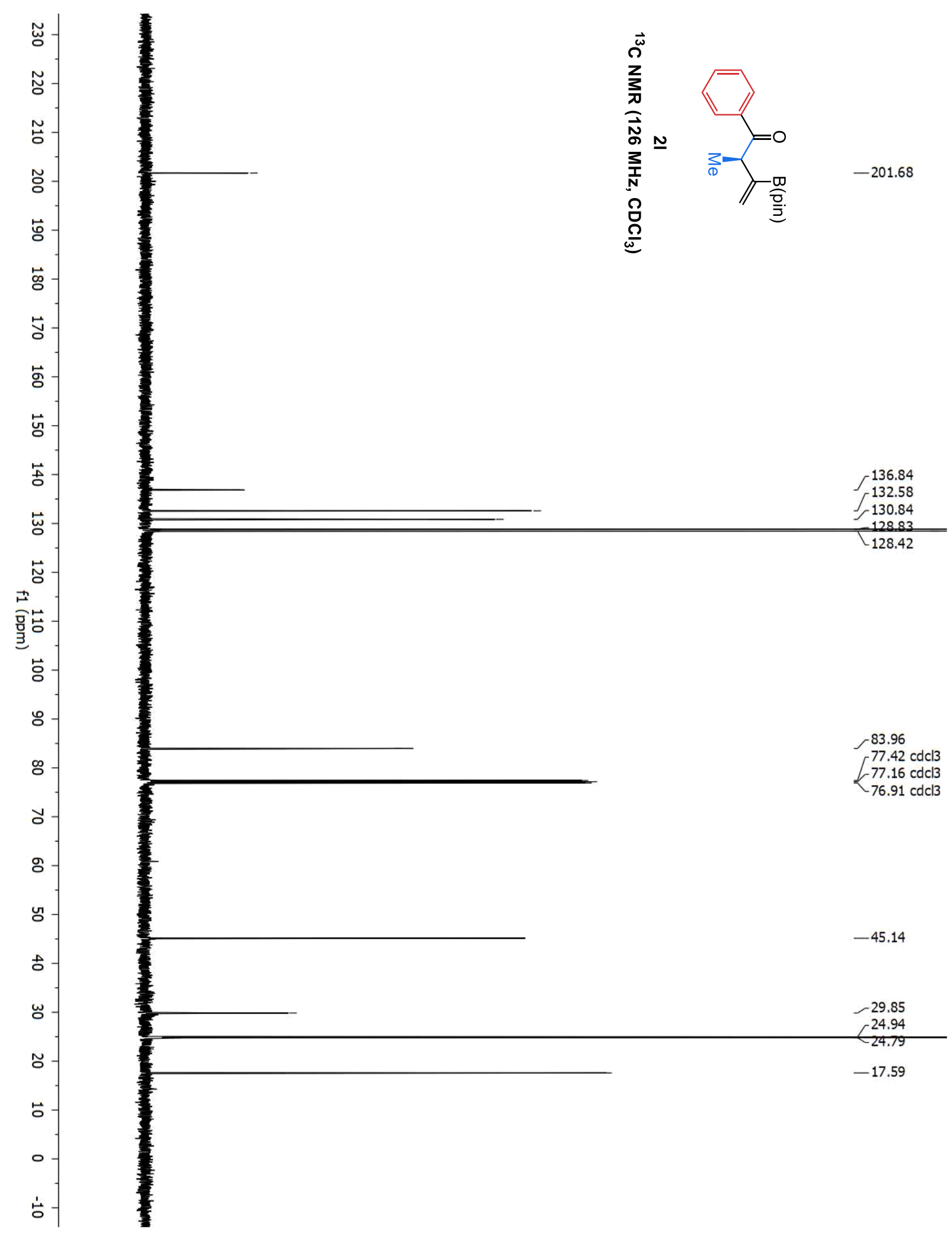



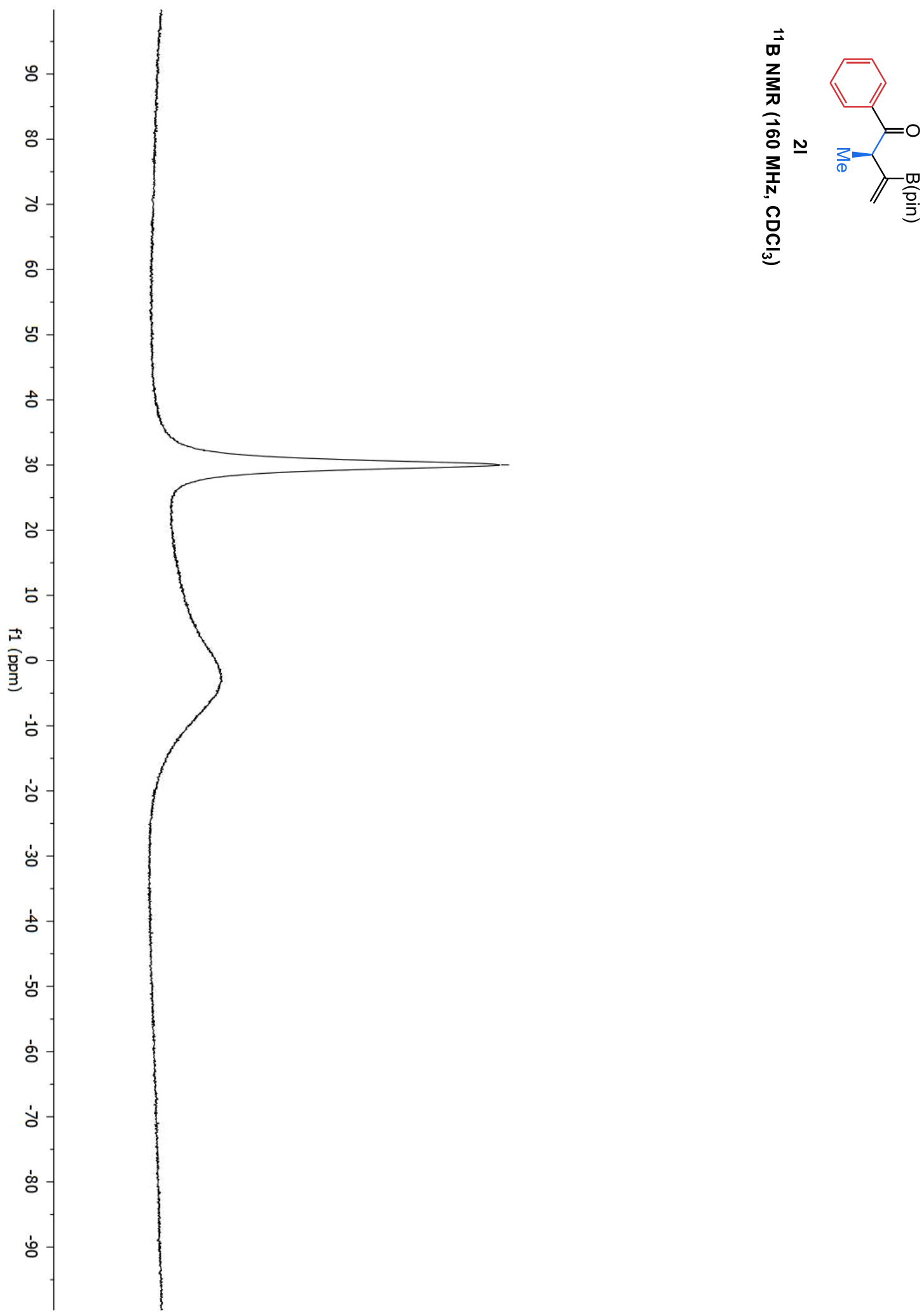


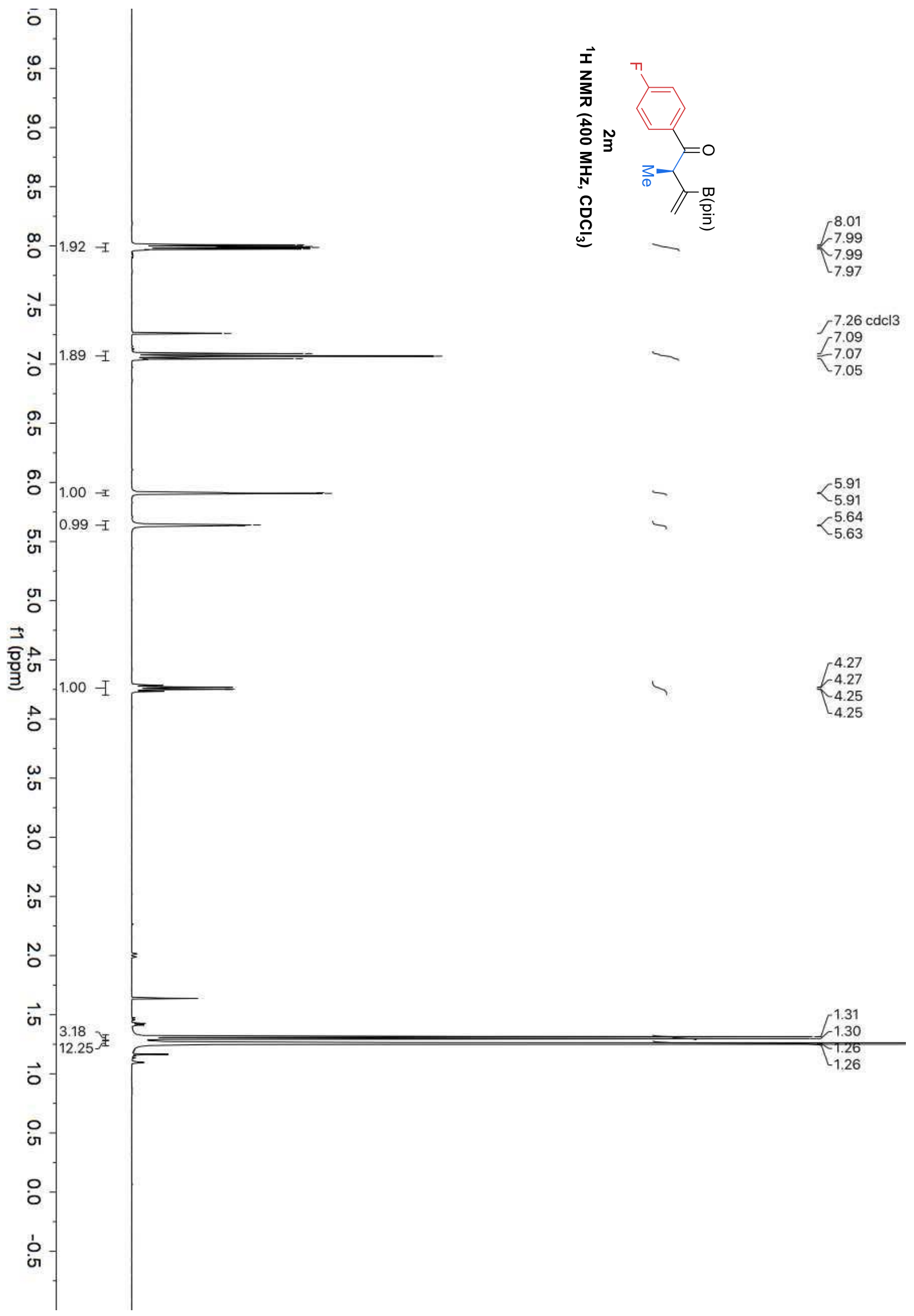




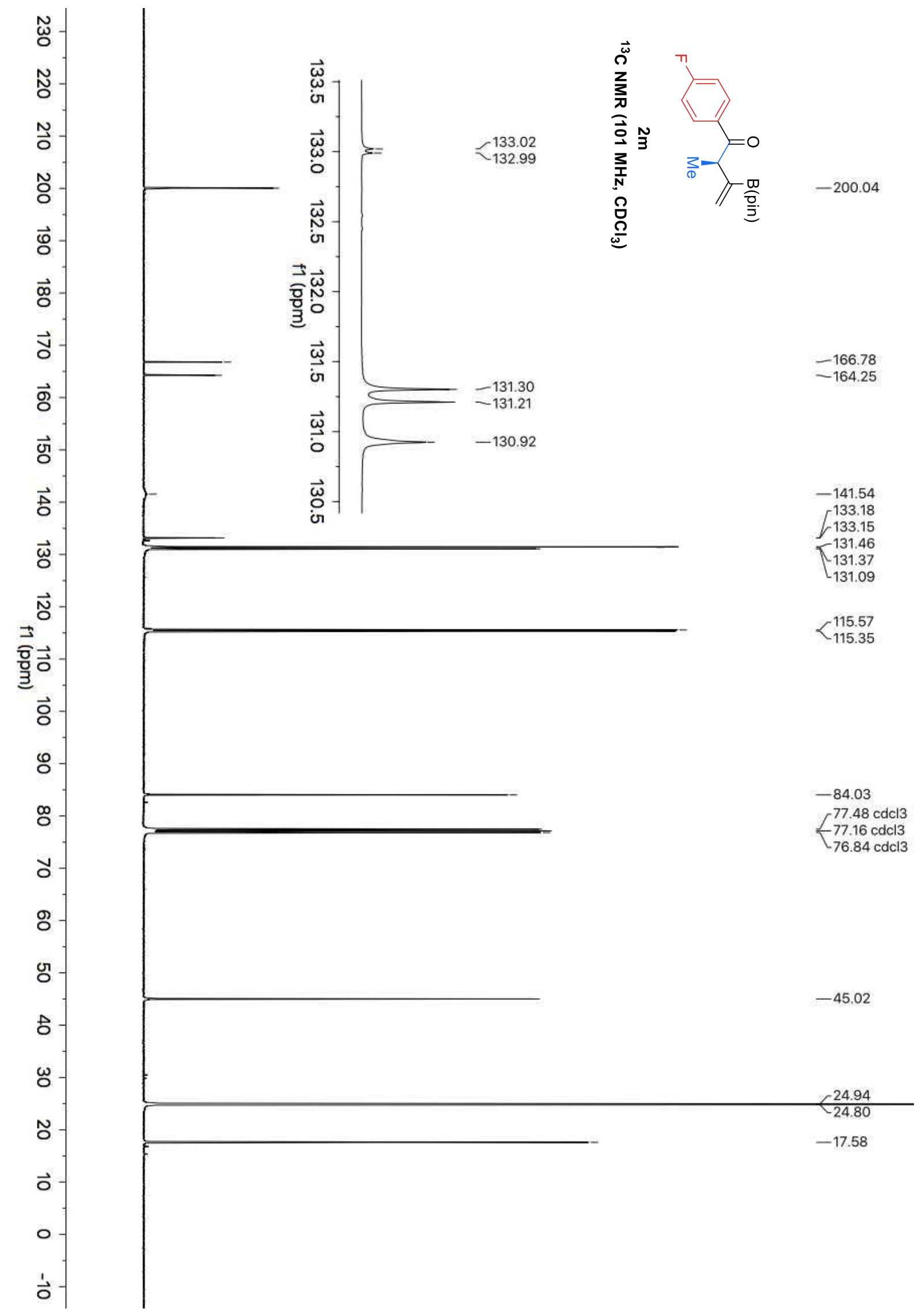




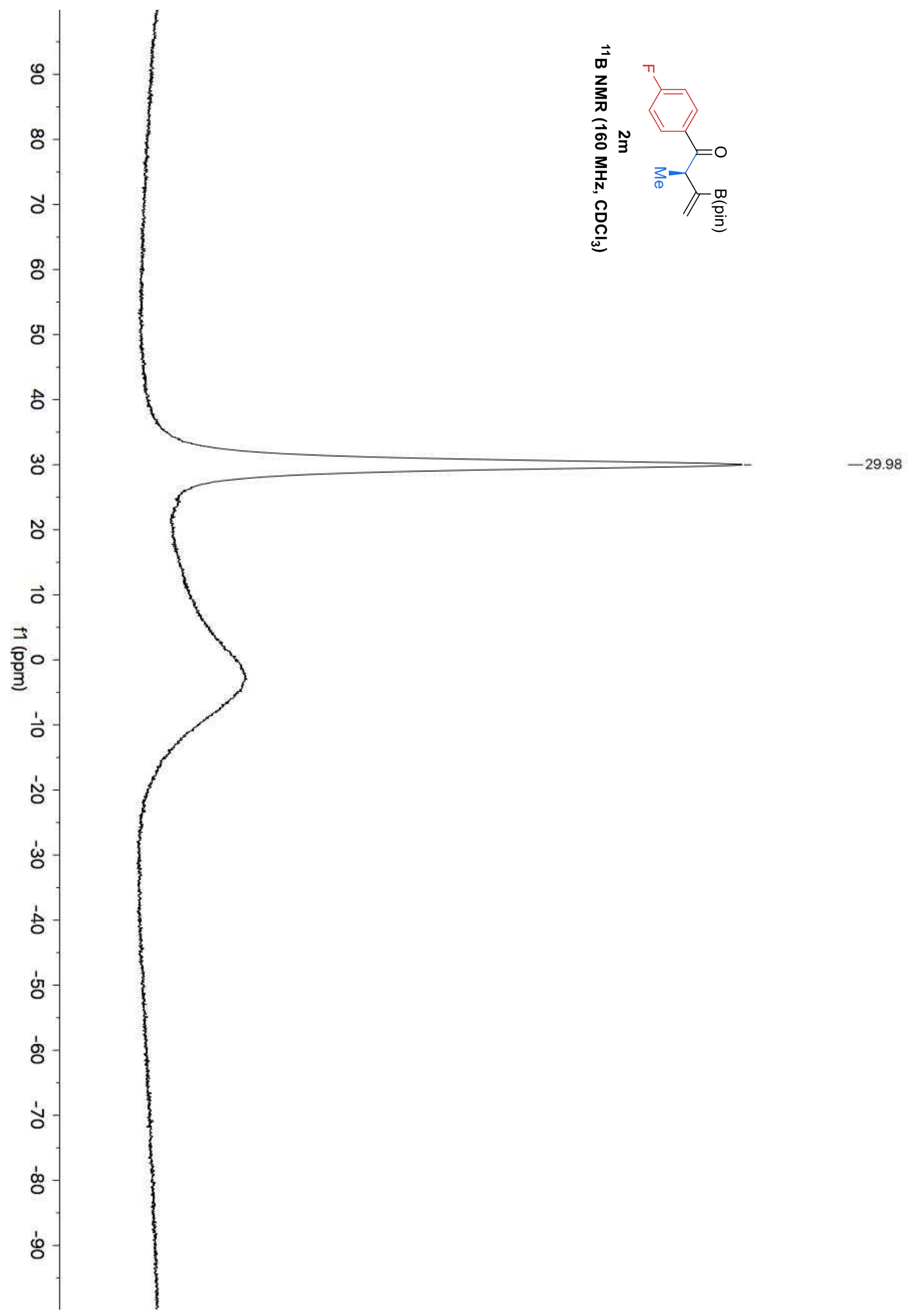




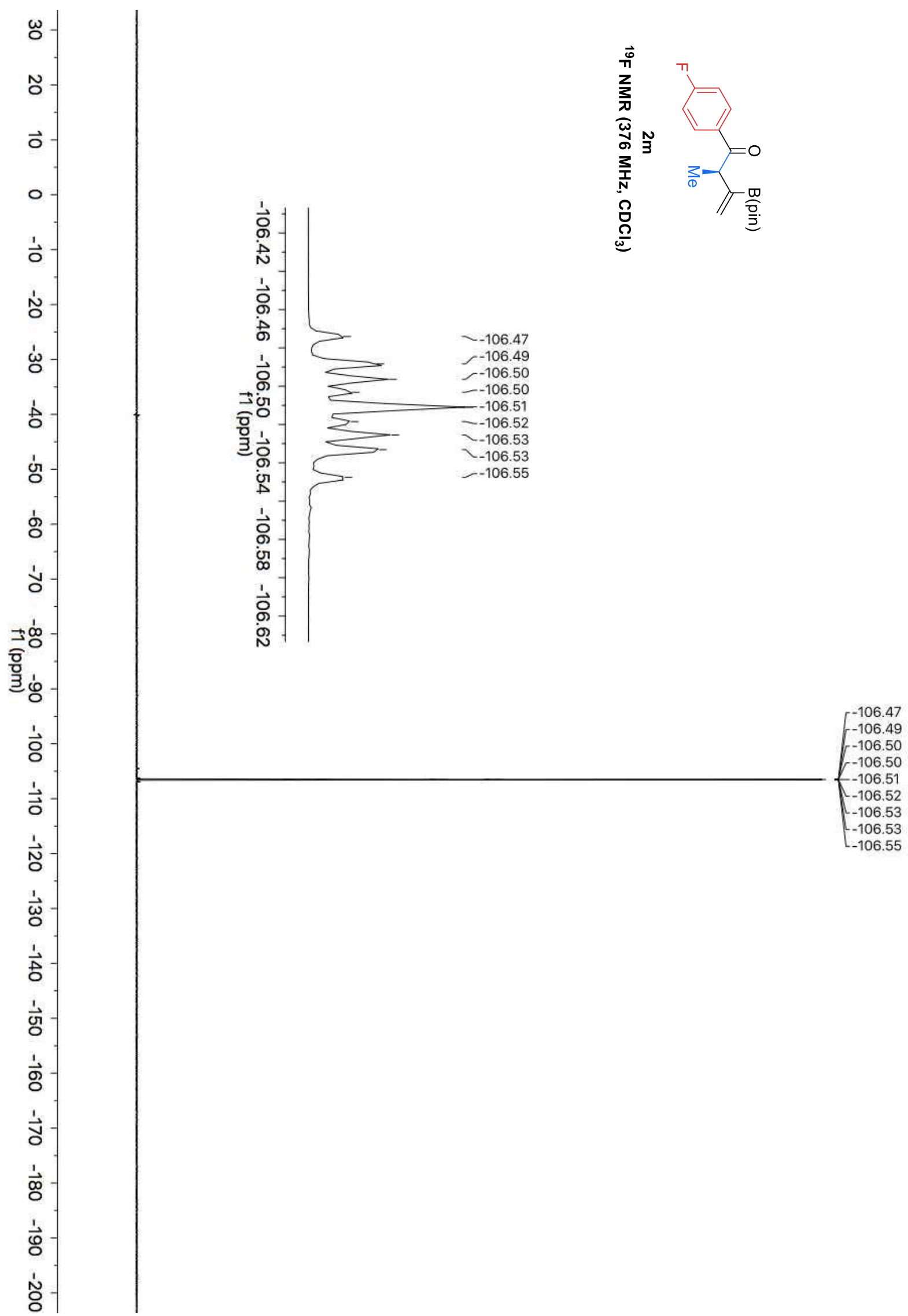




\subsection{With $\alpha, \beta$-unsaturated nitriles}

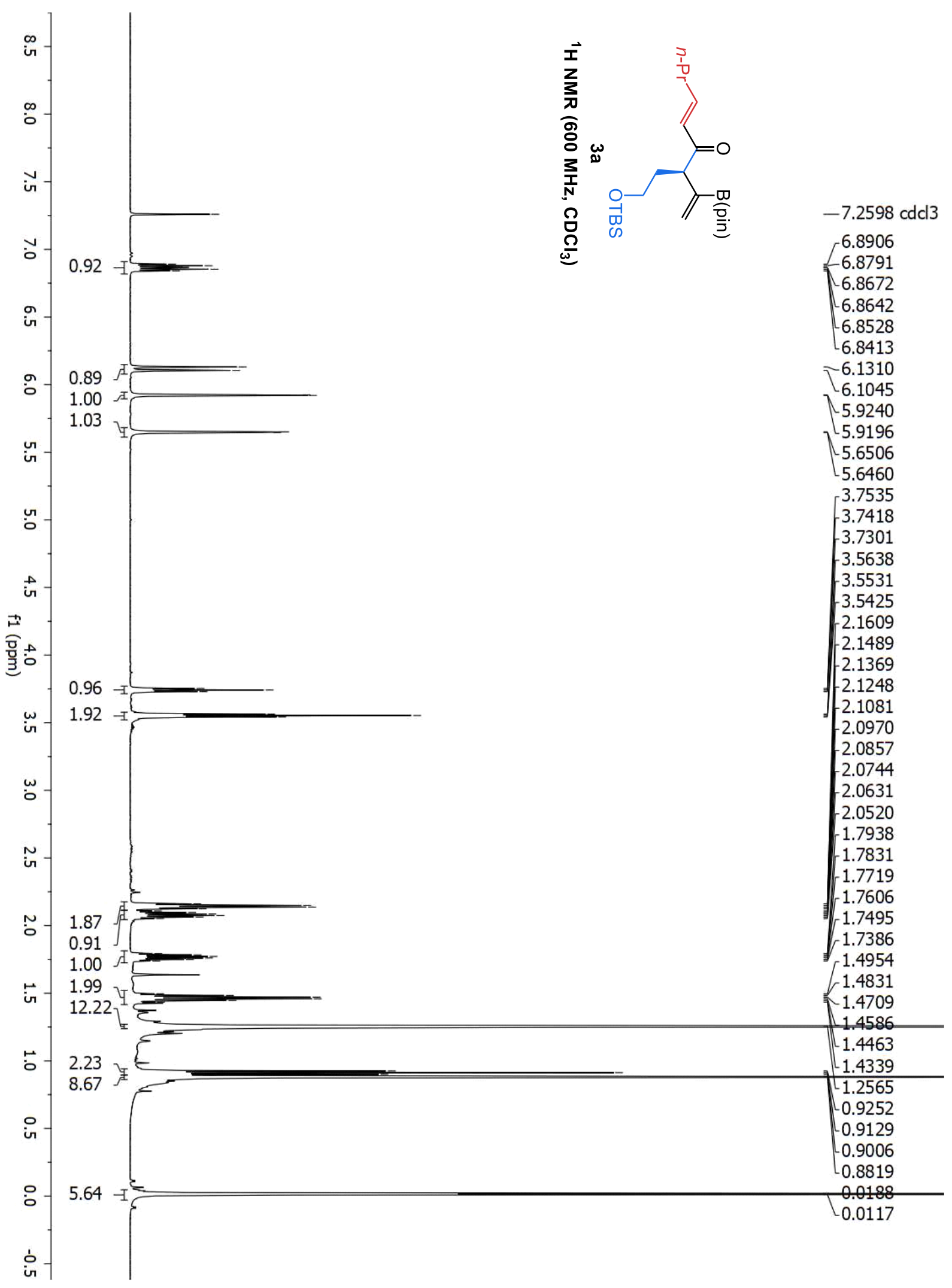


Del Pozo, et al., Supplementary Materials; Page 156

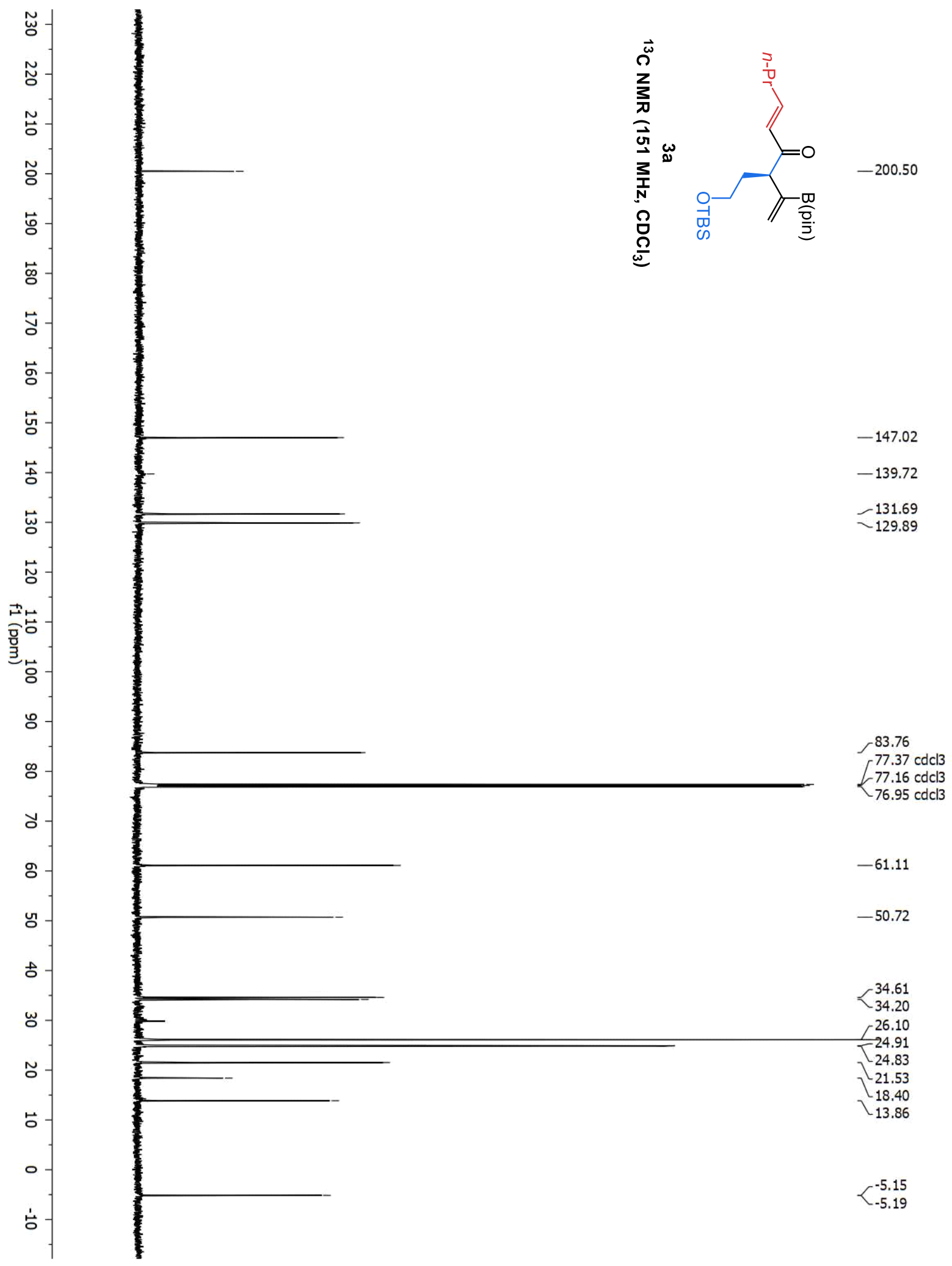



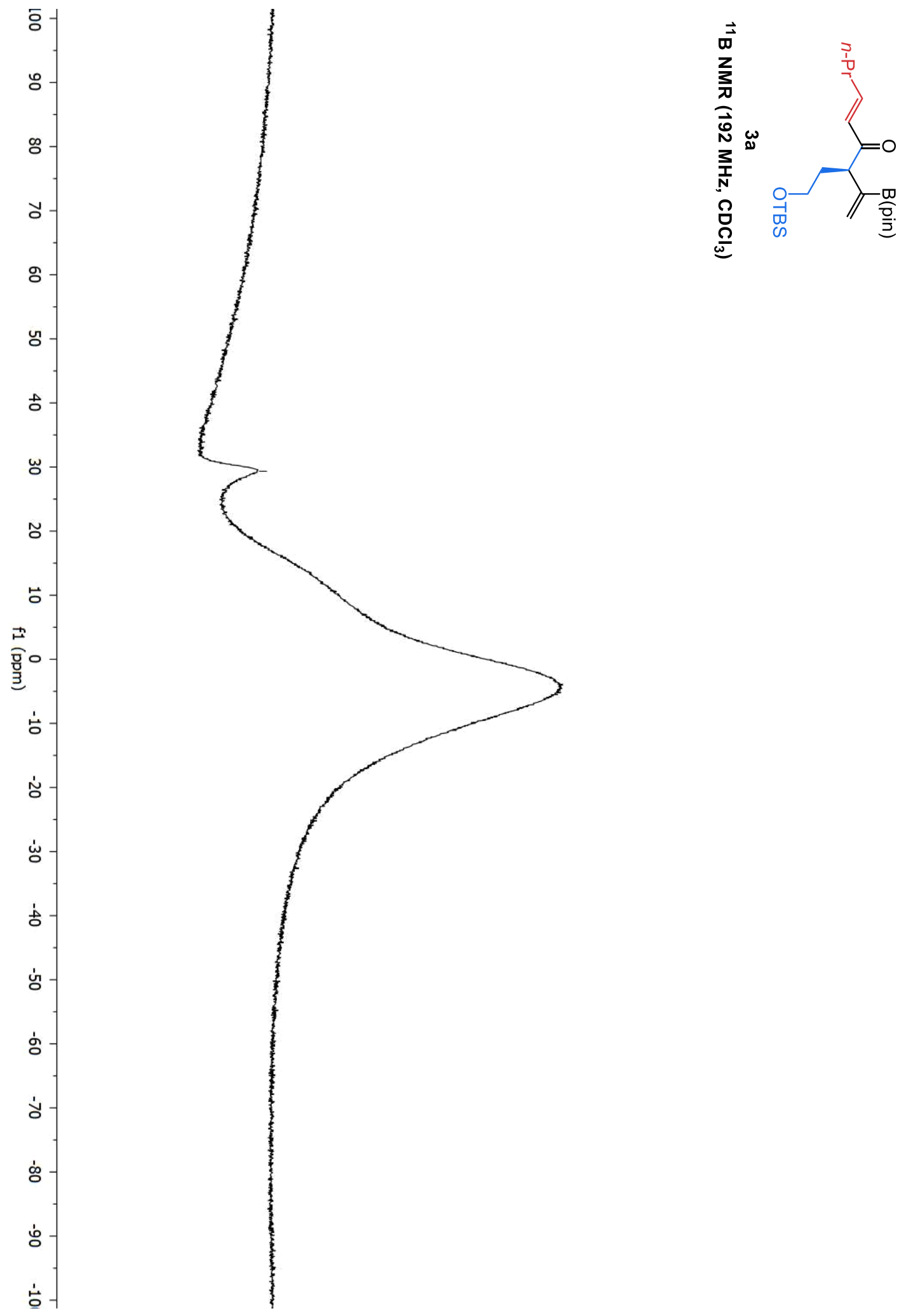


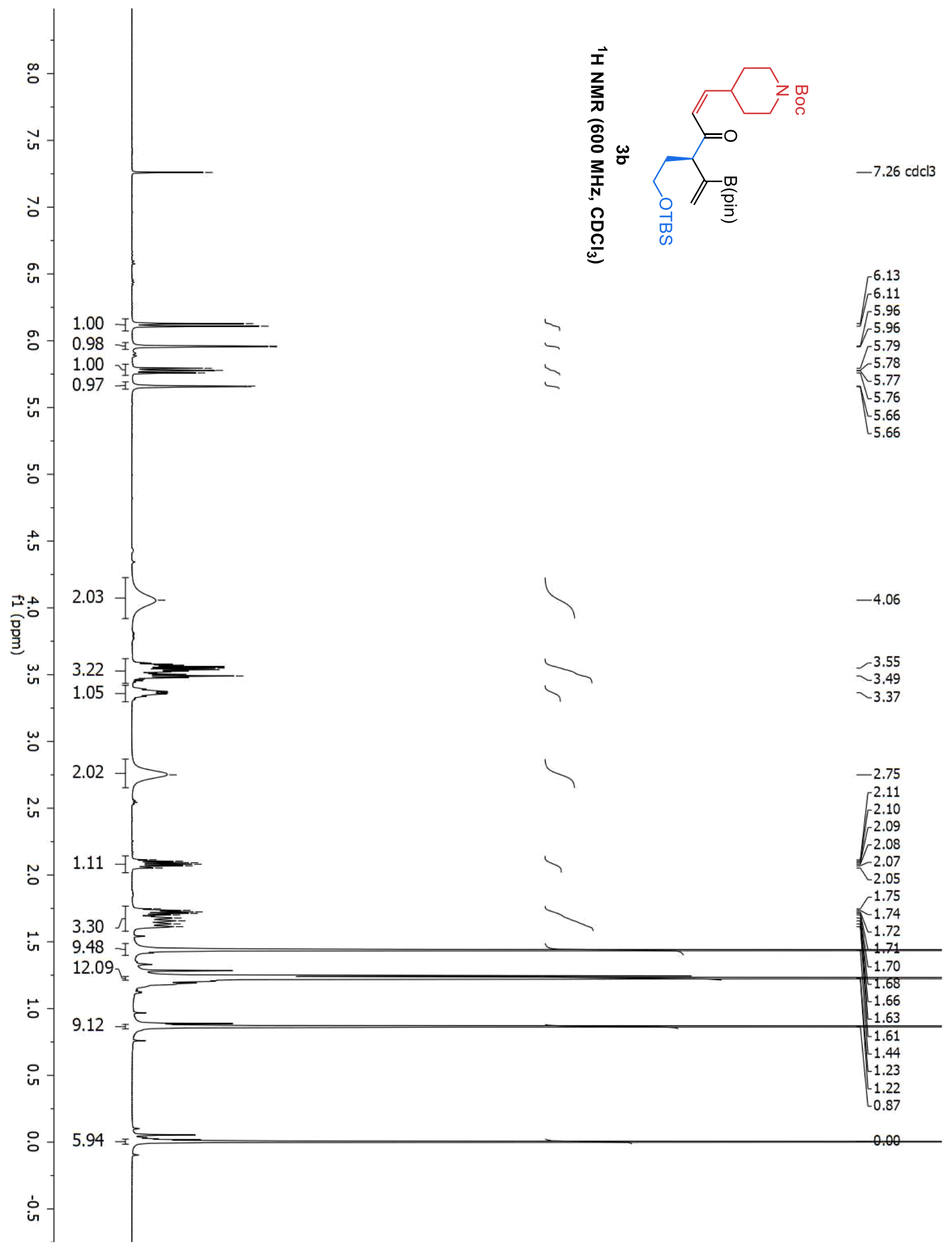


Del Pozo, et al., Supplementary Materials; Page 159

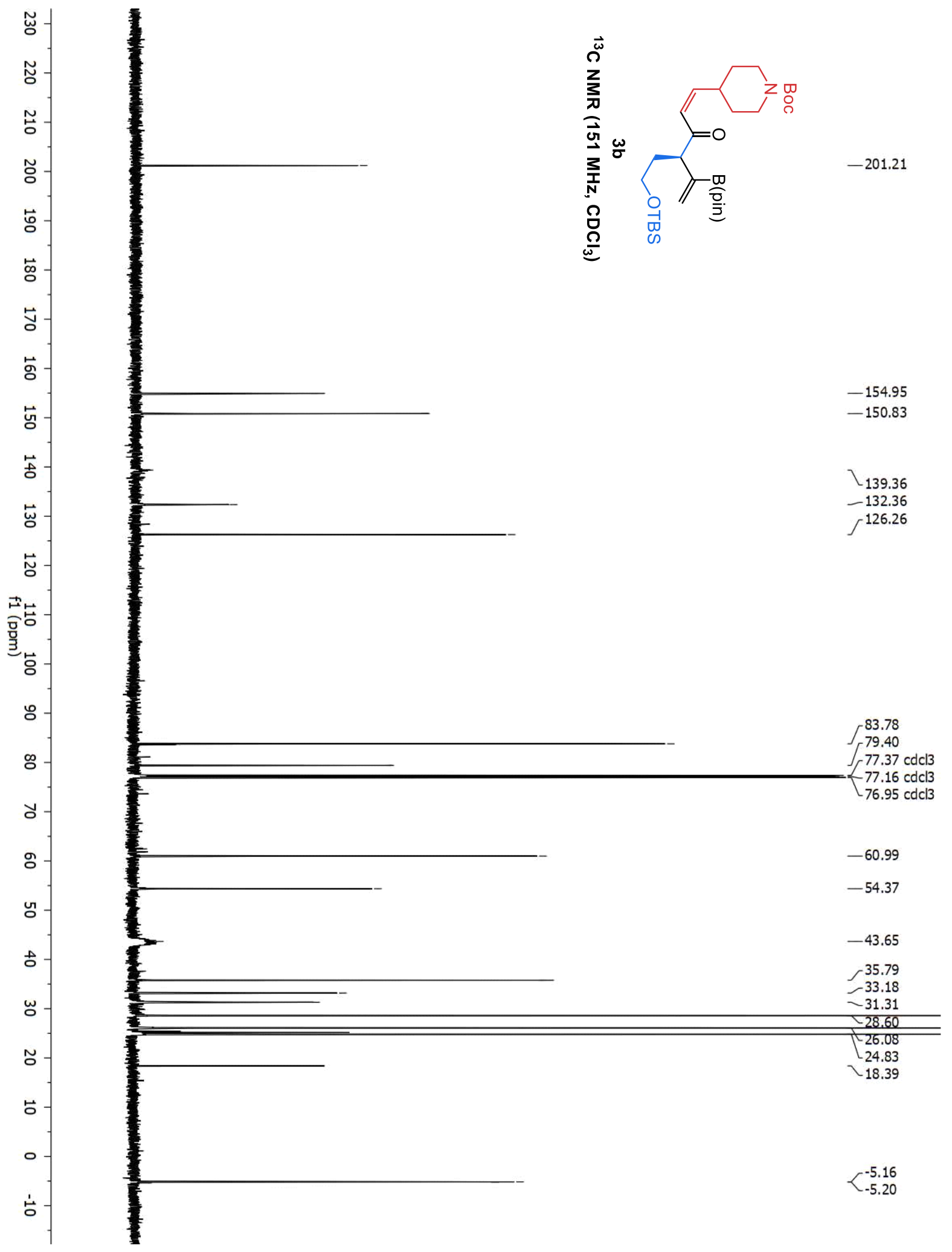




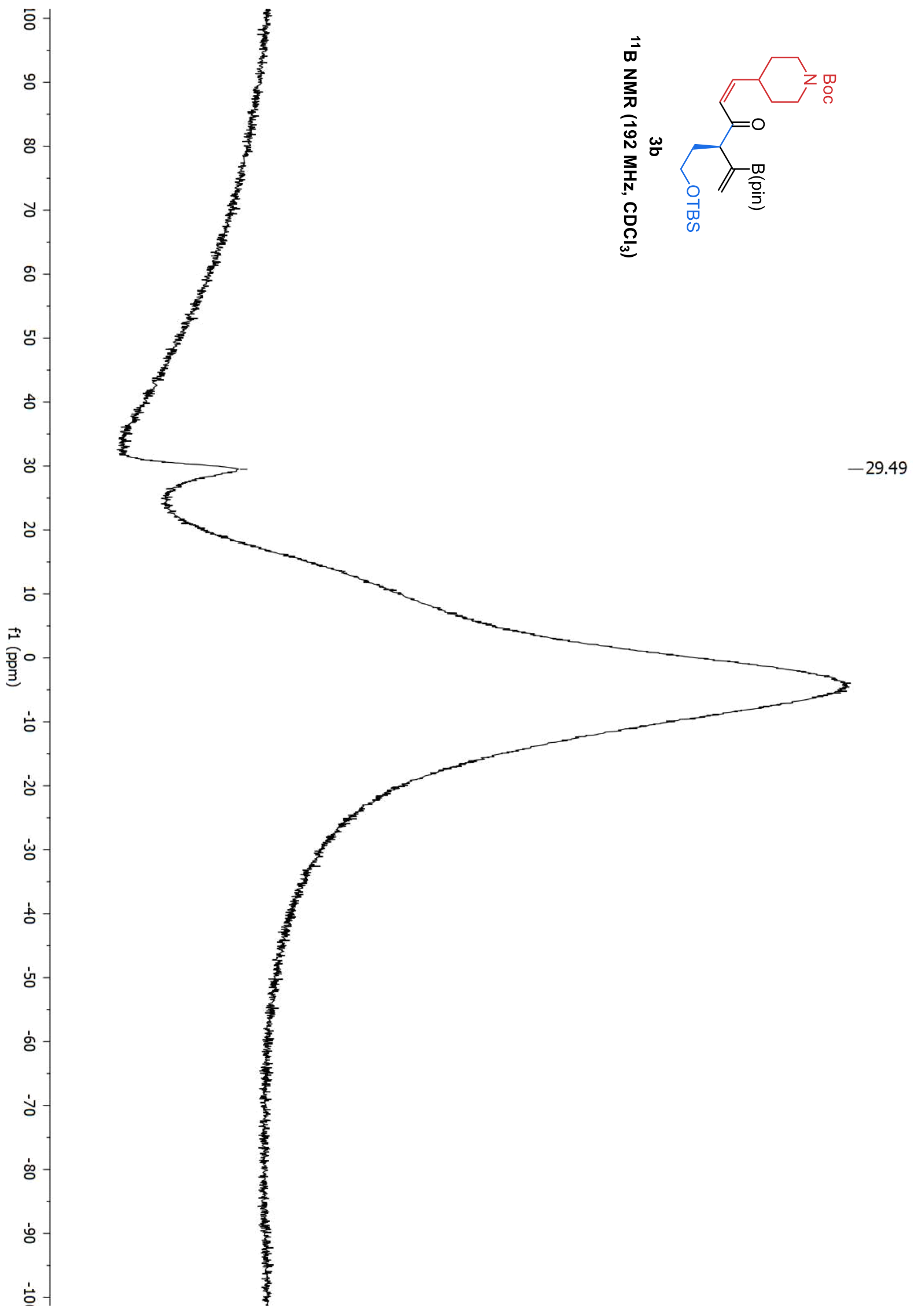




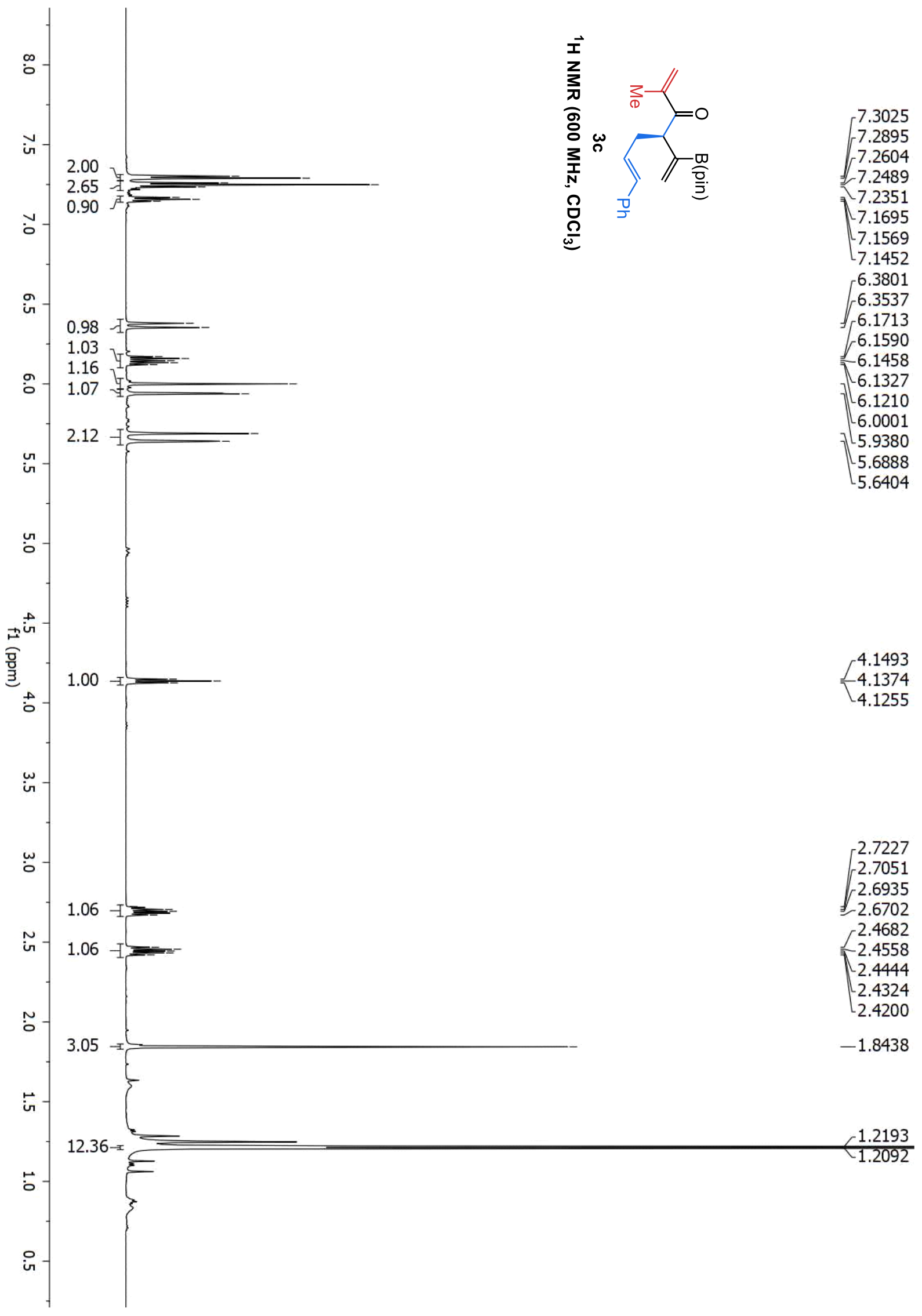




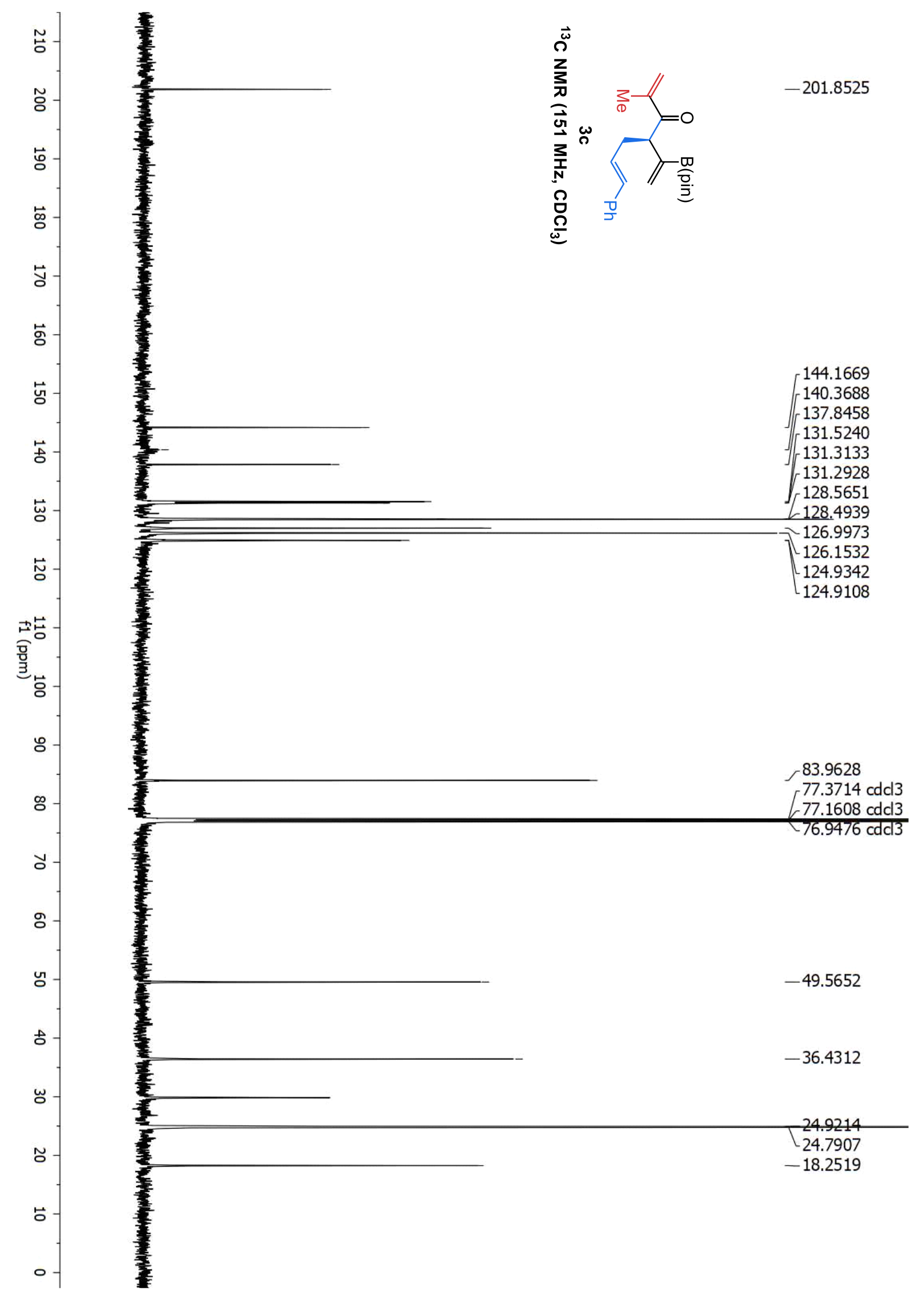


Del Pozo, et al., Supplementary Materials; Page 163

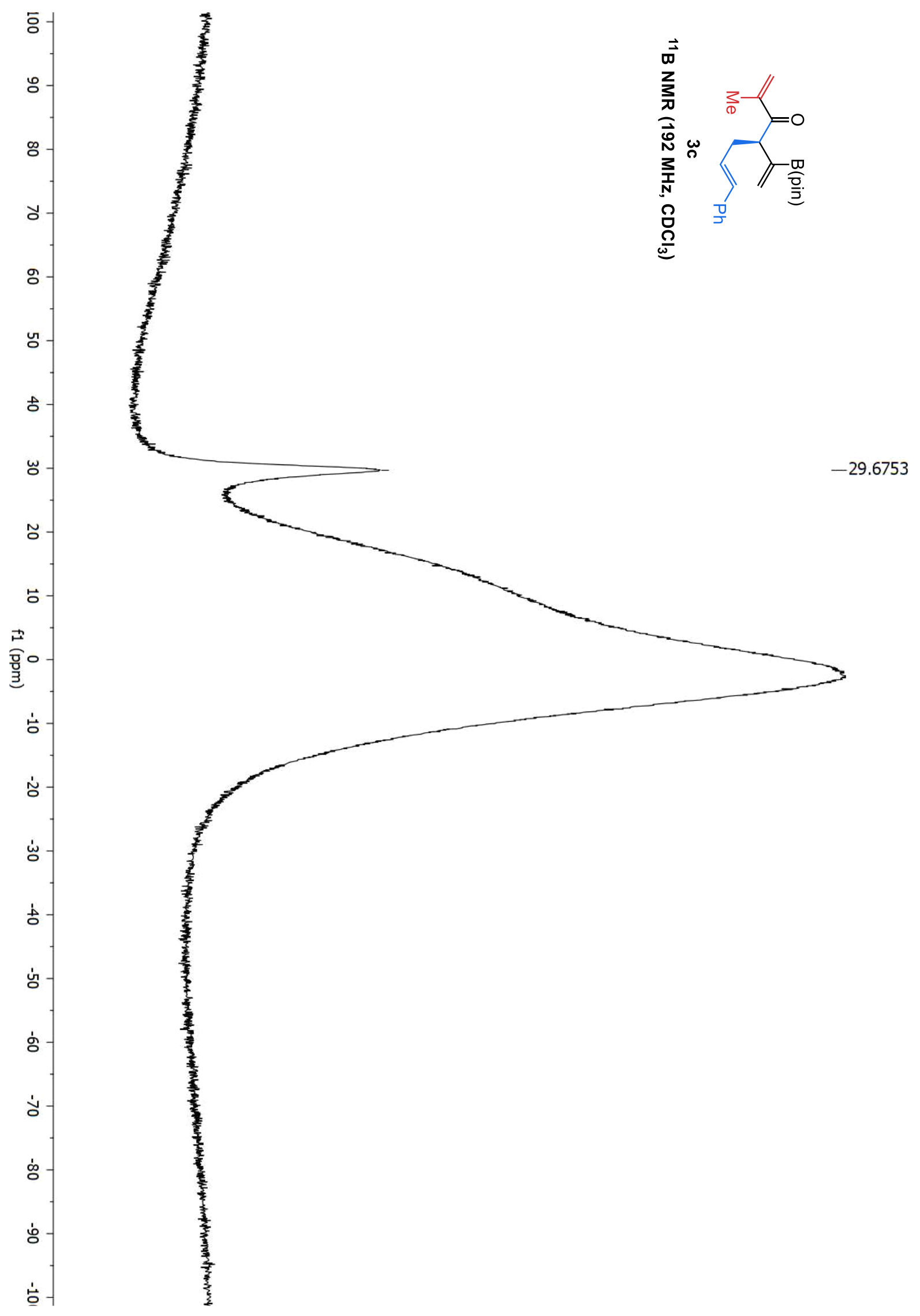




\subsection{With alkyl nitriles}

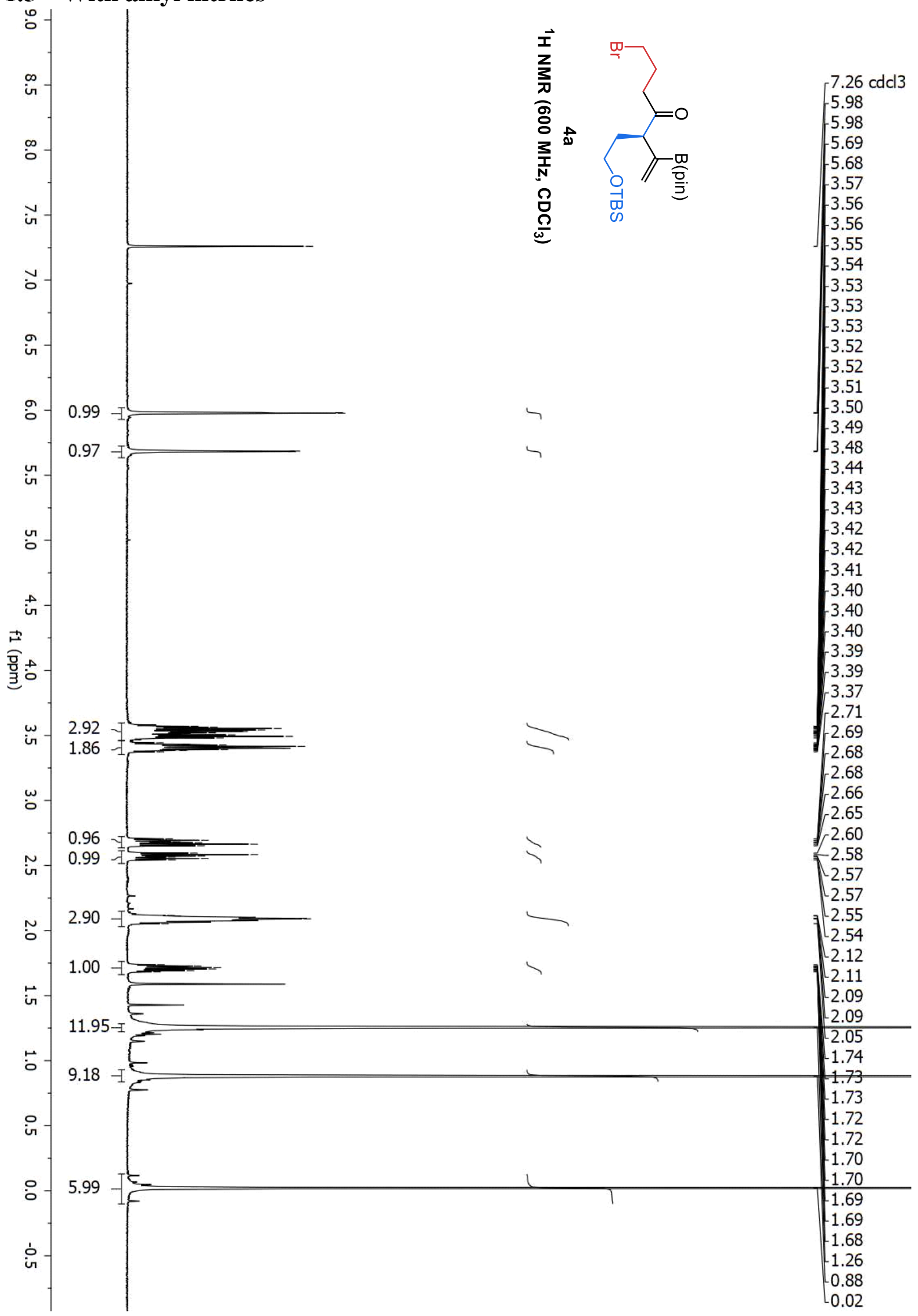




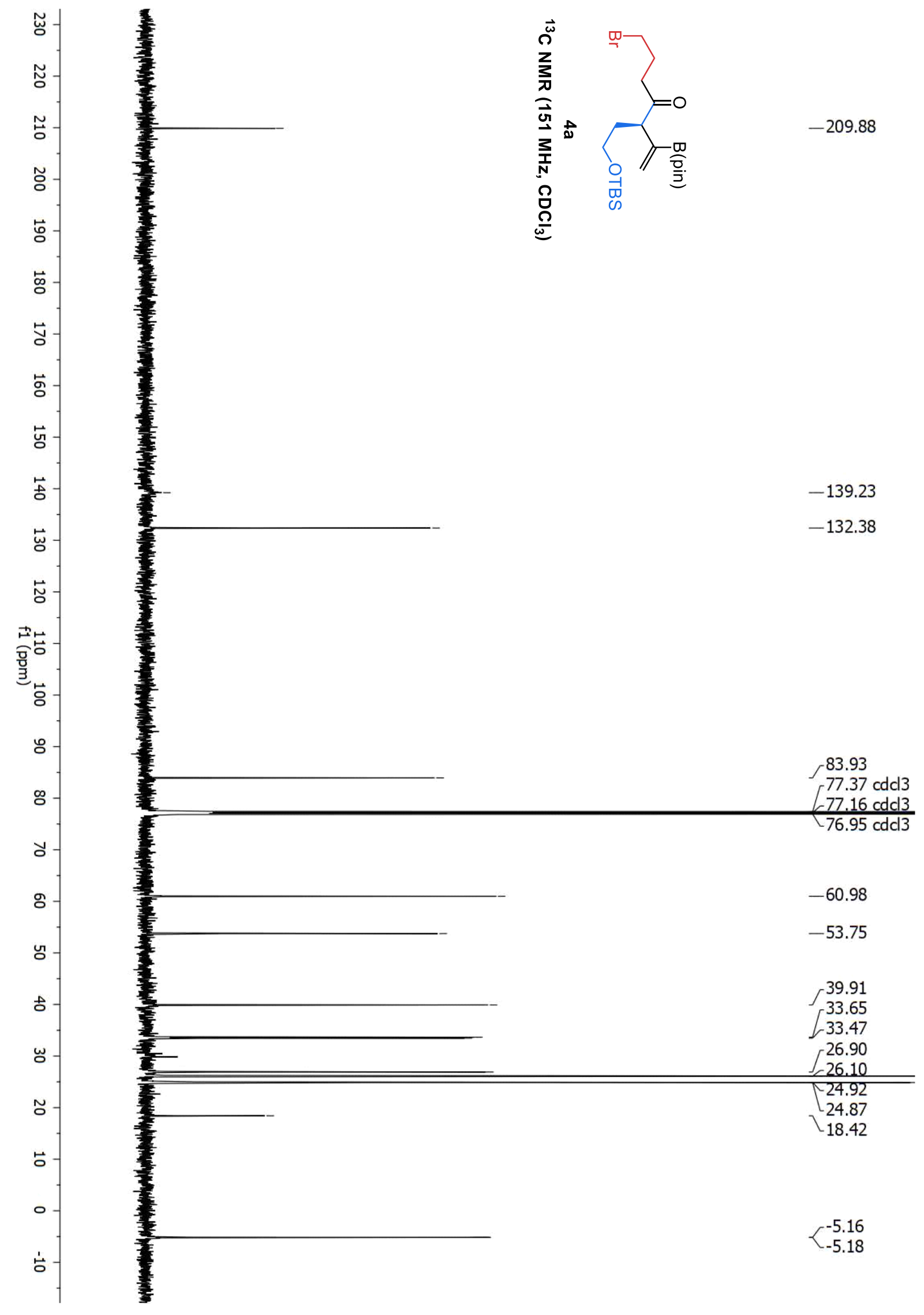




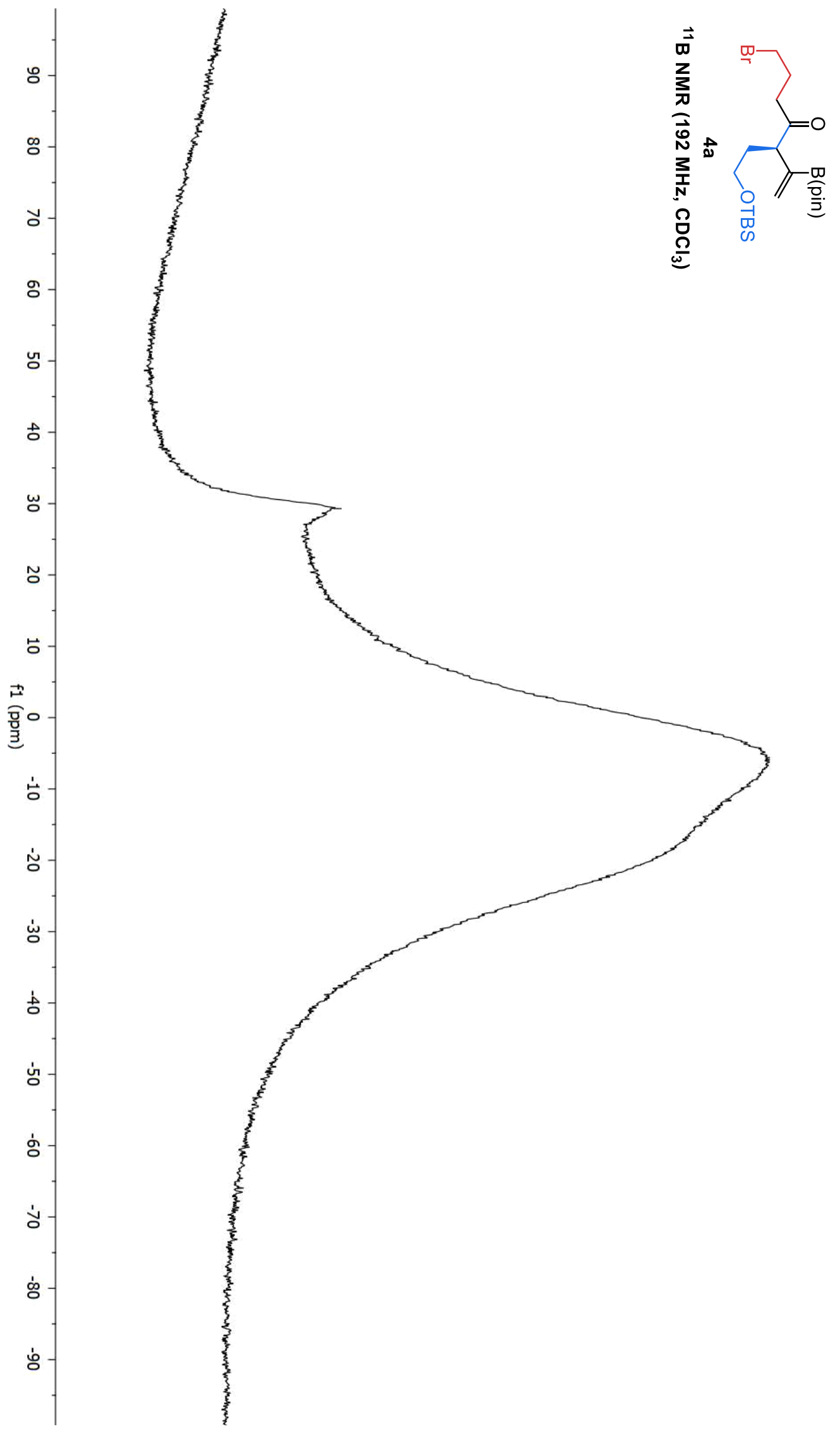




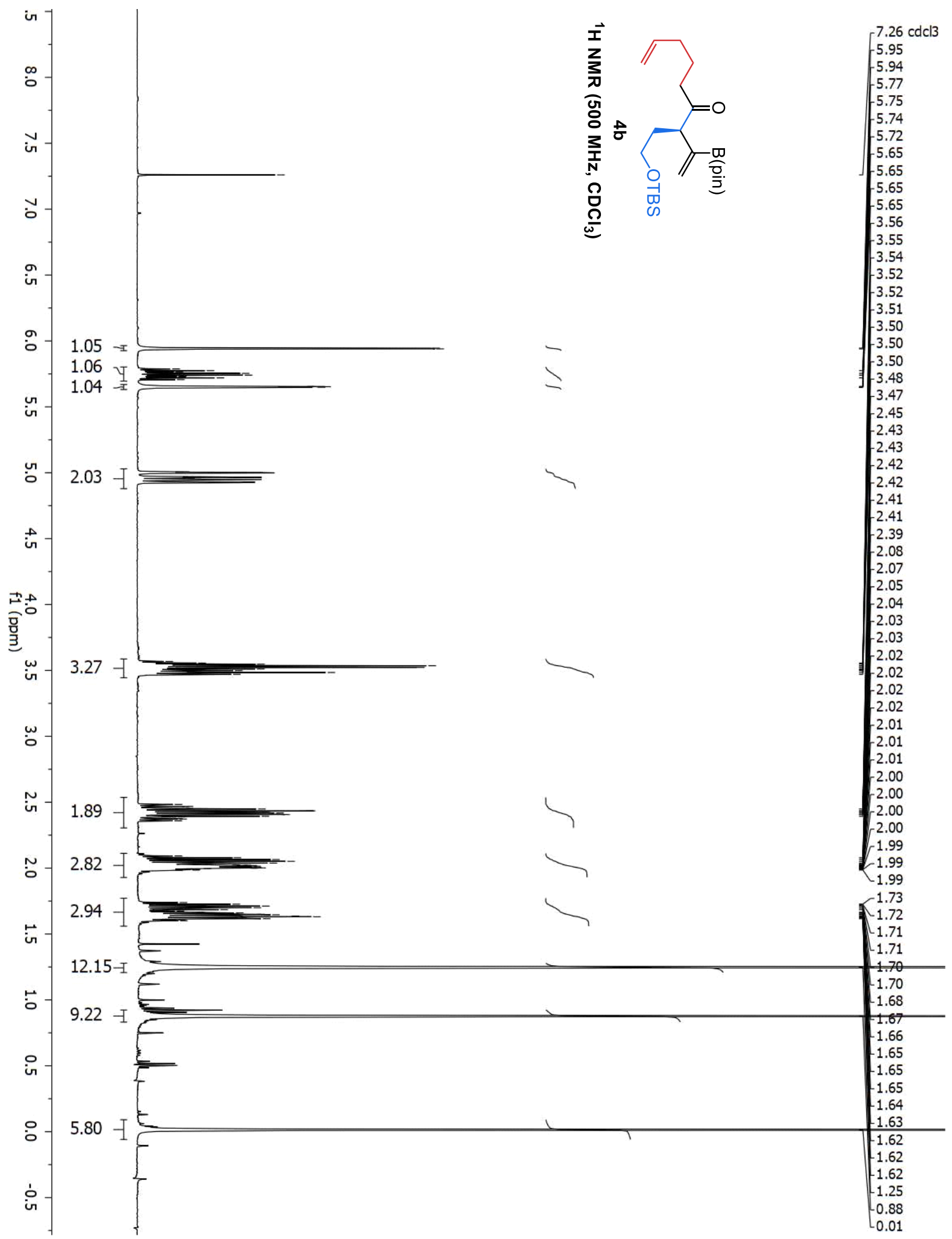




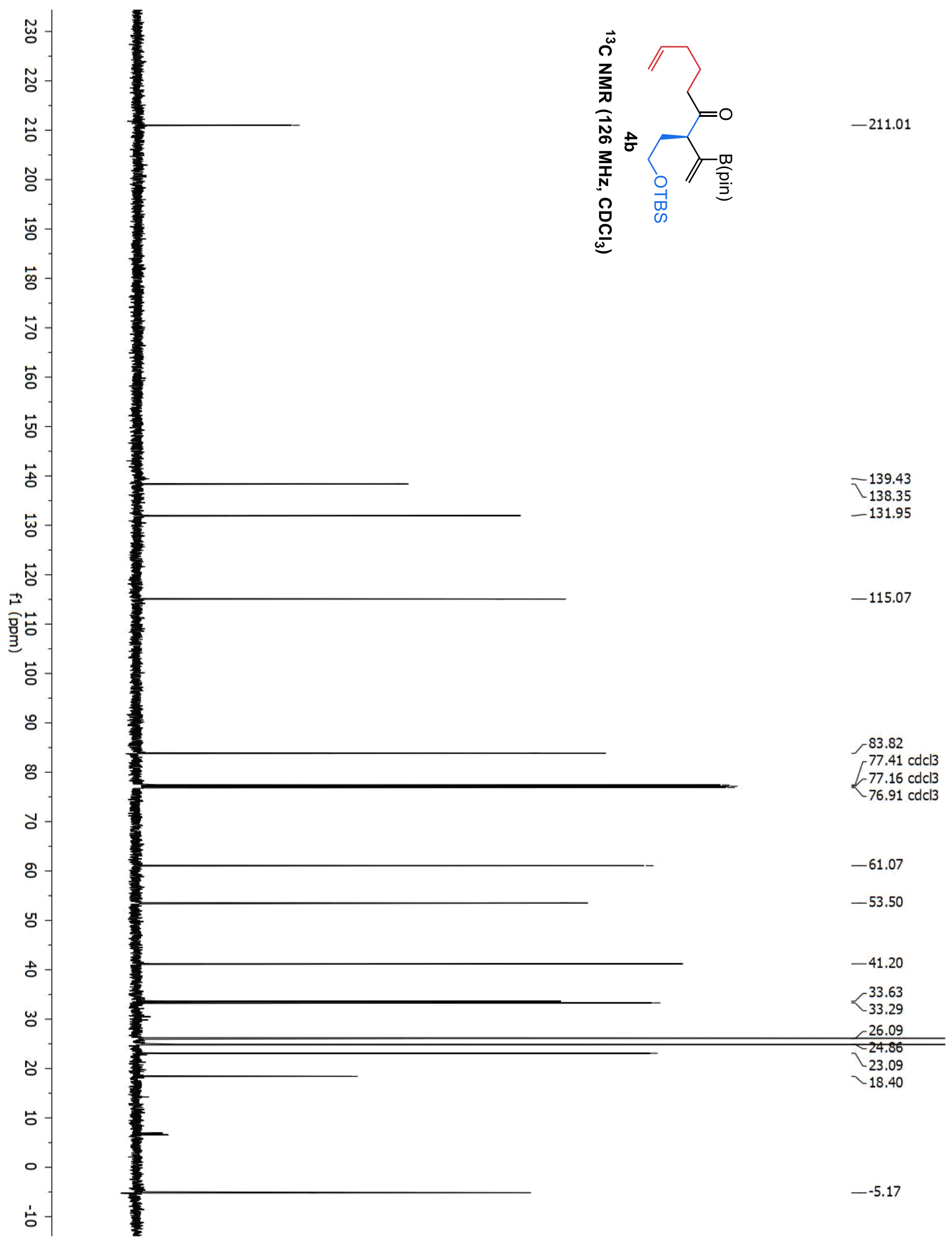


Del Pozo, et al., Supplementary Materials; Page 169
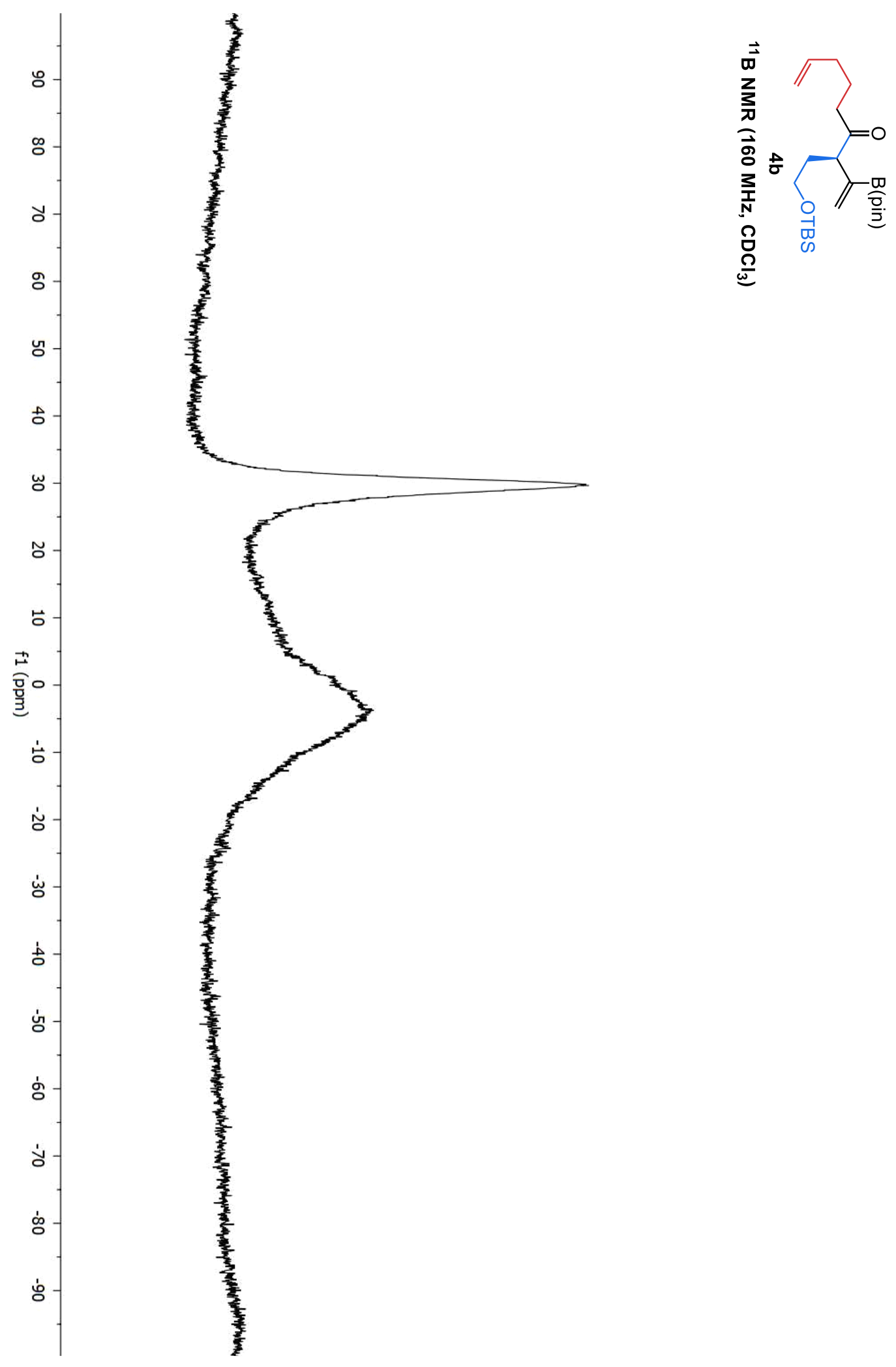

$-29.66$ 


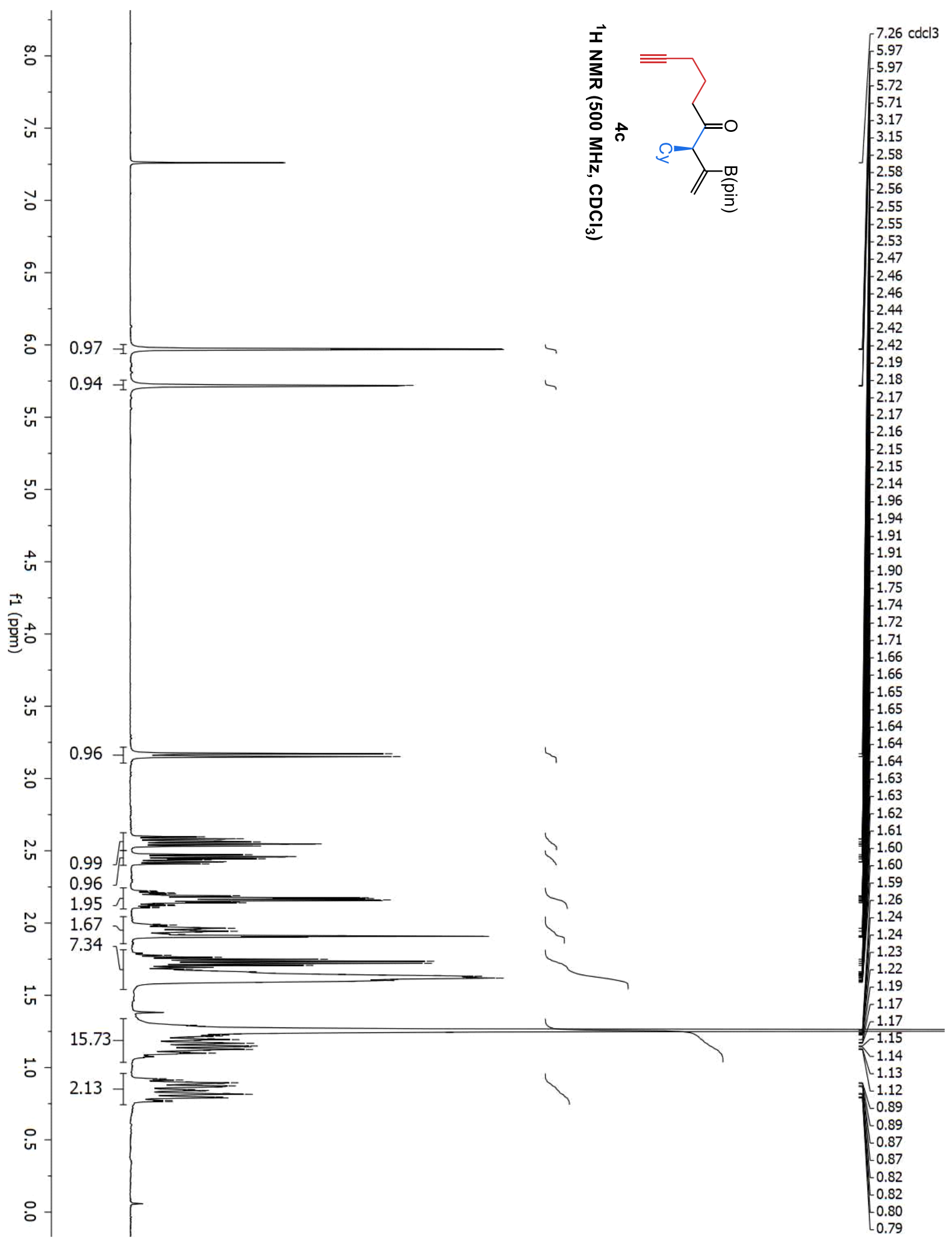




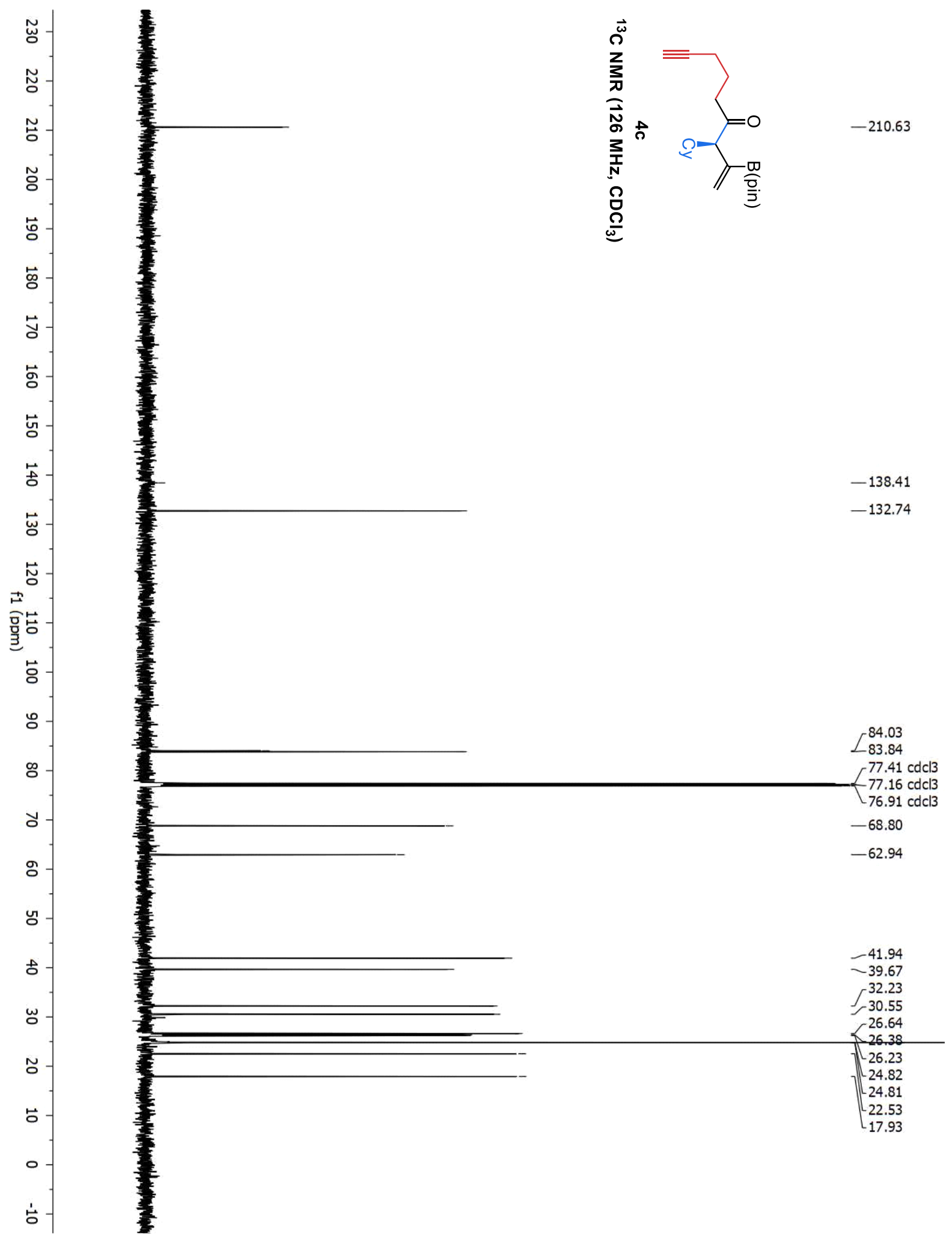


Del Pozo, et al., Supplementary Materials; Page 172

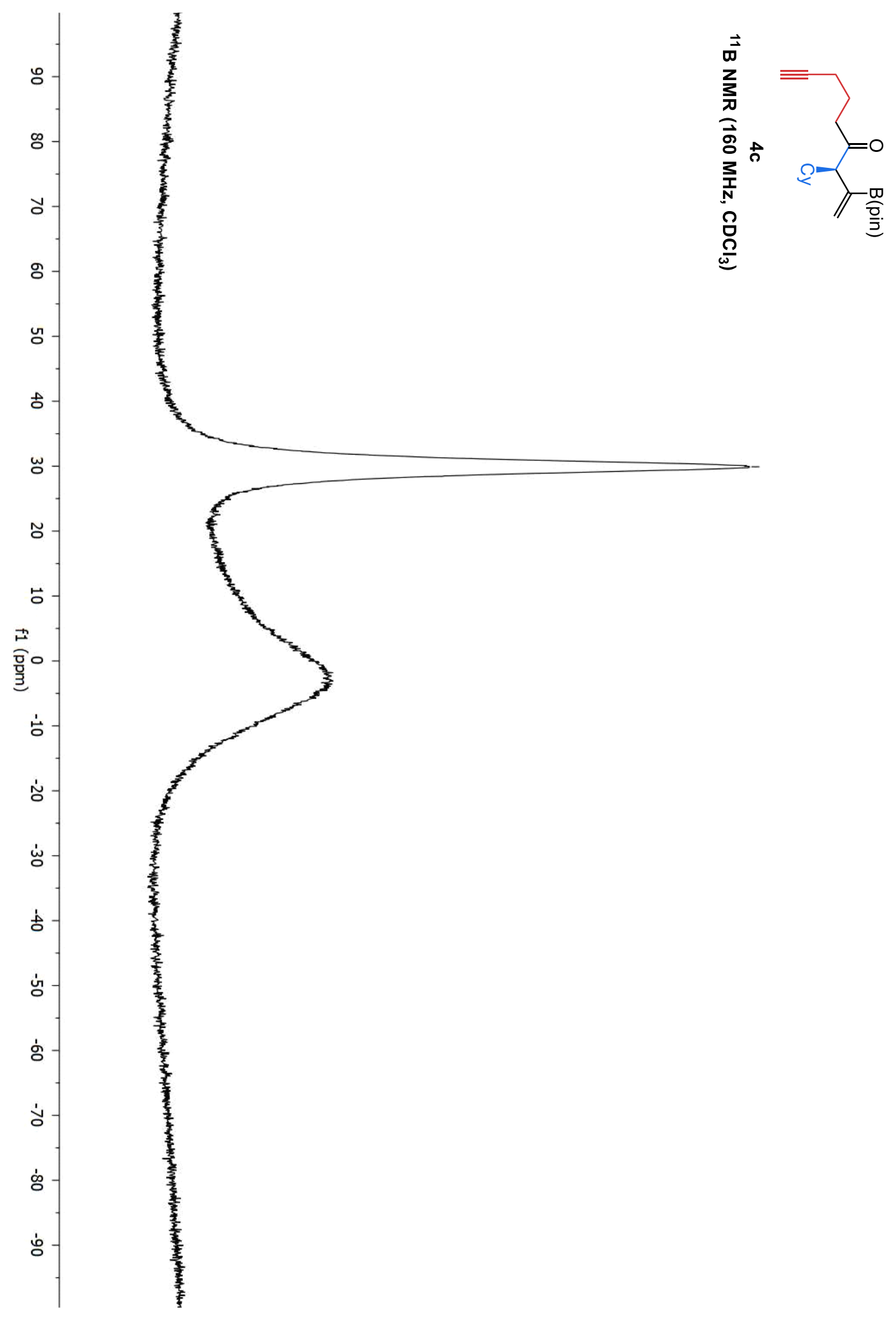

$-29.90$ 


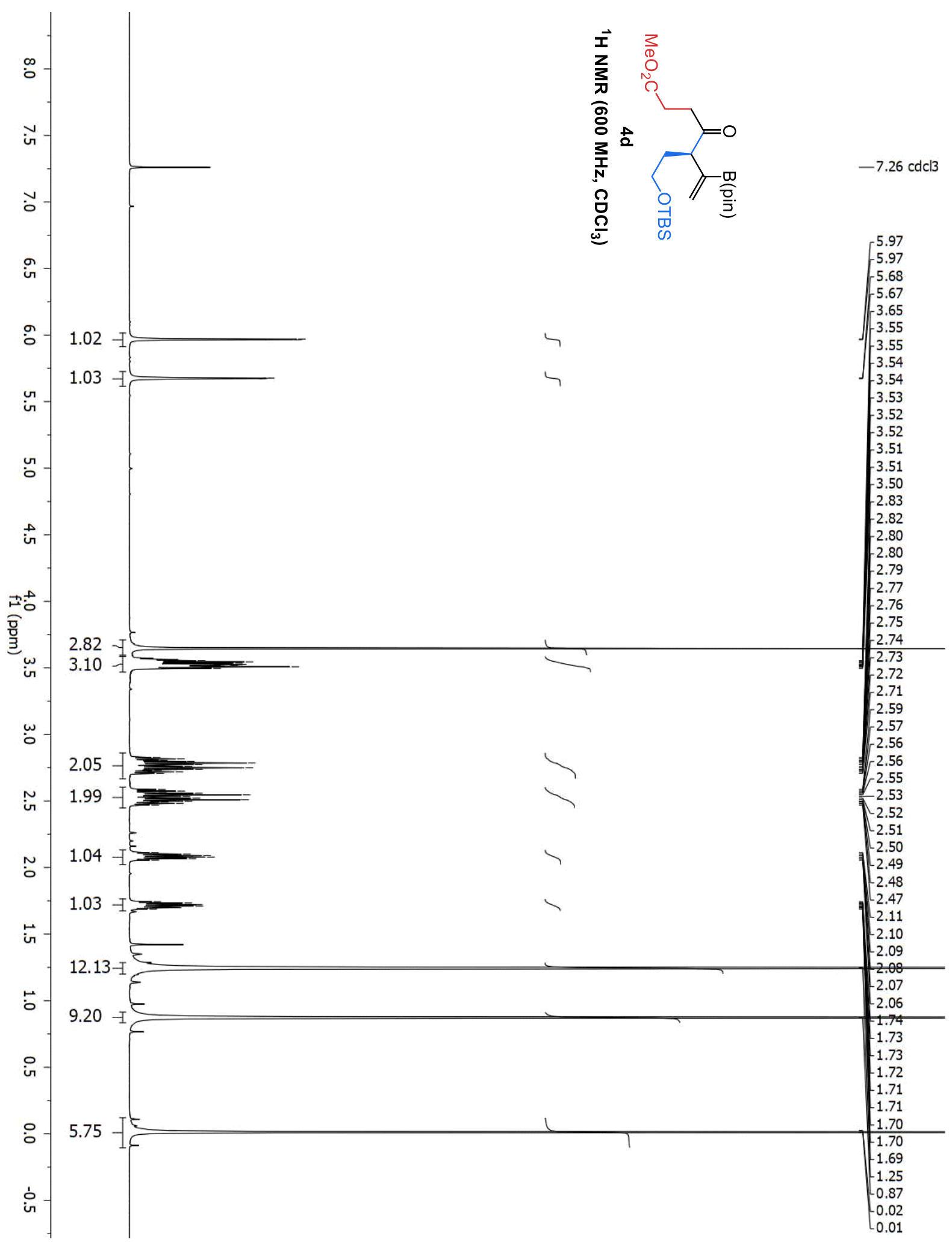


Del Pozo, et al., Supplementary Materials; Page 174

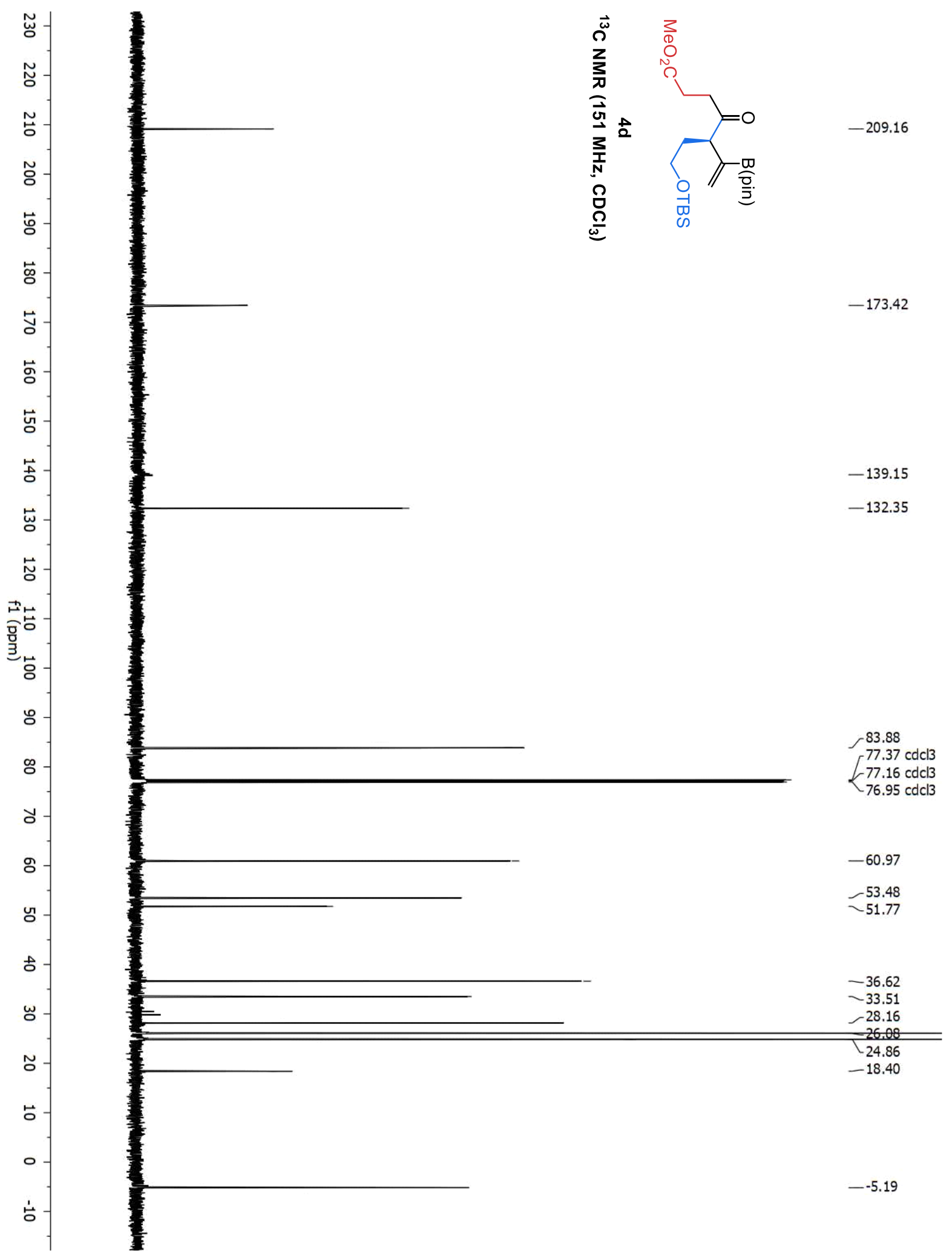



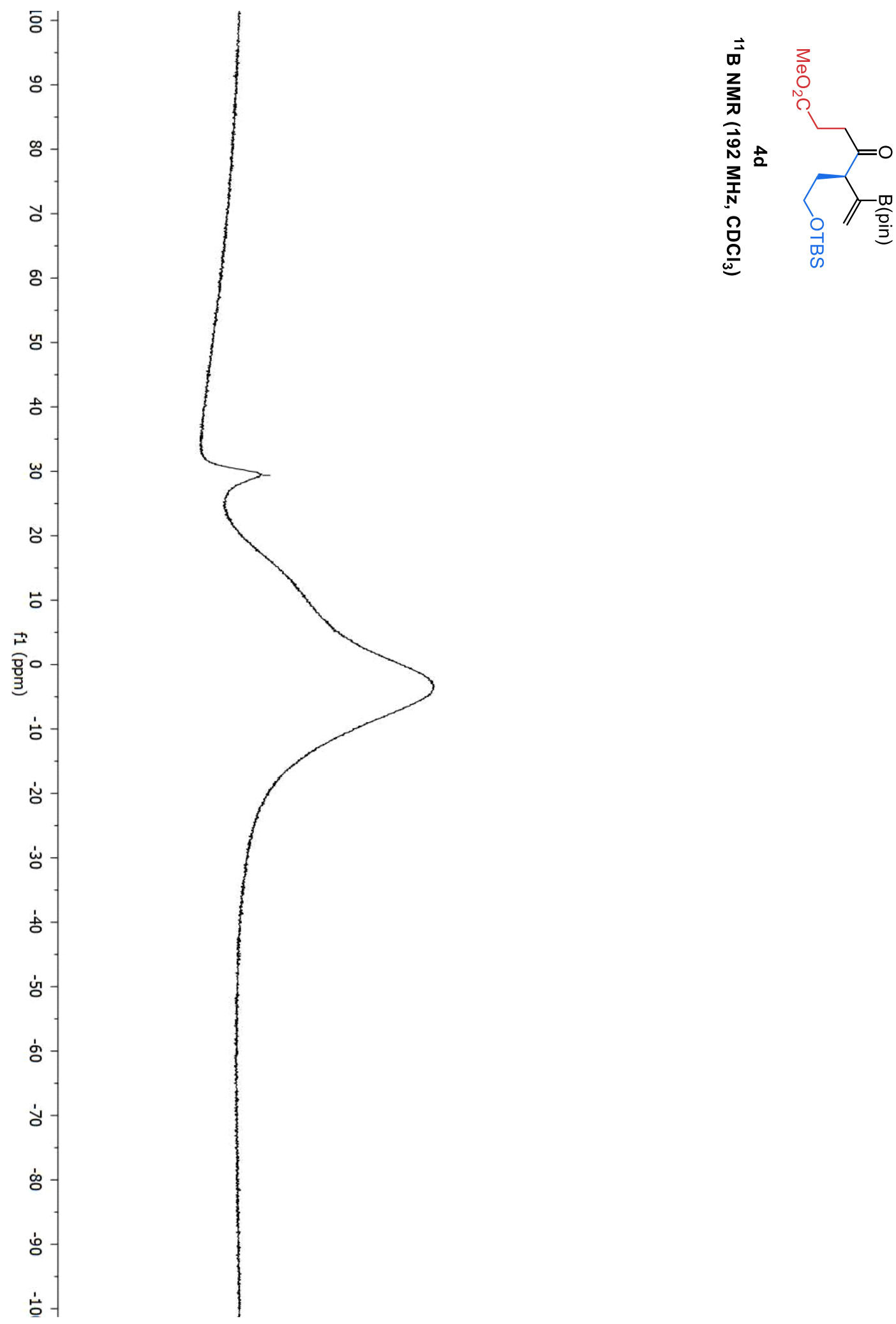


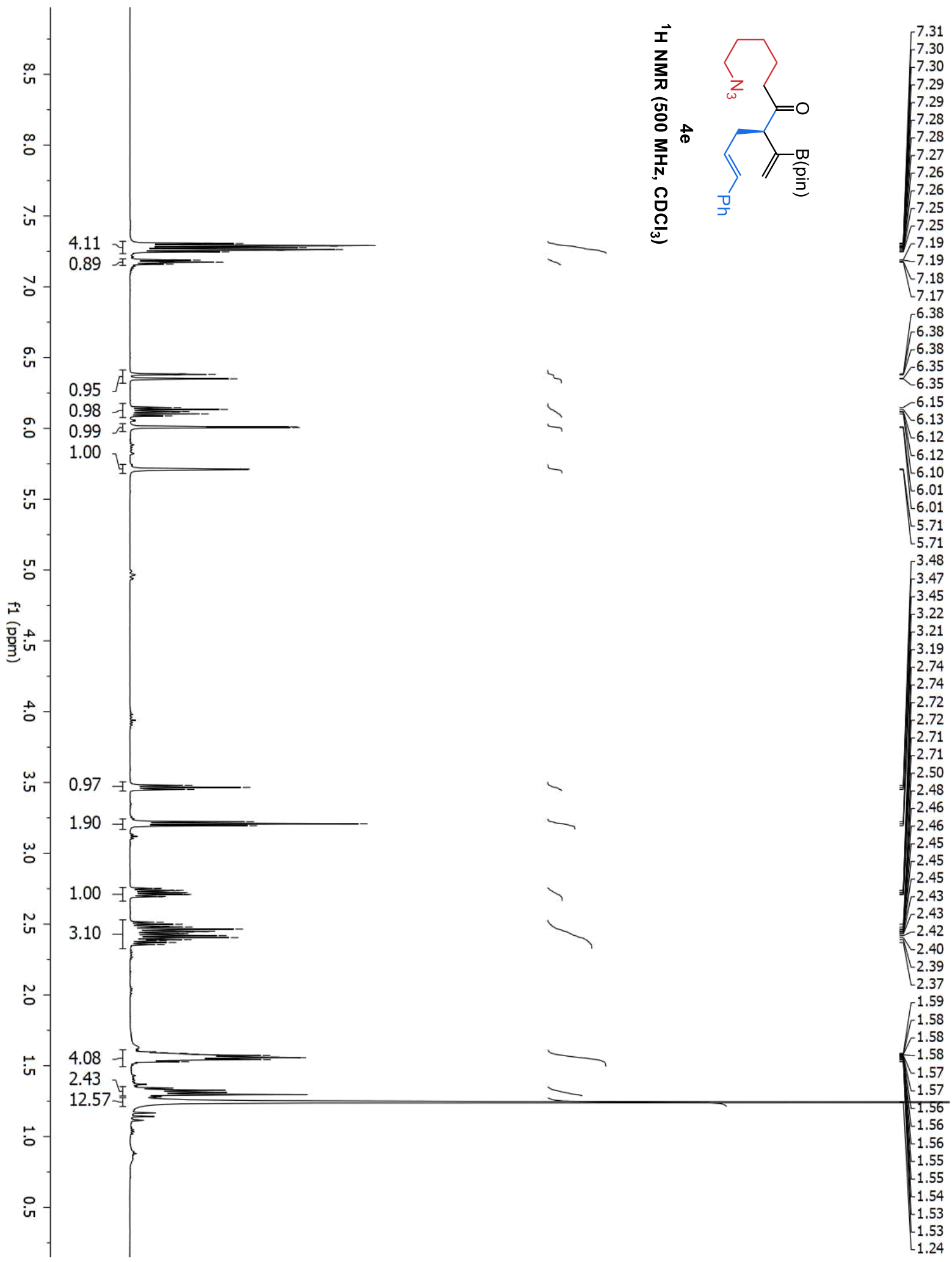




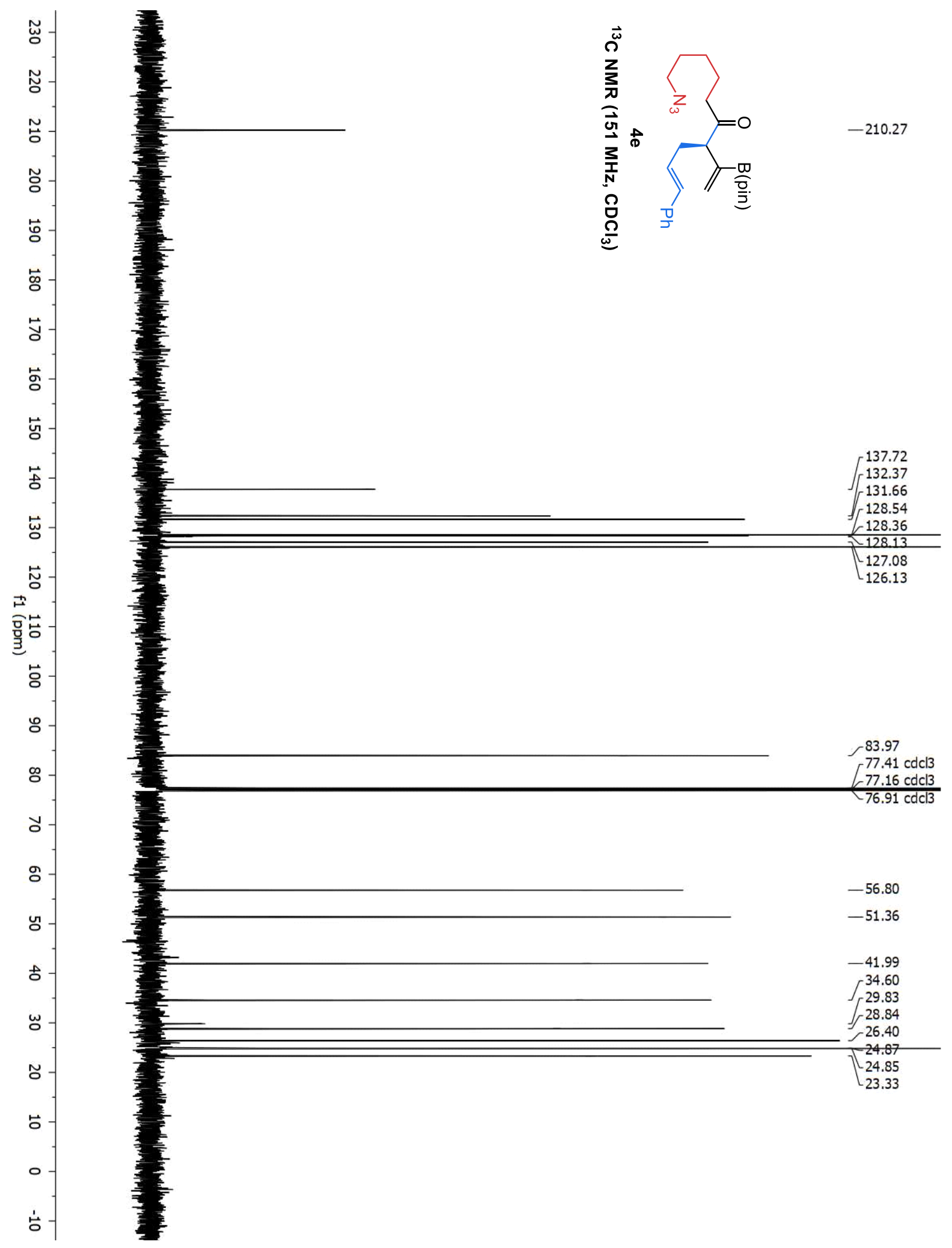




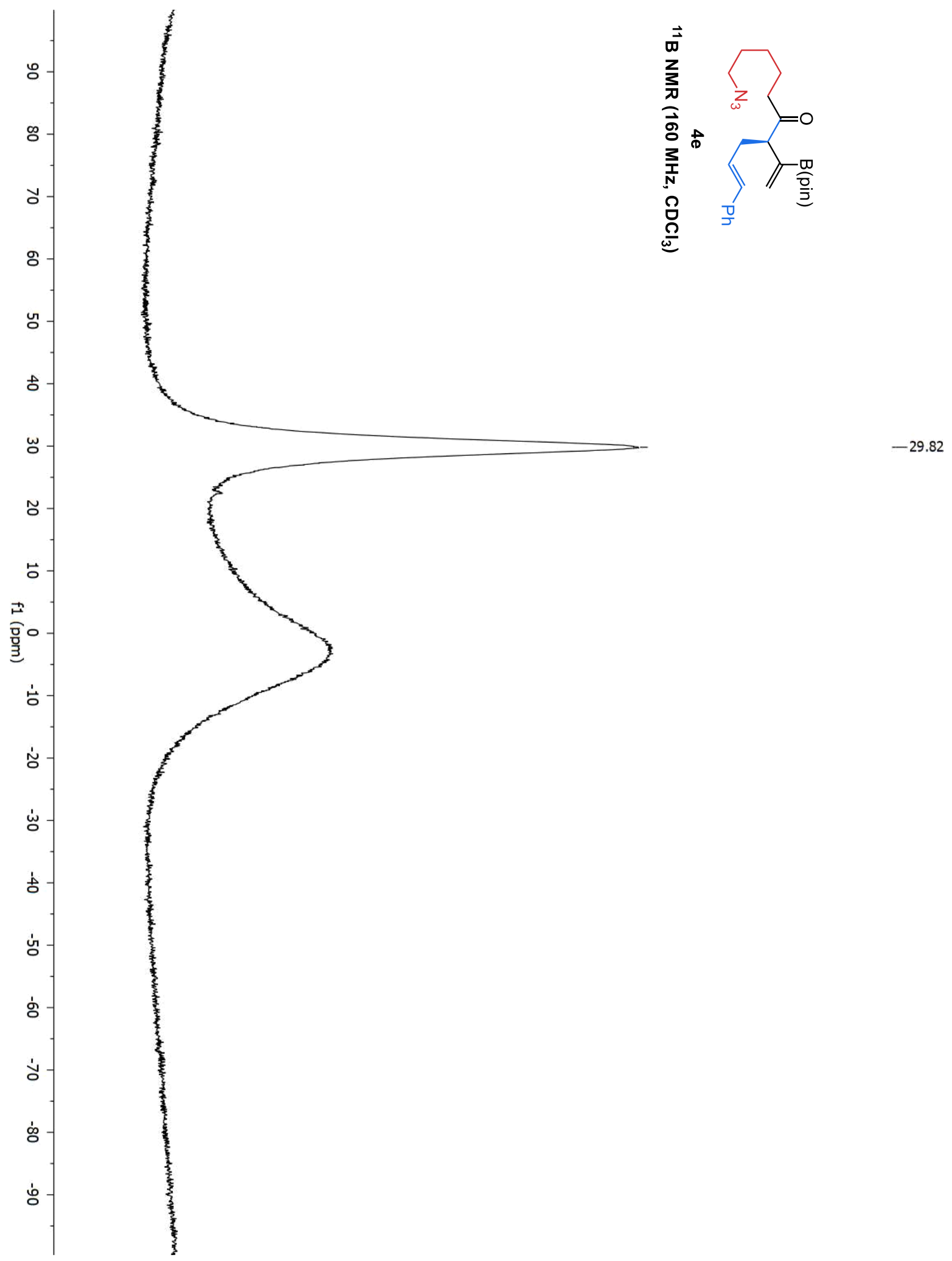




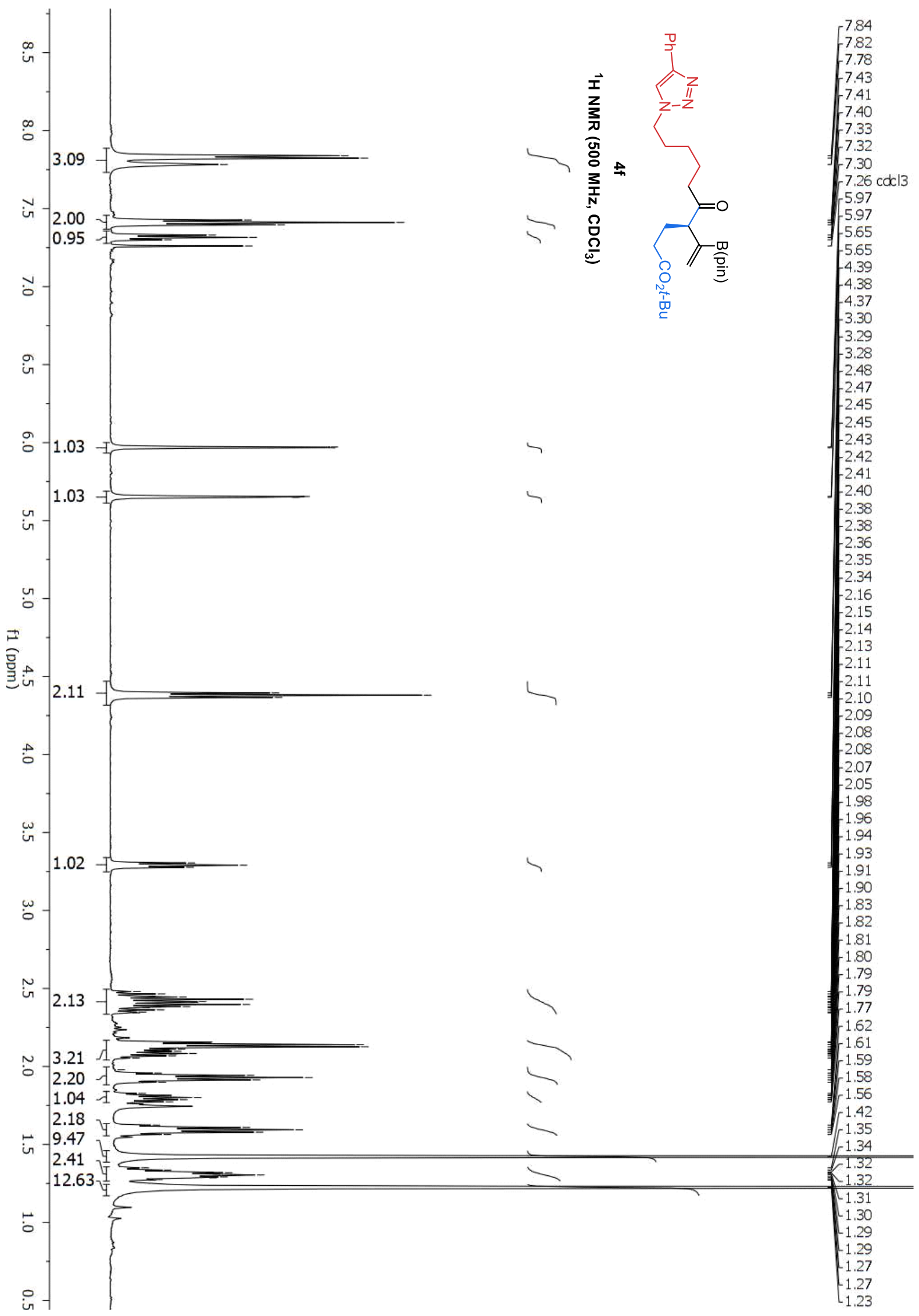




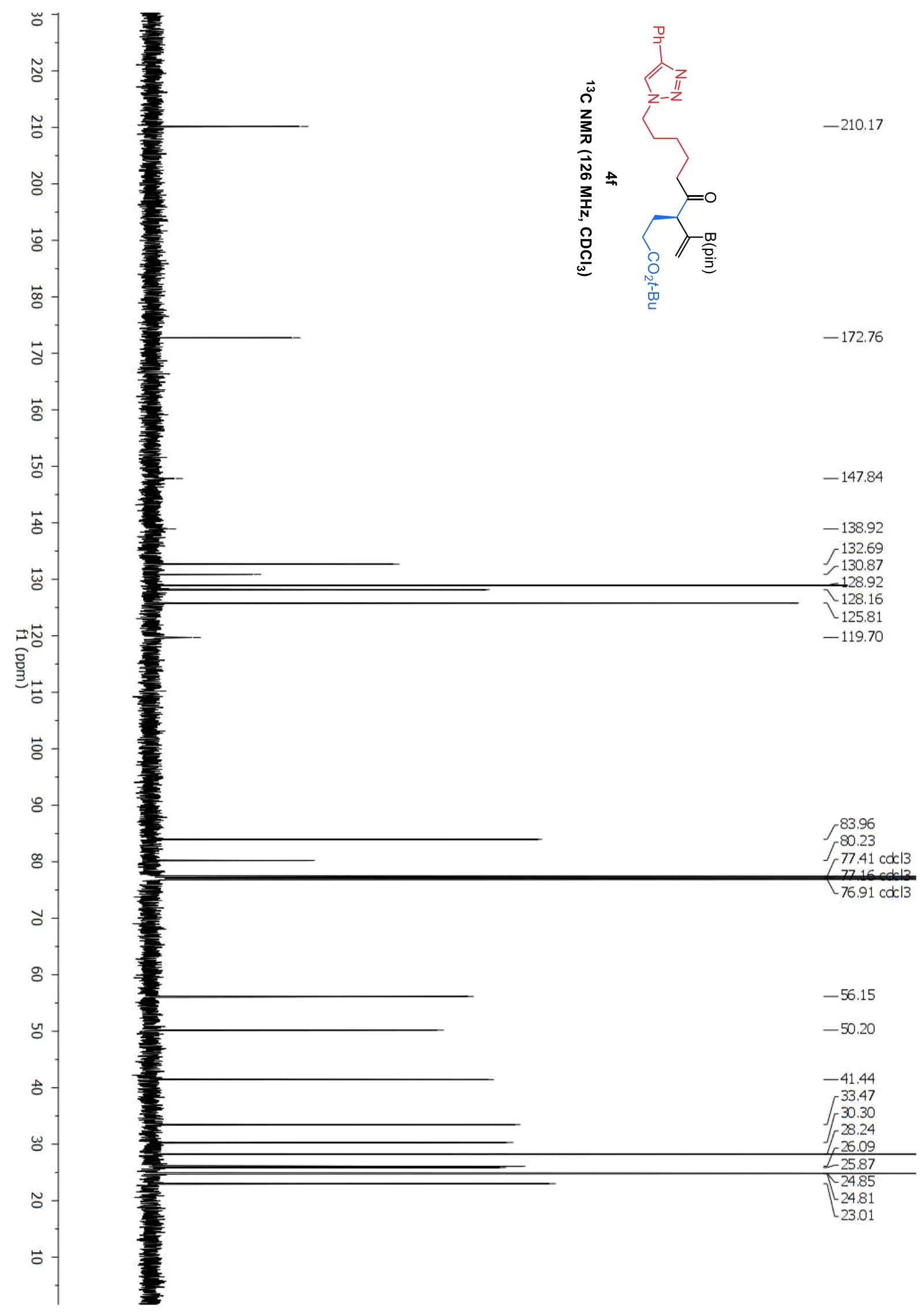




$$
\frac{1}{5}
$$




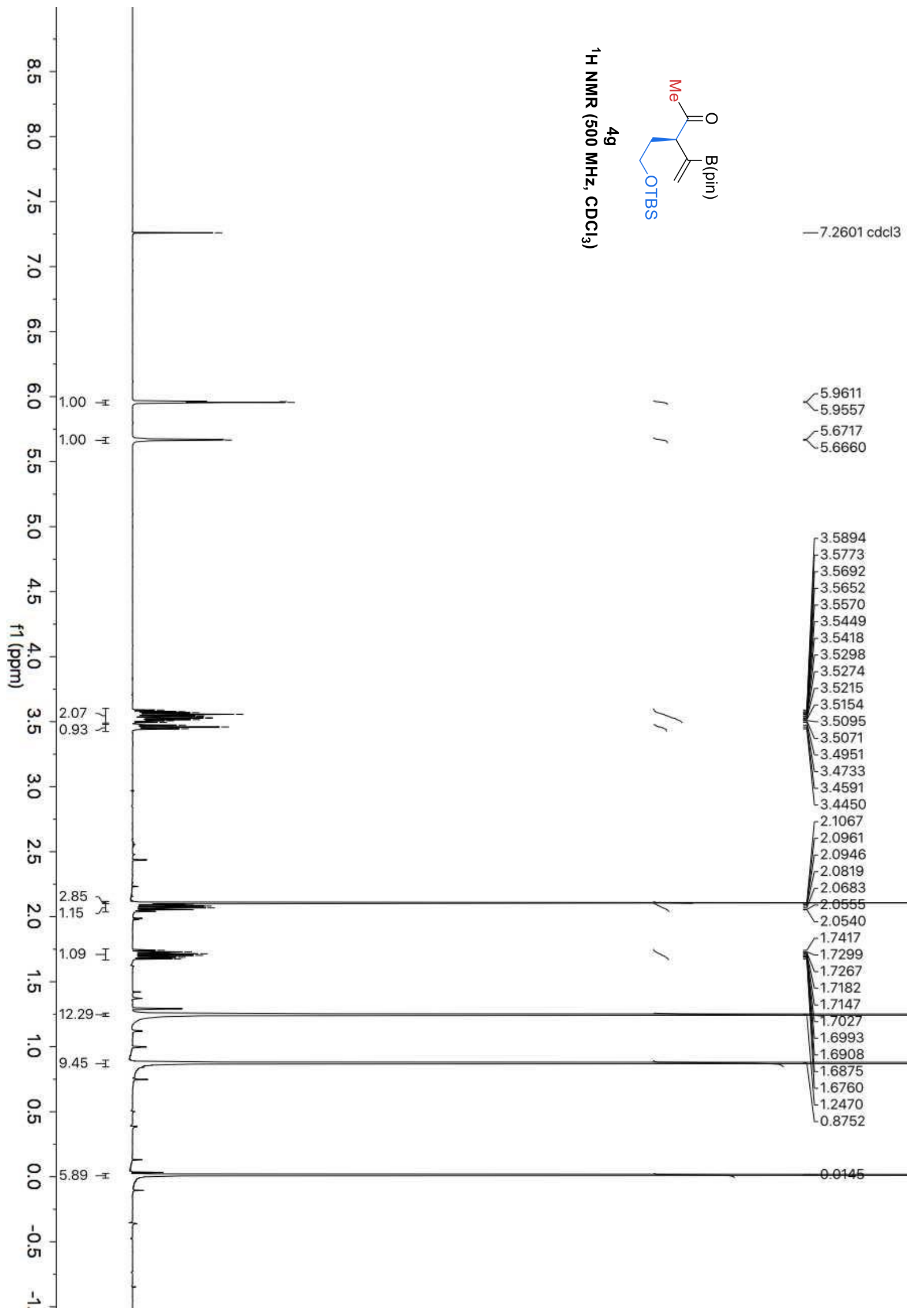




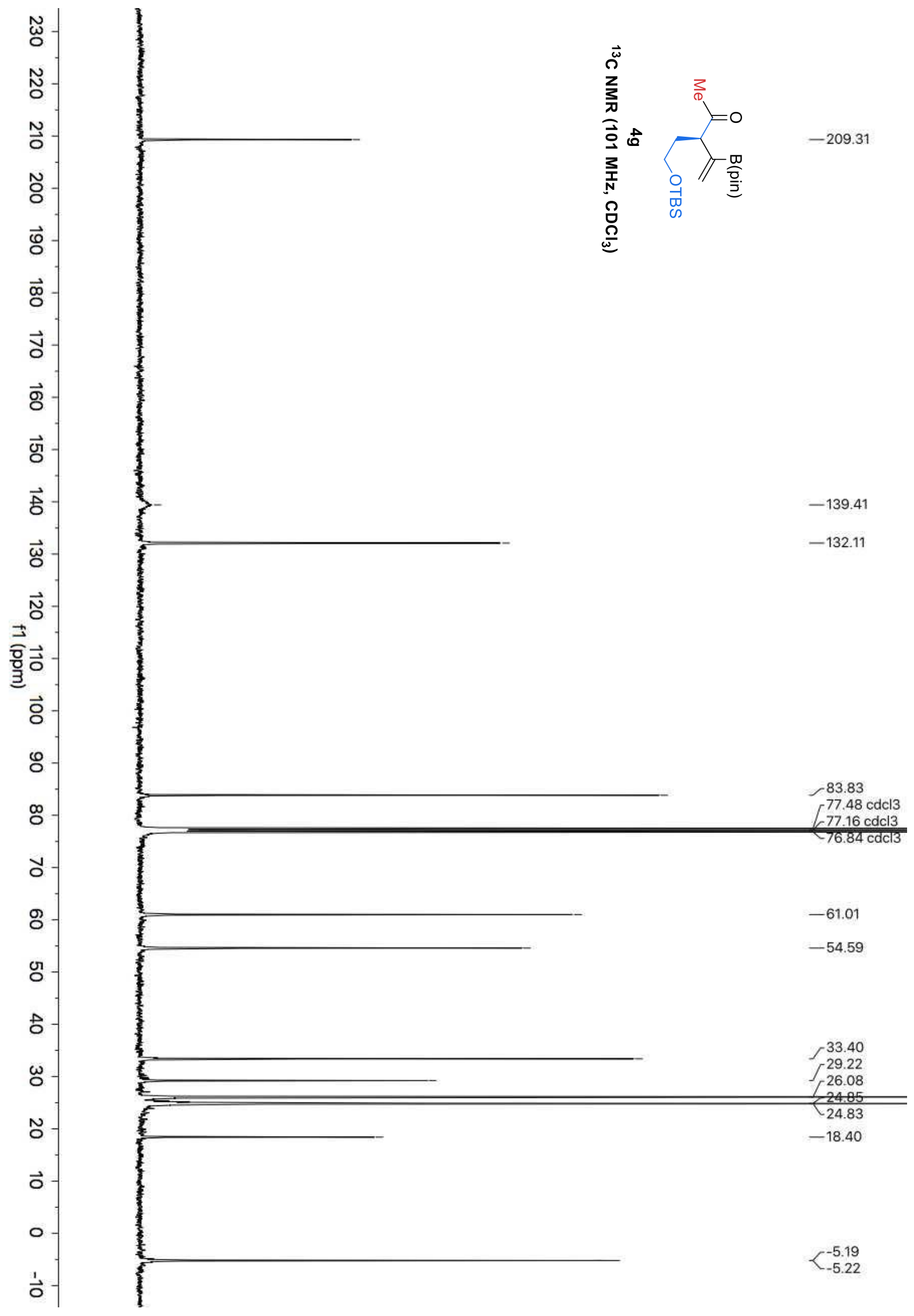




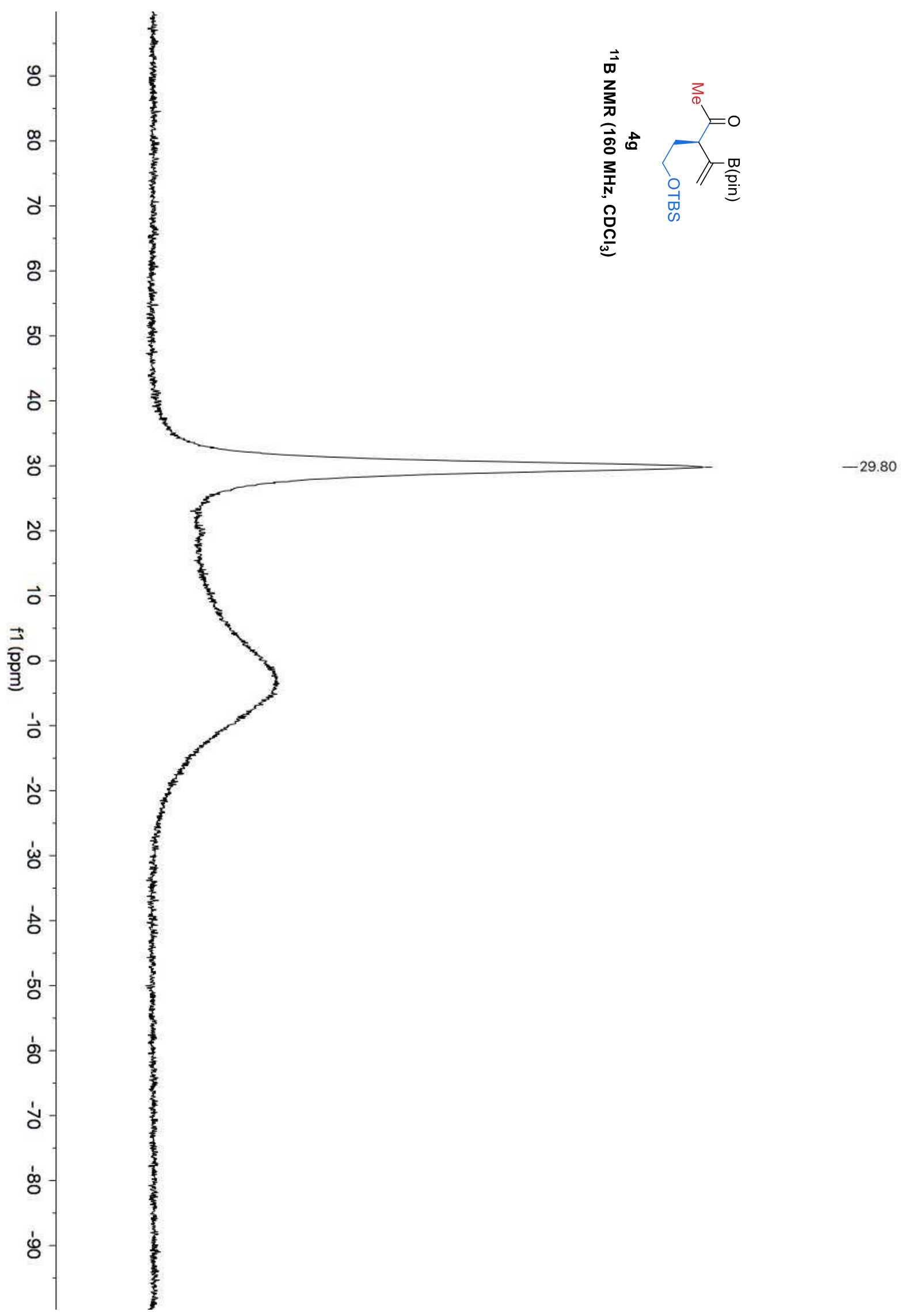




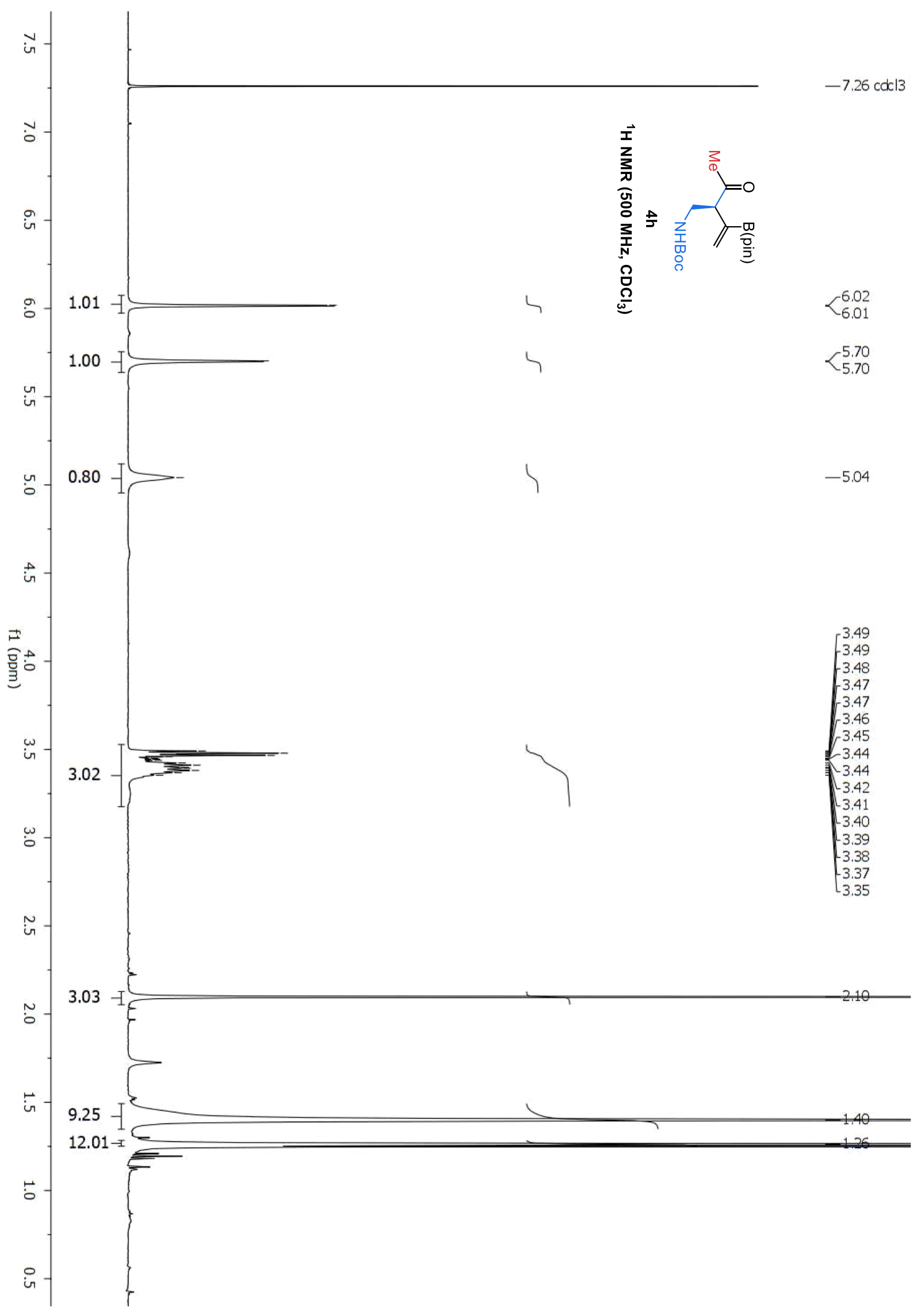




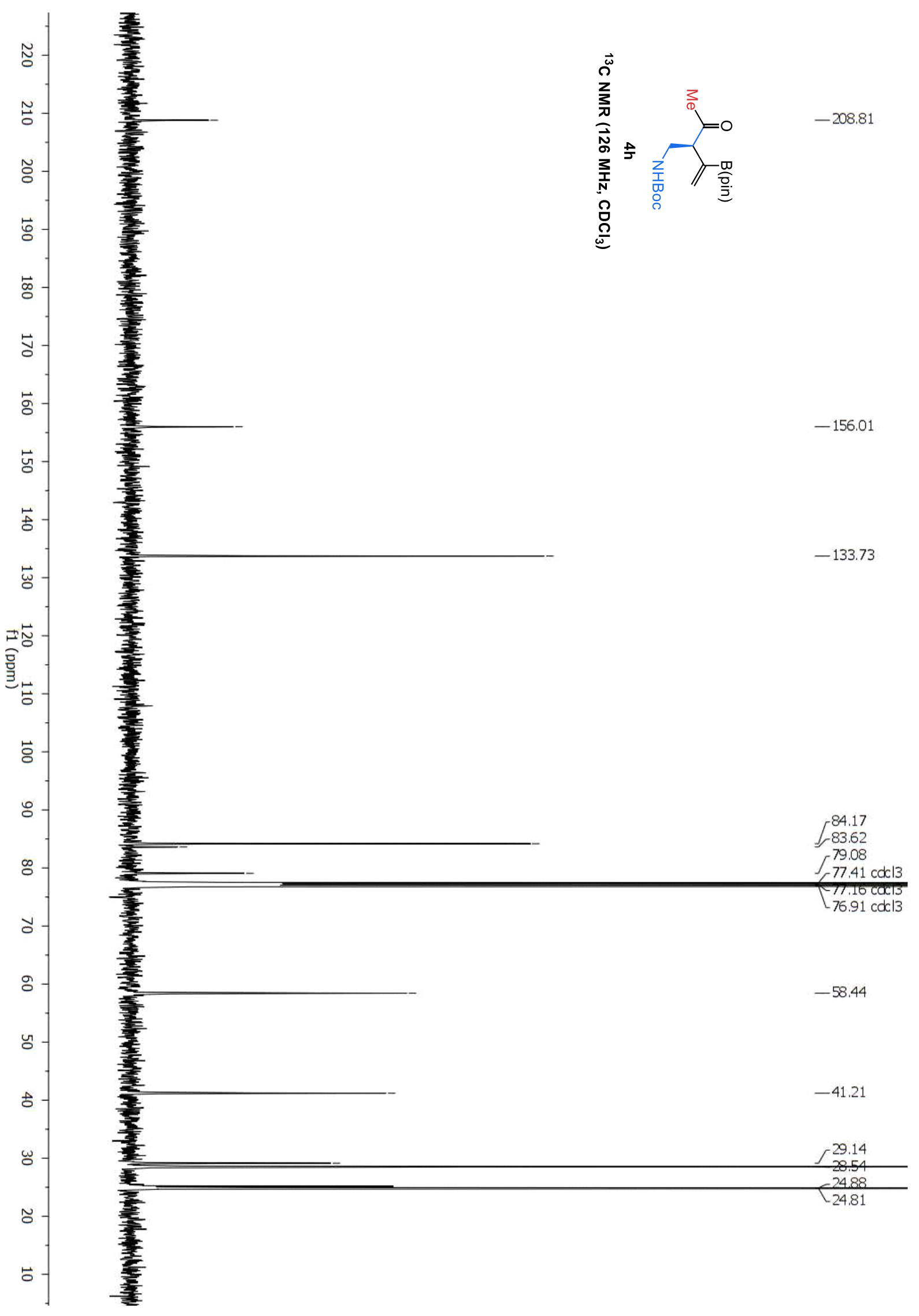


Del Pozo, et al., Supplementary Materials; Page 187

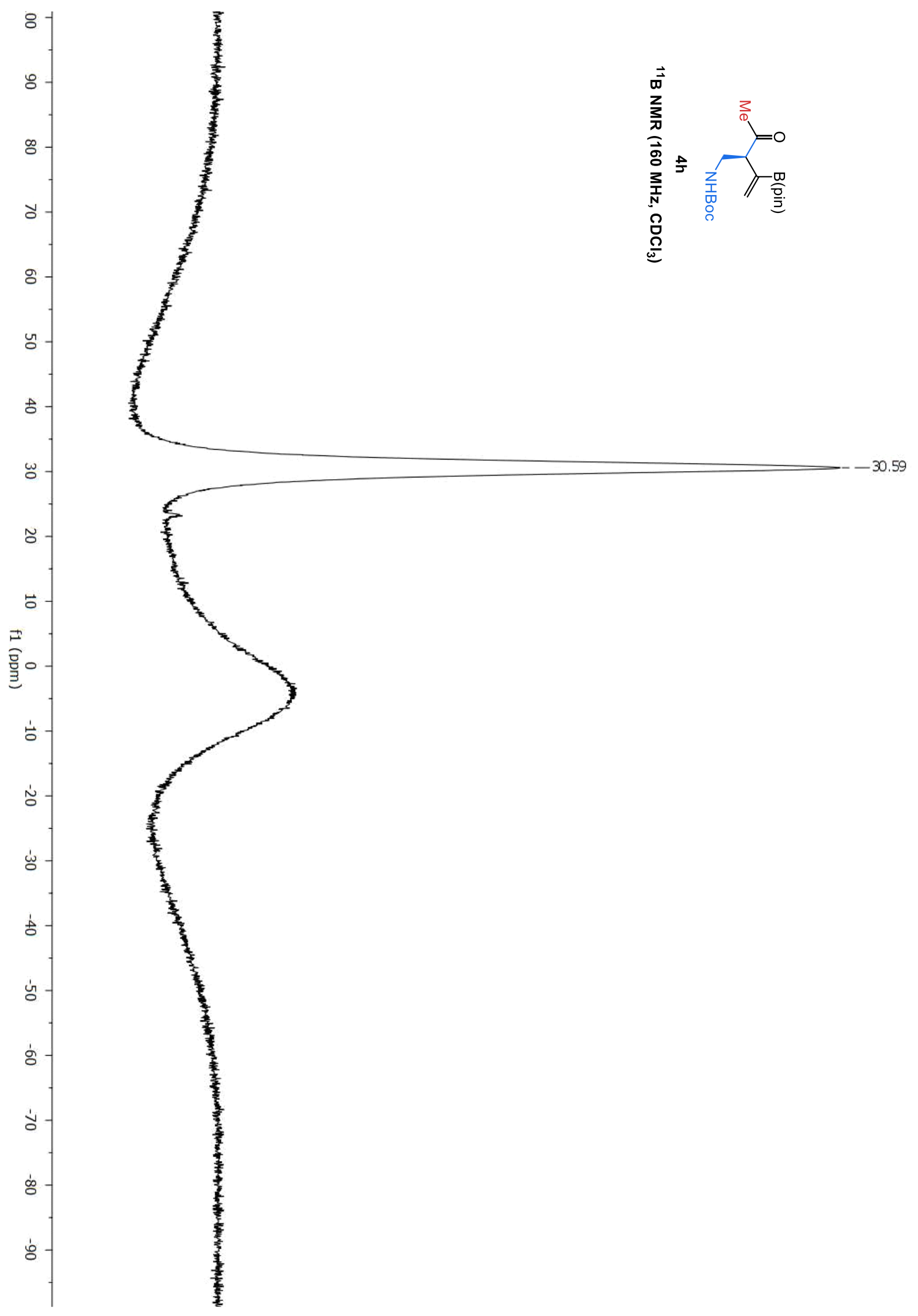




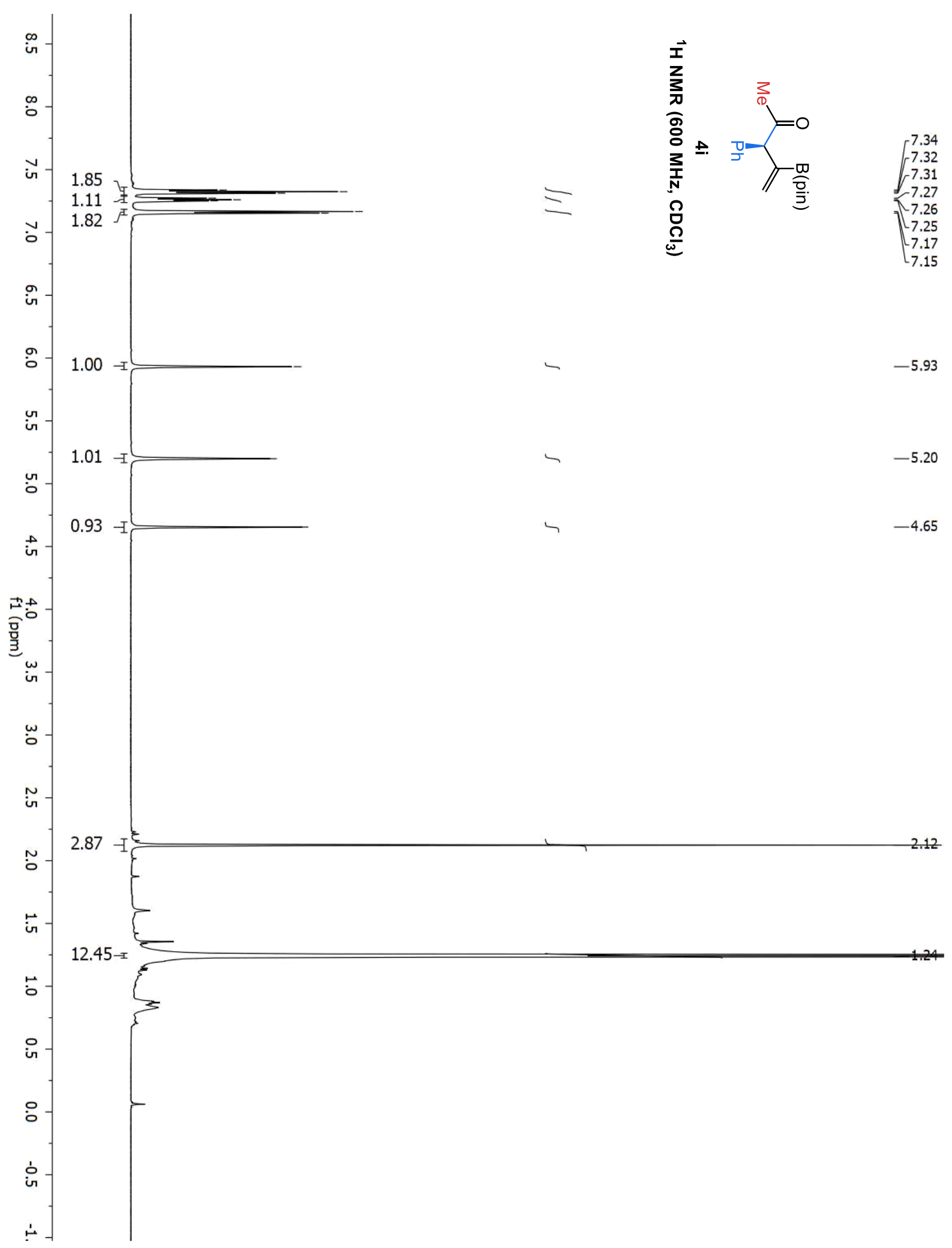




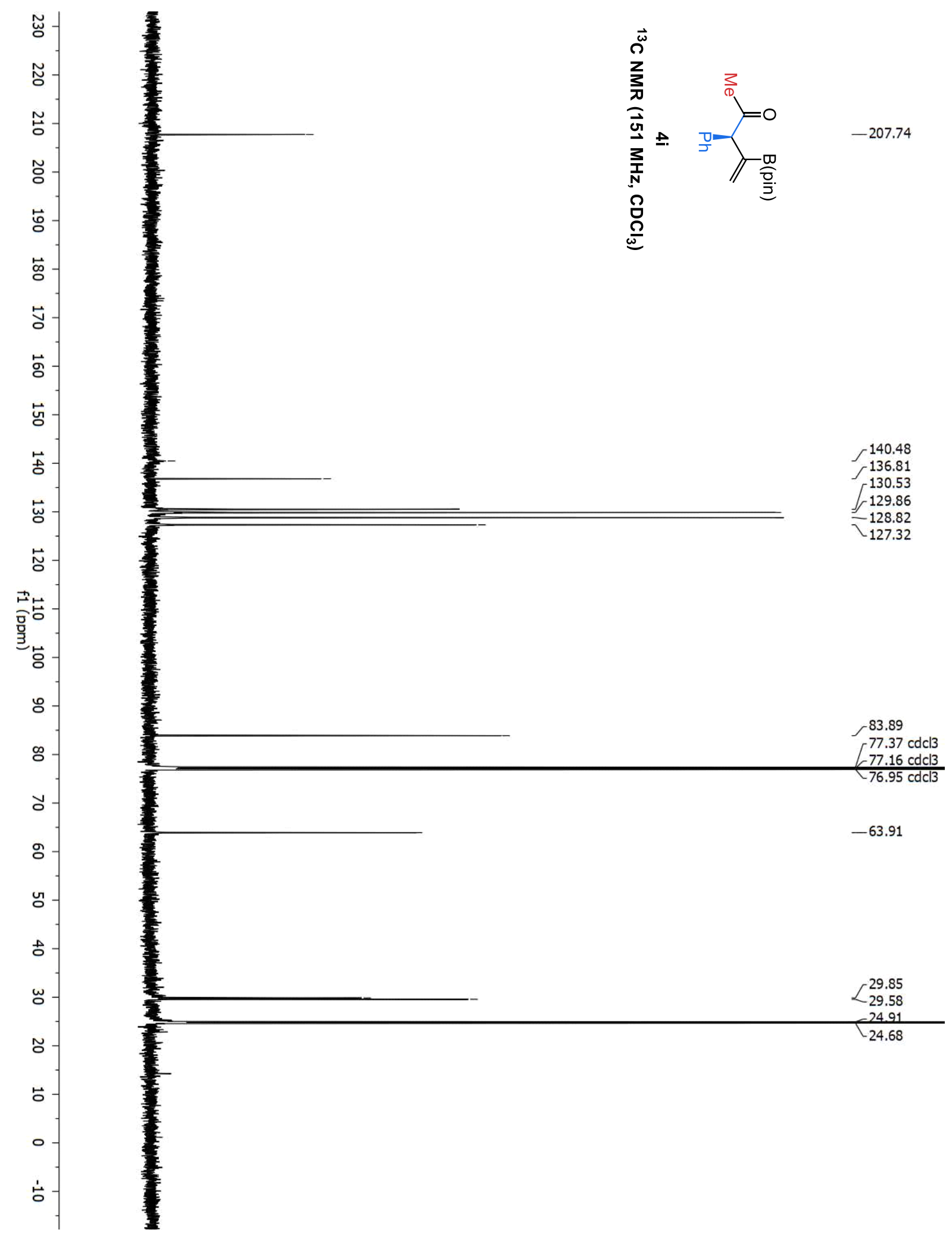


Del Pozo, et al., Supplementary Materials; Page 190

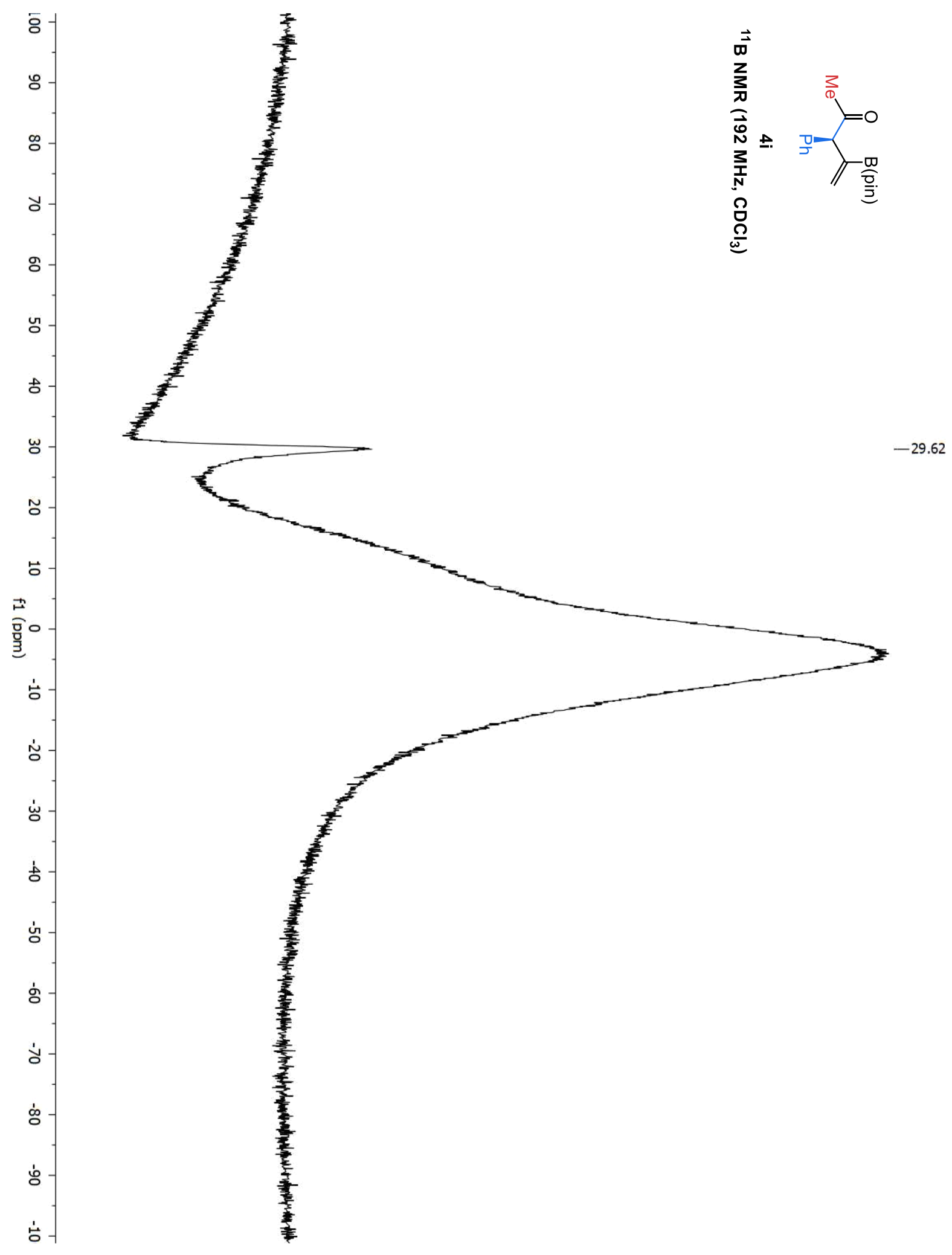




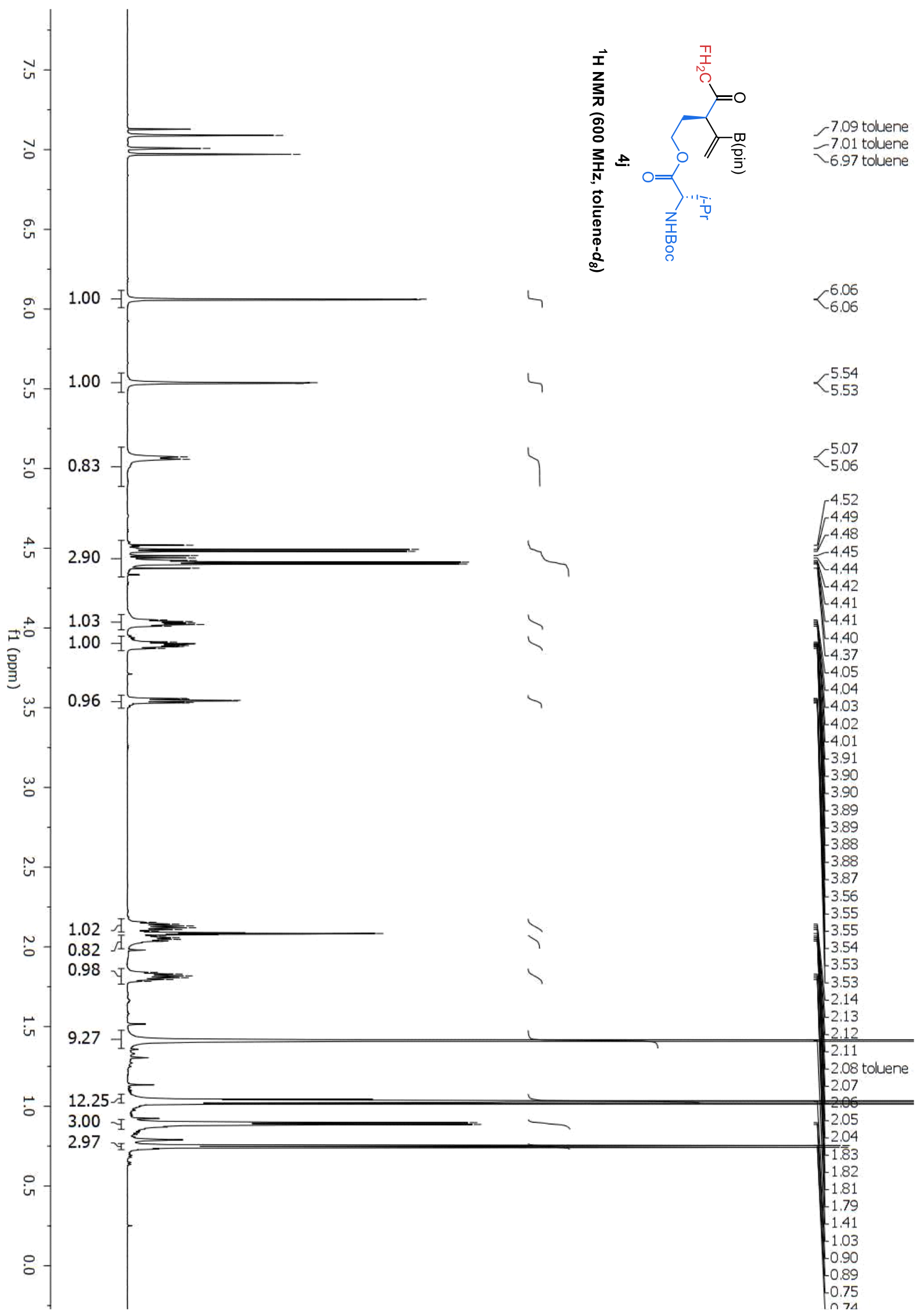




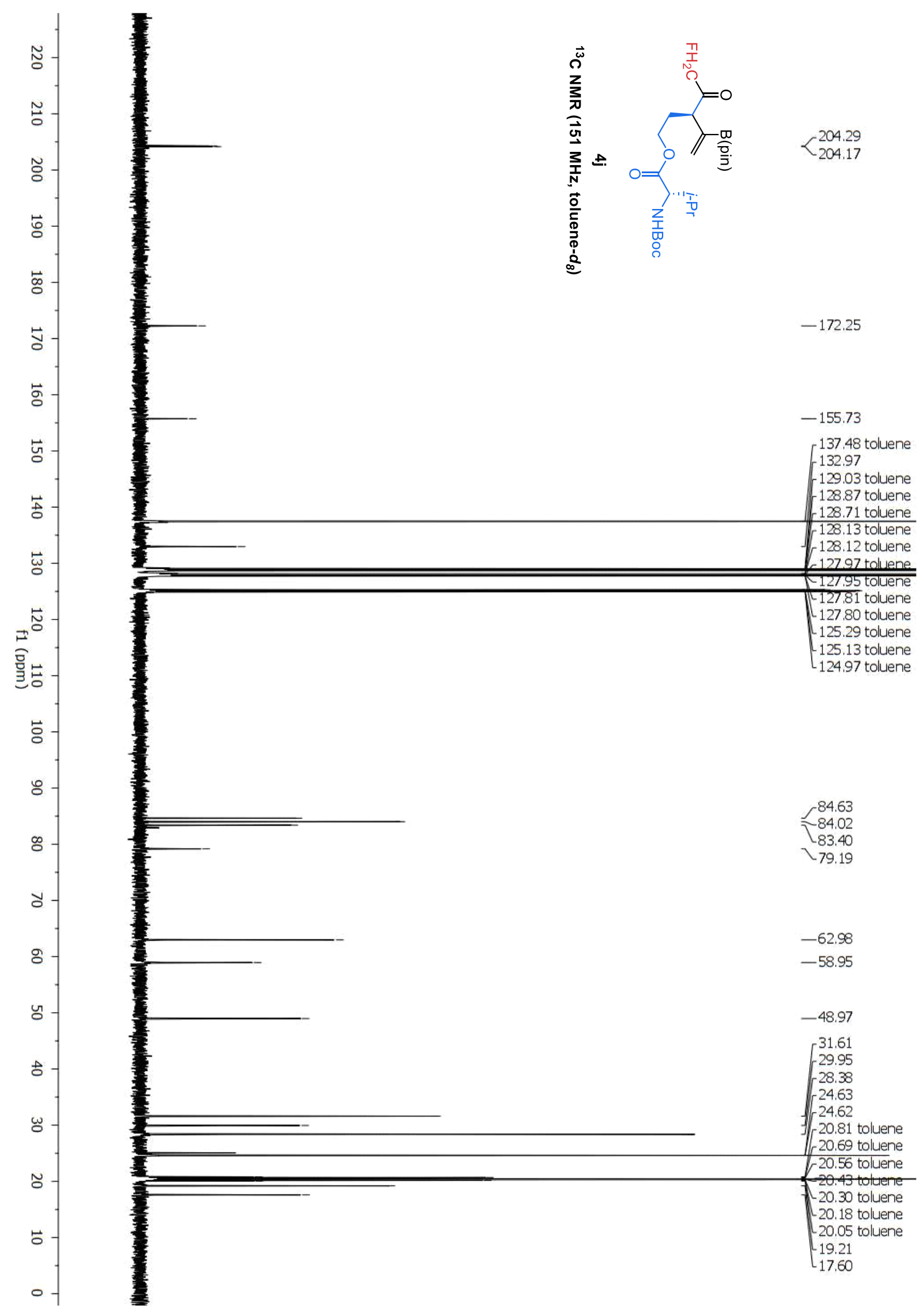


Del Pozo, et al., Supplementary Materials; Page 193

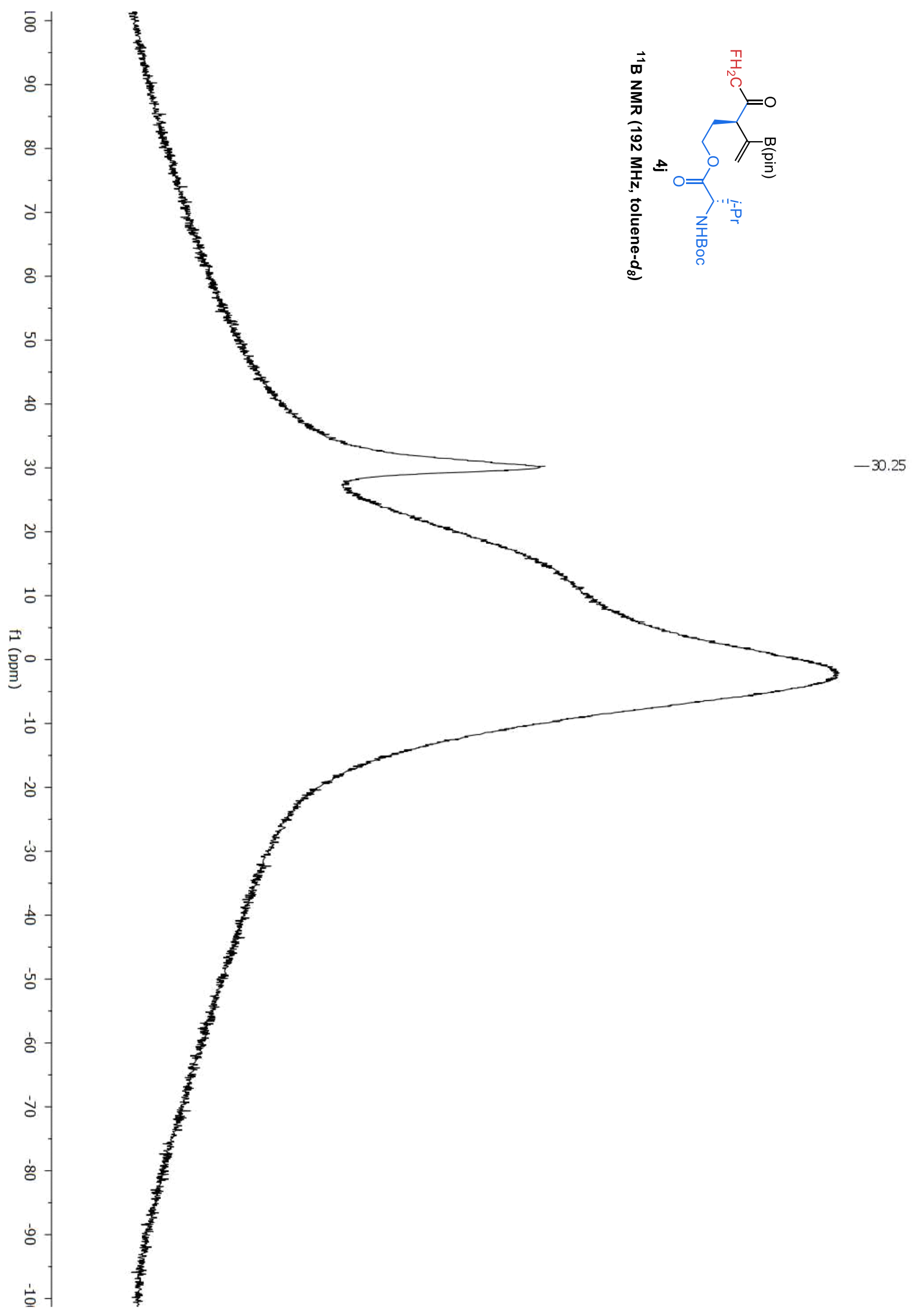




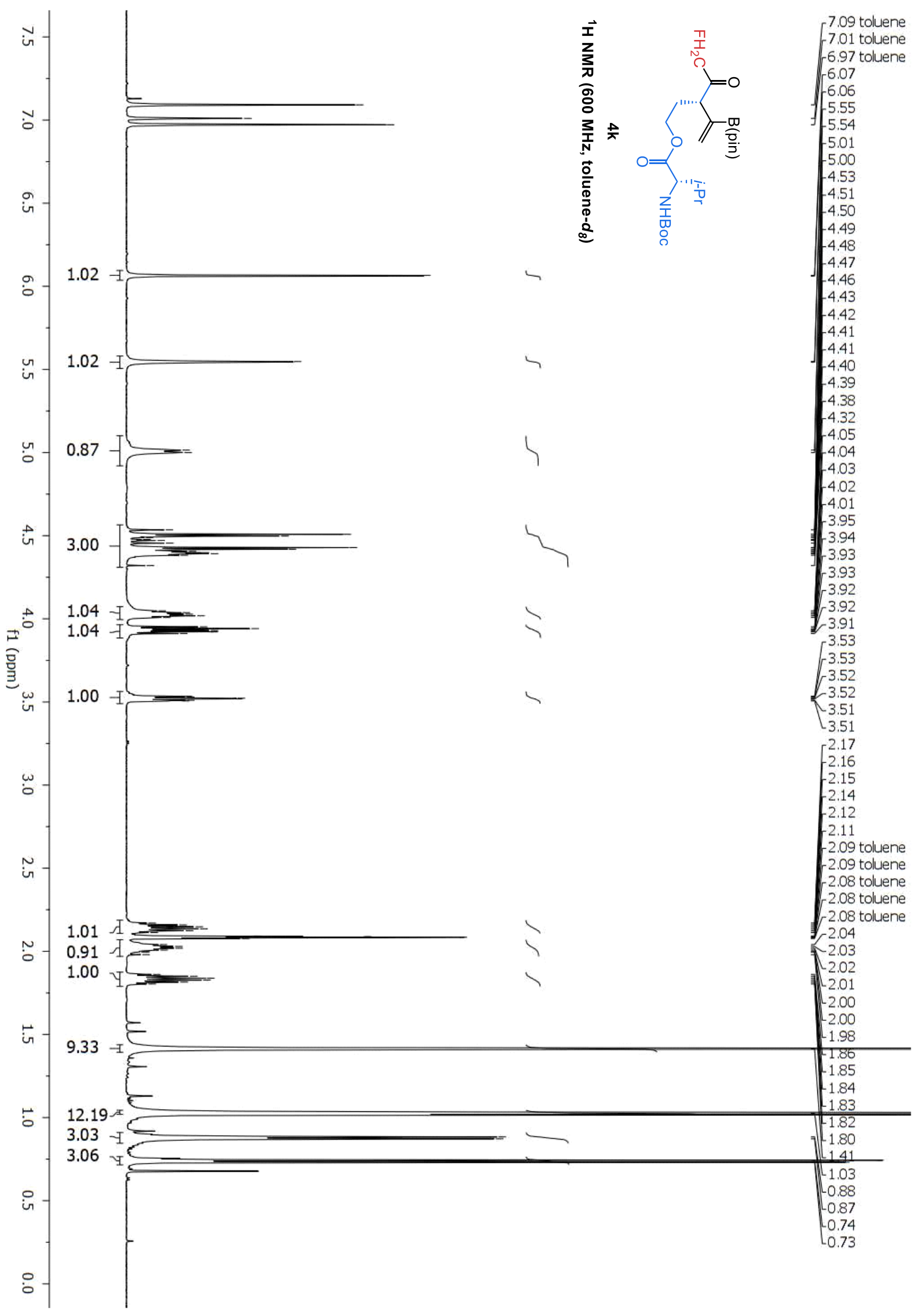




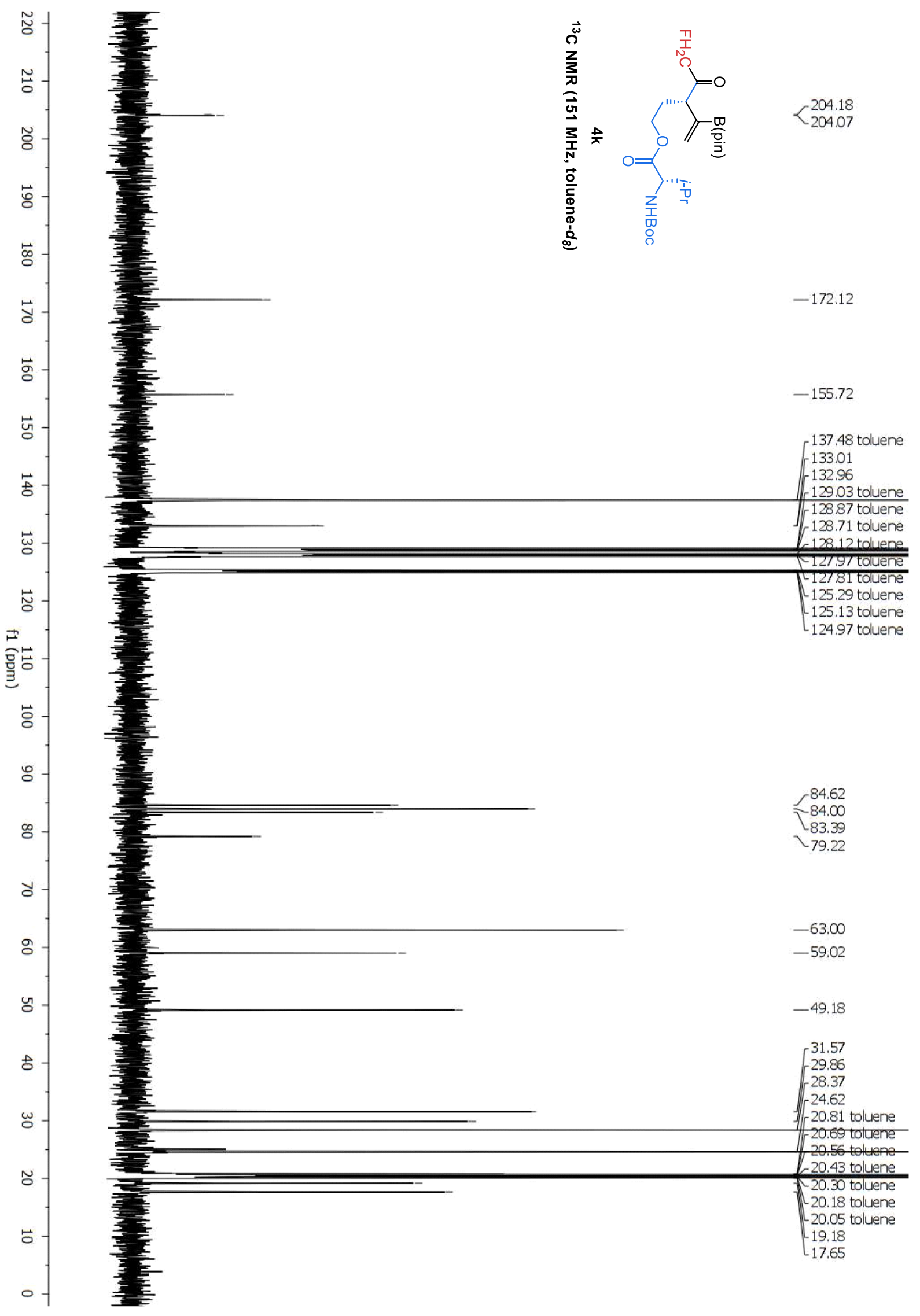


Del Pozo, et al., Supplementary Materials; Page 196

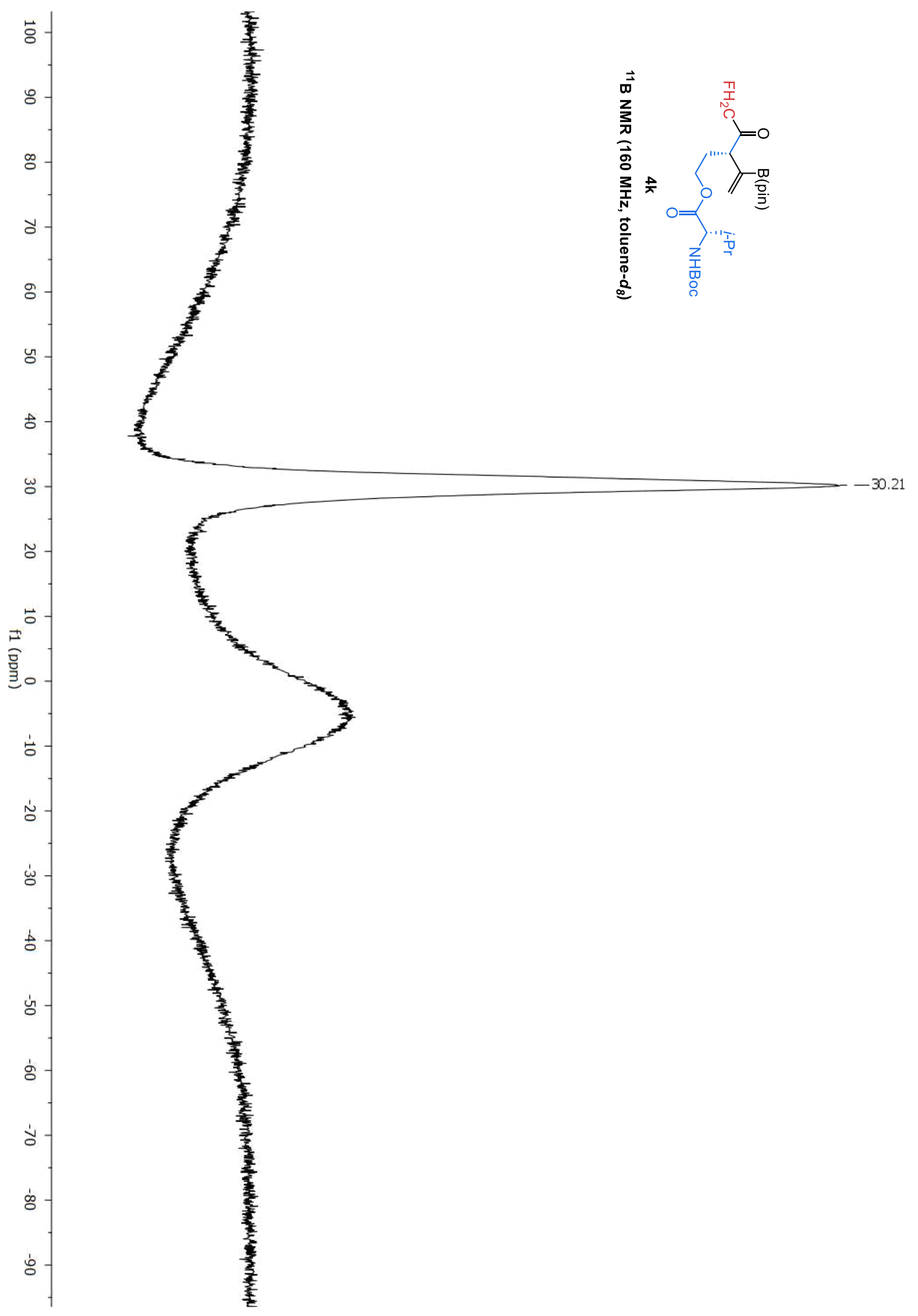




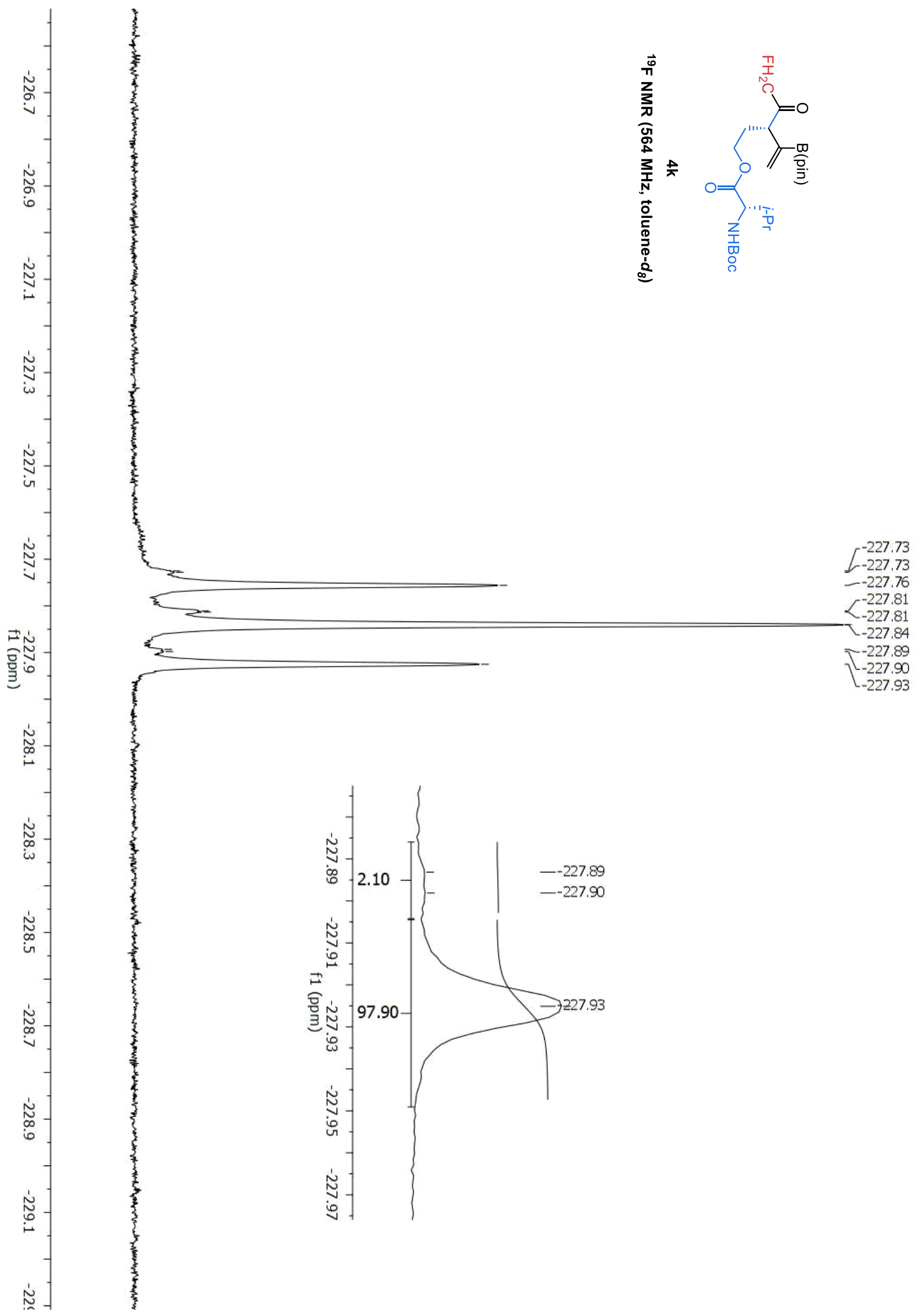




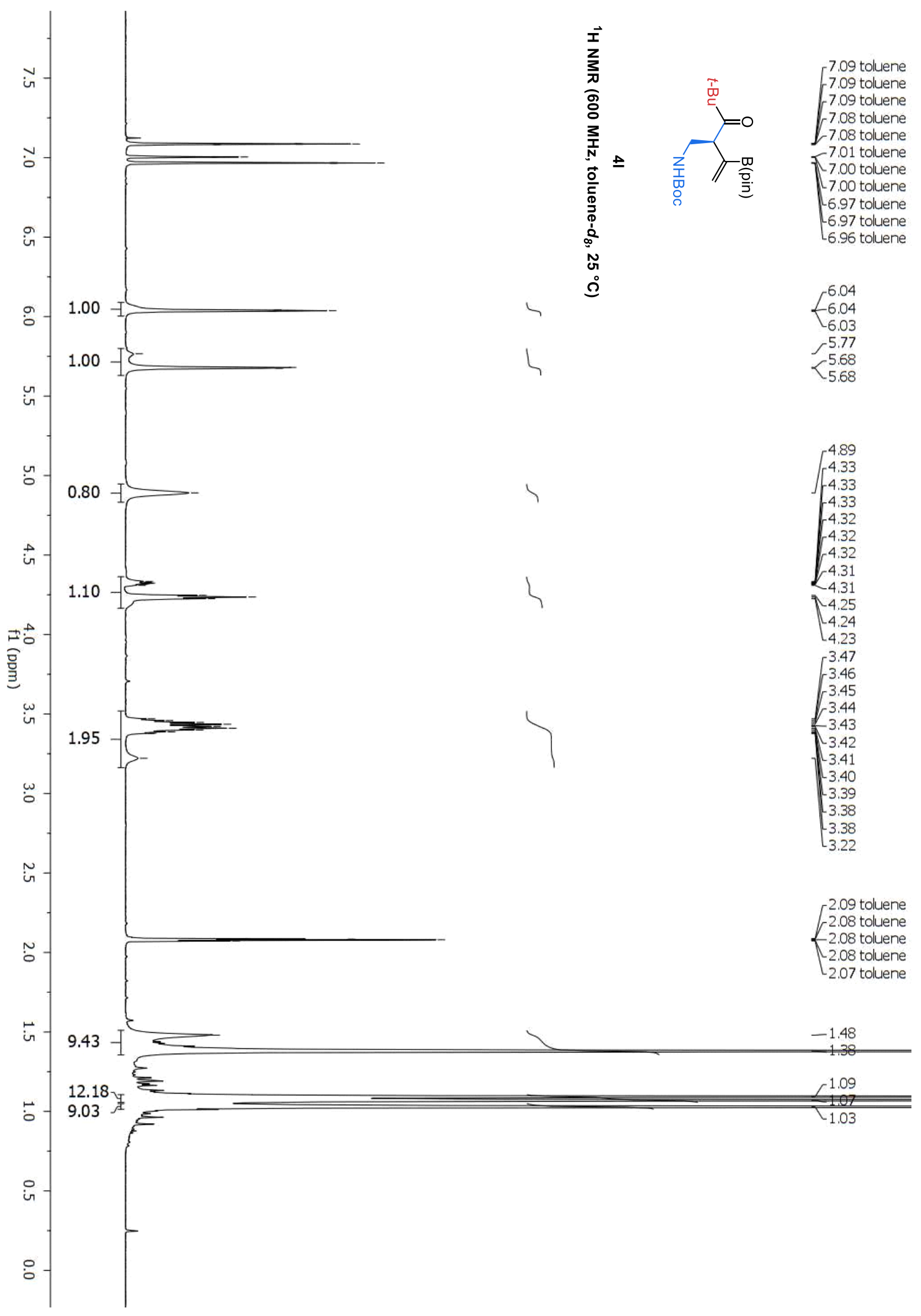




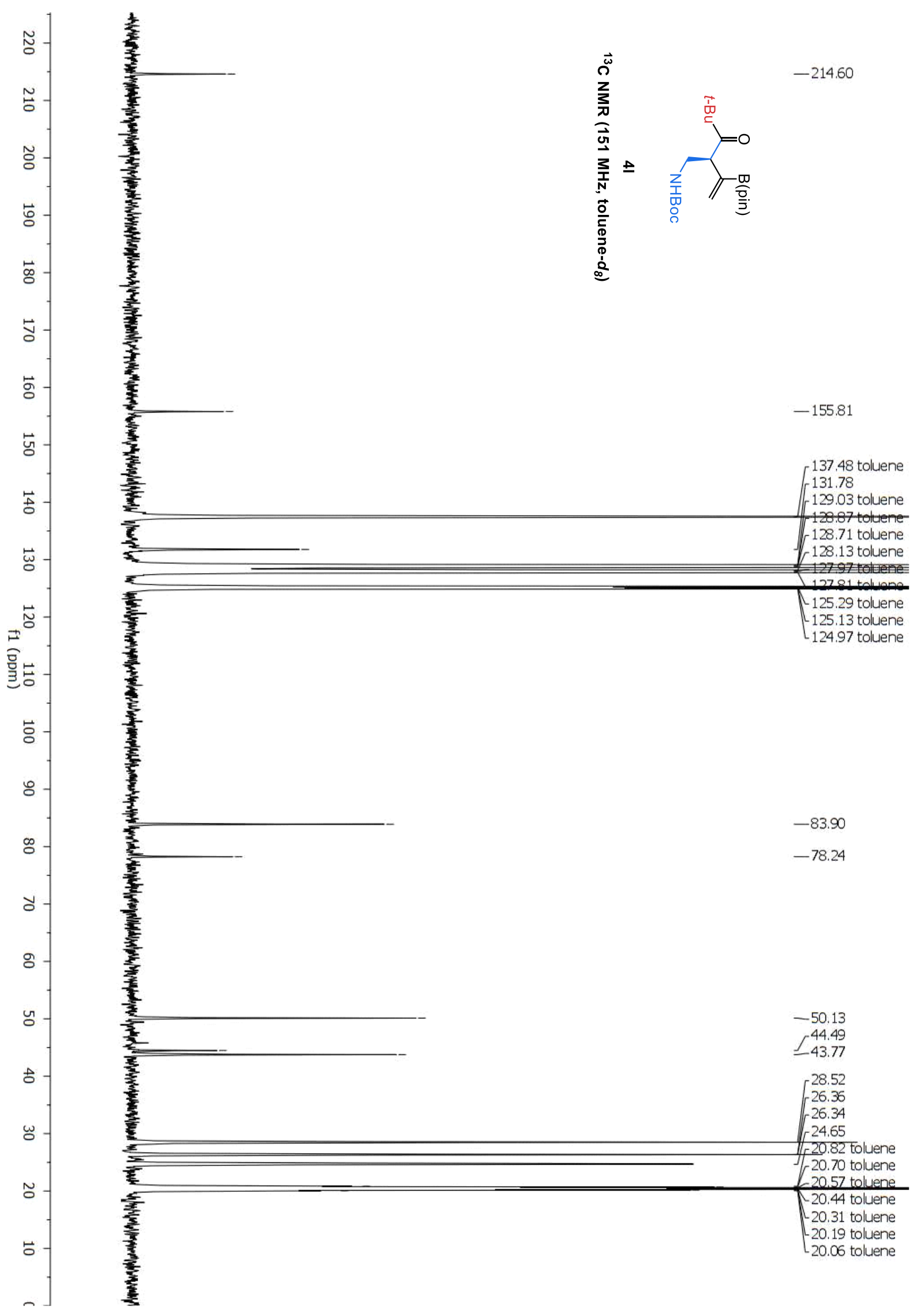


Del Pozo, et al., Supplementary Materials; Page 200

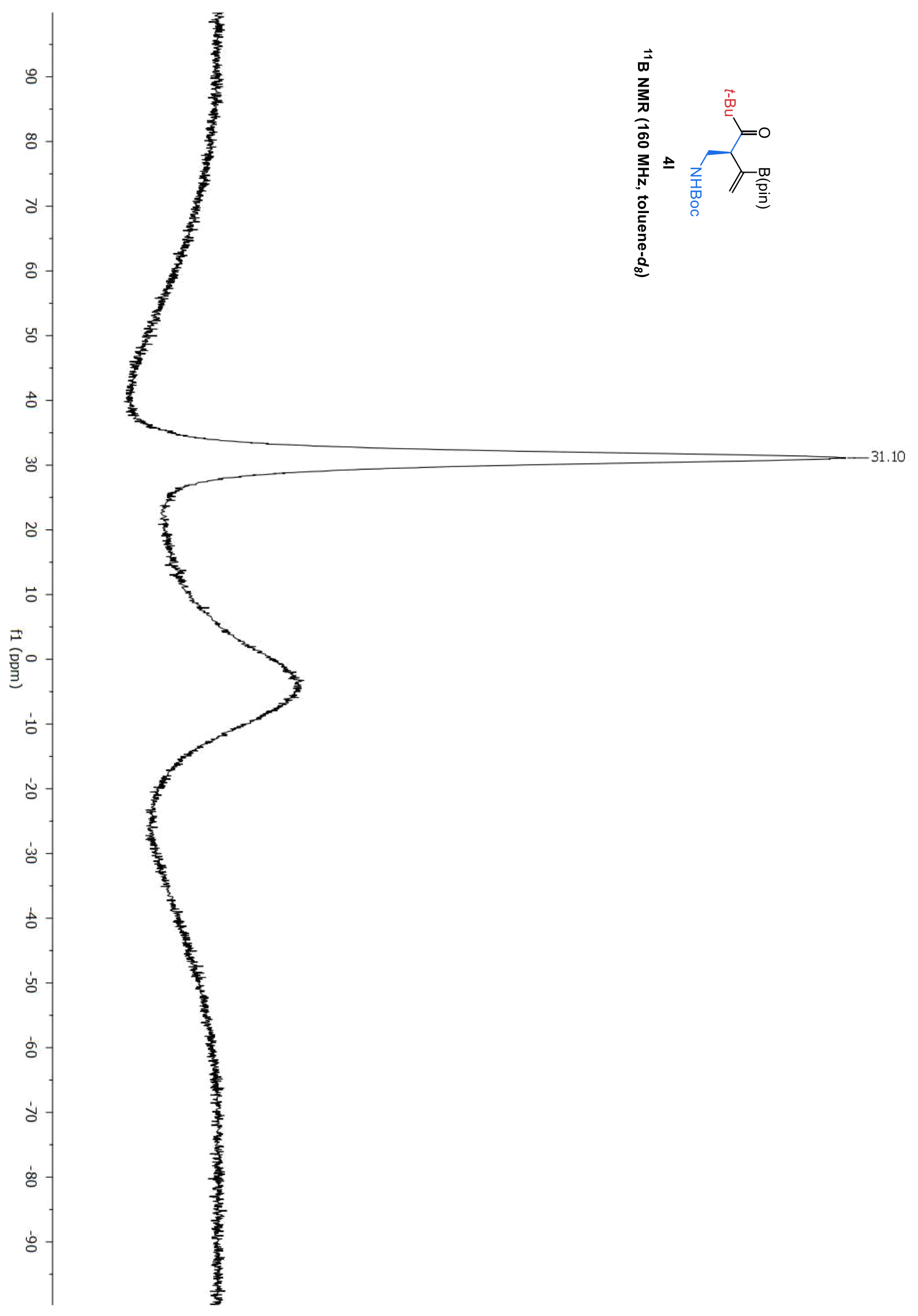




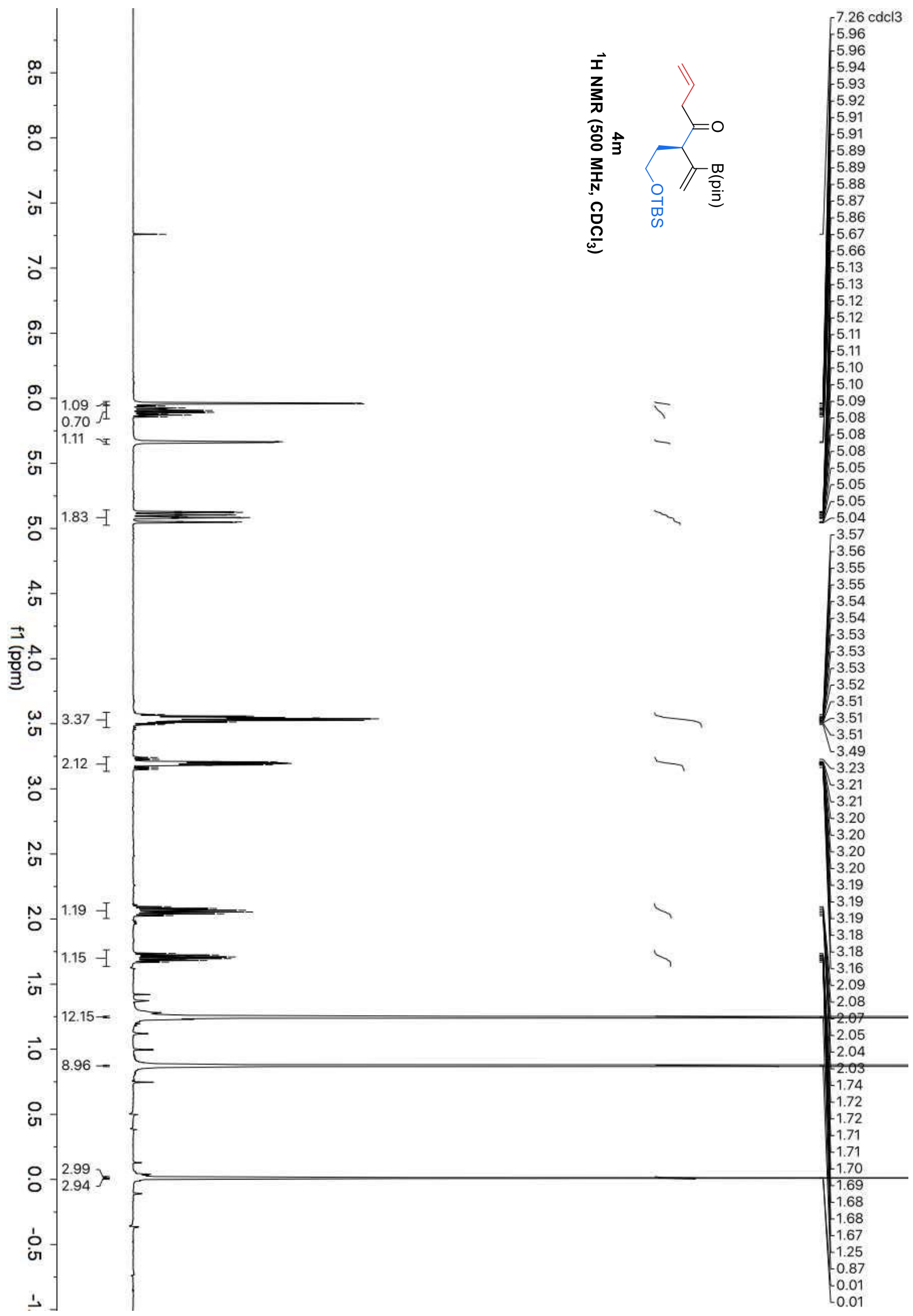




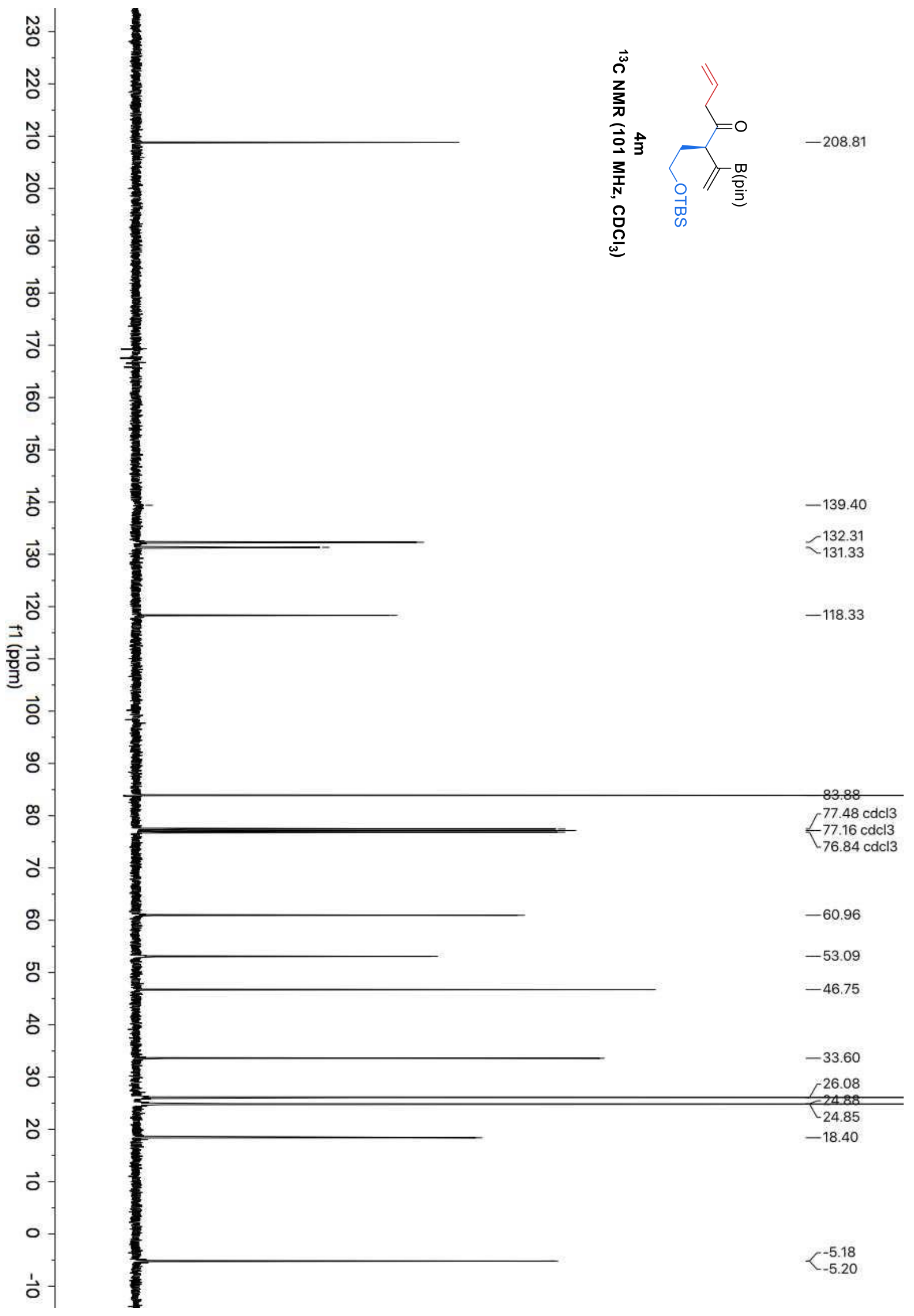




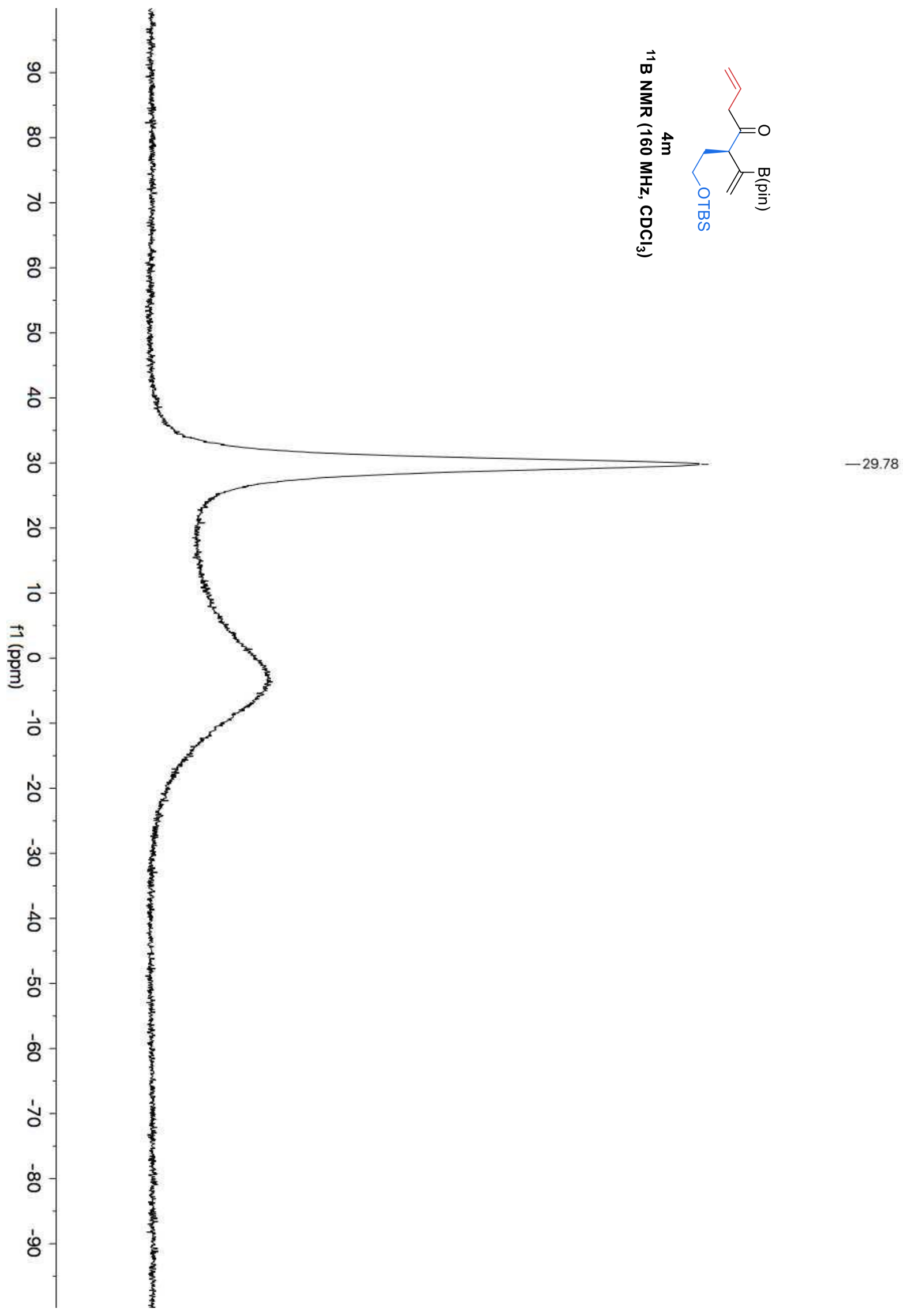




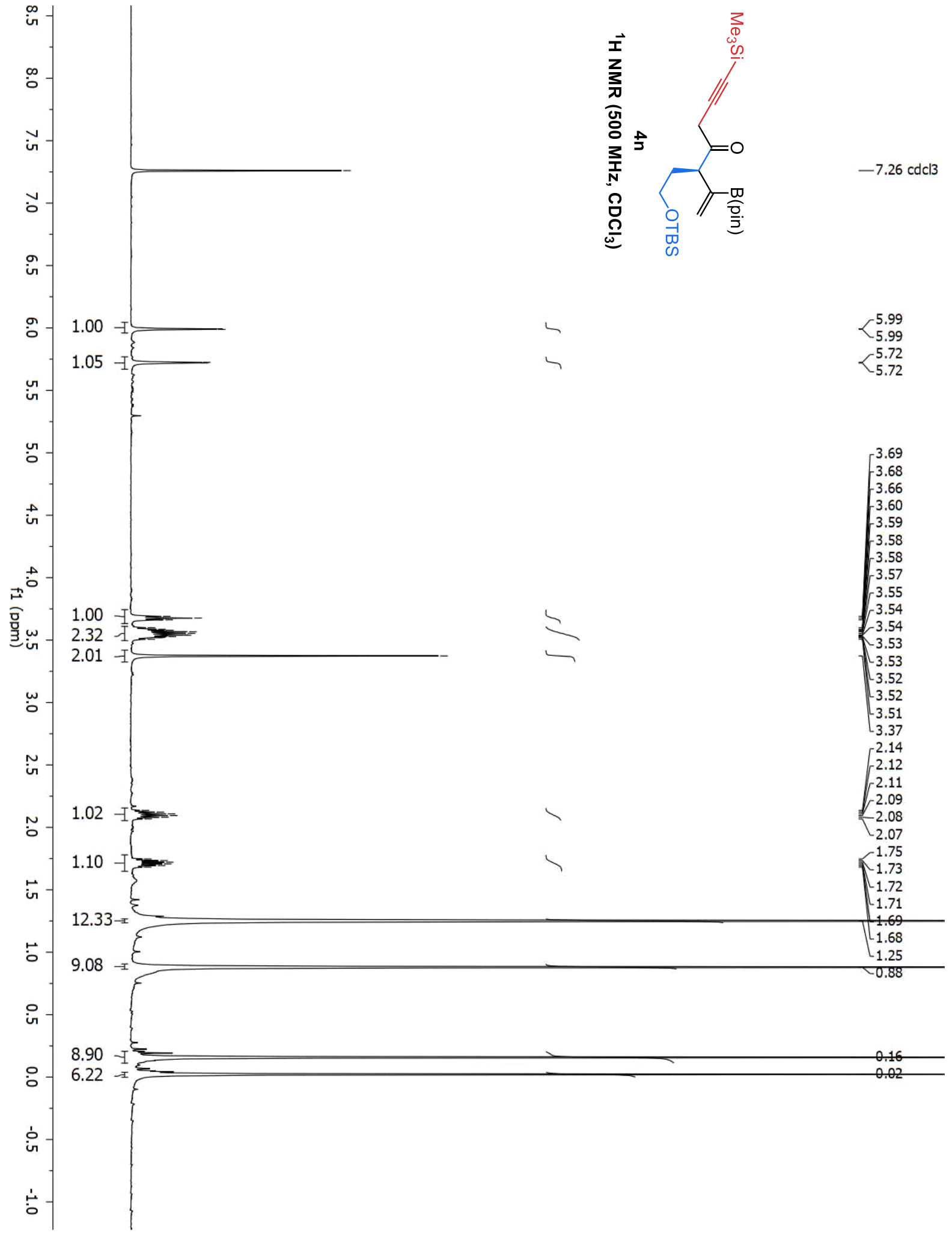




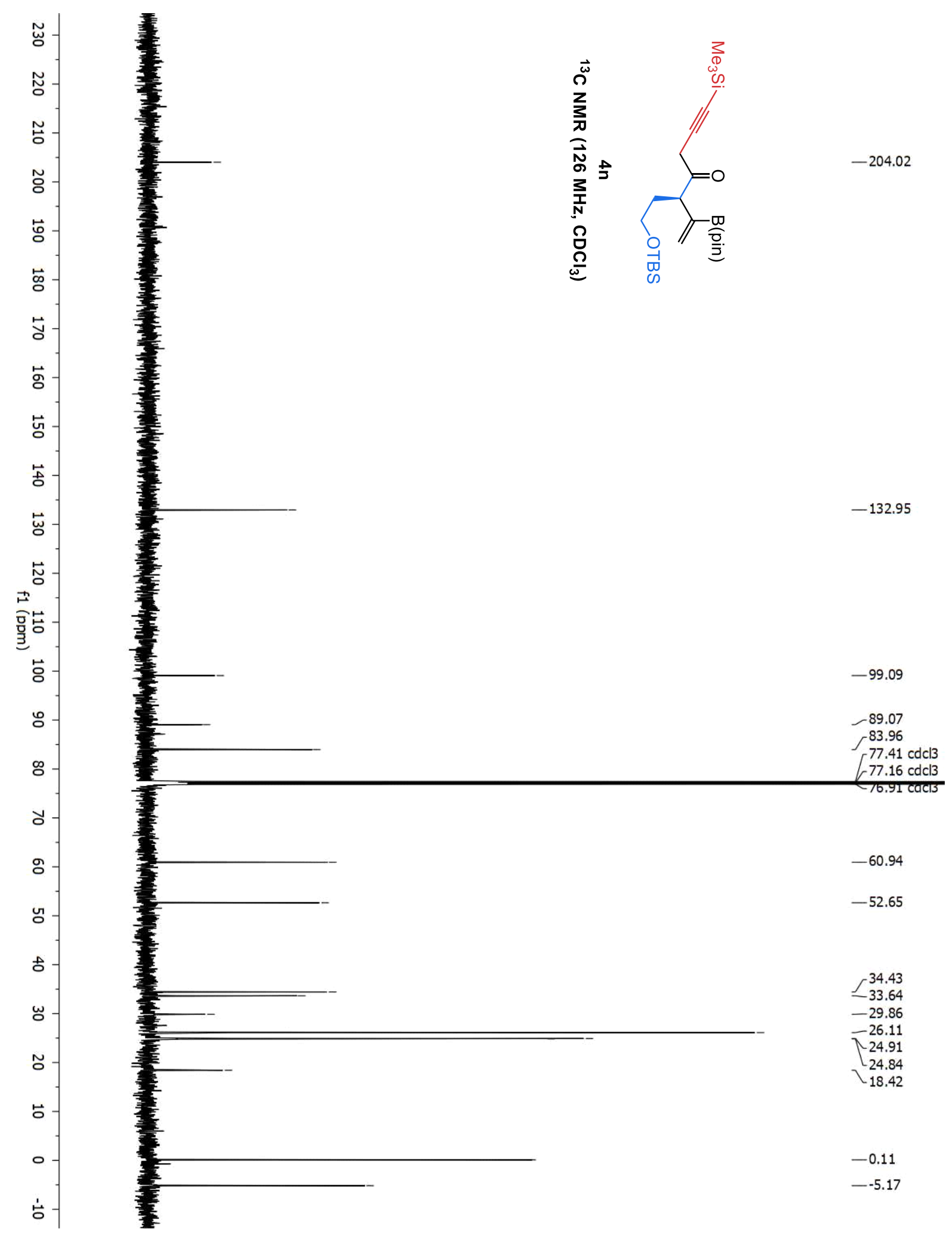




$$
\xi^{\prime \prime}
$$




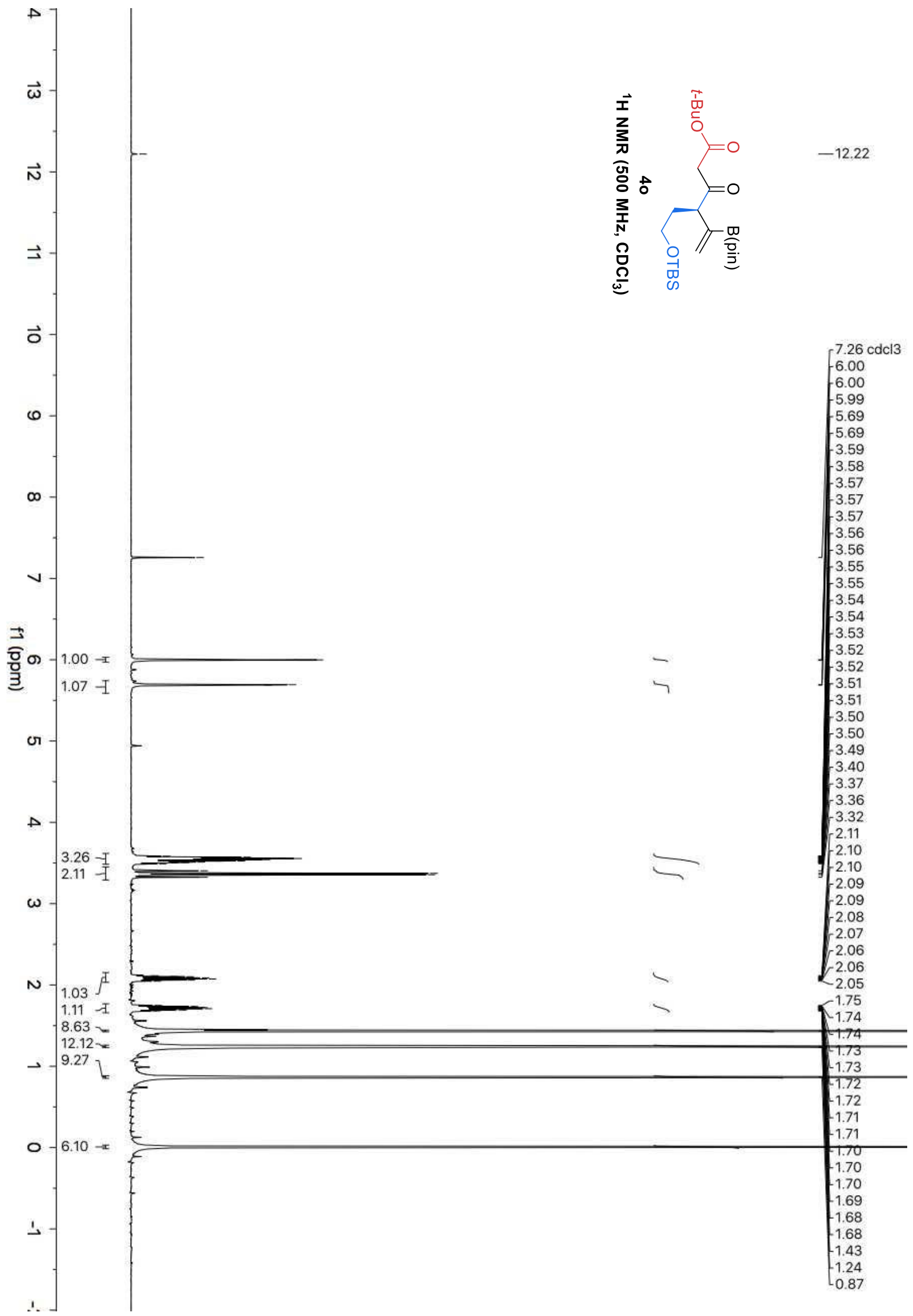




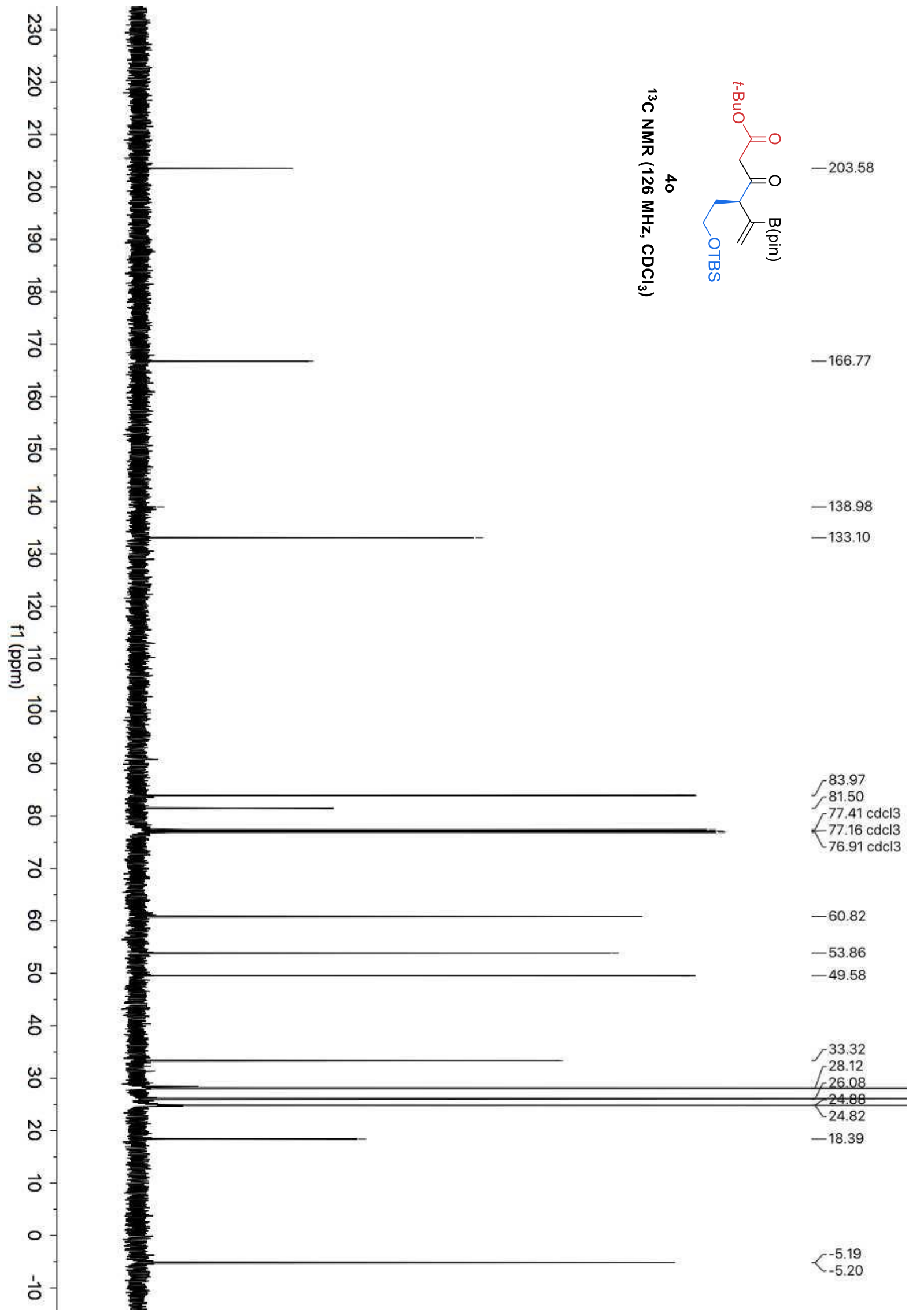


Del Pozo, et al., Supplementary Materials; Page 209

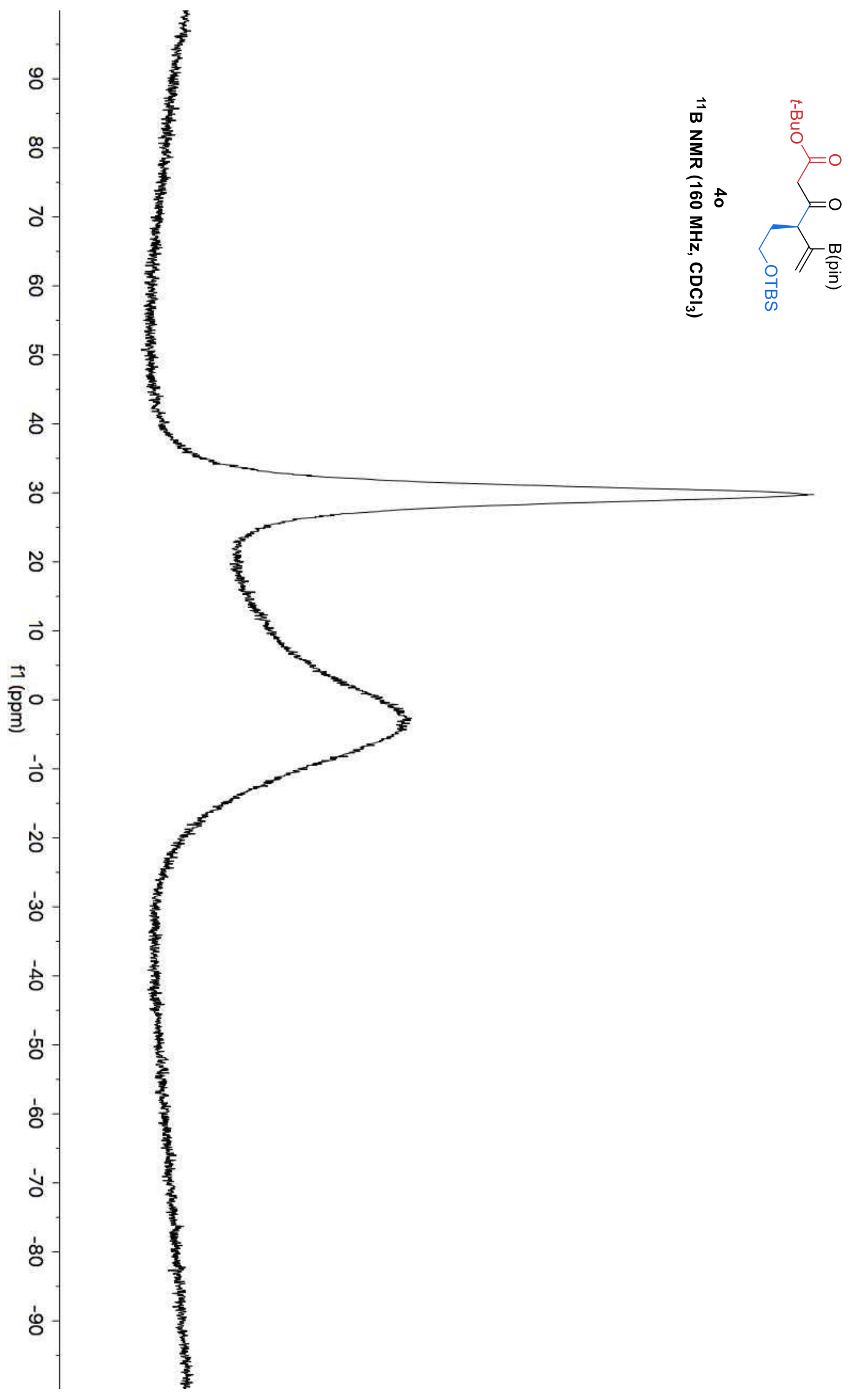

$-29.75$ 


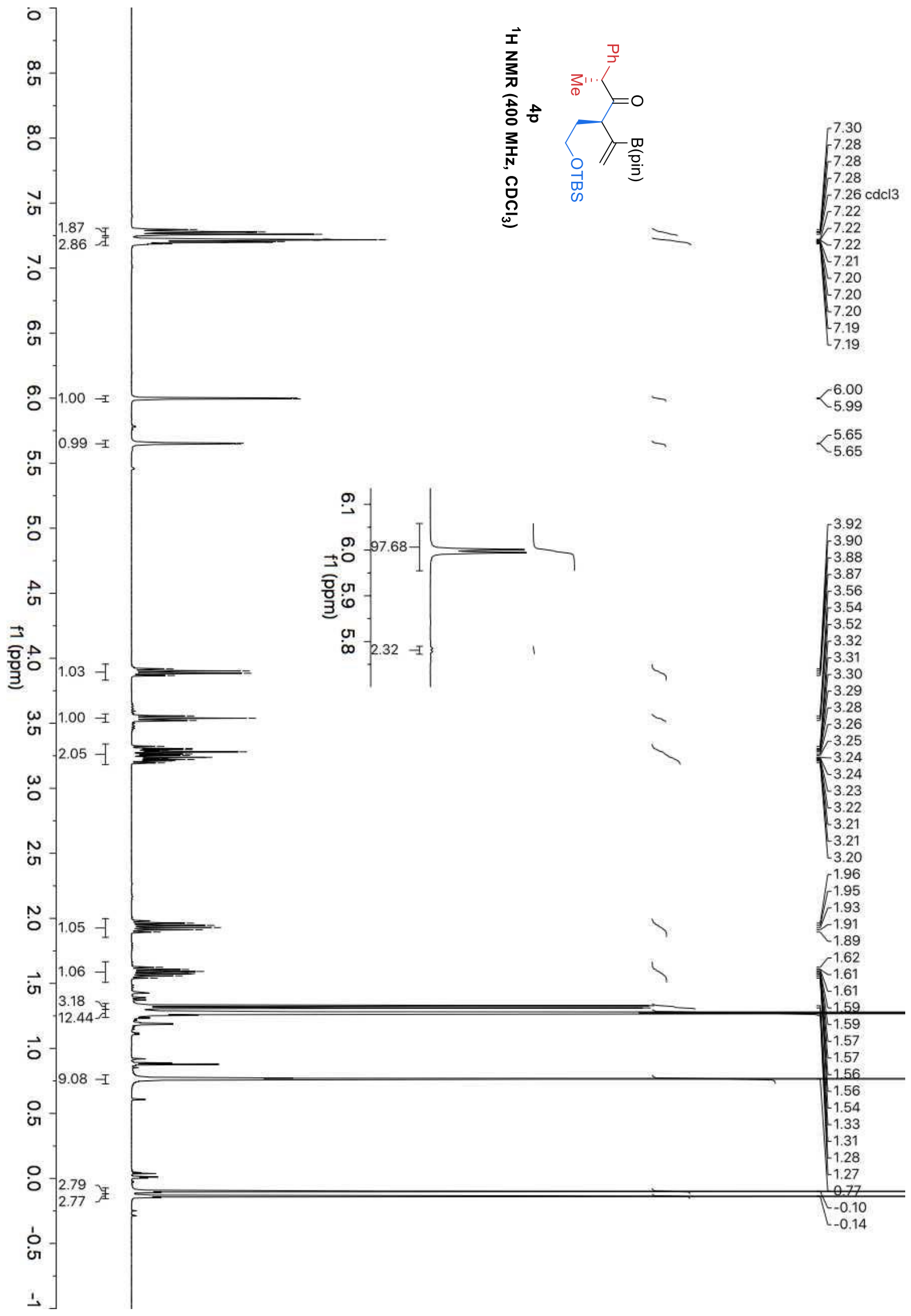




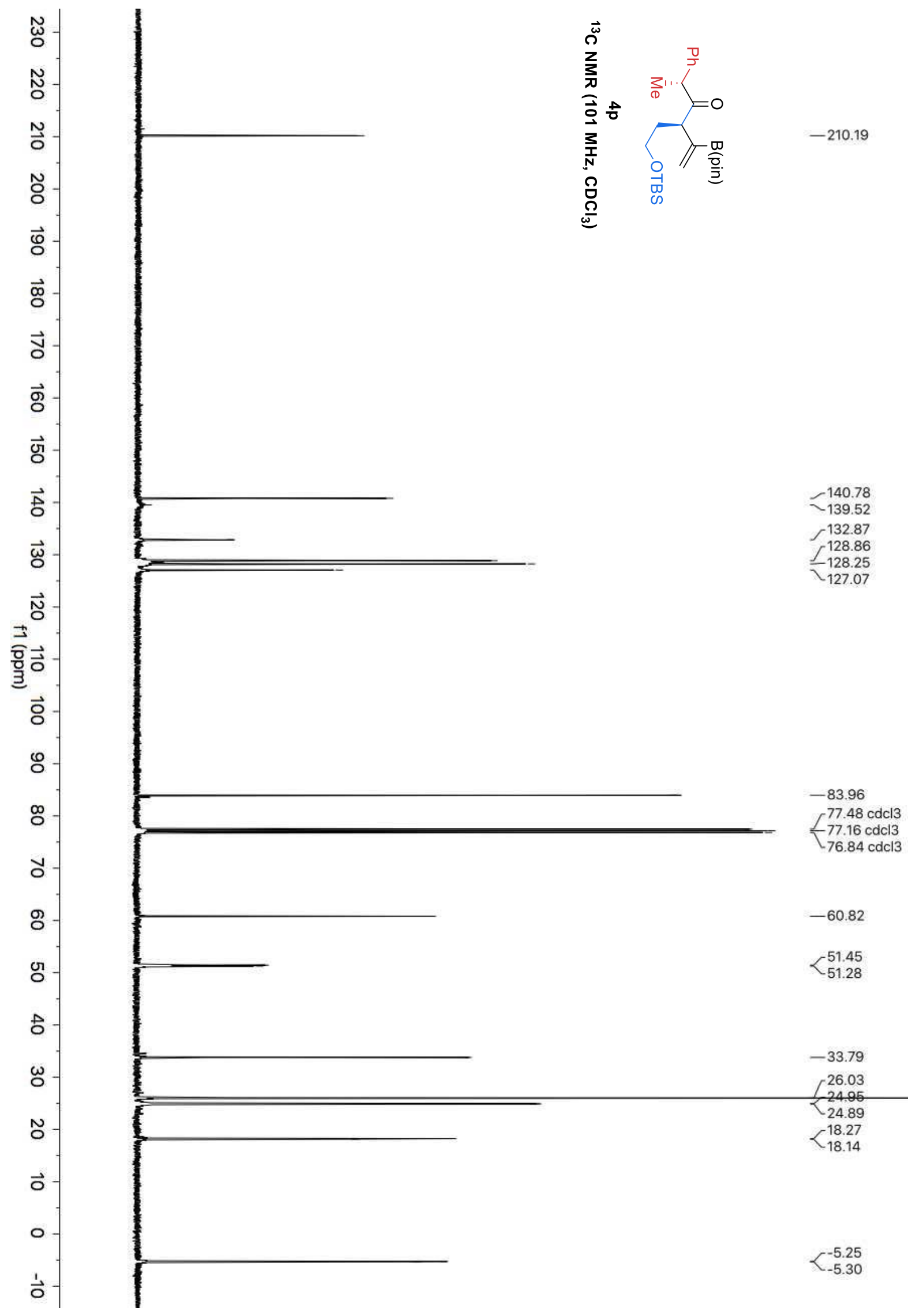




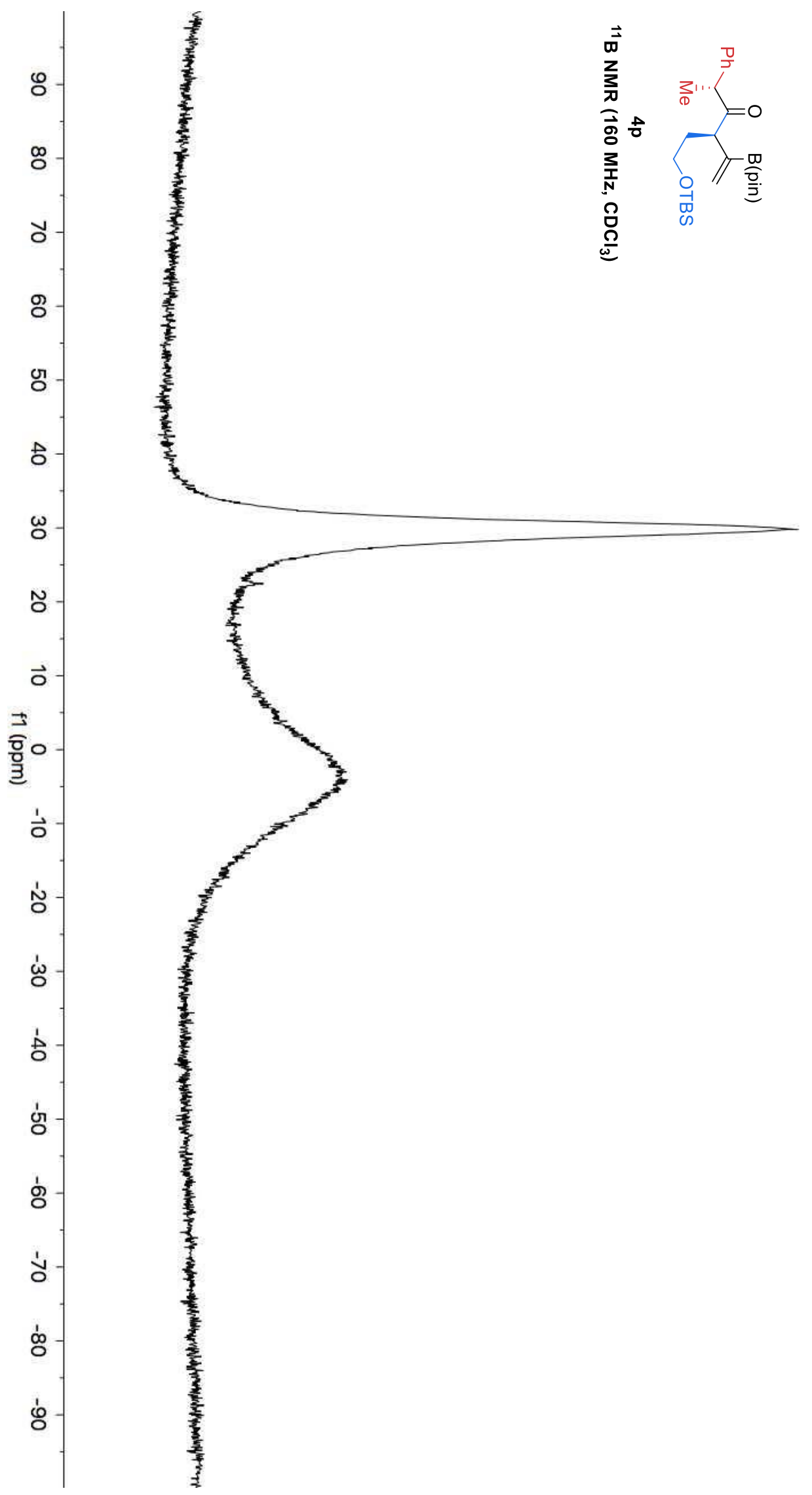




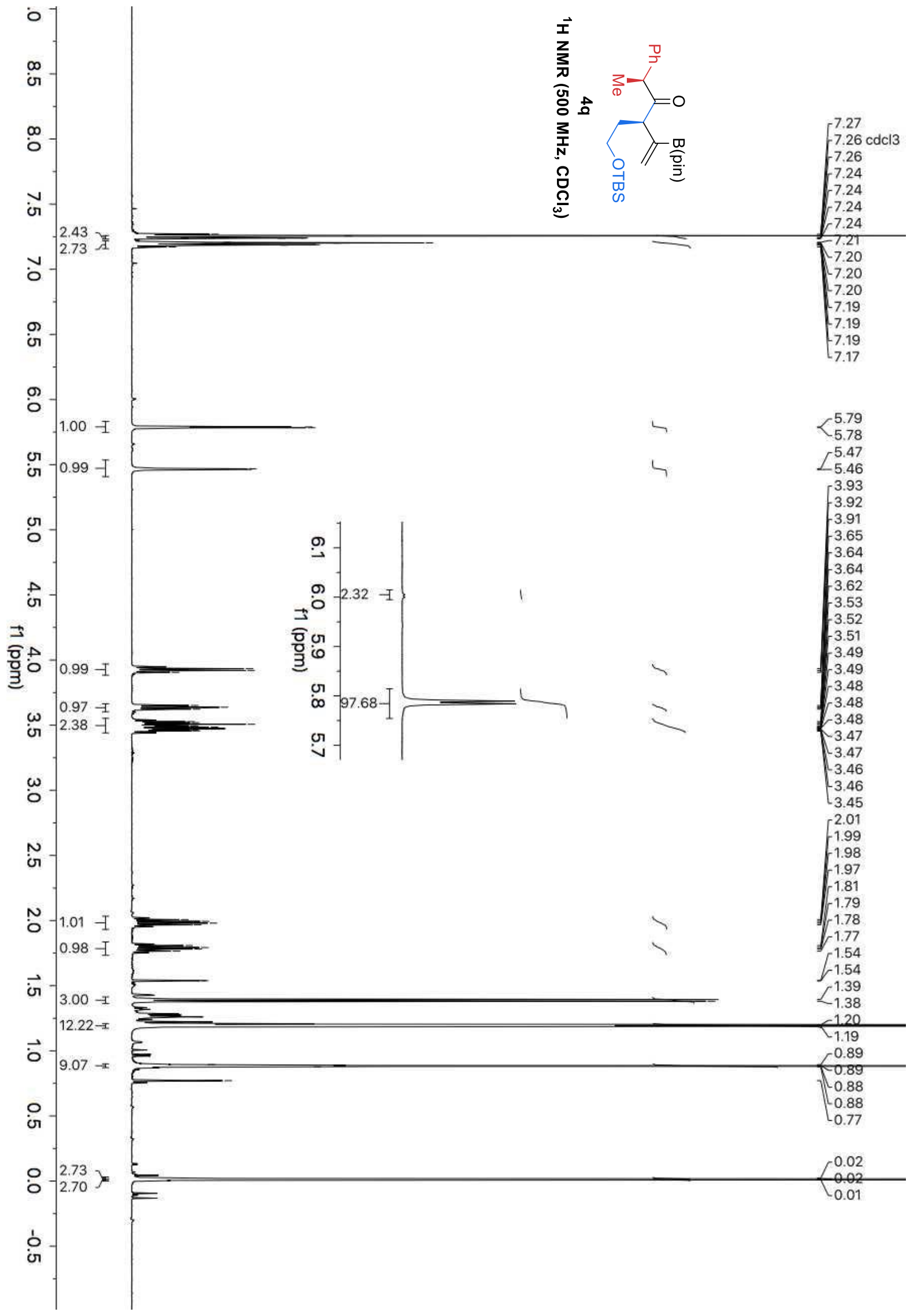




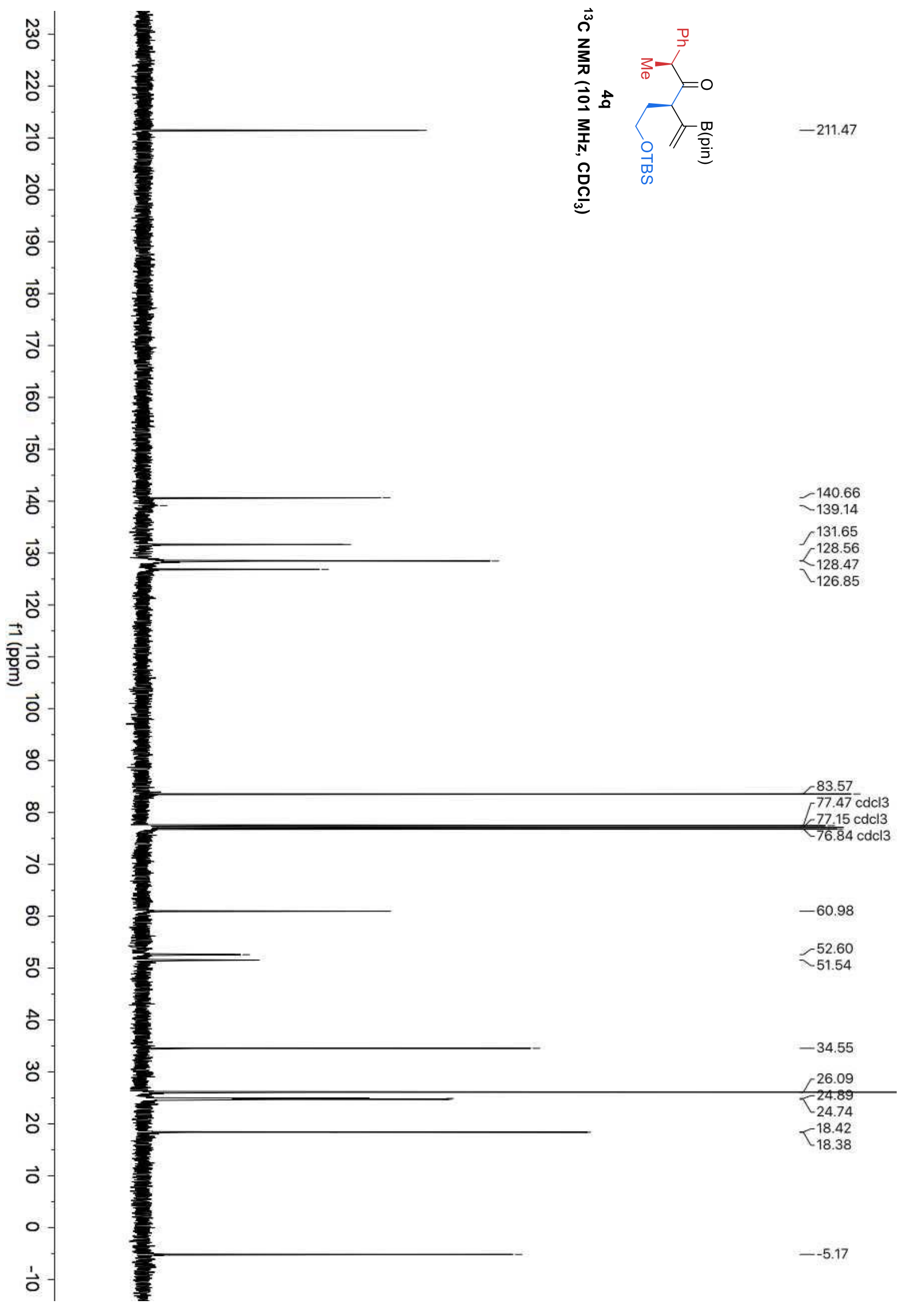


Del Pozo, et al., Supplementary Materials; Page 215

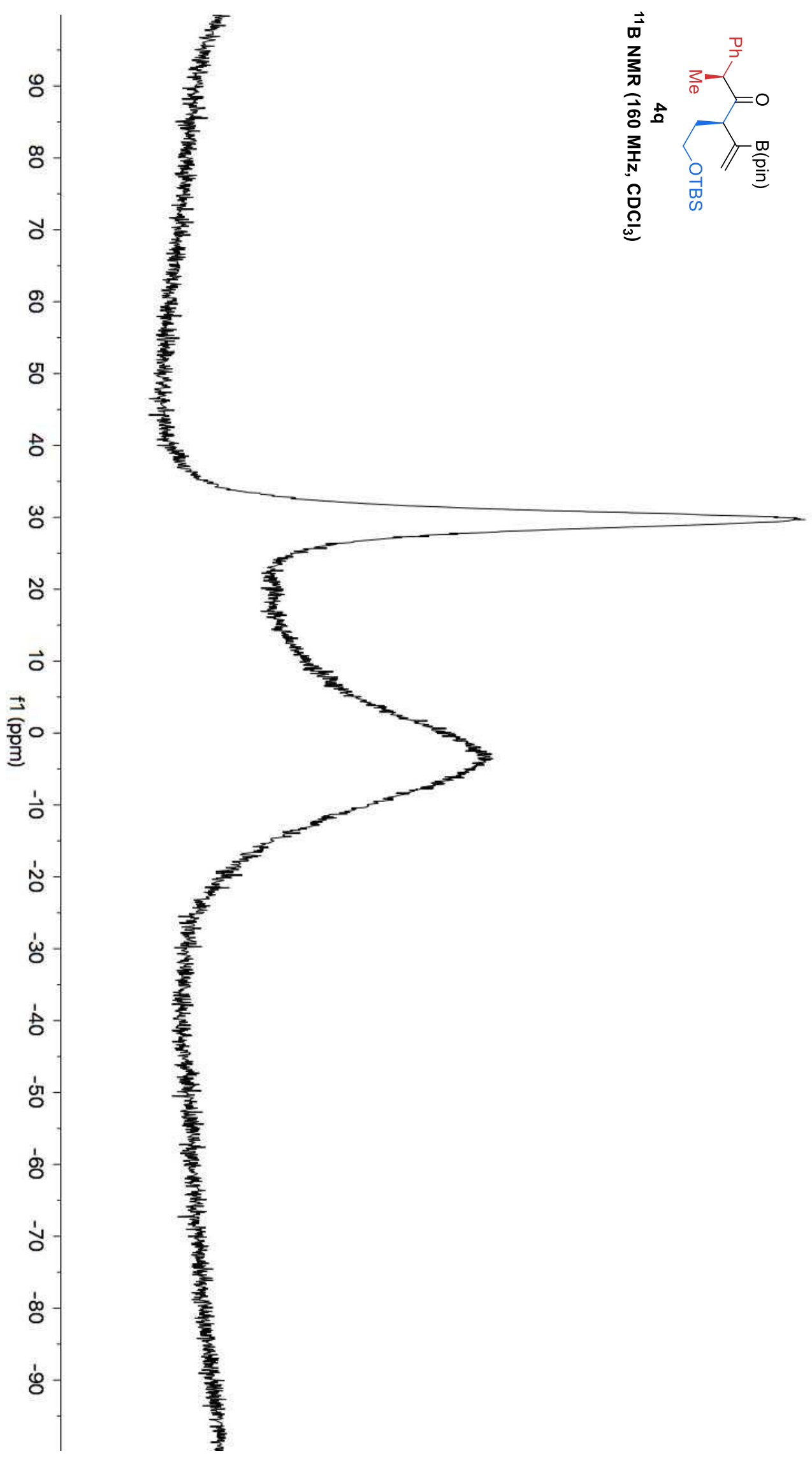

$-29.70$ 


\subsection{With 1,1 disubstituted allenes}

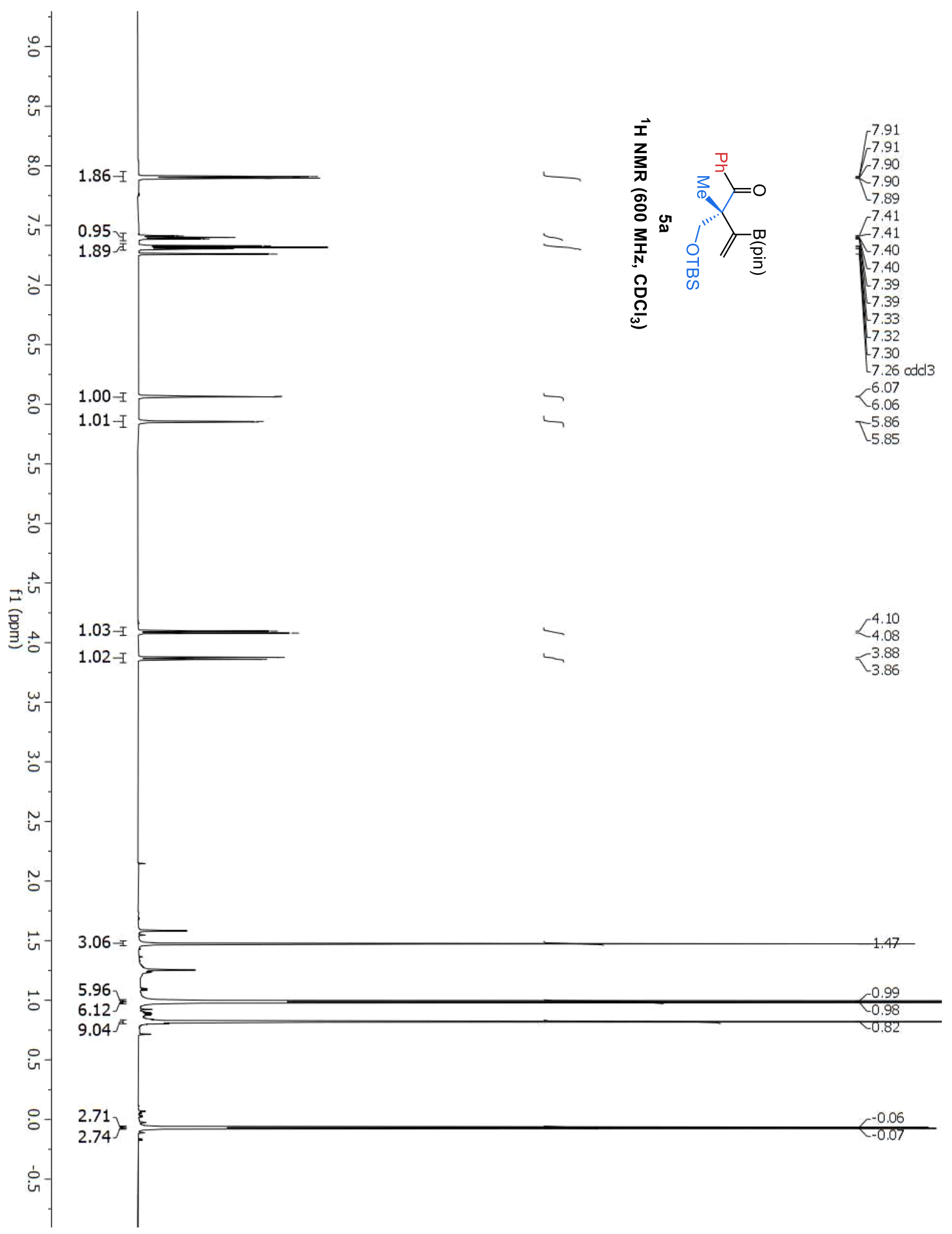




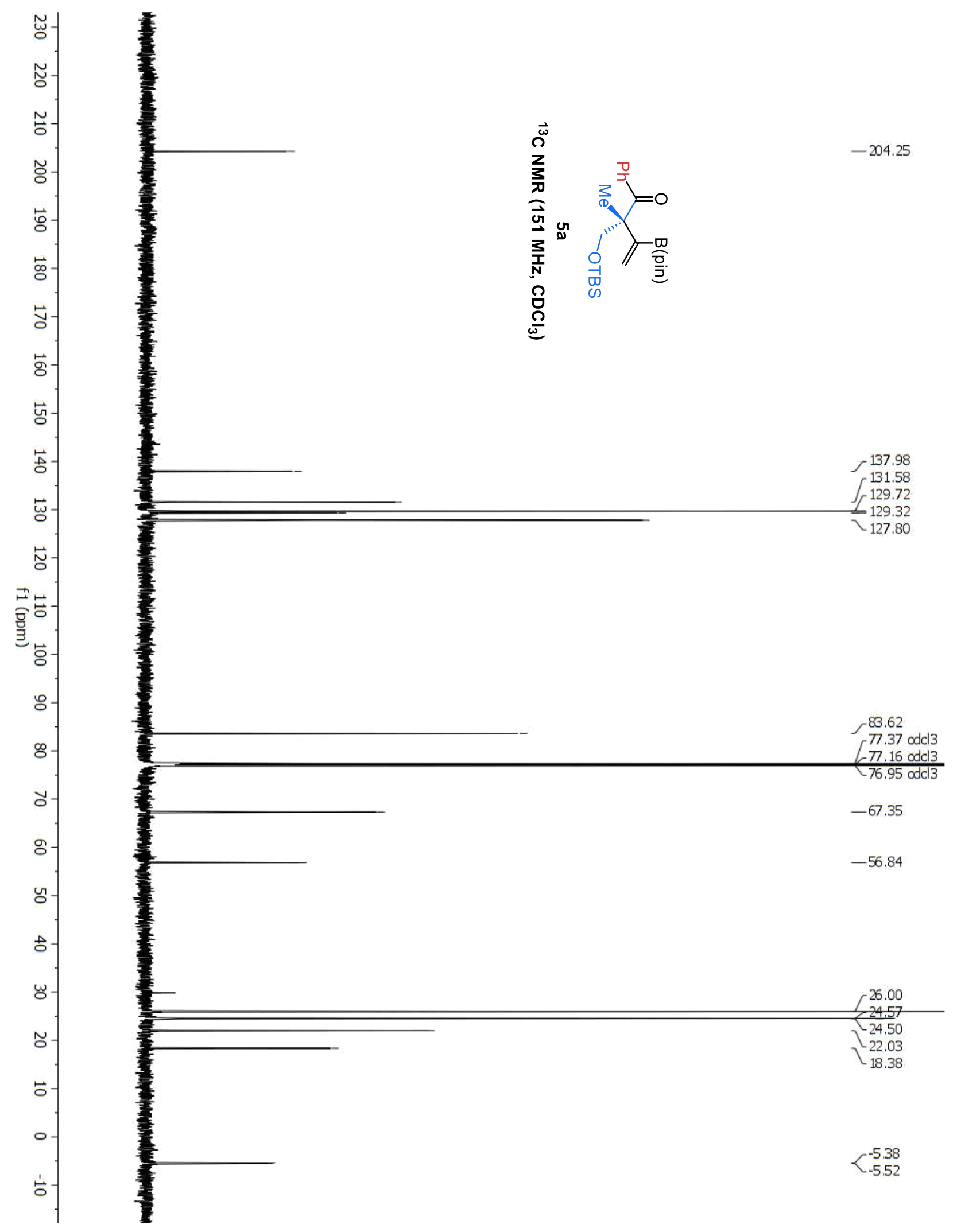


Del Pozo, et al., Supplementary Materials; Page 218

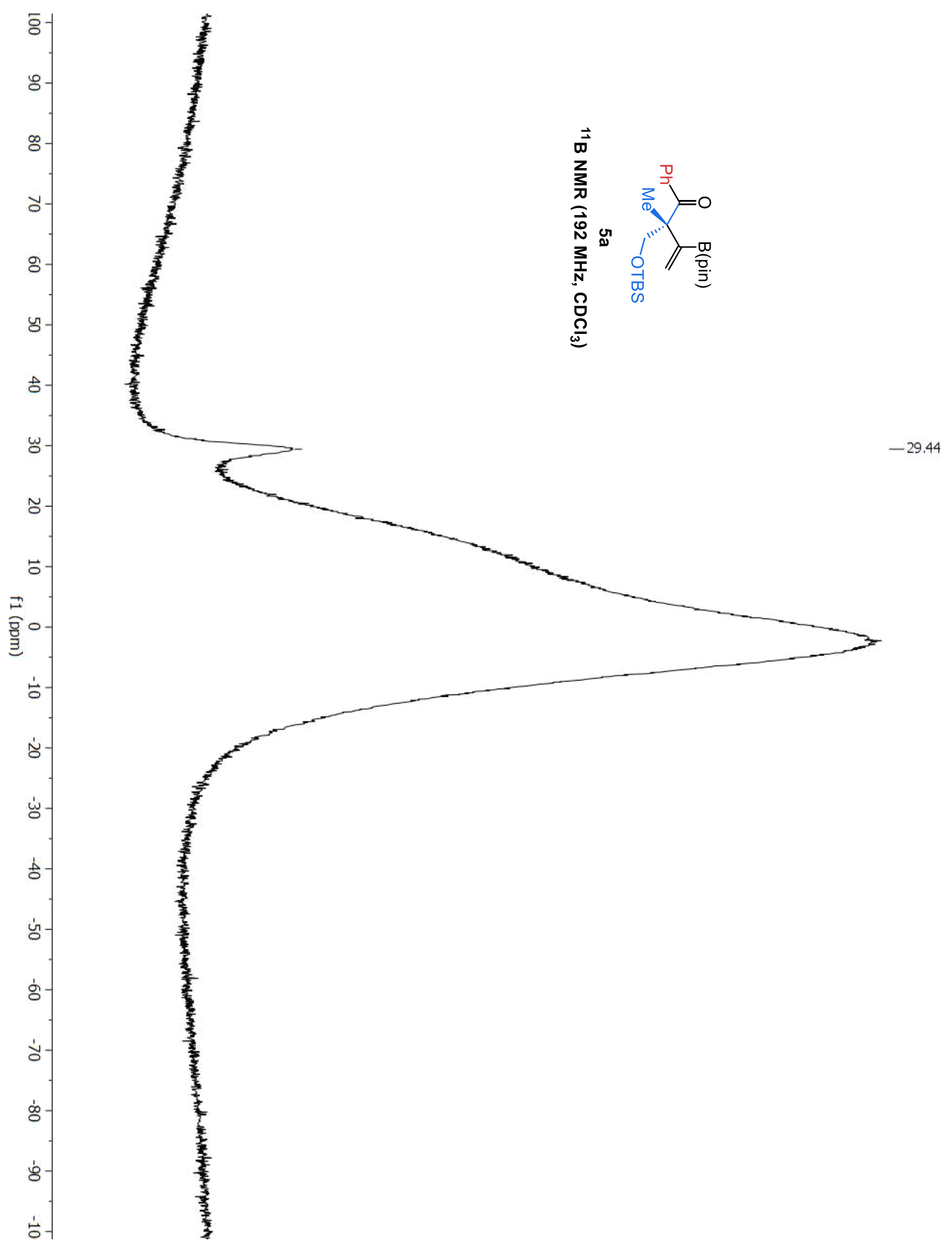




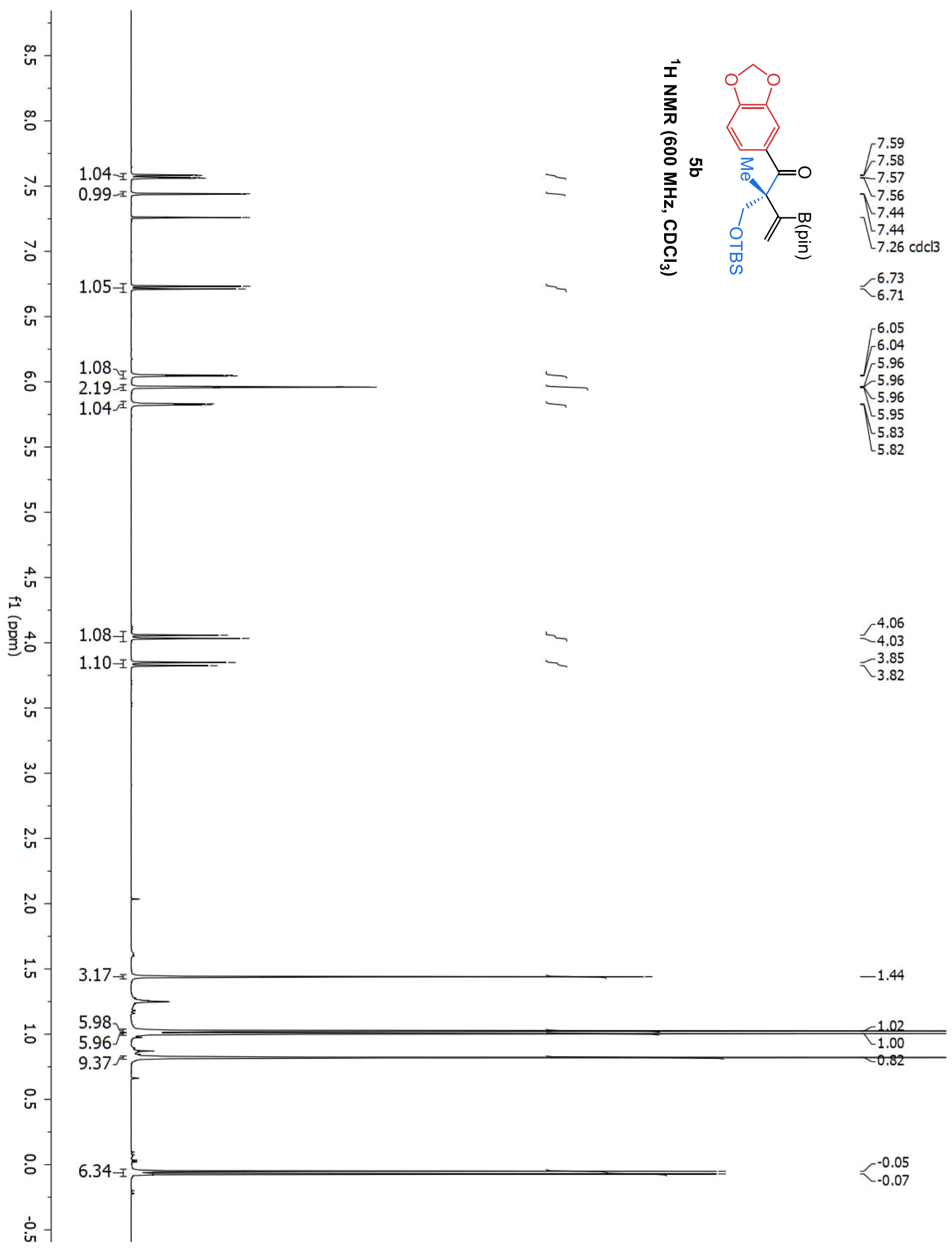




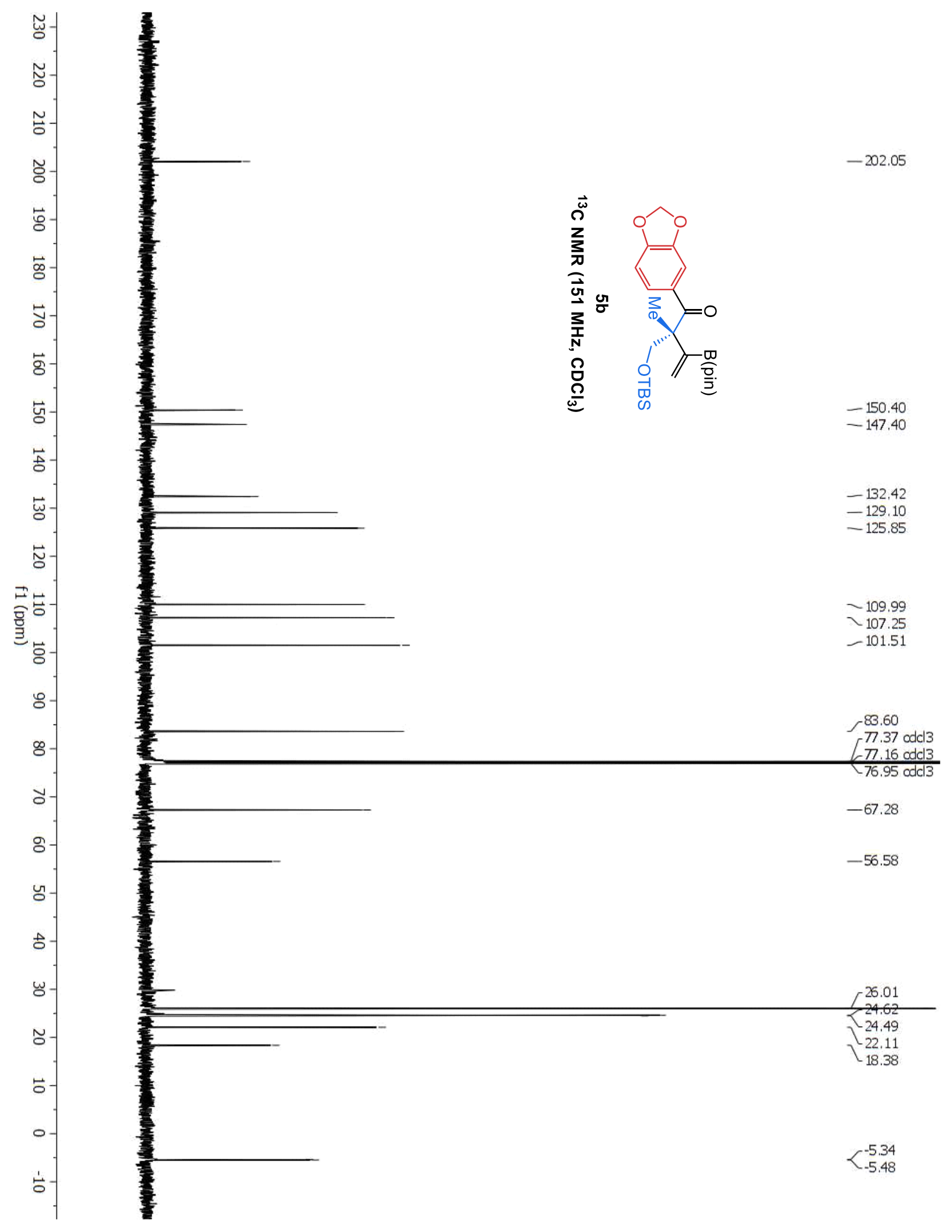


Del Pozo, et al., Supplementary Materials; Page 221

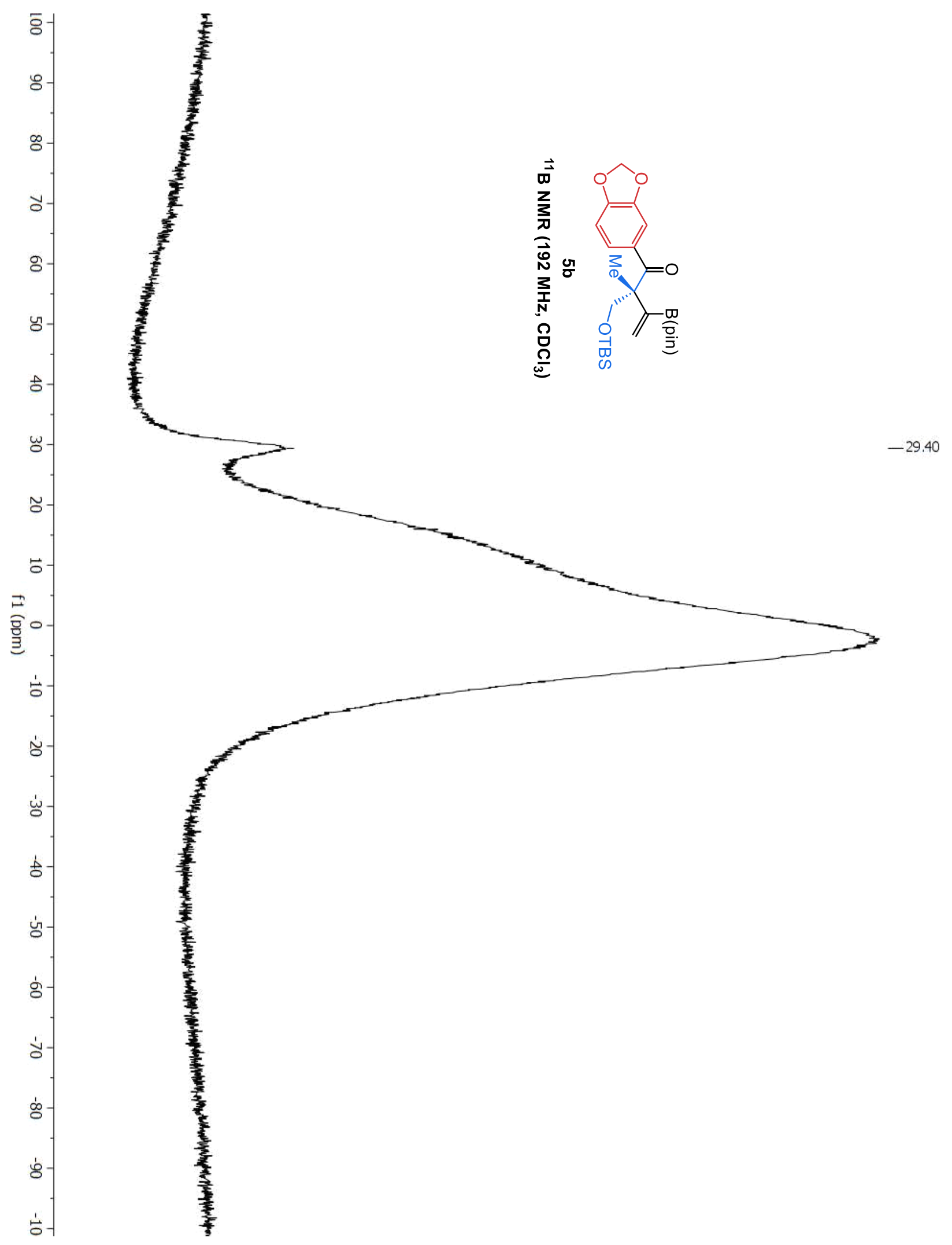




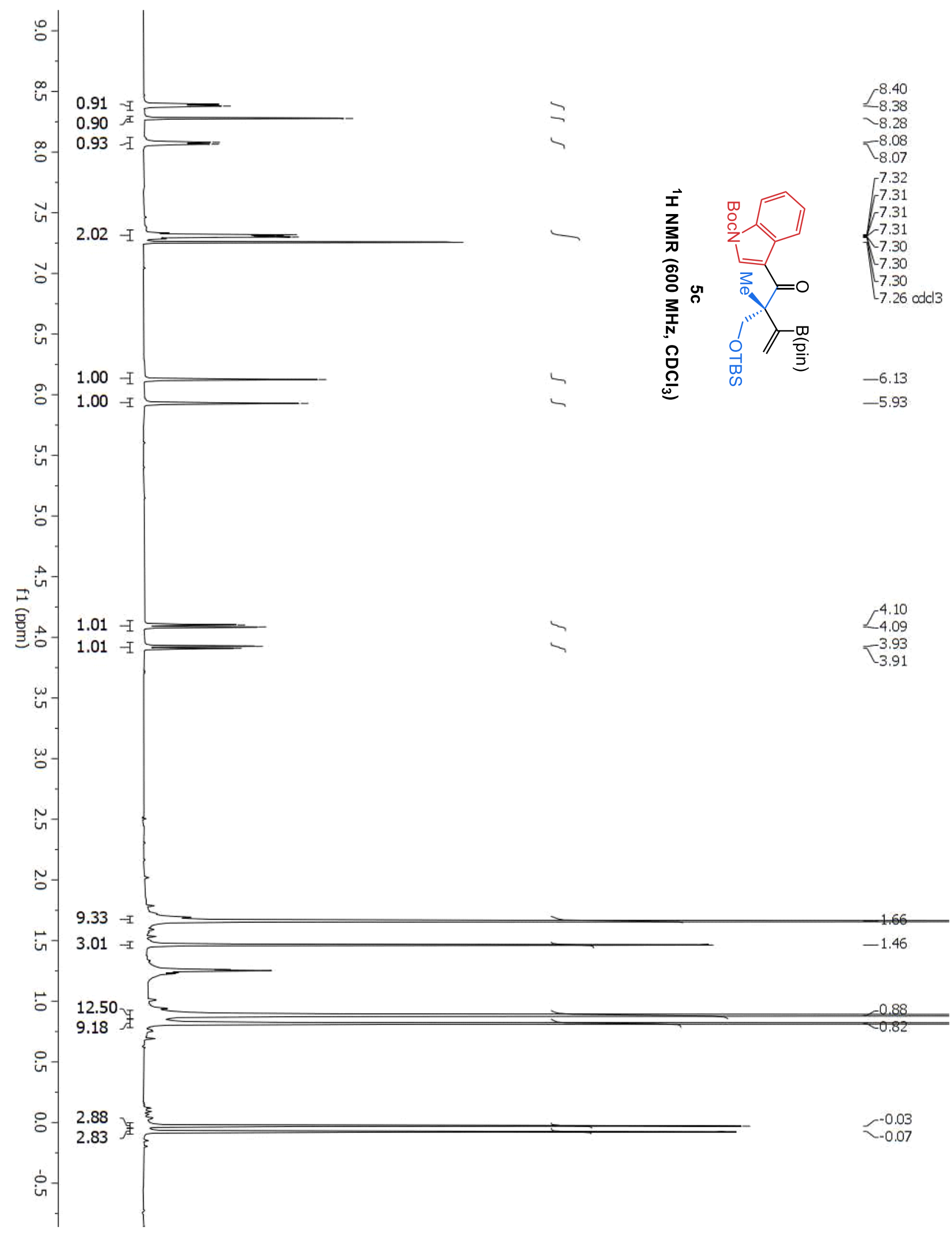




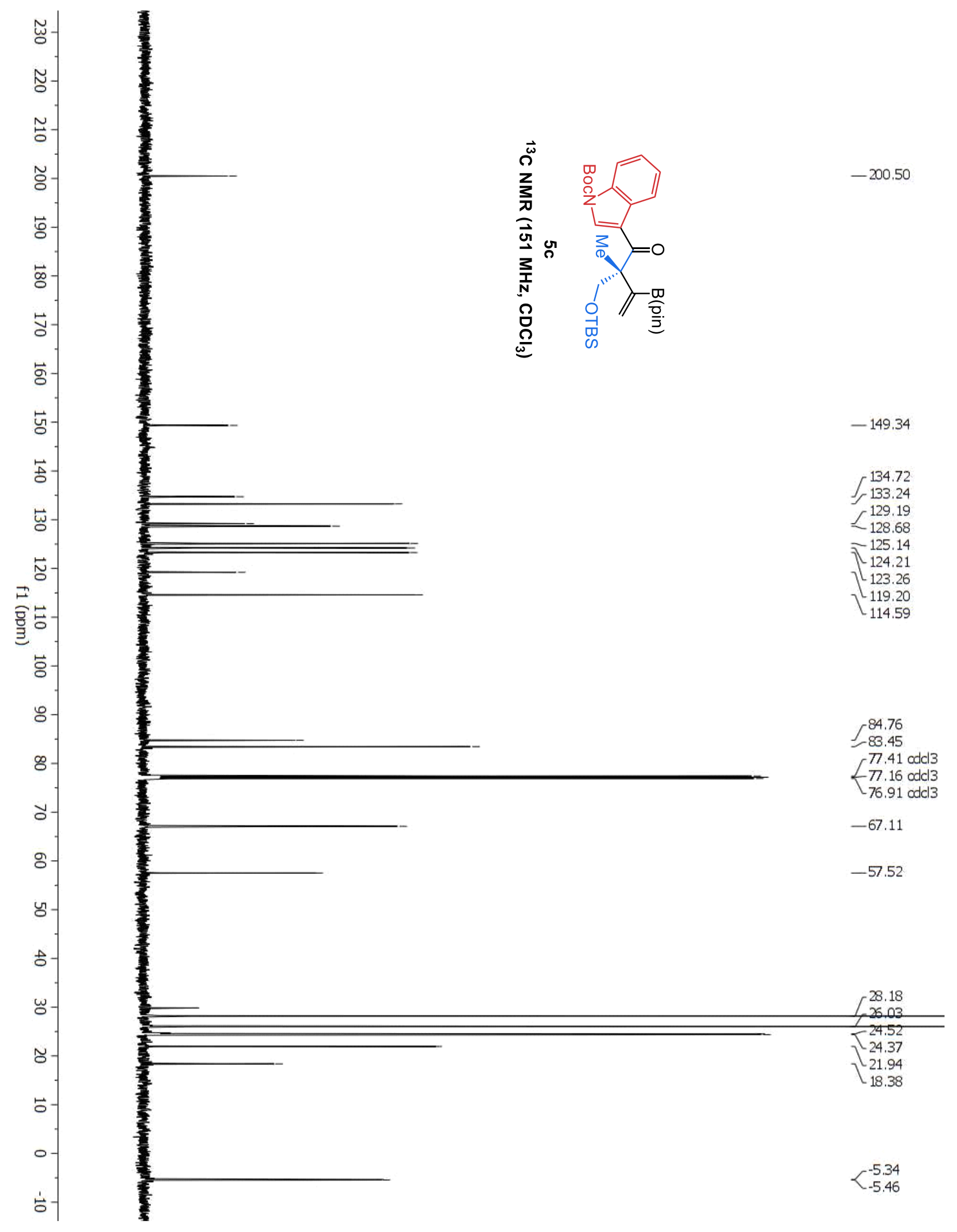


Del Pozo, et al., Supplementary Materials; Page 224

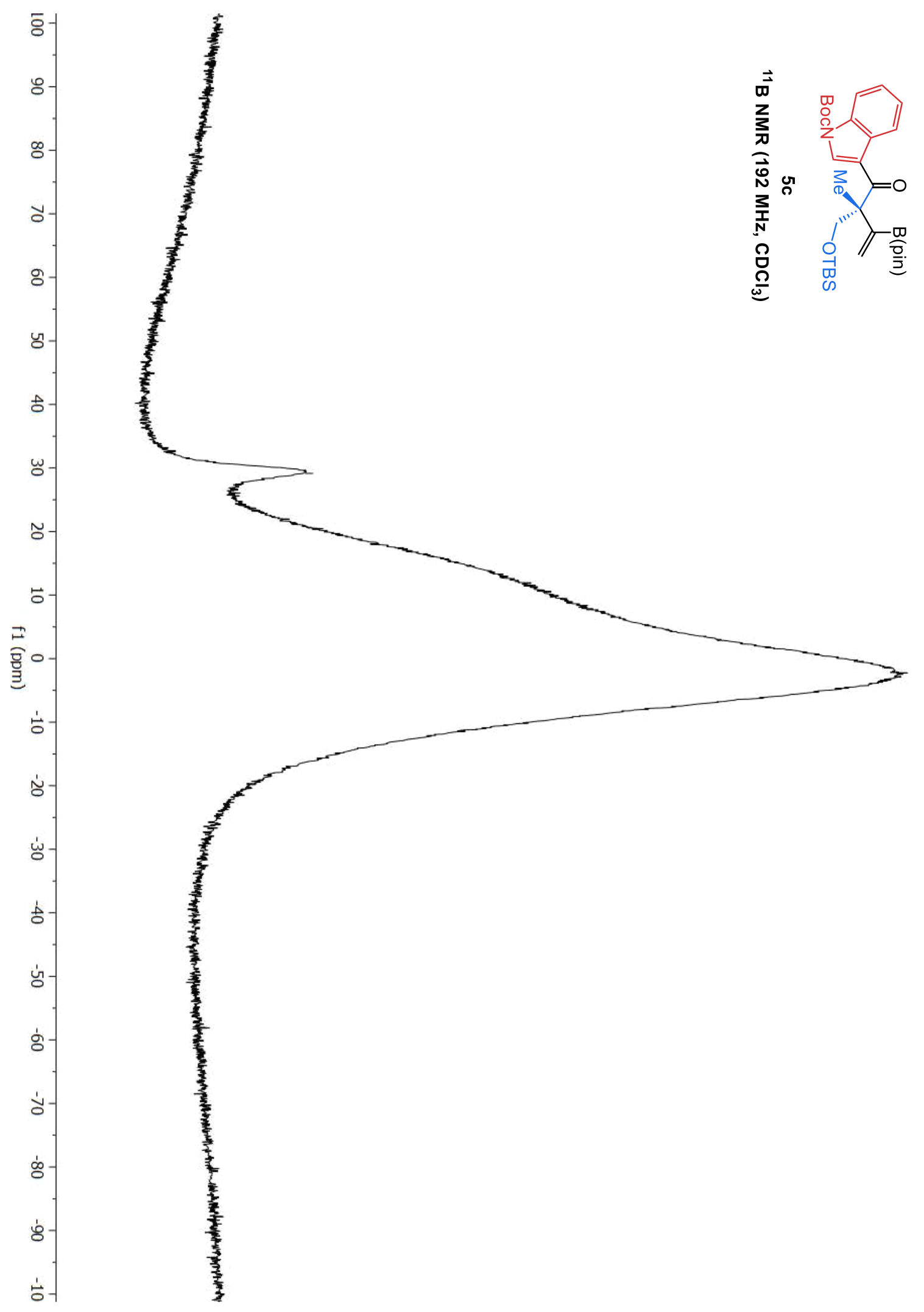

$-29.15$ 


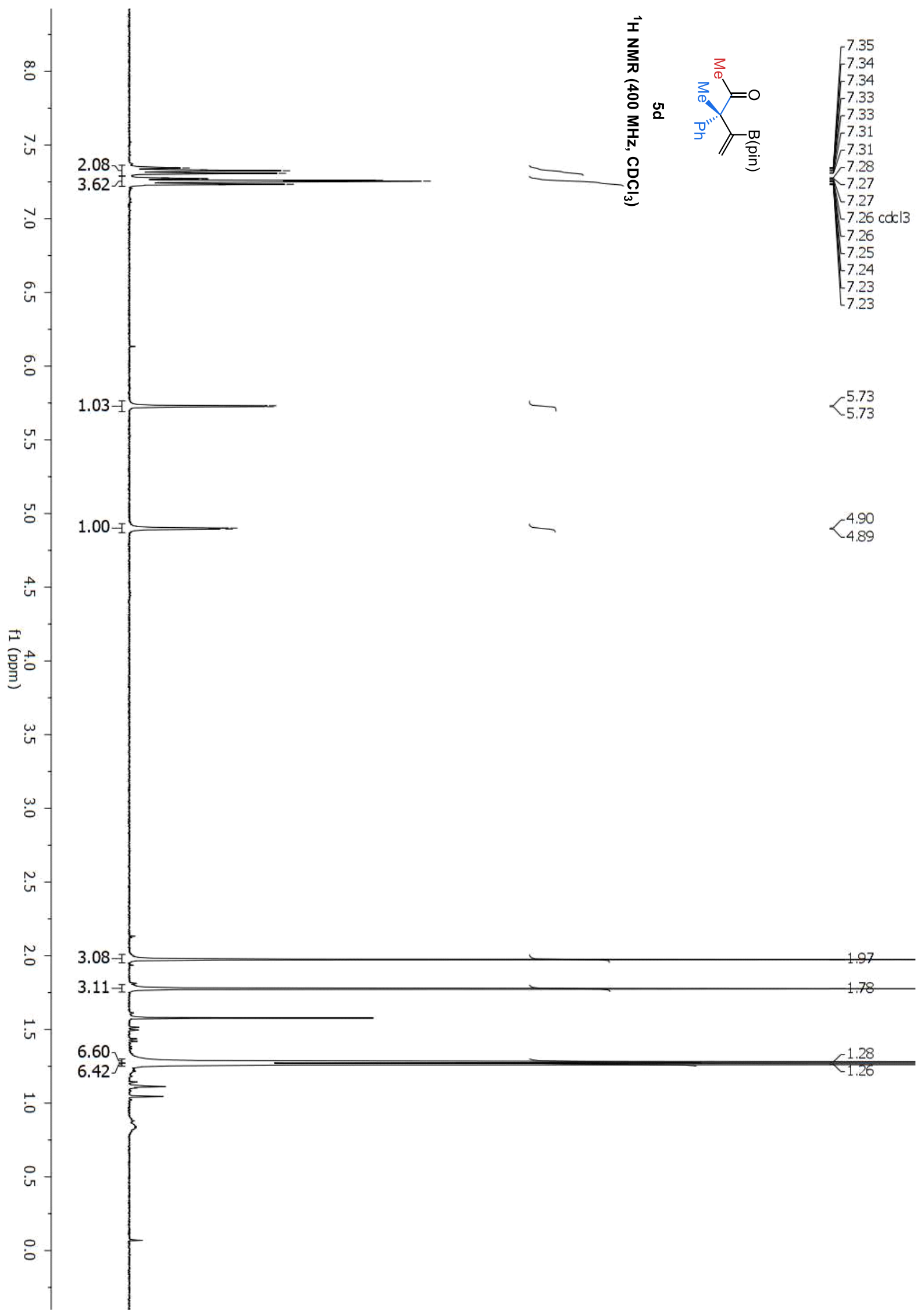




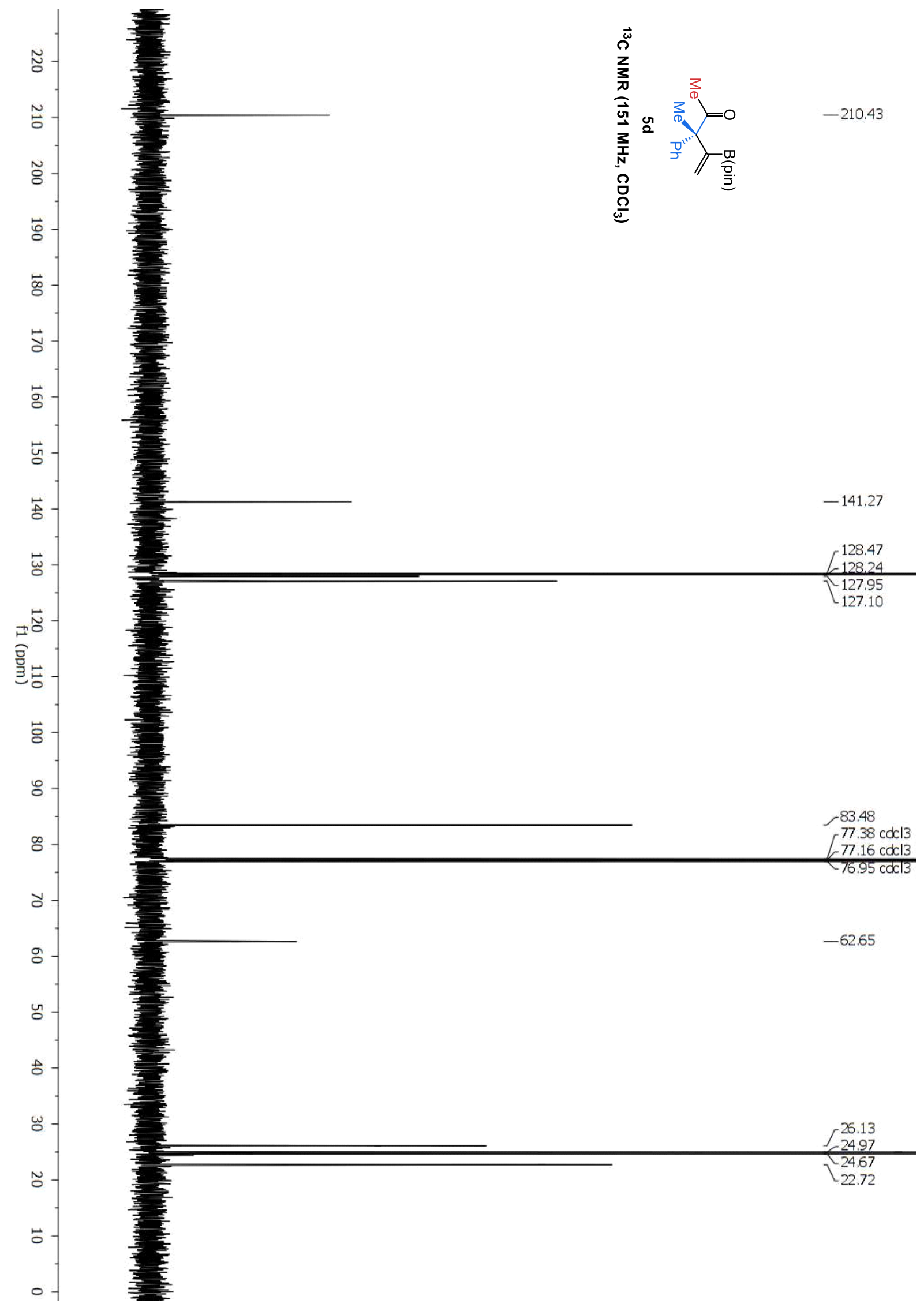


Del Pozo, et al., Supplementary Materials; Page 227

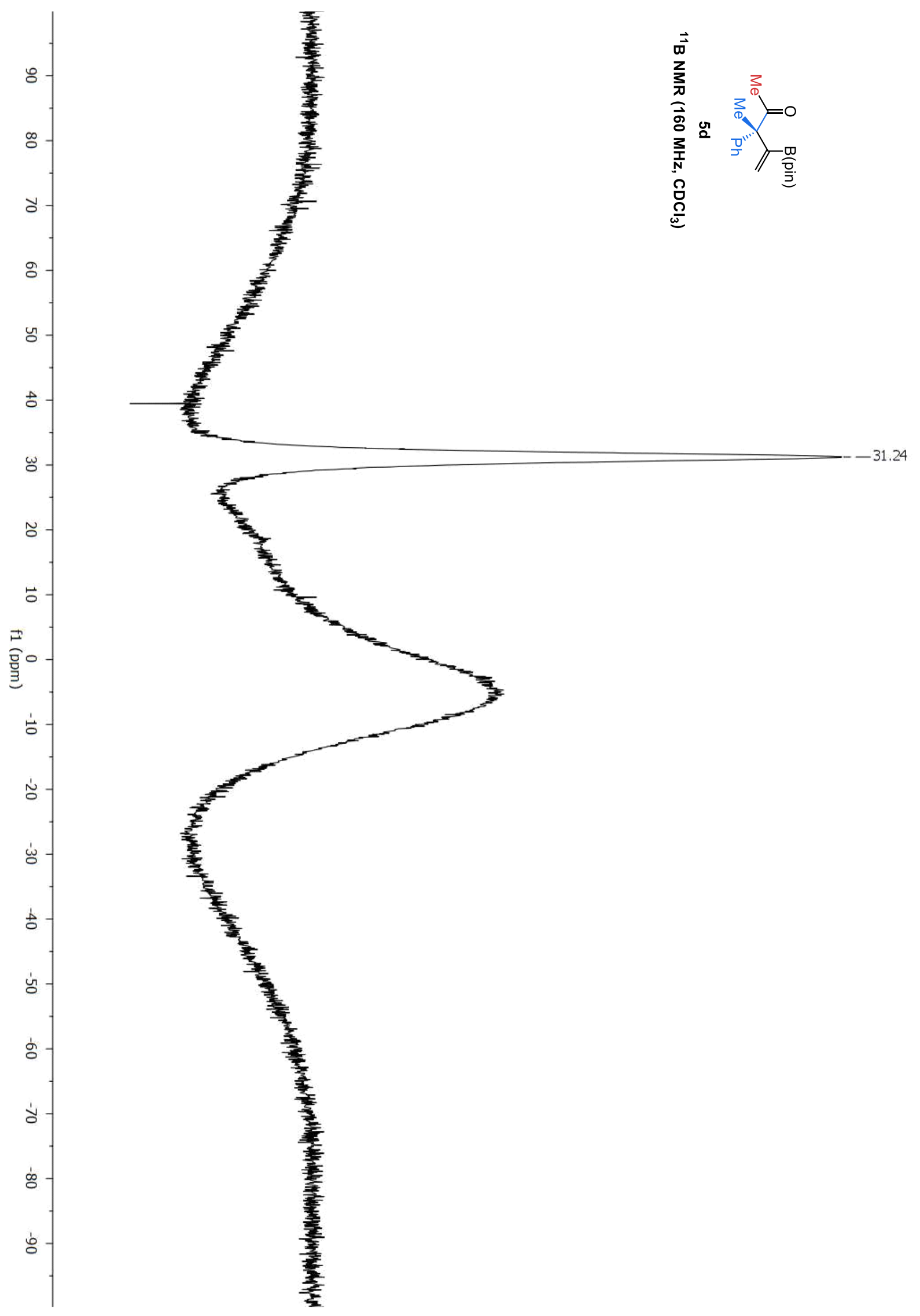




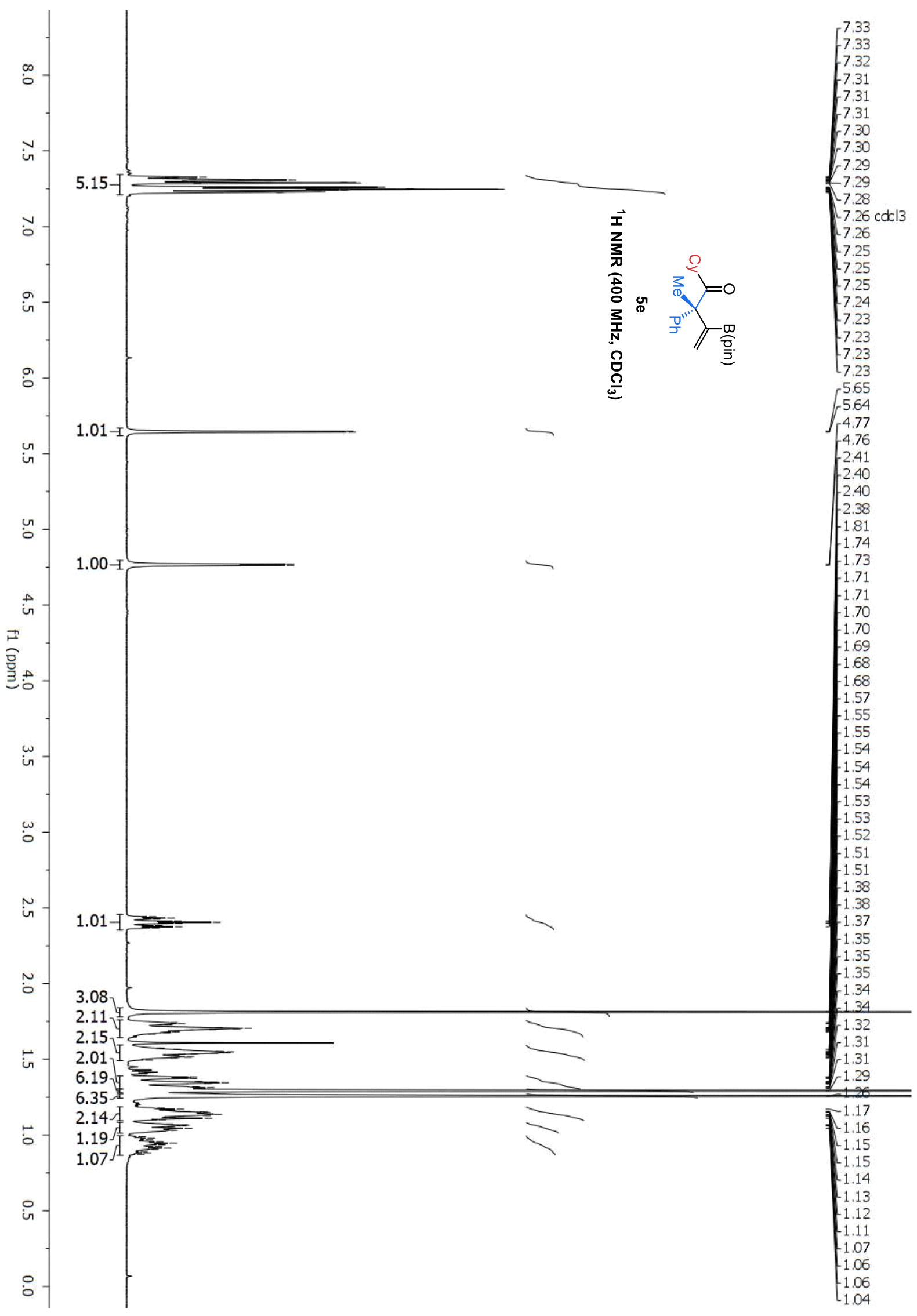




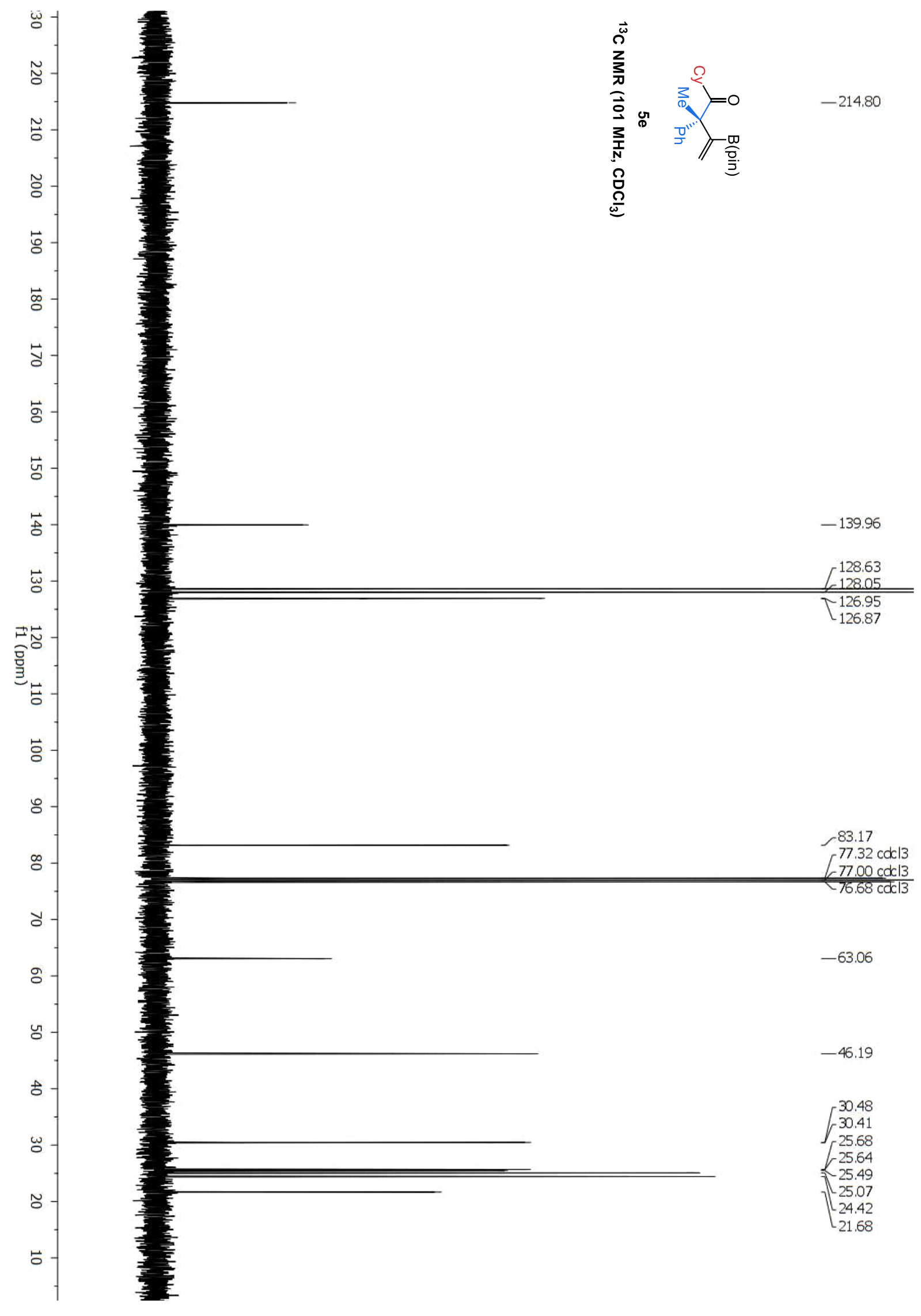


Del Pozo, et al., Supplementary Materials; Page 230

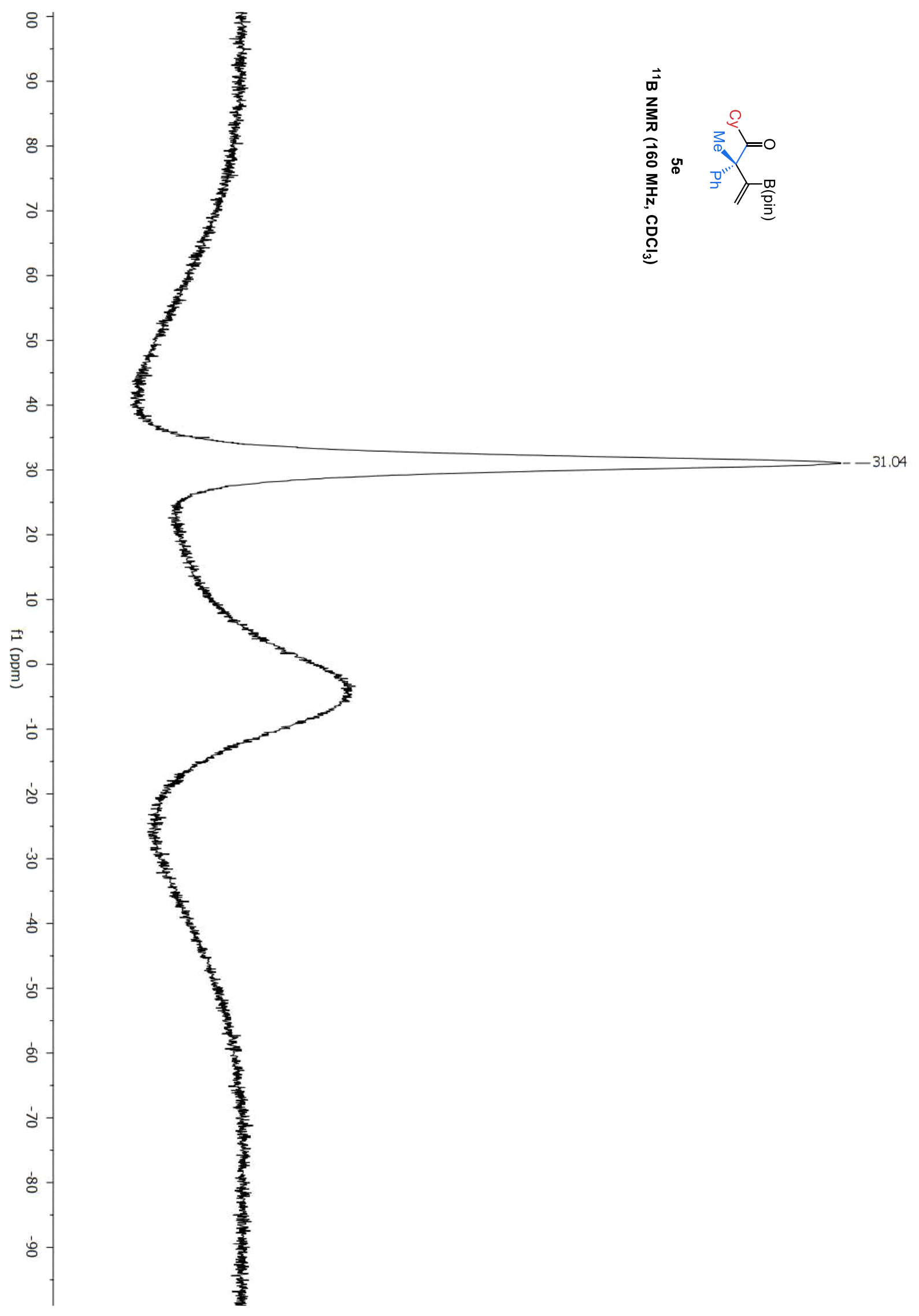




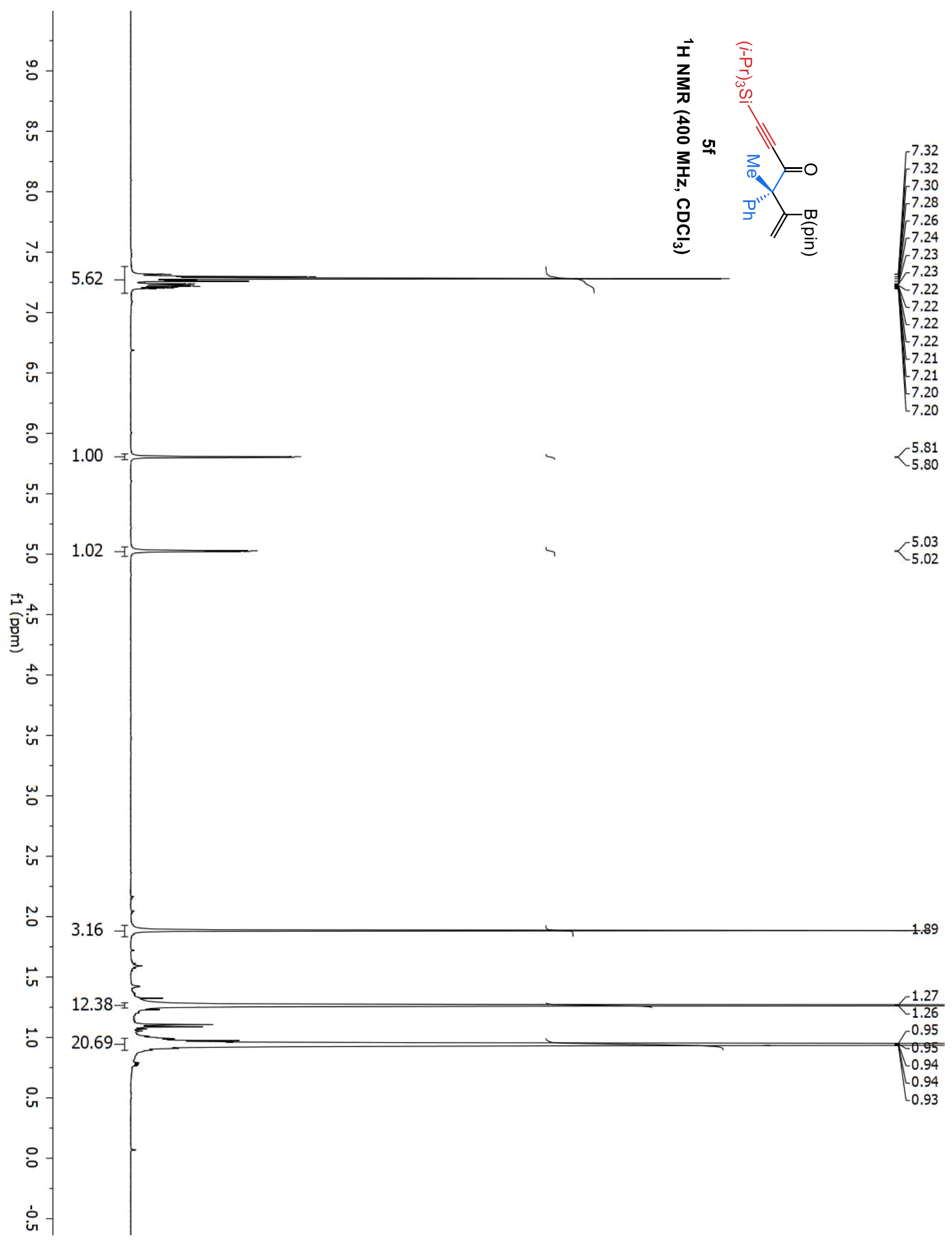




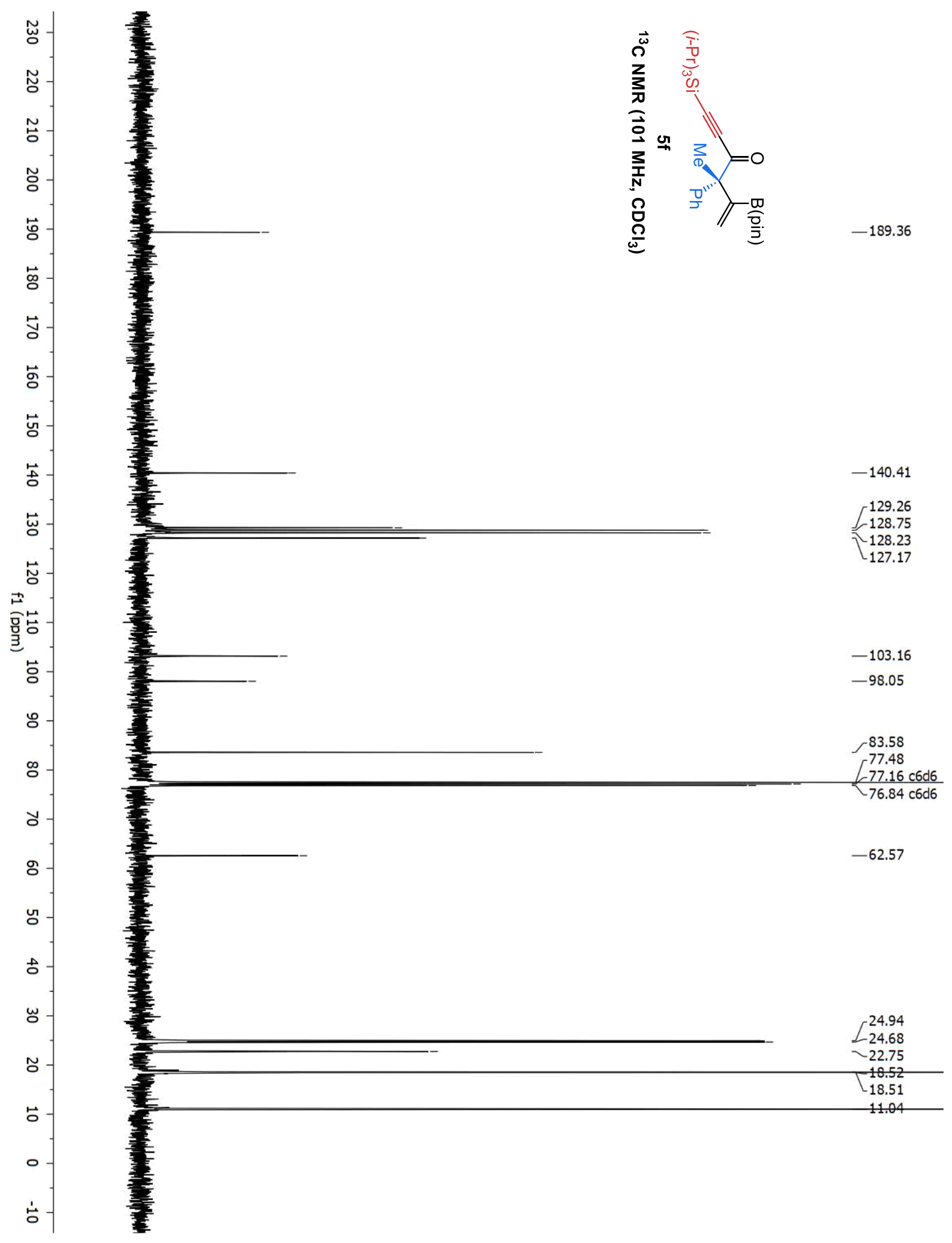



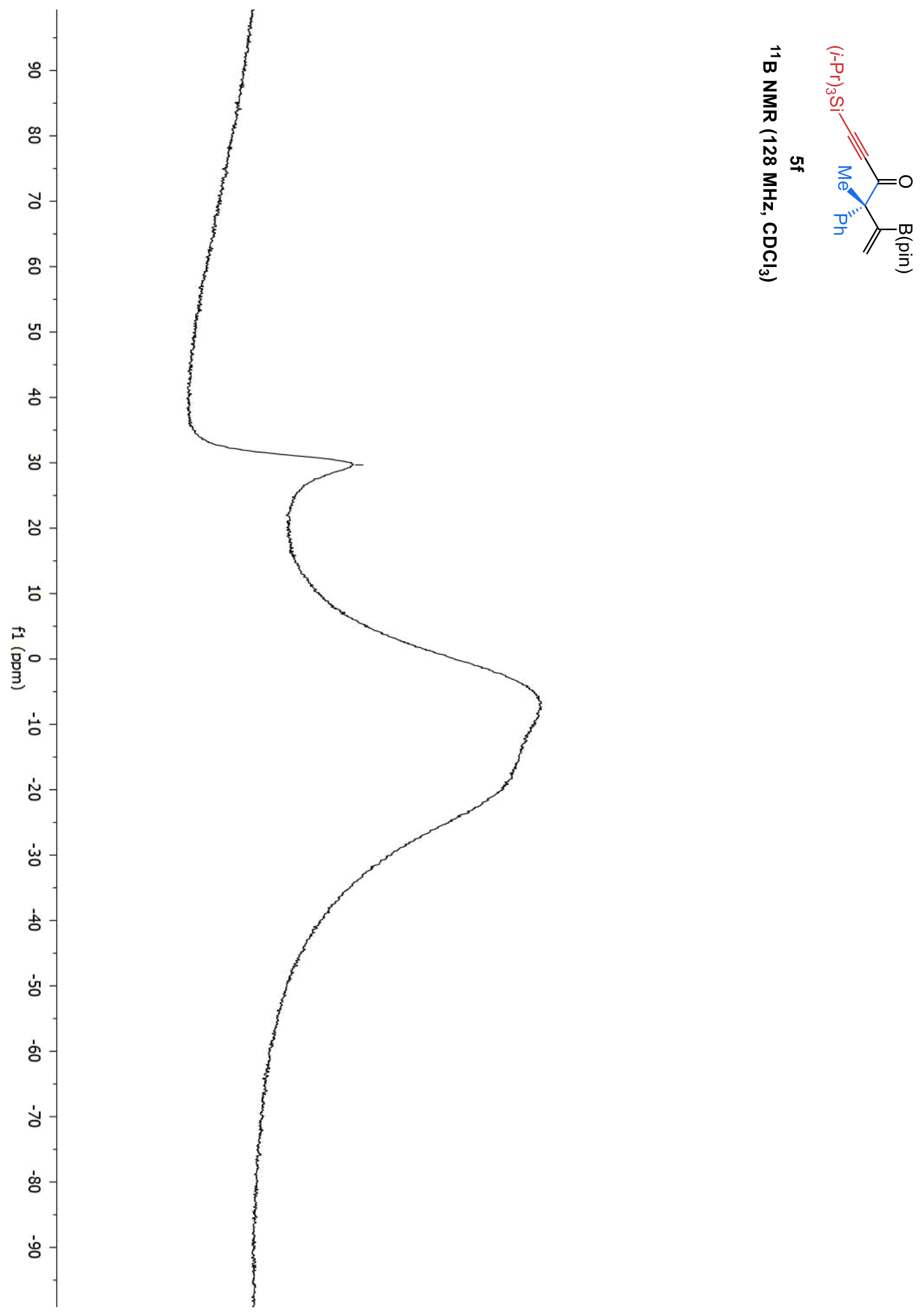


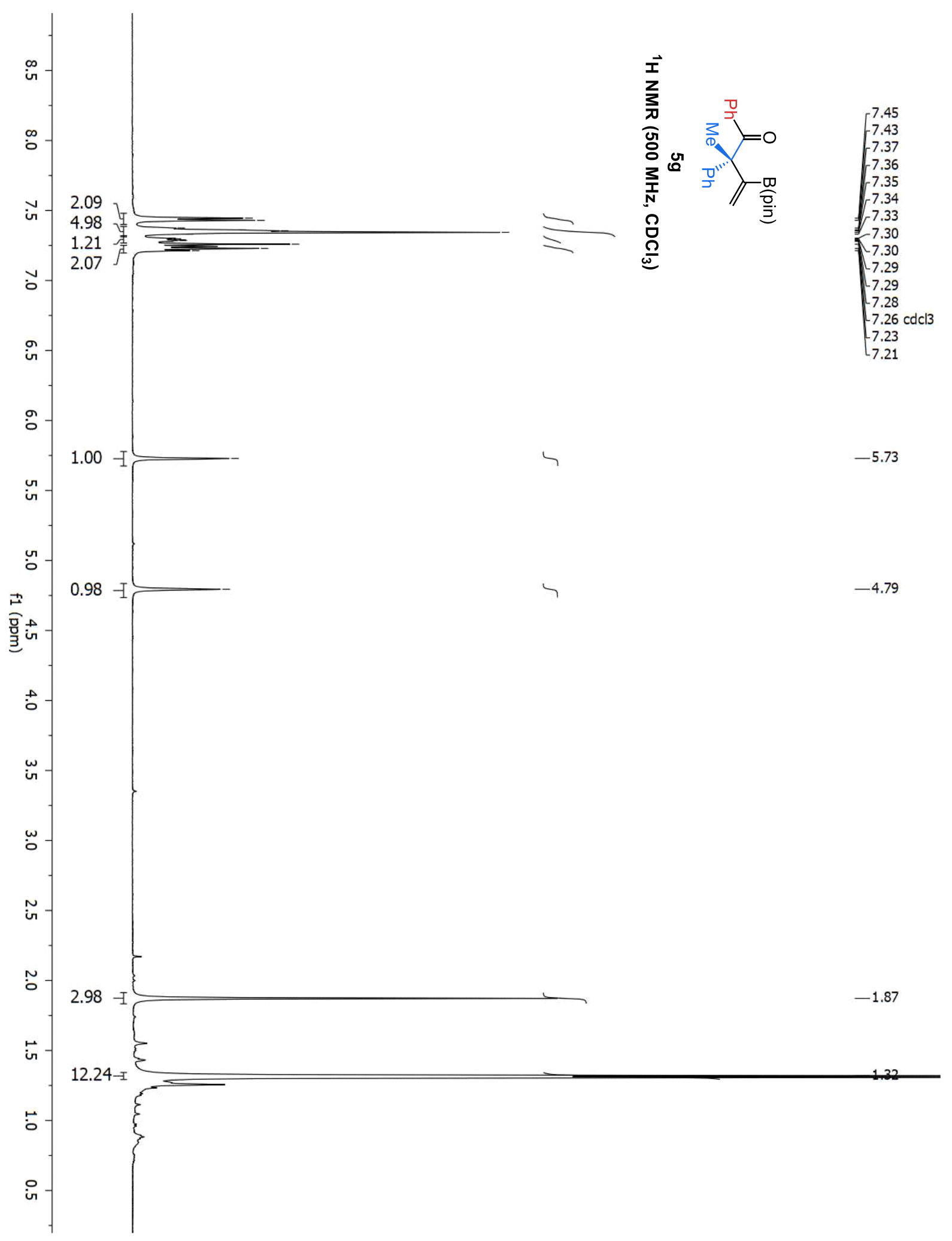




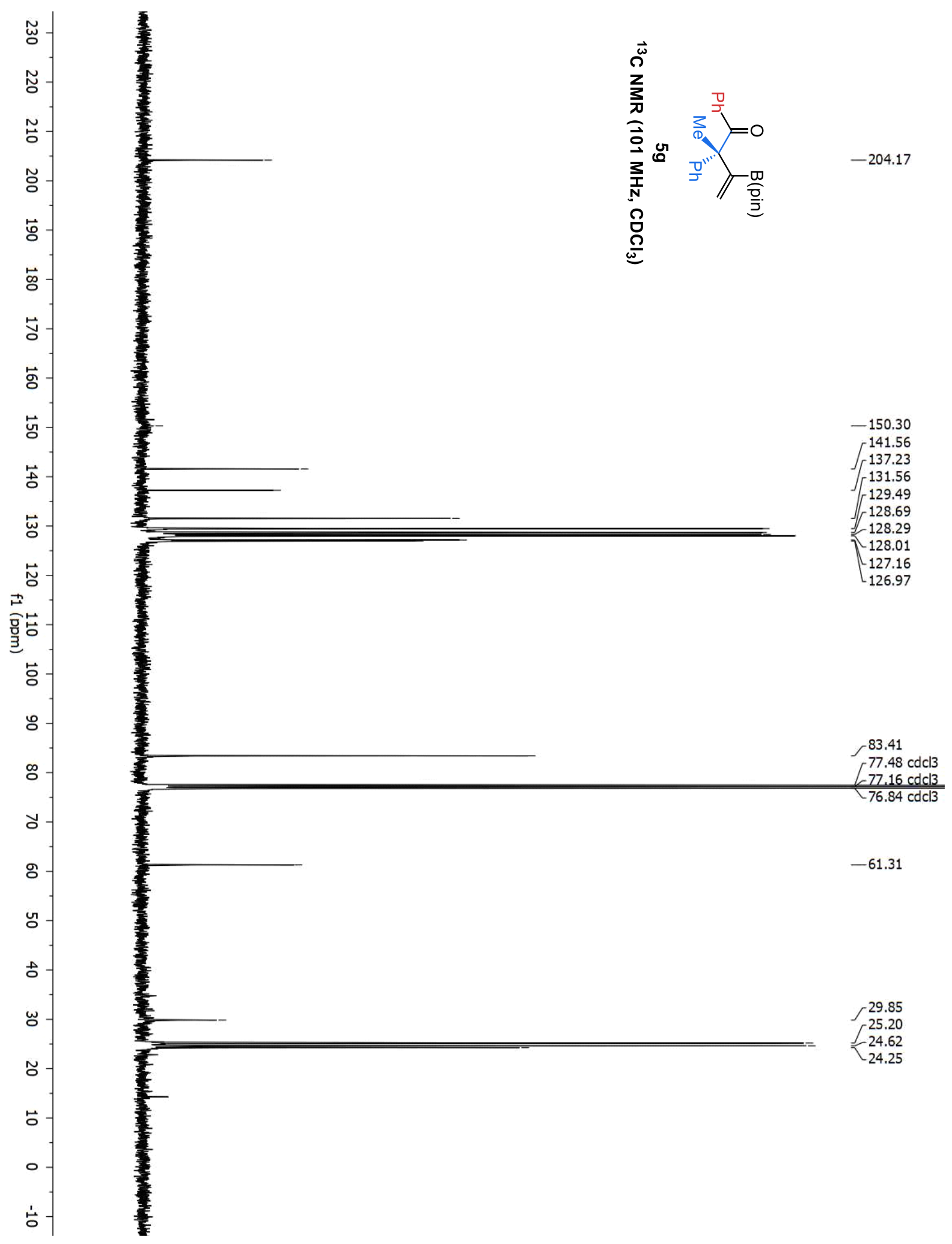




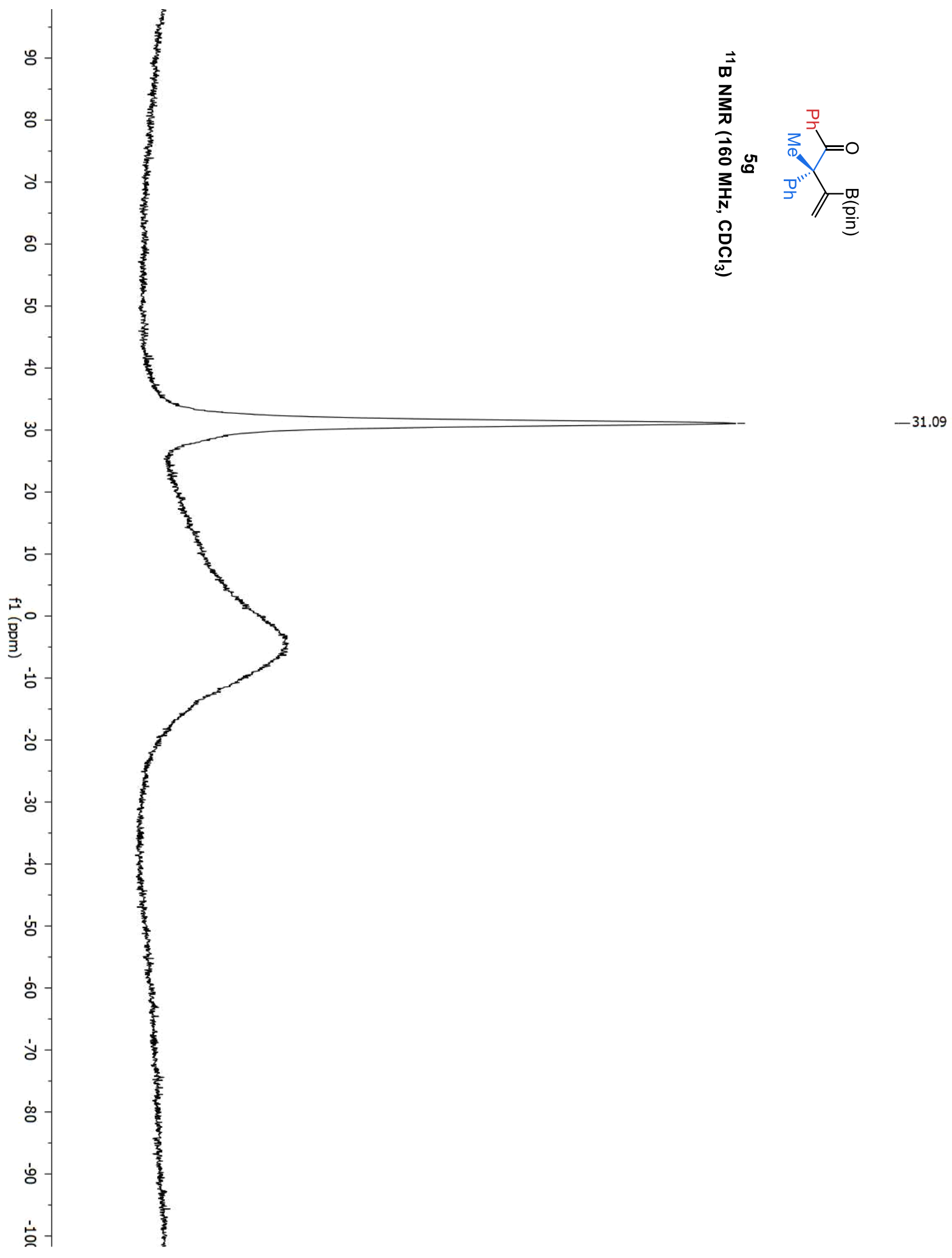




\subsection{With O-substituted allenes}

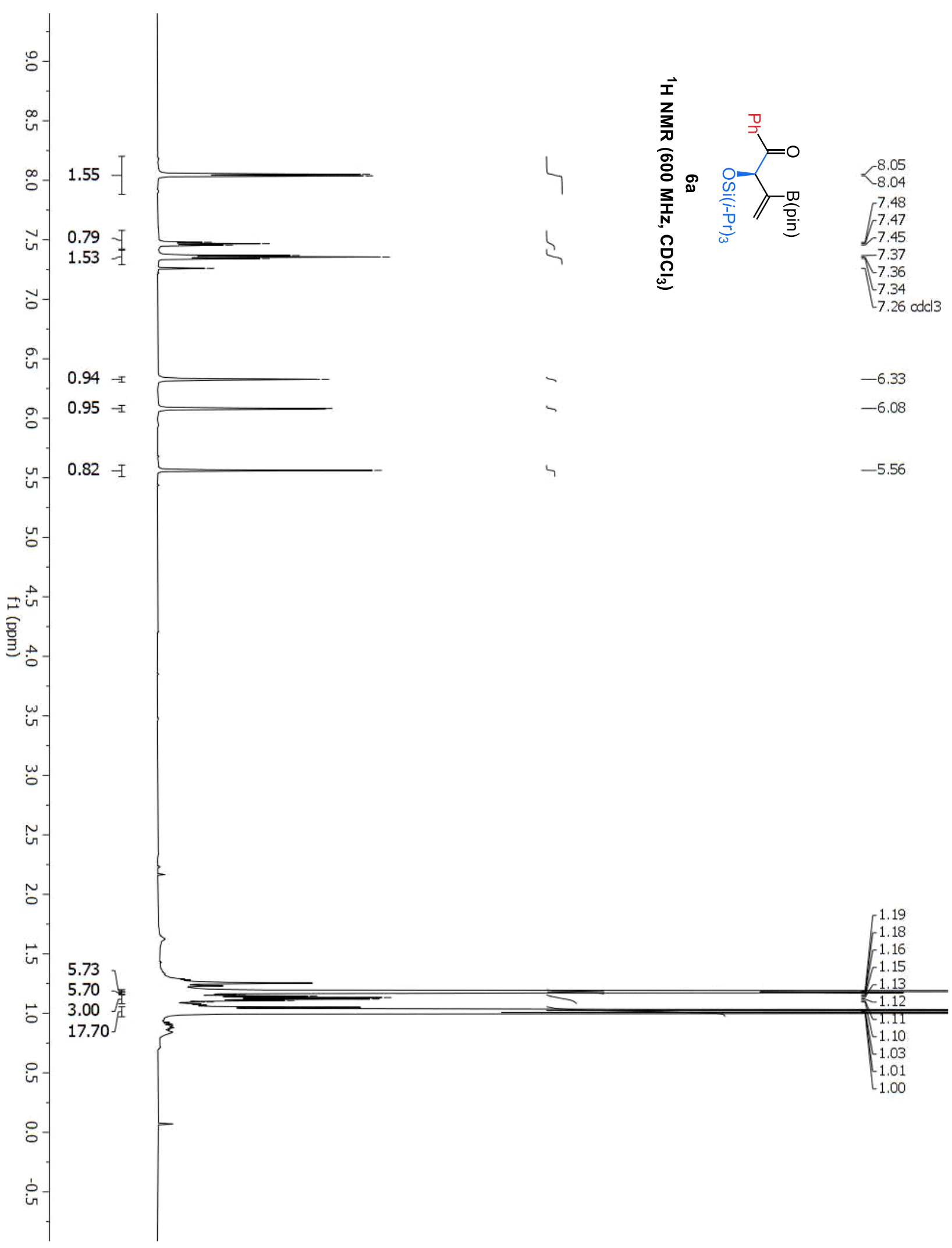


Del Pozo, et al., Supplementary Materials; Page 238

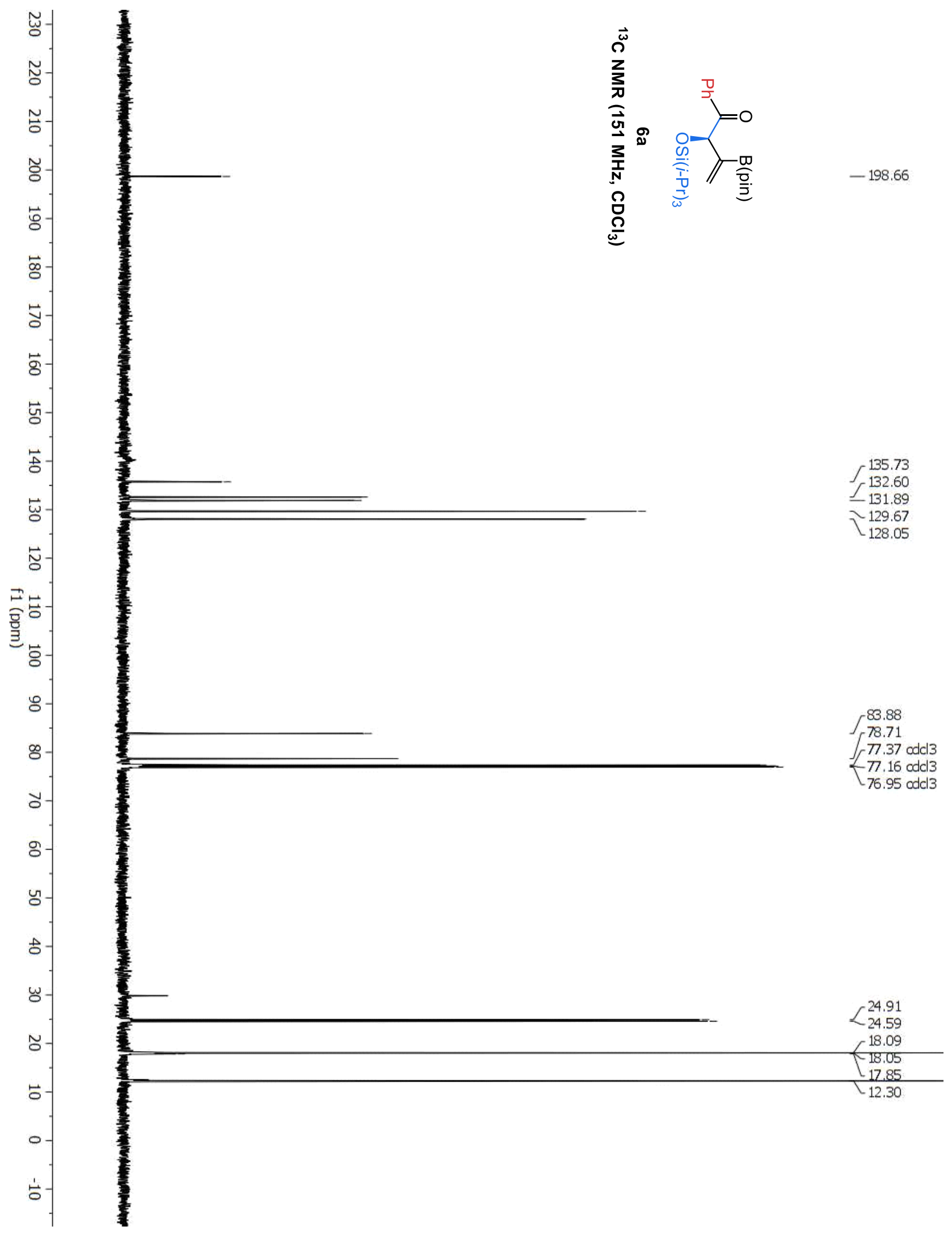




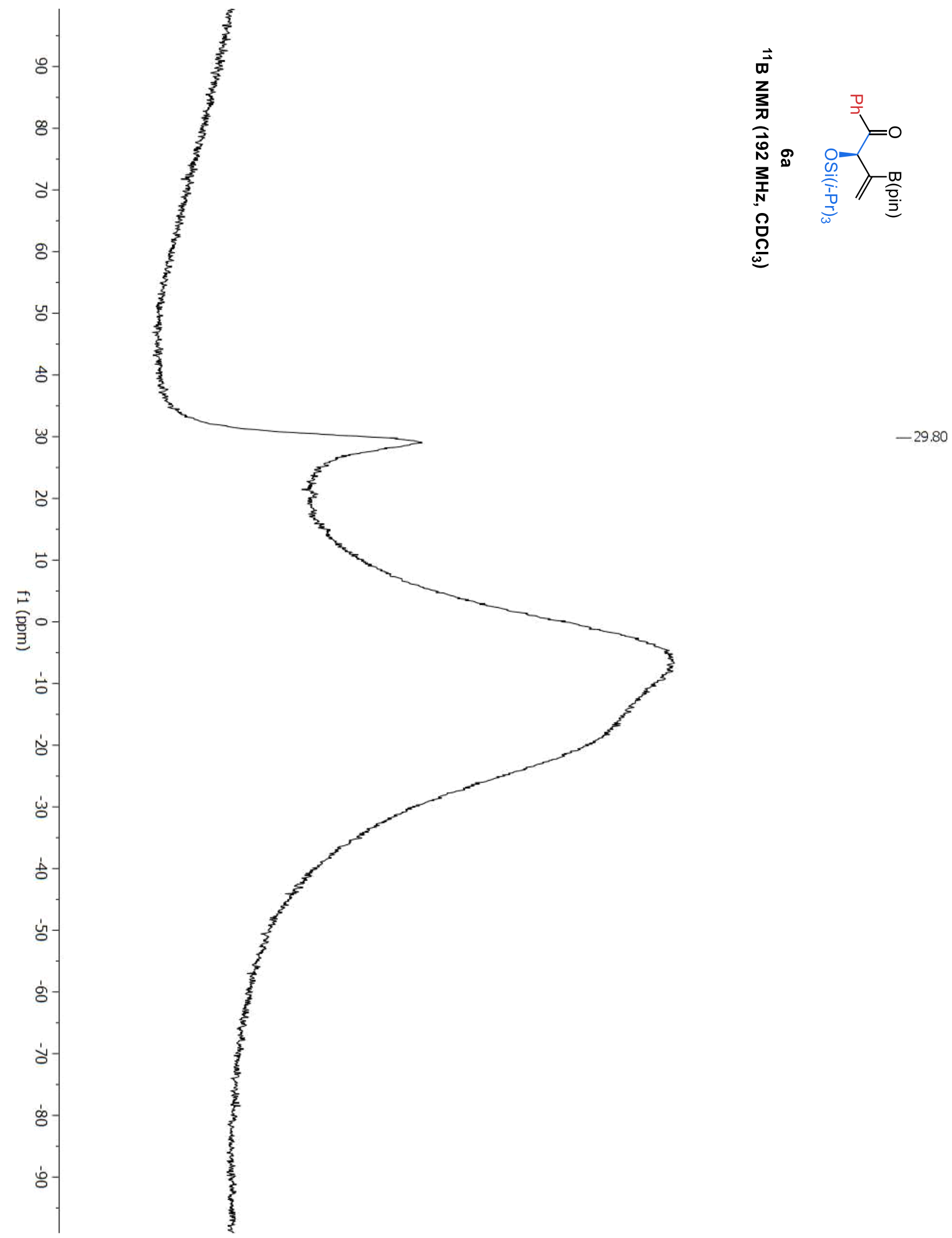




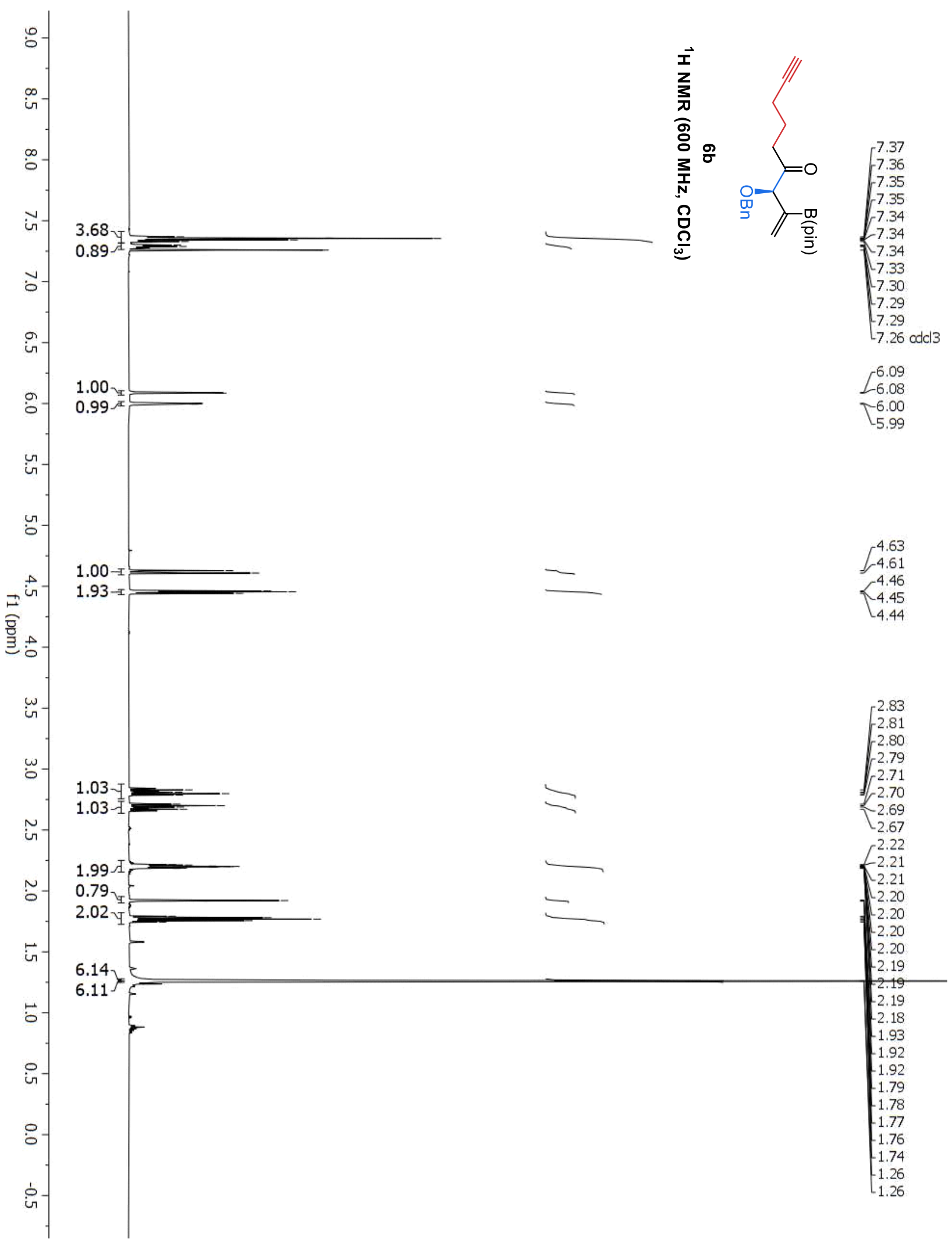




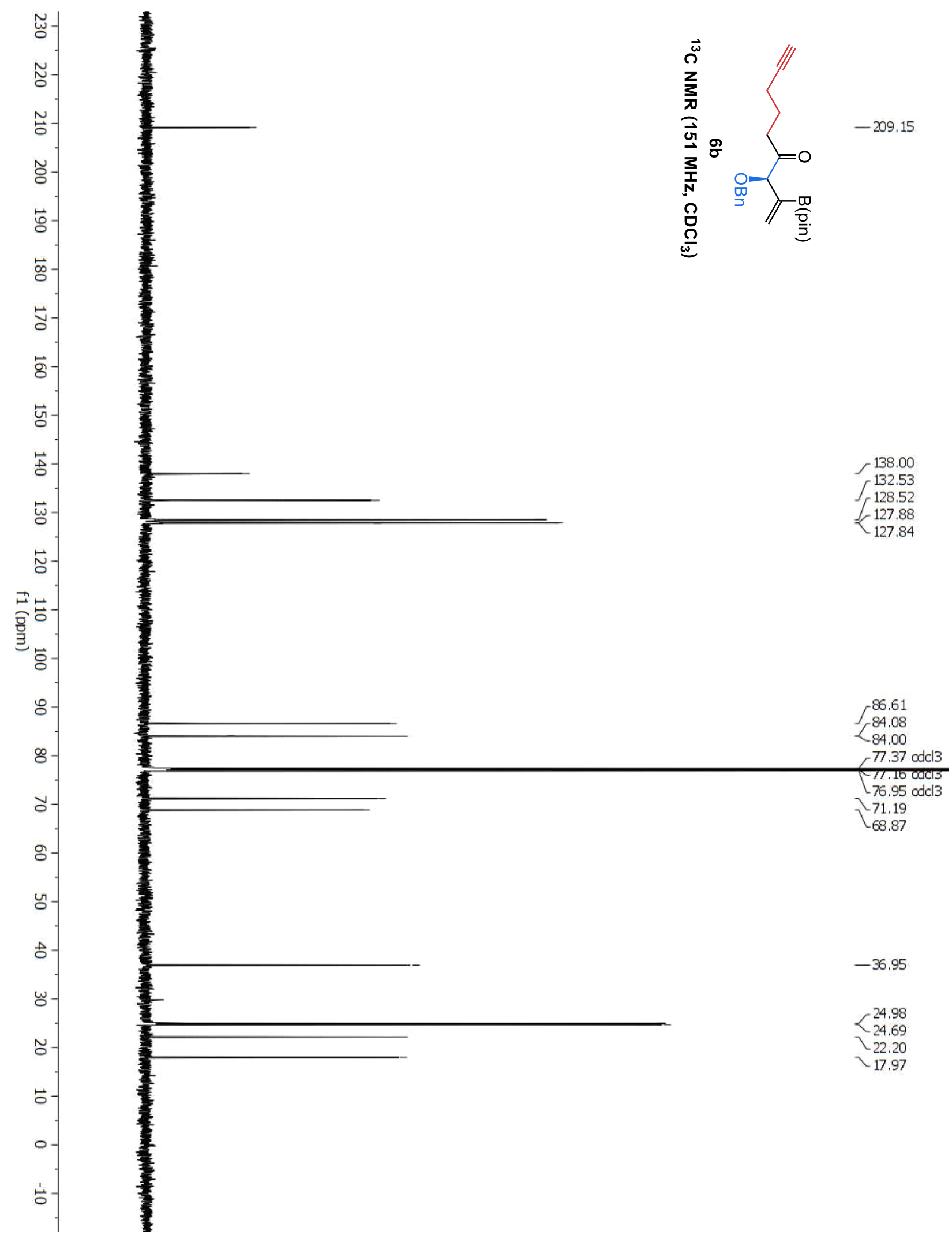


Del Pozo, et al., Supplementary Materials; Page 242

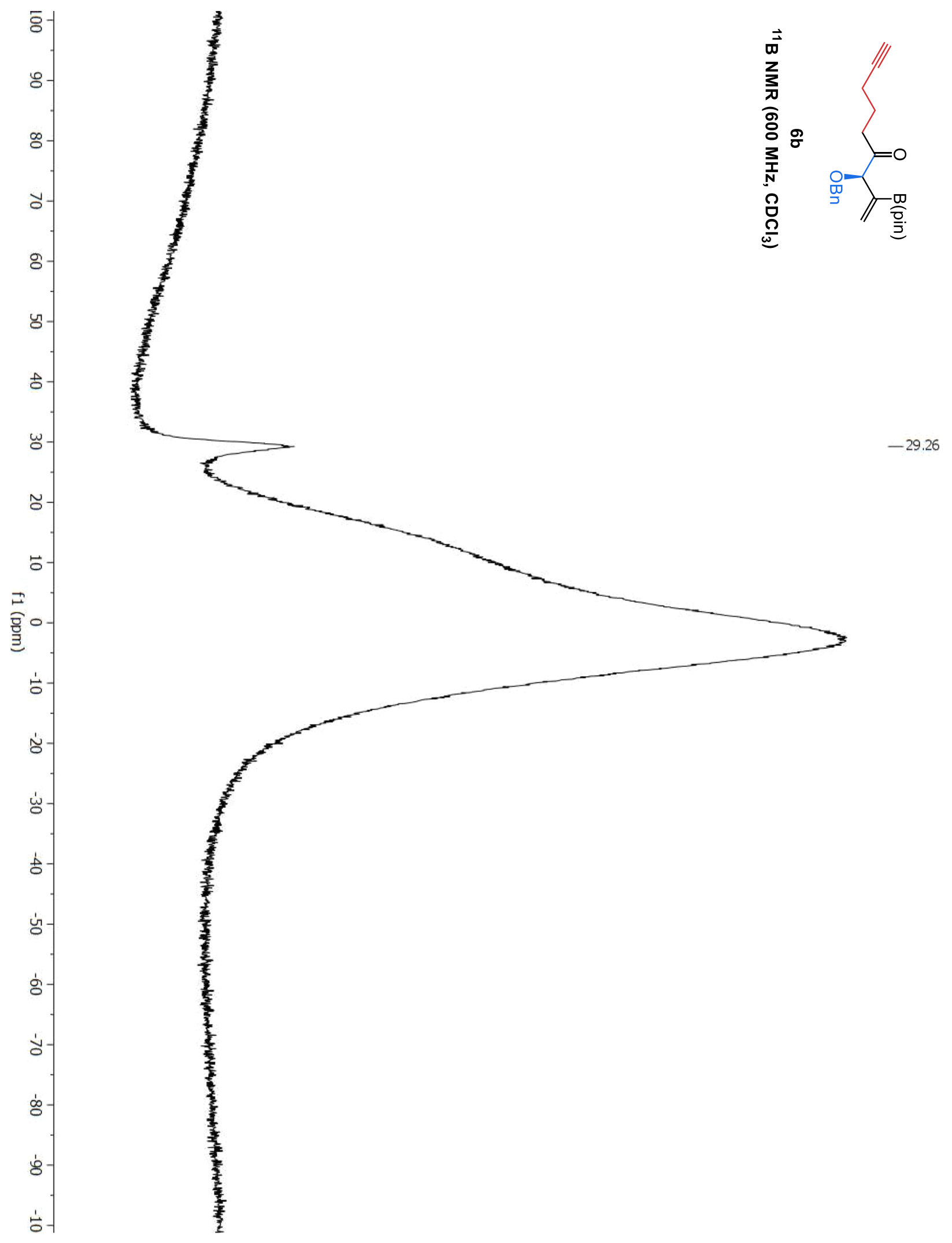




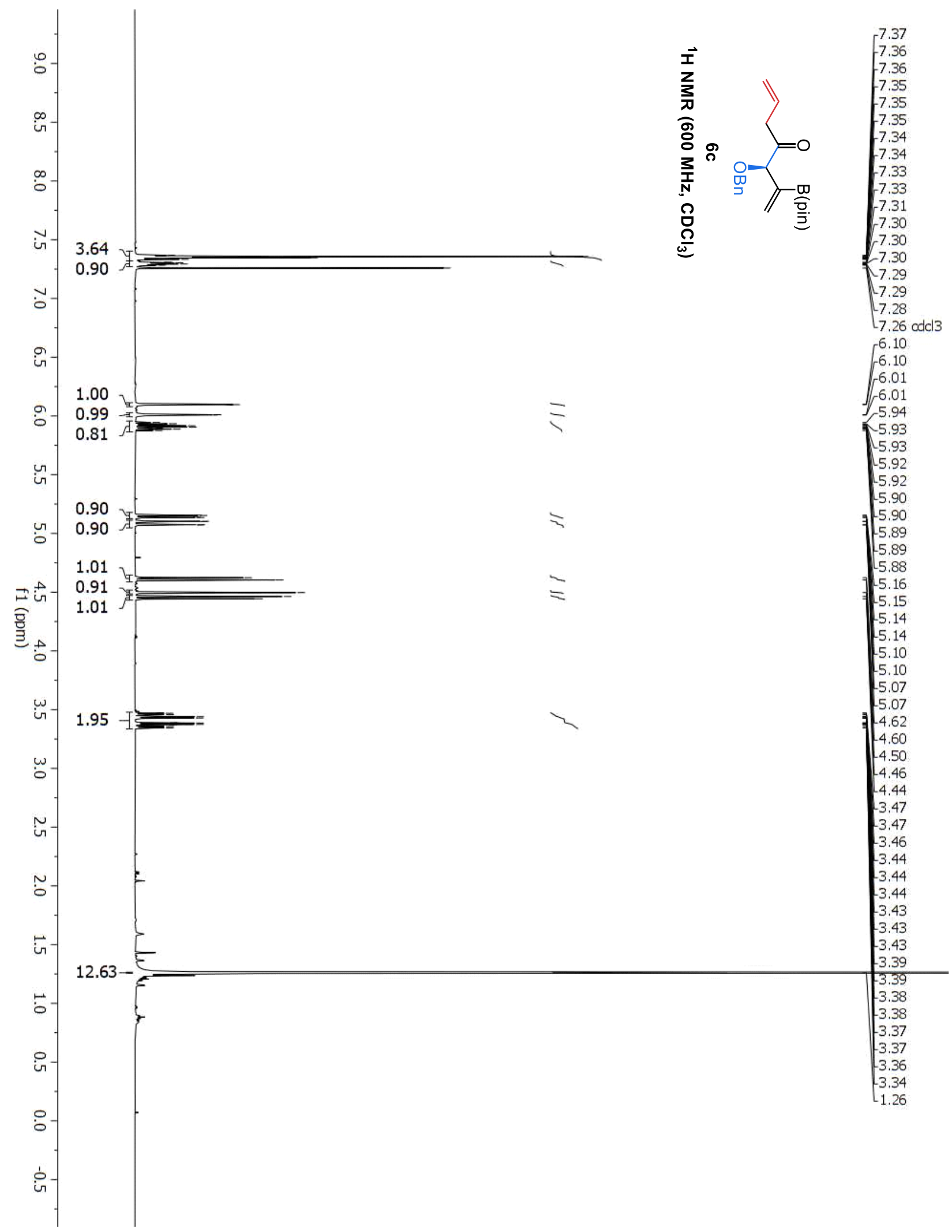




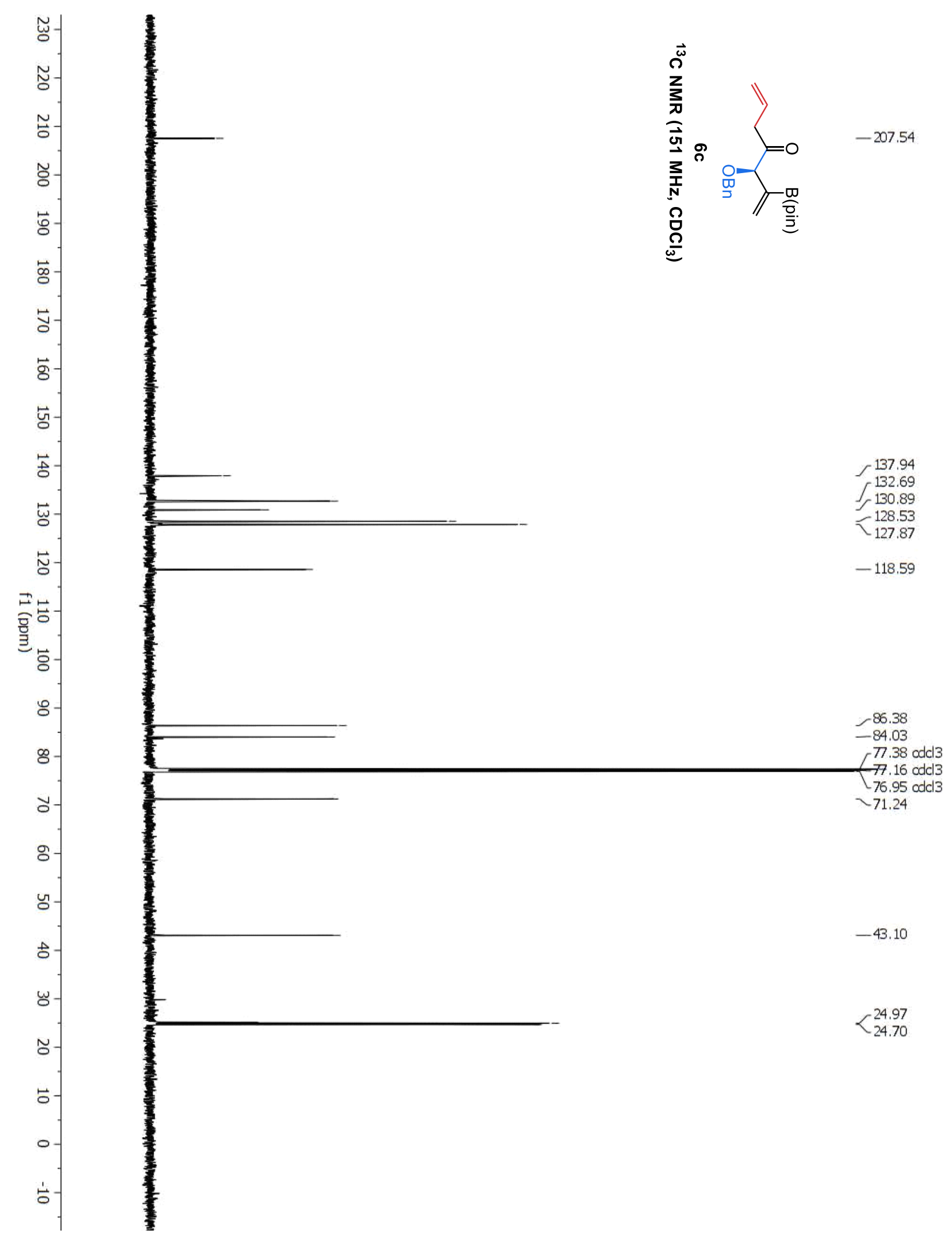


Del Pozo, et al., Supplementary Materials; Page 245

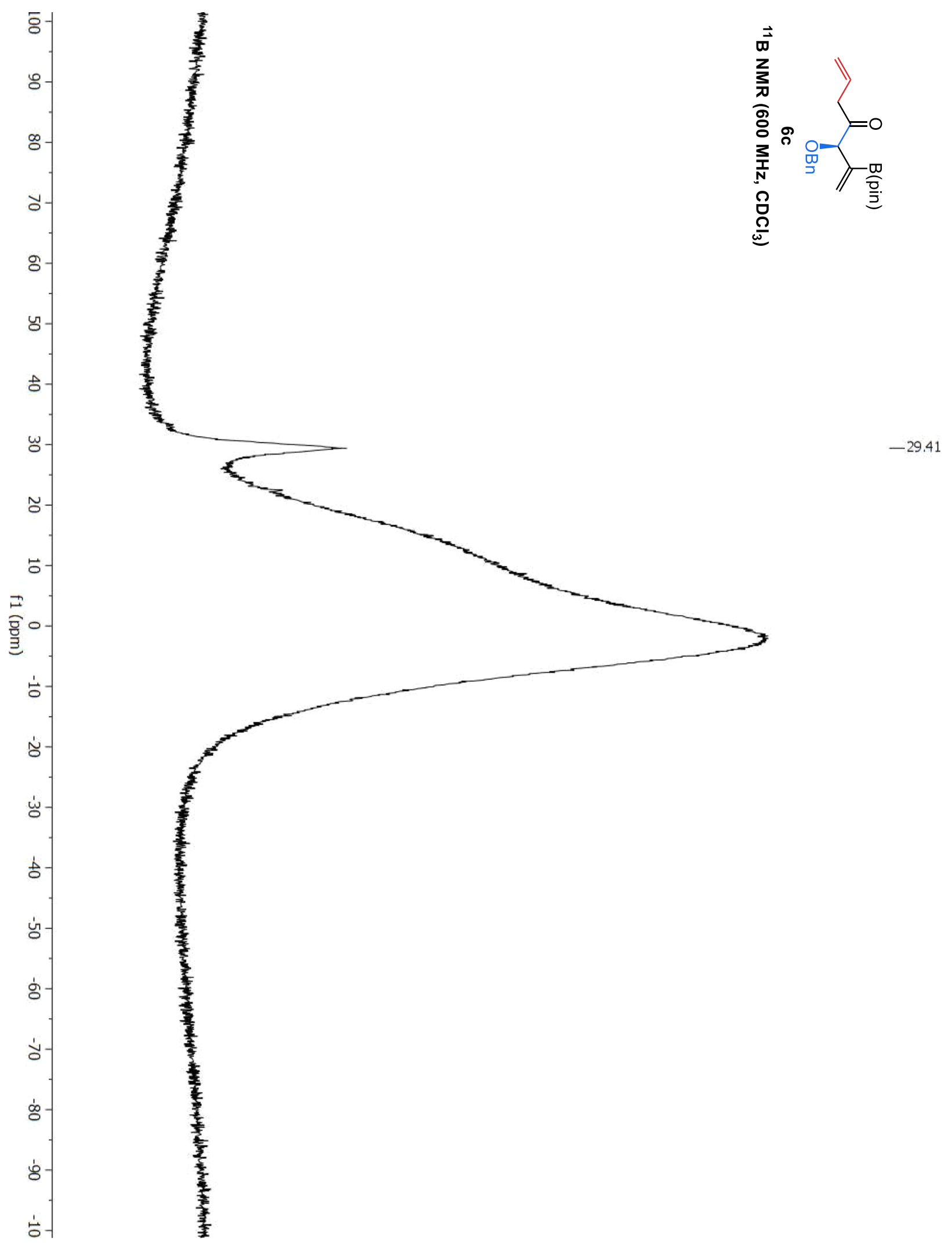




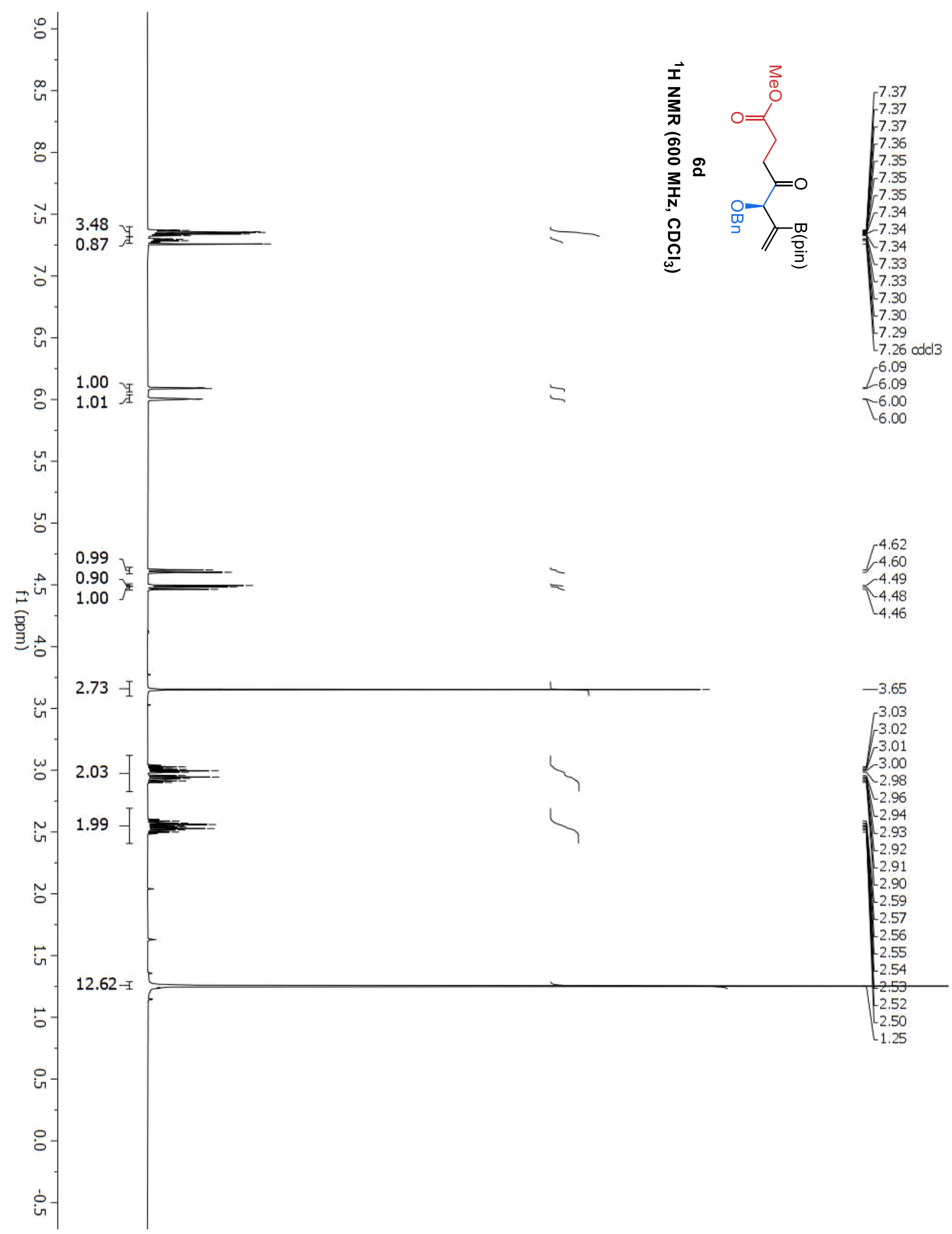




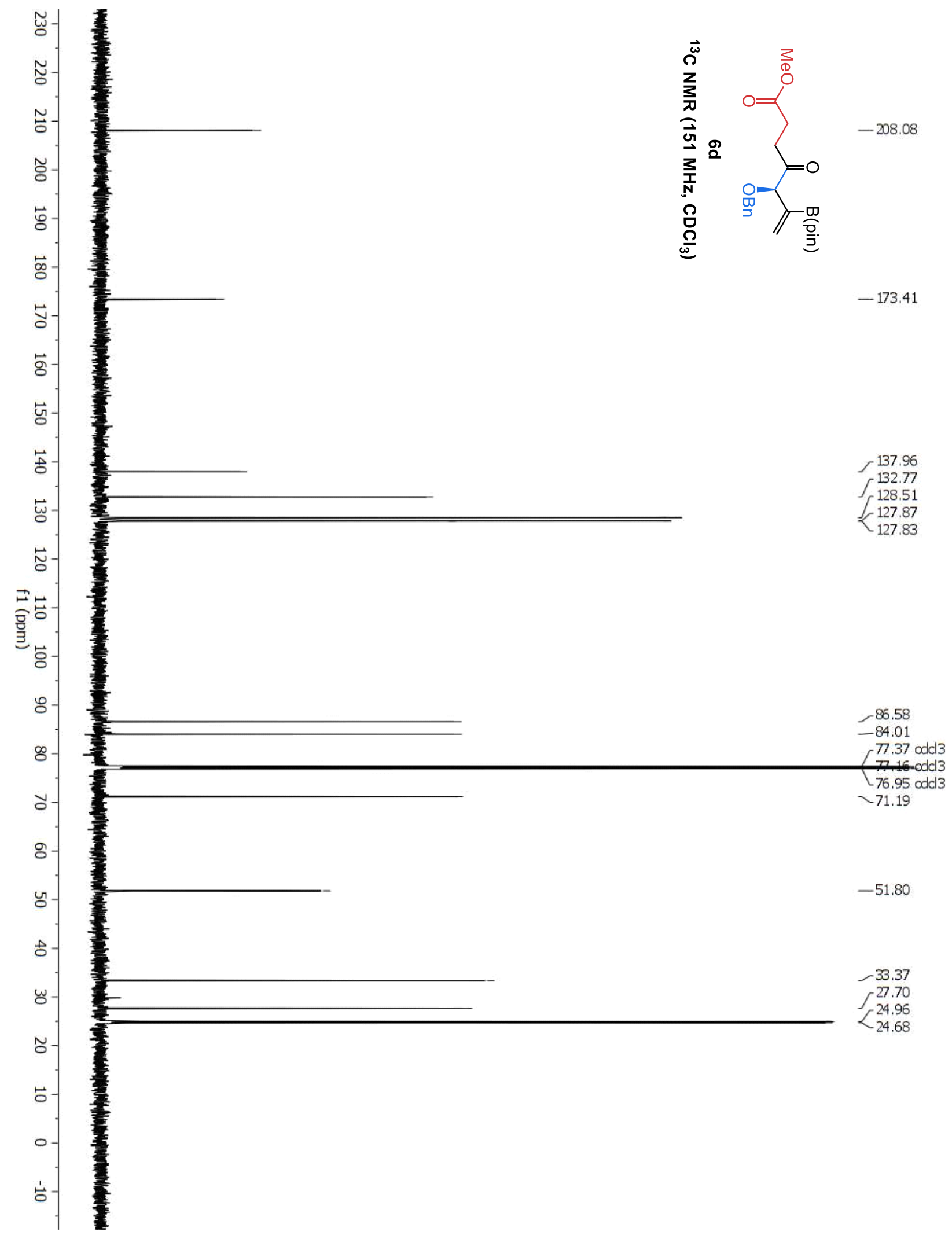


Del Pozo, et al., Supplementary Materials; Page 248

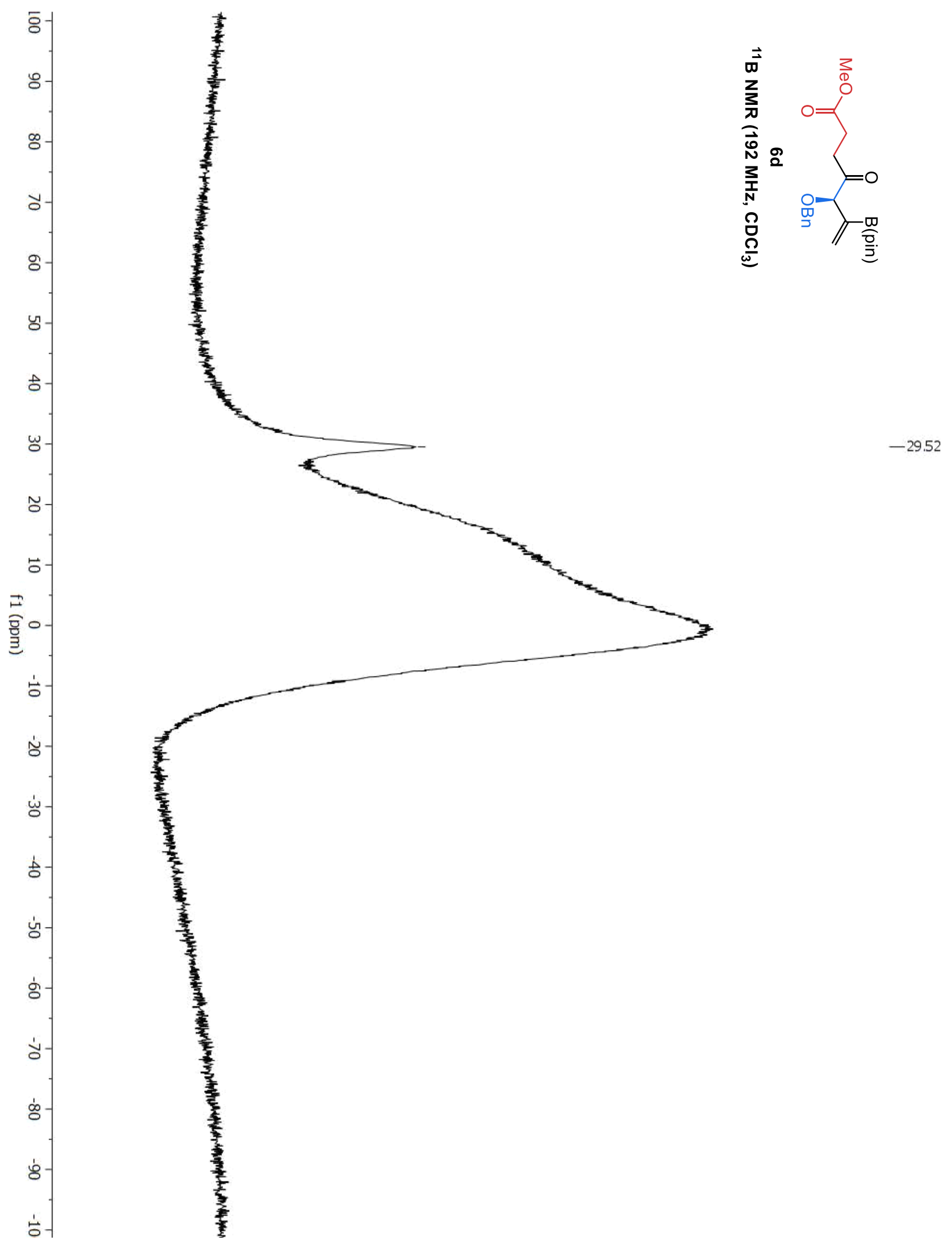




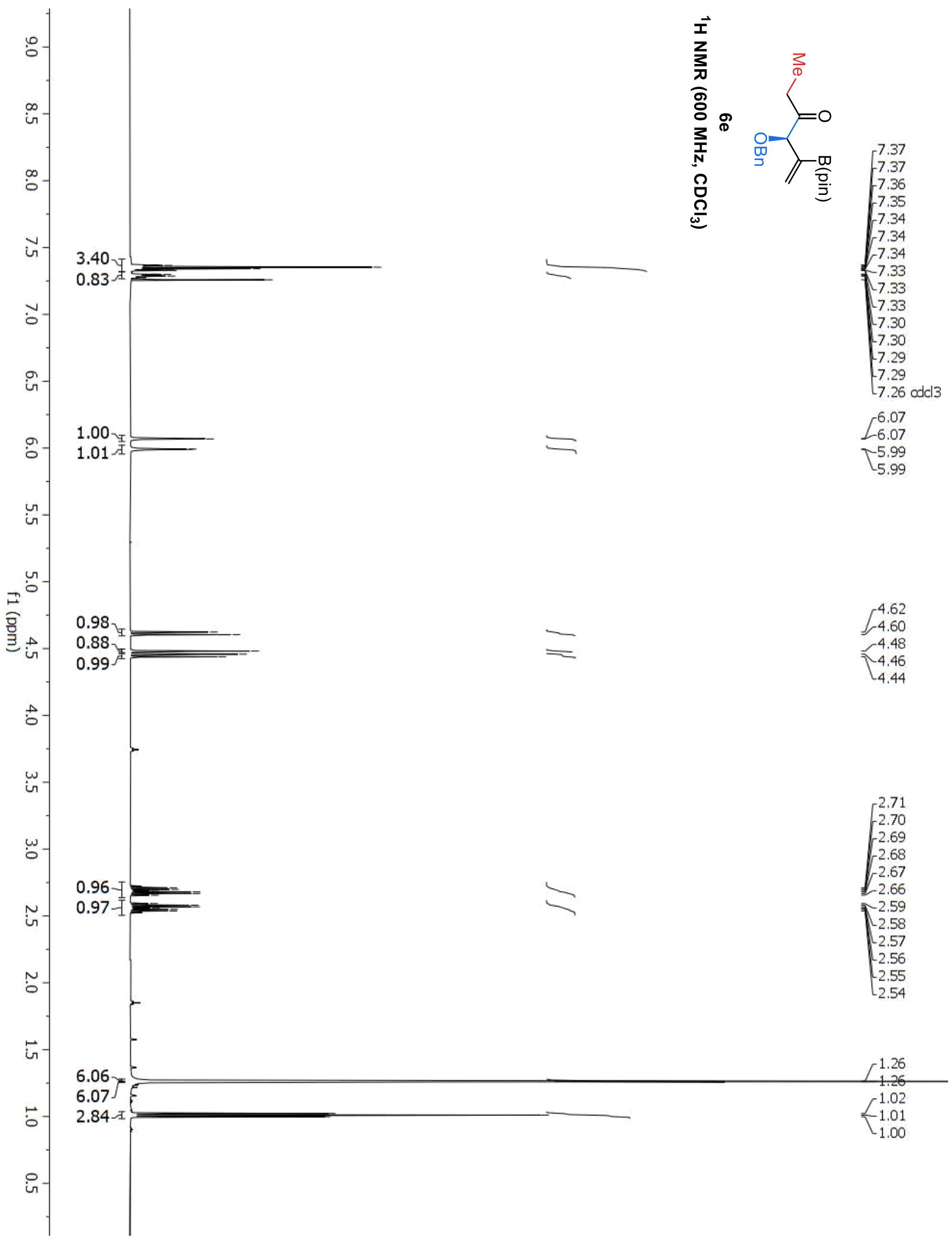




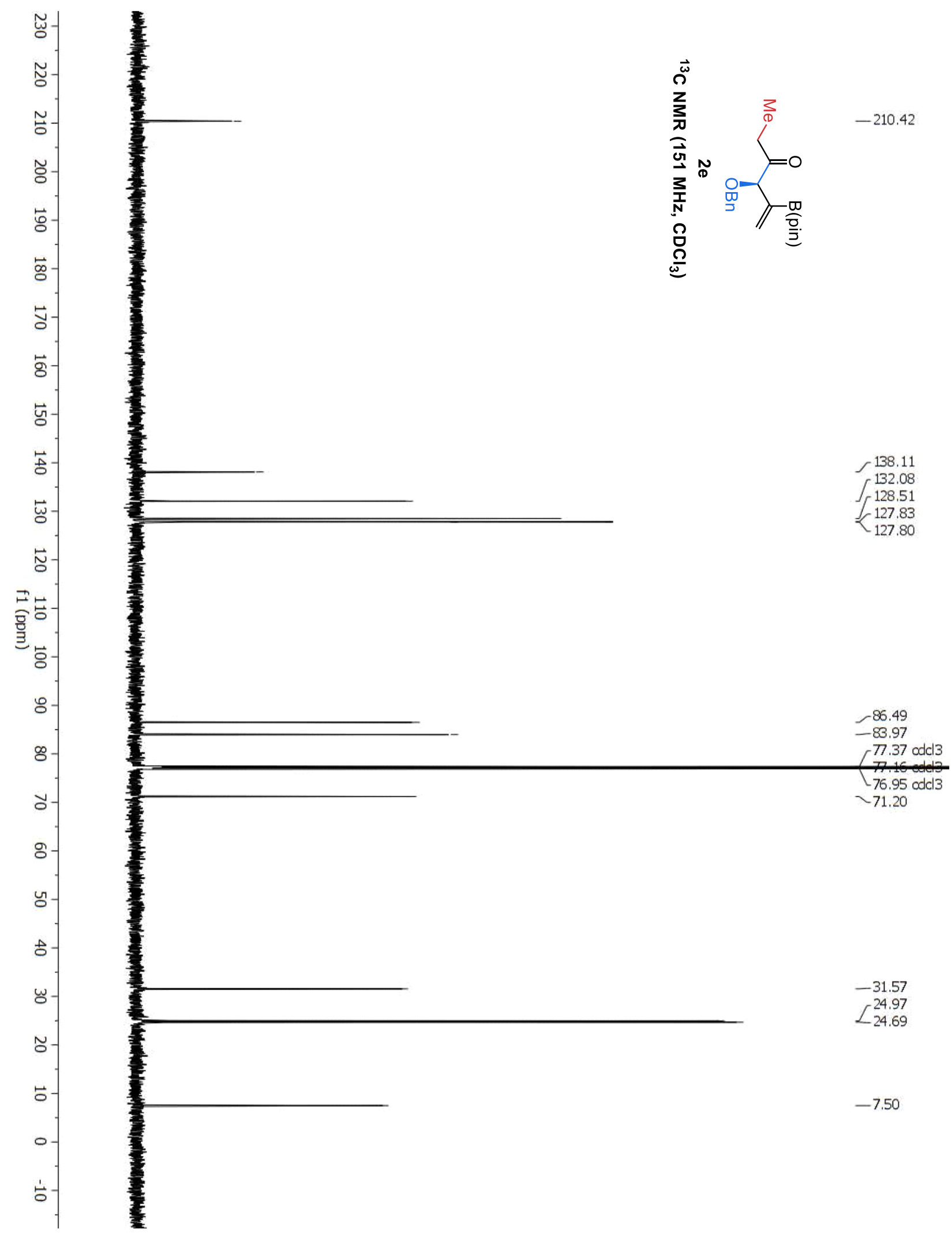


Del Pozo, et al., Supplementary Materials; Page 251

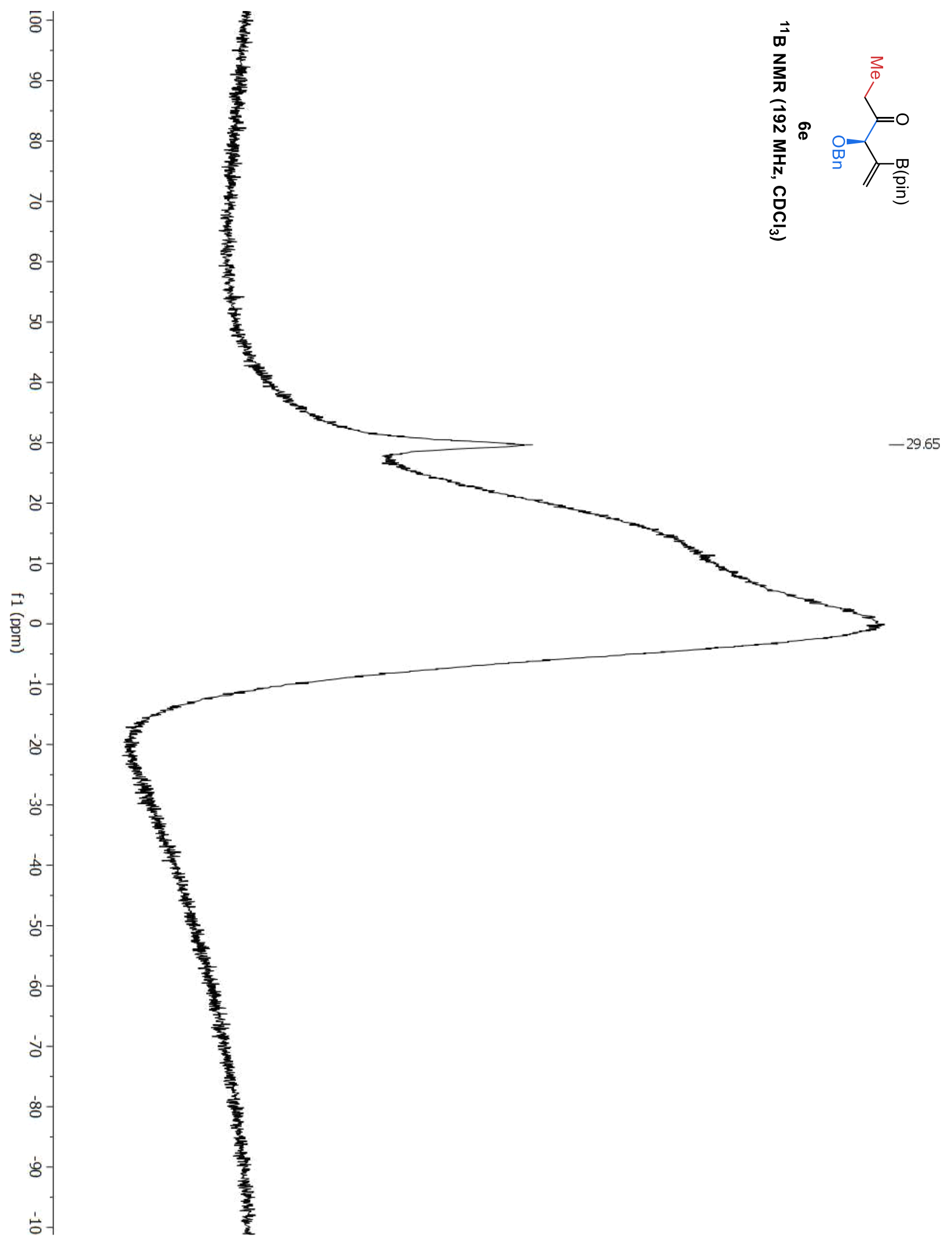




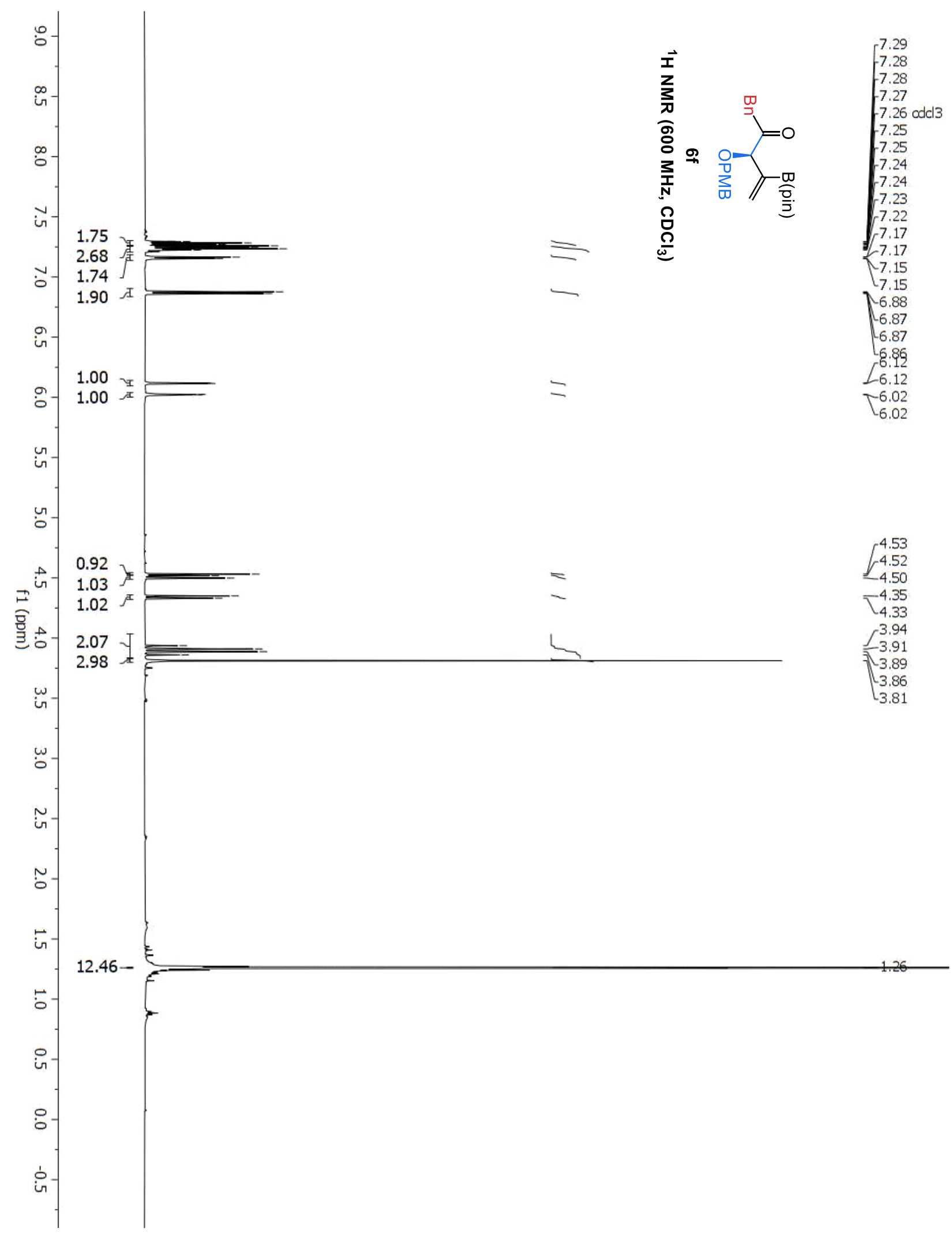




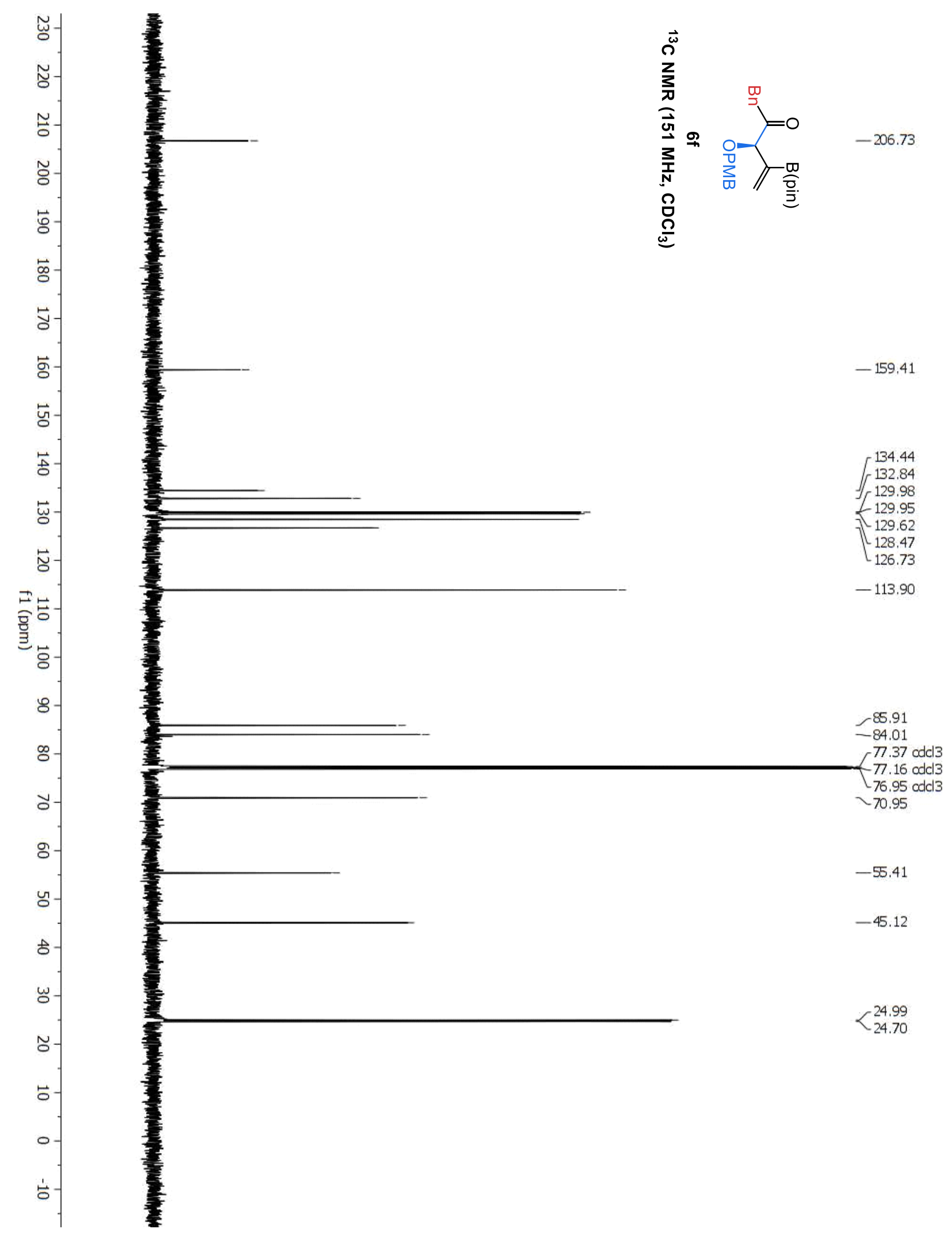




$$
l^{2}
$$




\subsection{Tertiary alcohols through diastereoselective addition}

The tertiary alcohol products were often obtained as mixtures of diastereomers. Expansions of well resolved signals correasponding to either diastereomer have been included in the spectra and diastereomeric purity was determined by ${ }^{1} \mathrm{H}$ NMR in $\mathrm{CDCl}_{3}$ with $\sim 50 \mu \mathrm{L} \mathrm{D}_{2} \mathrm{O}$.

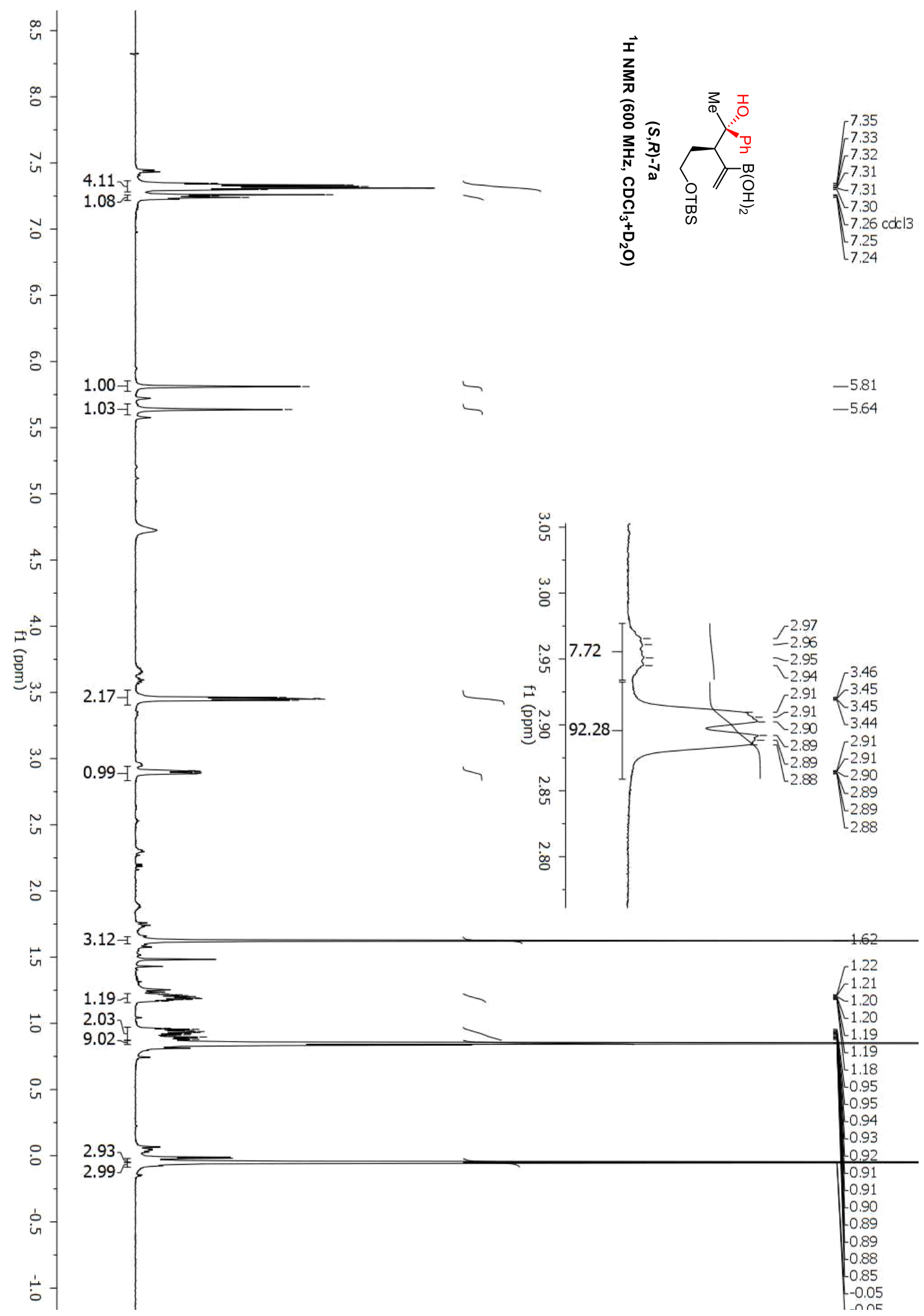




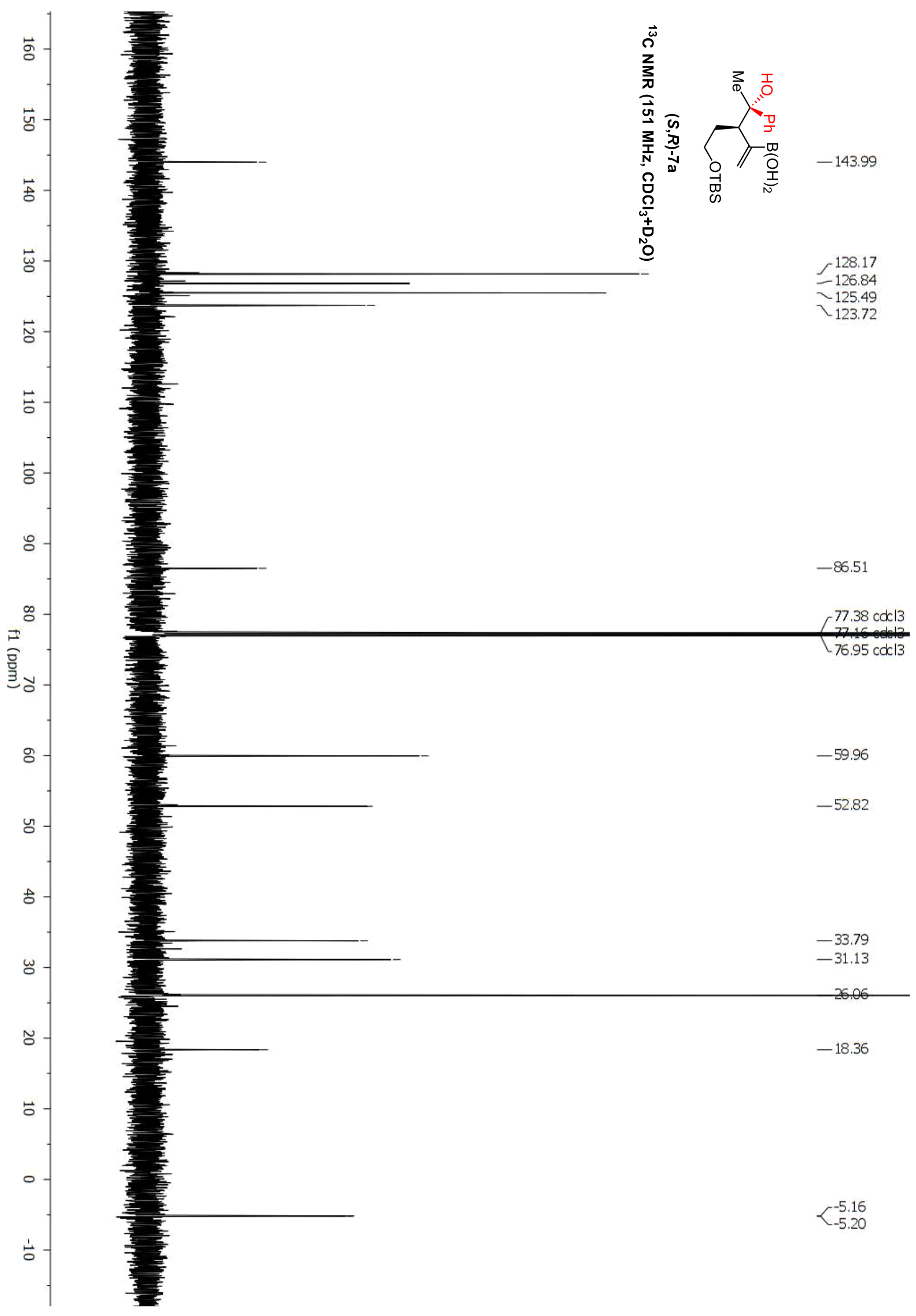


Del Pozo, et al., Supplementary Materials; Page 257

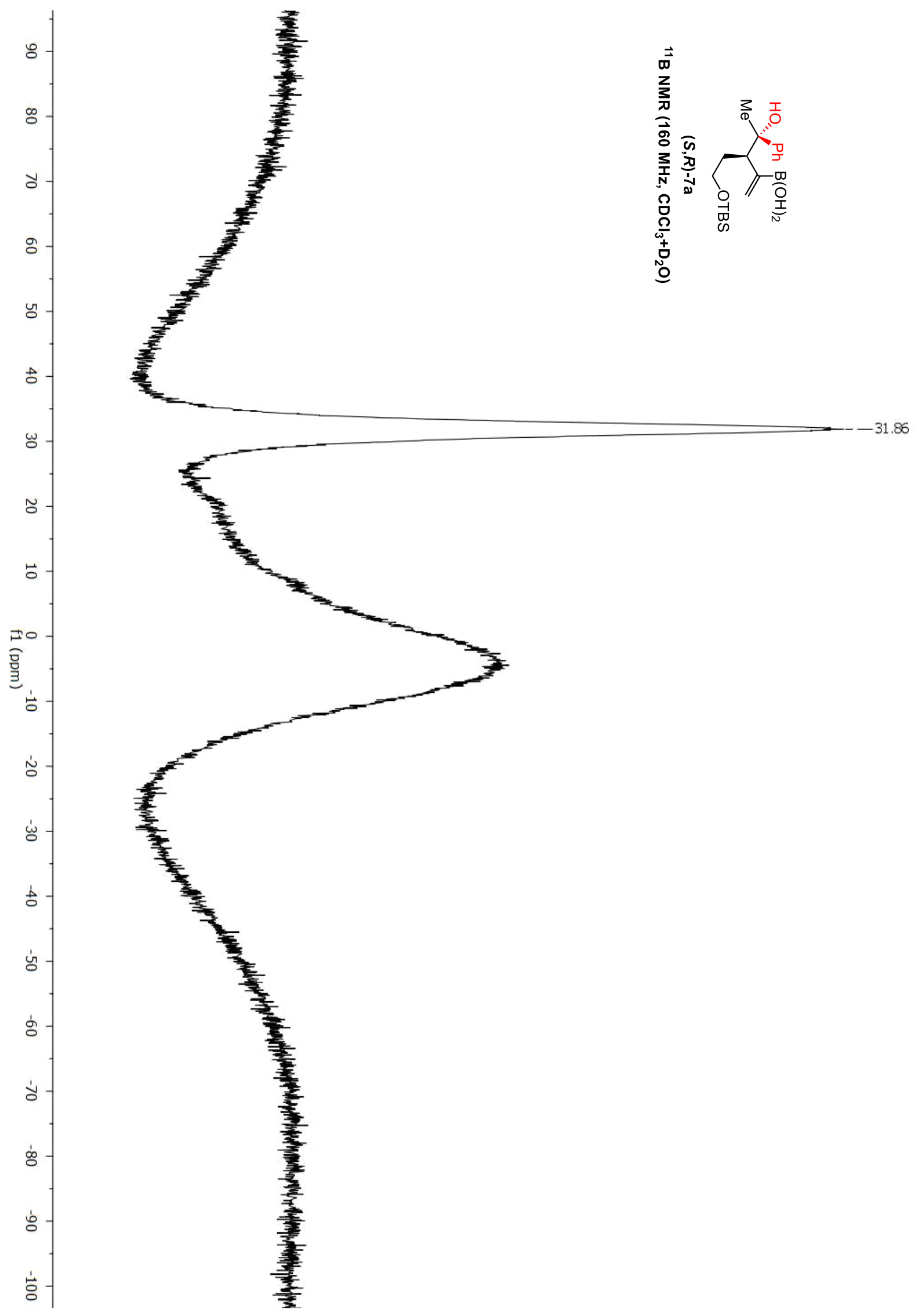




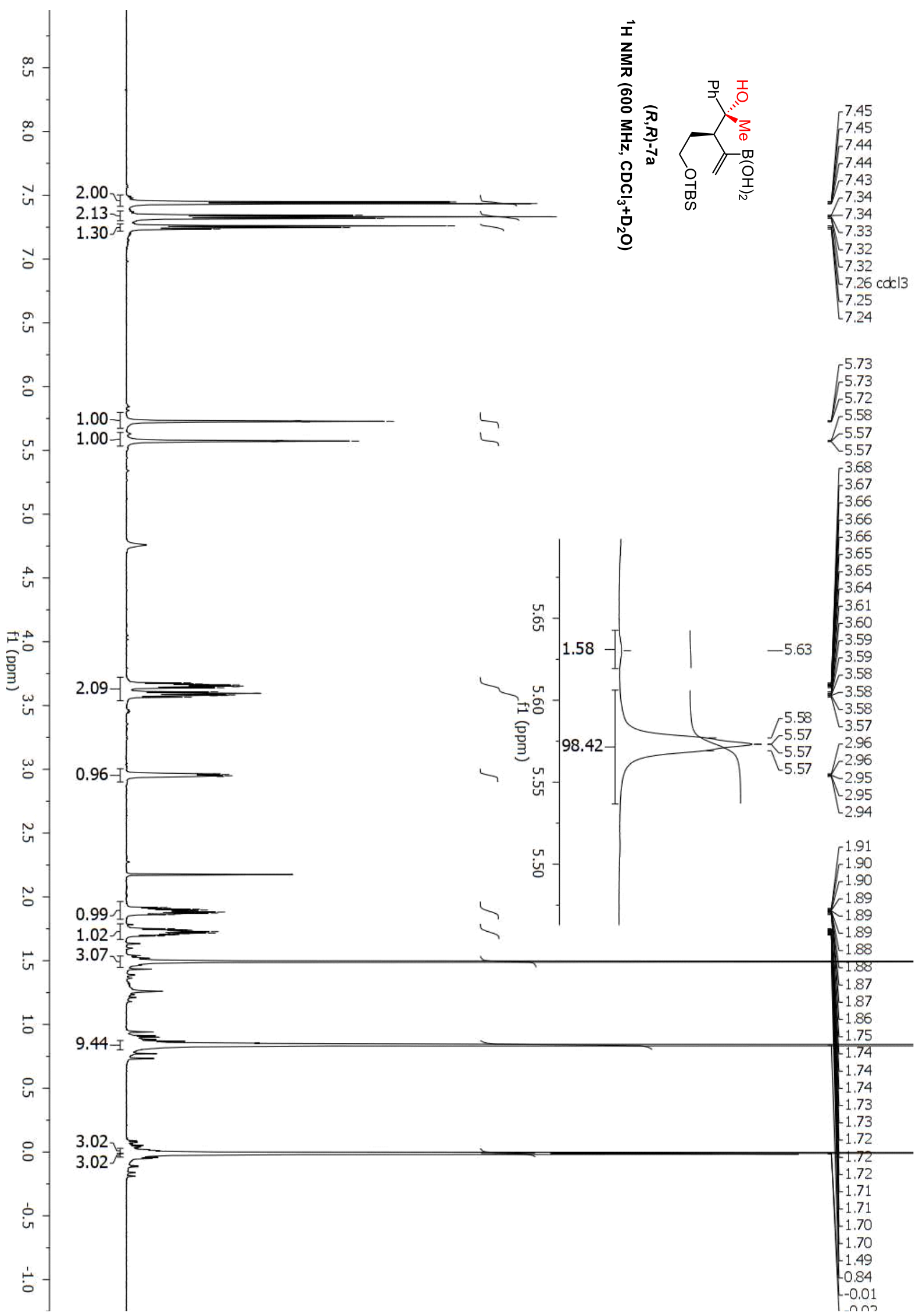




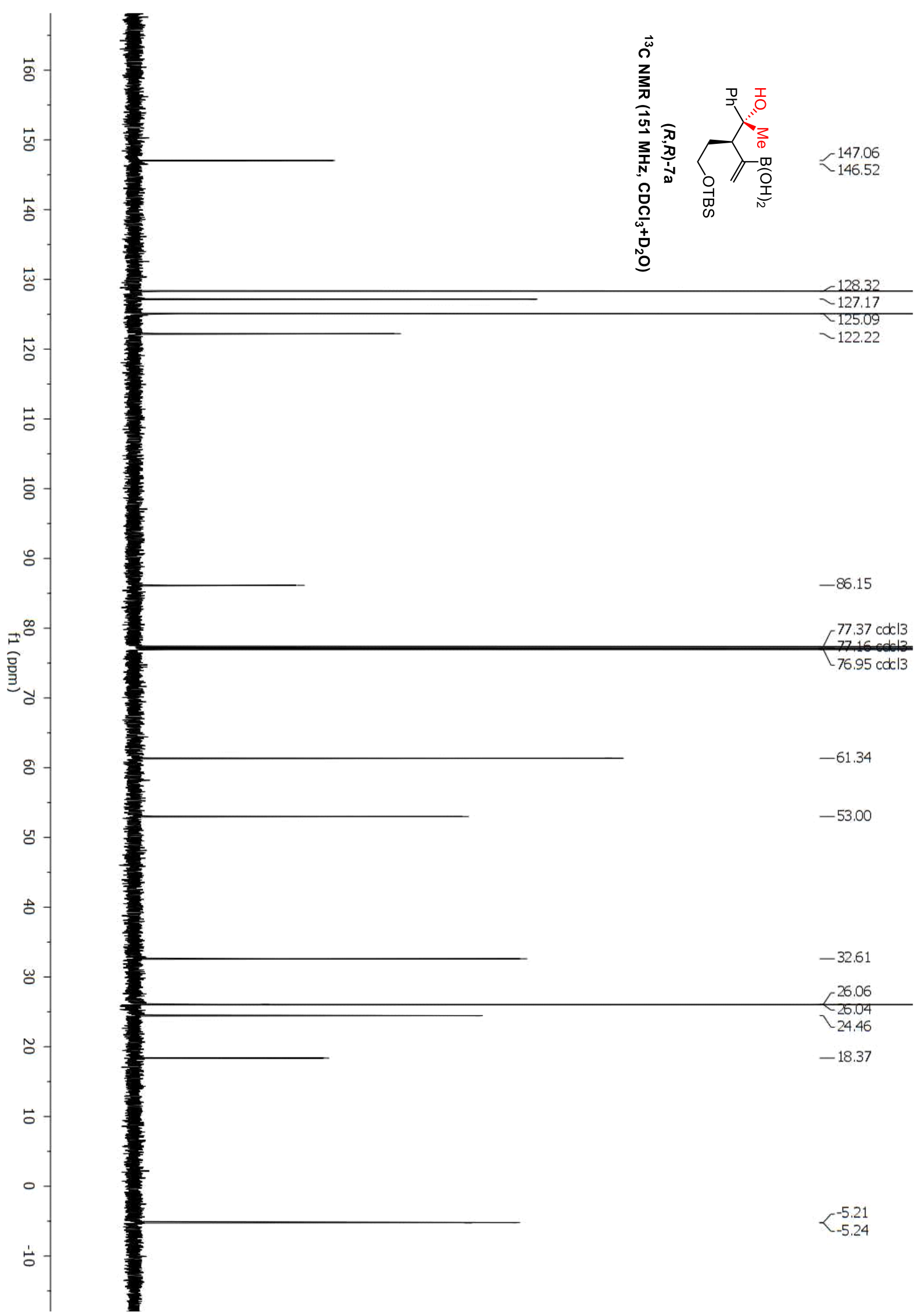


Del Pozo, et al., Supplementary Materials; Page 260

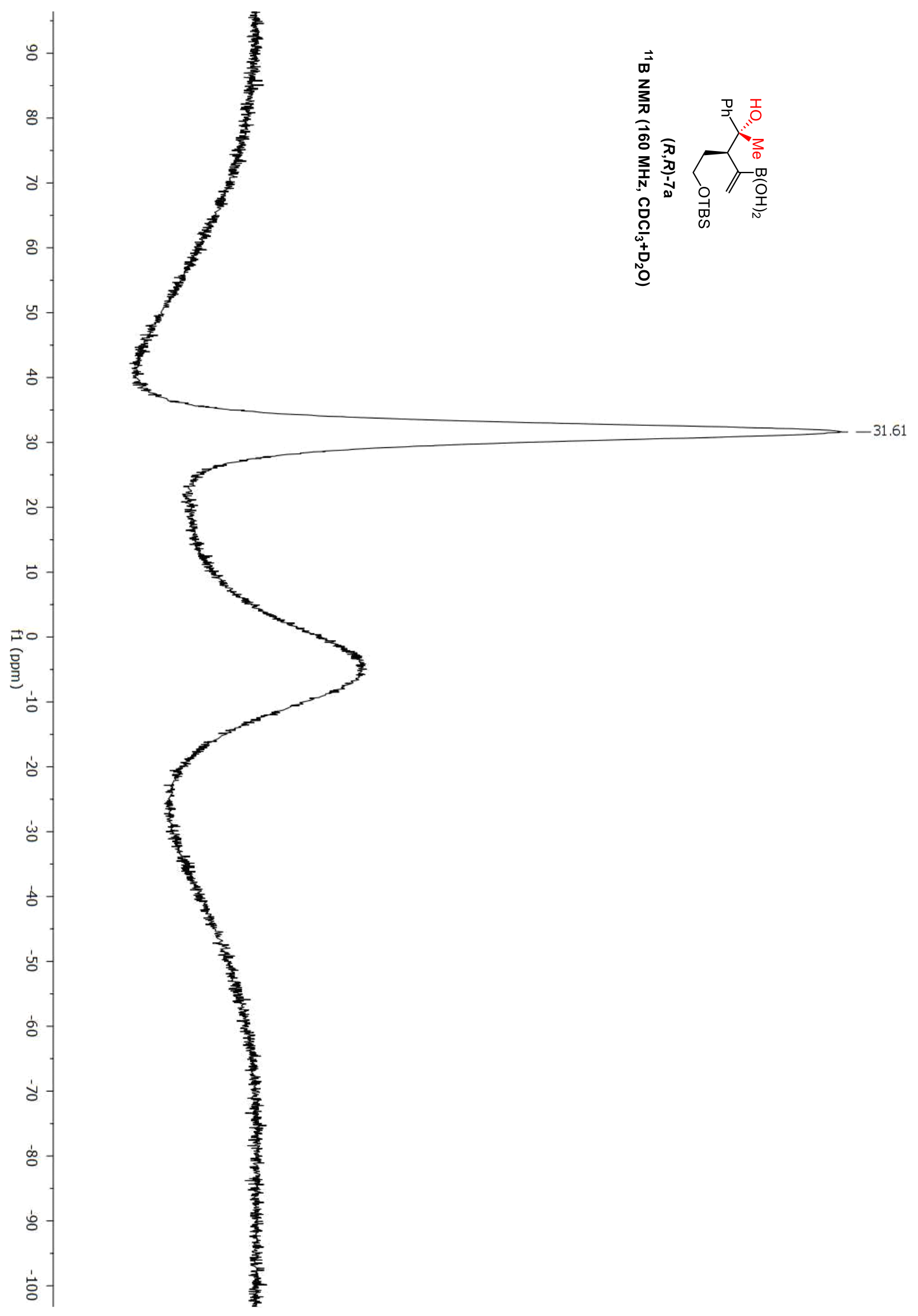




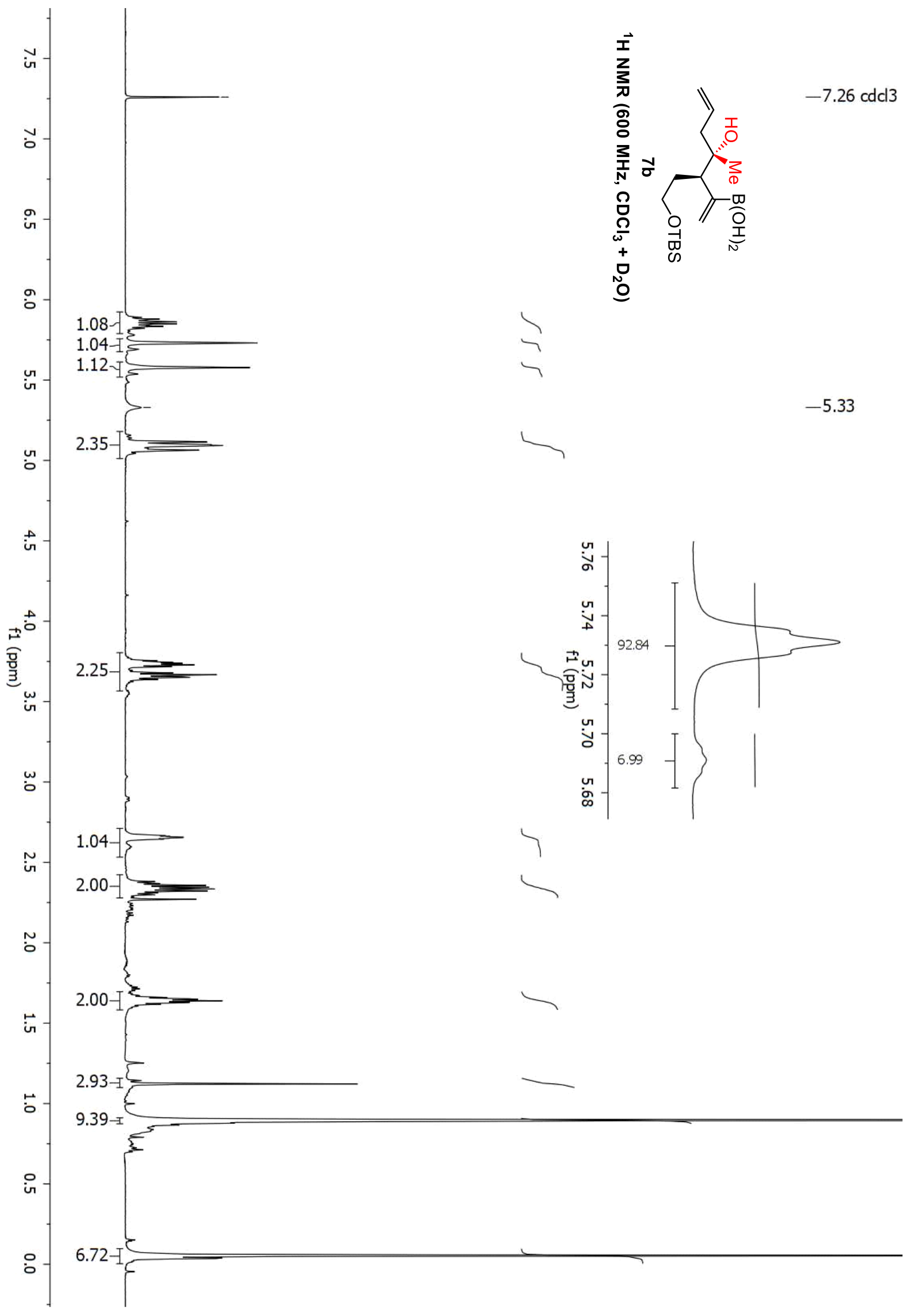




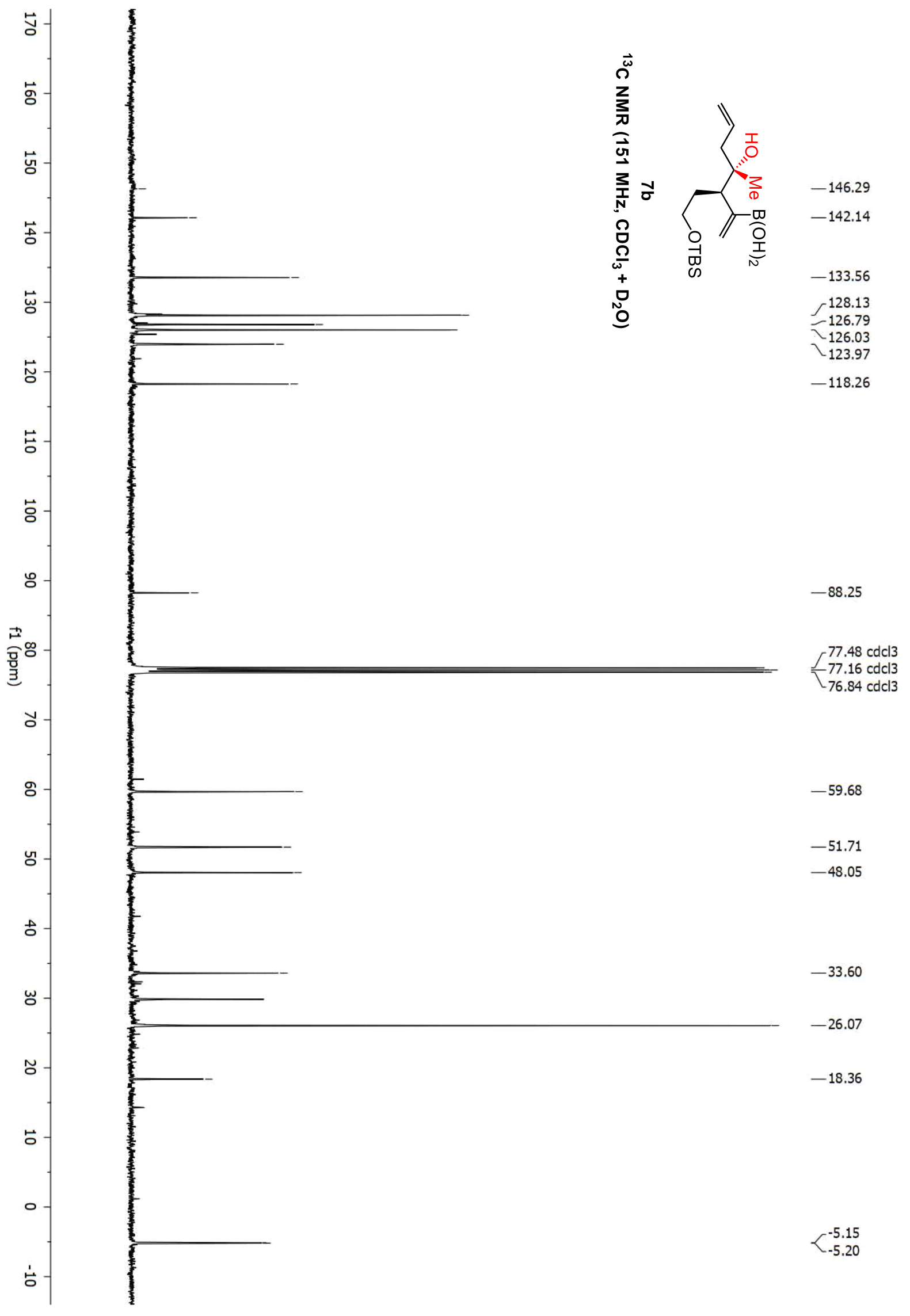


Del Pozo, et al., Supplementary Materials; Page 263

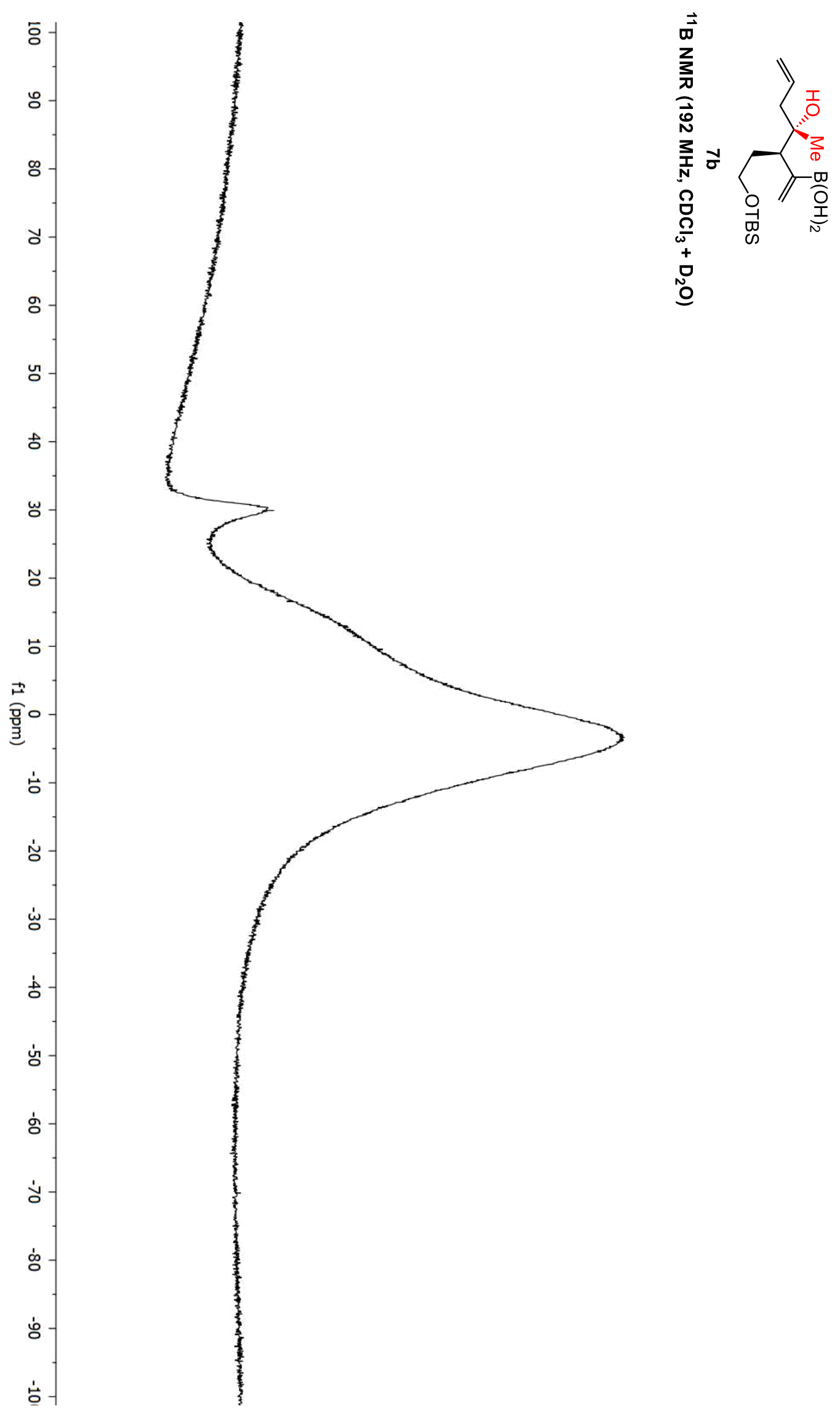

$-29.91$ 


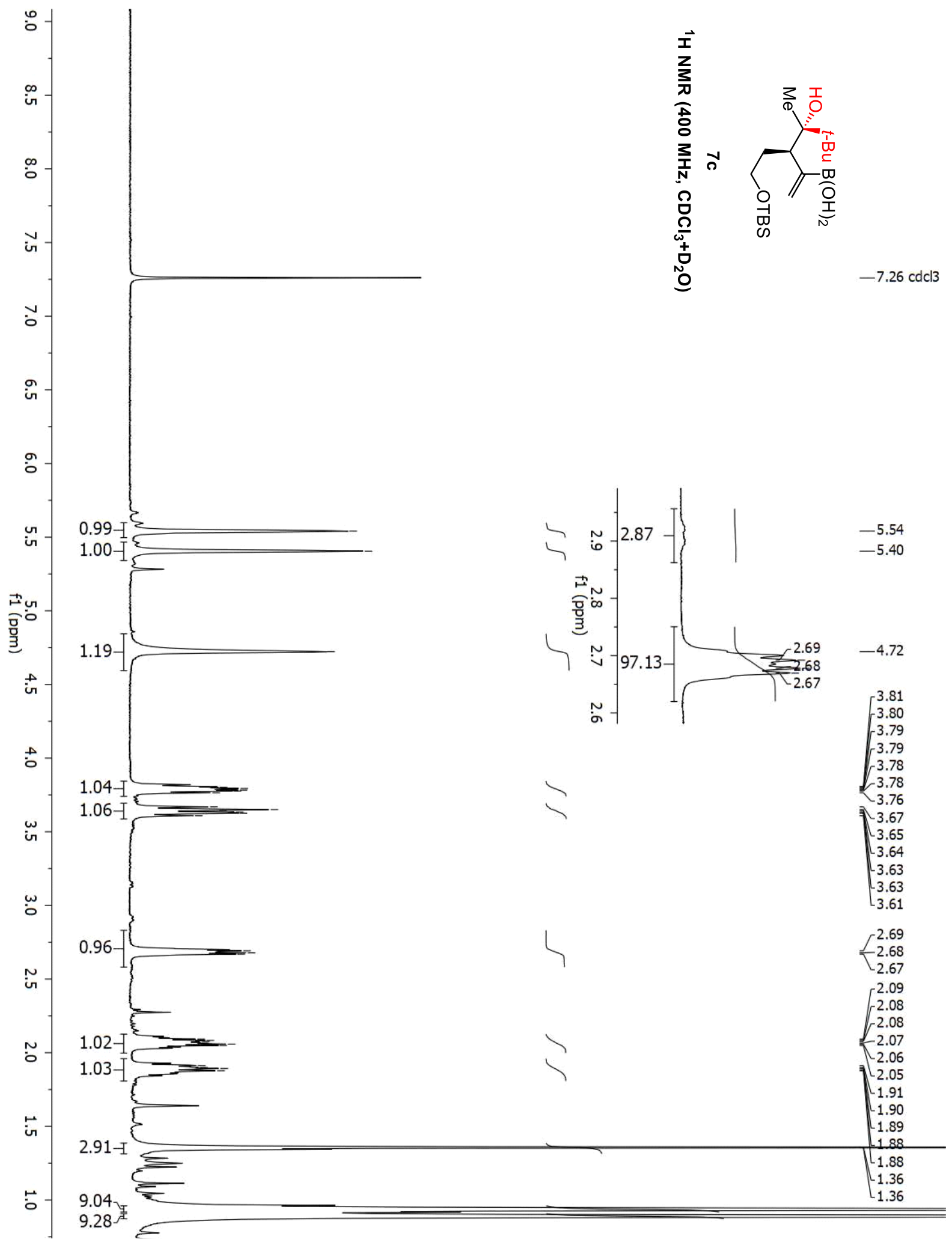




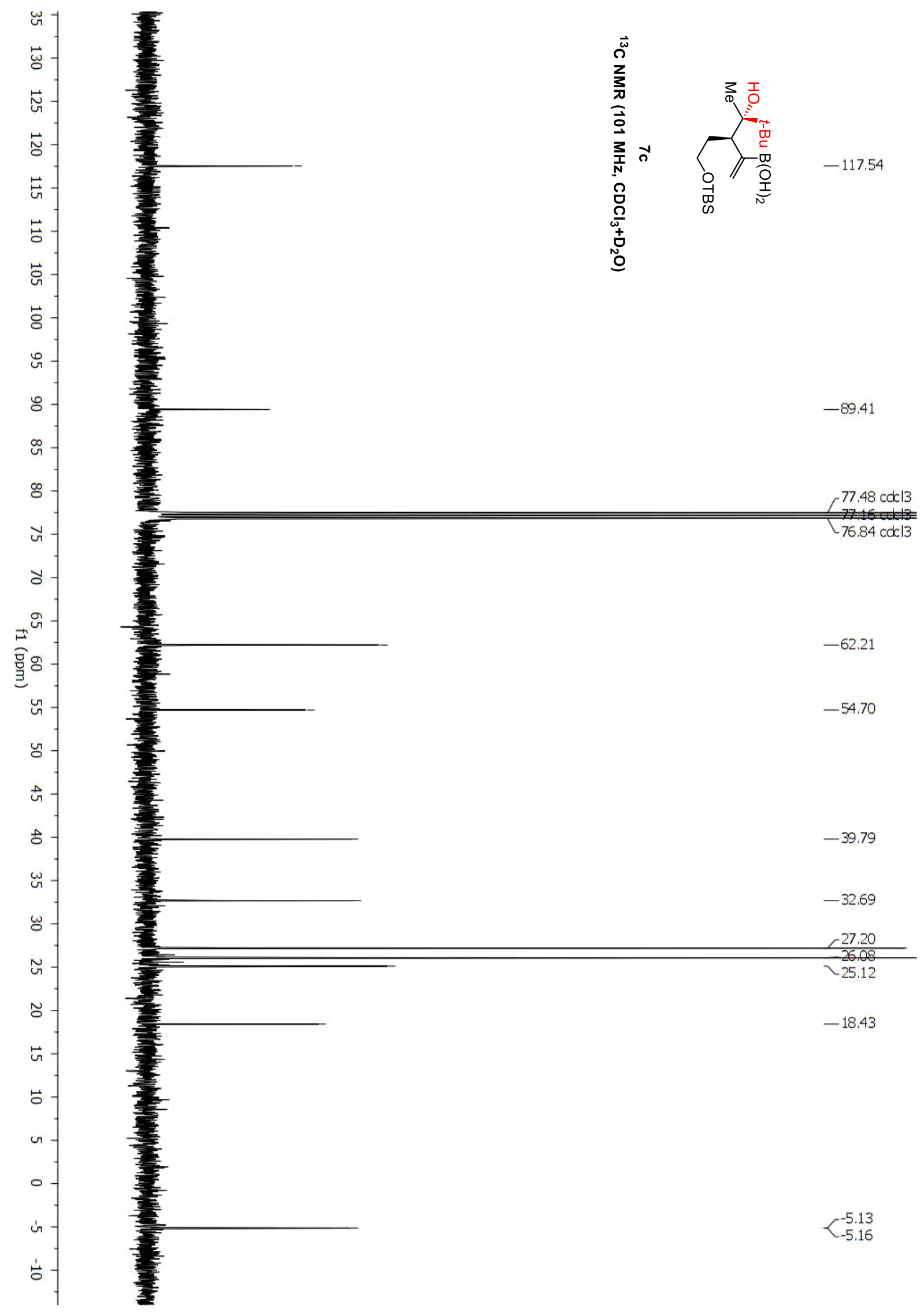


Del Pozo, et al., Supplementary Materials; Page 266

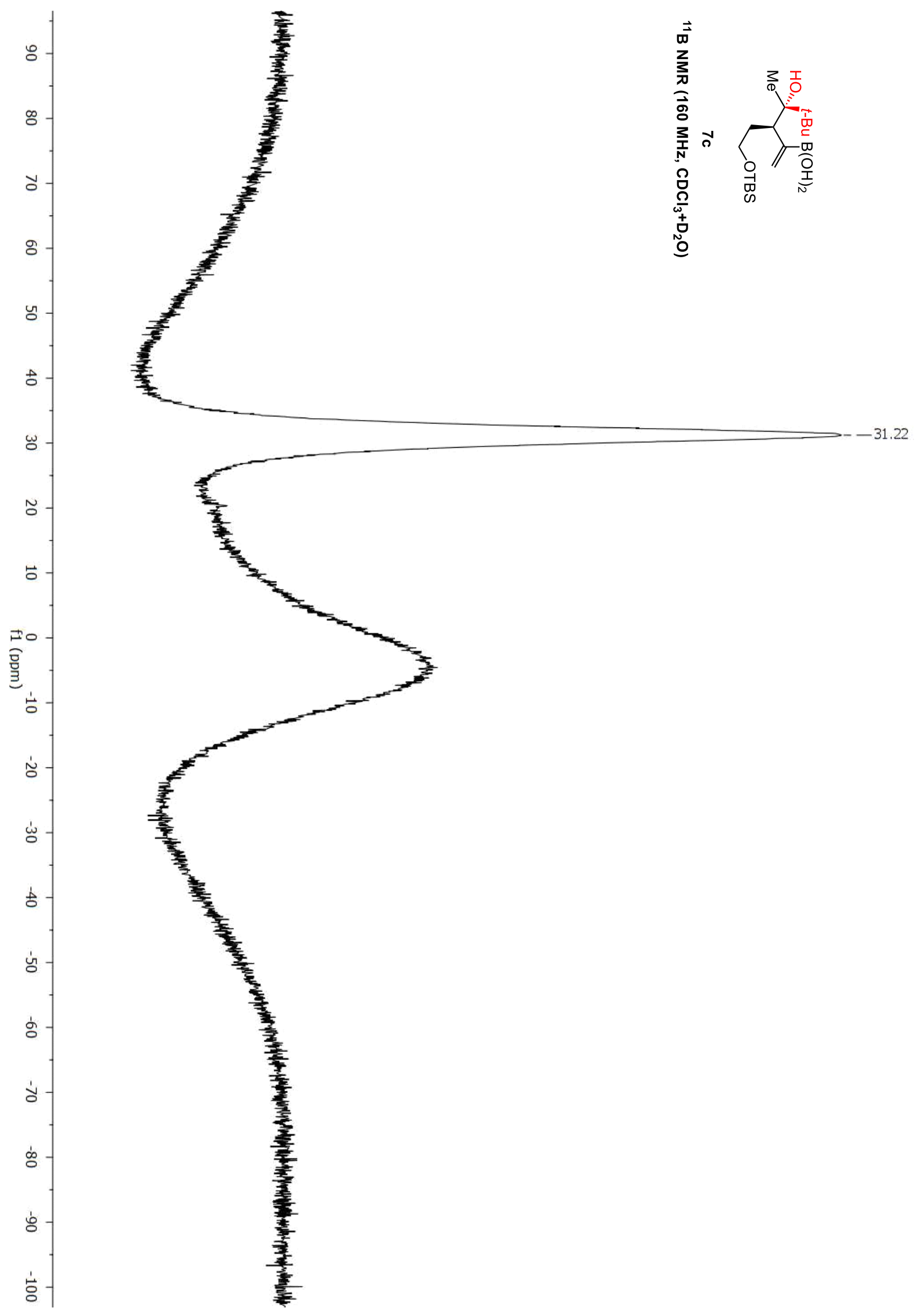




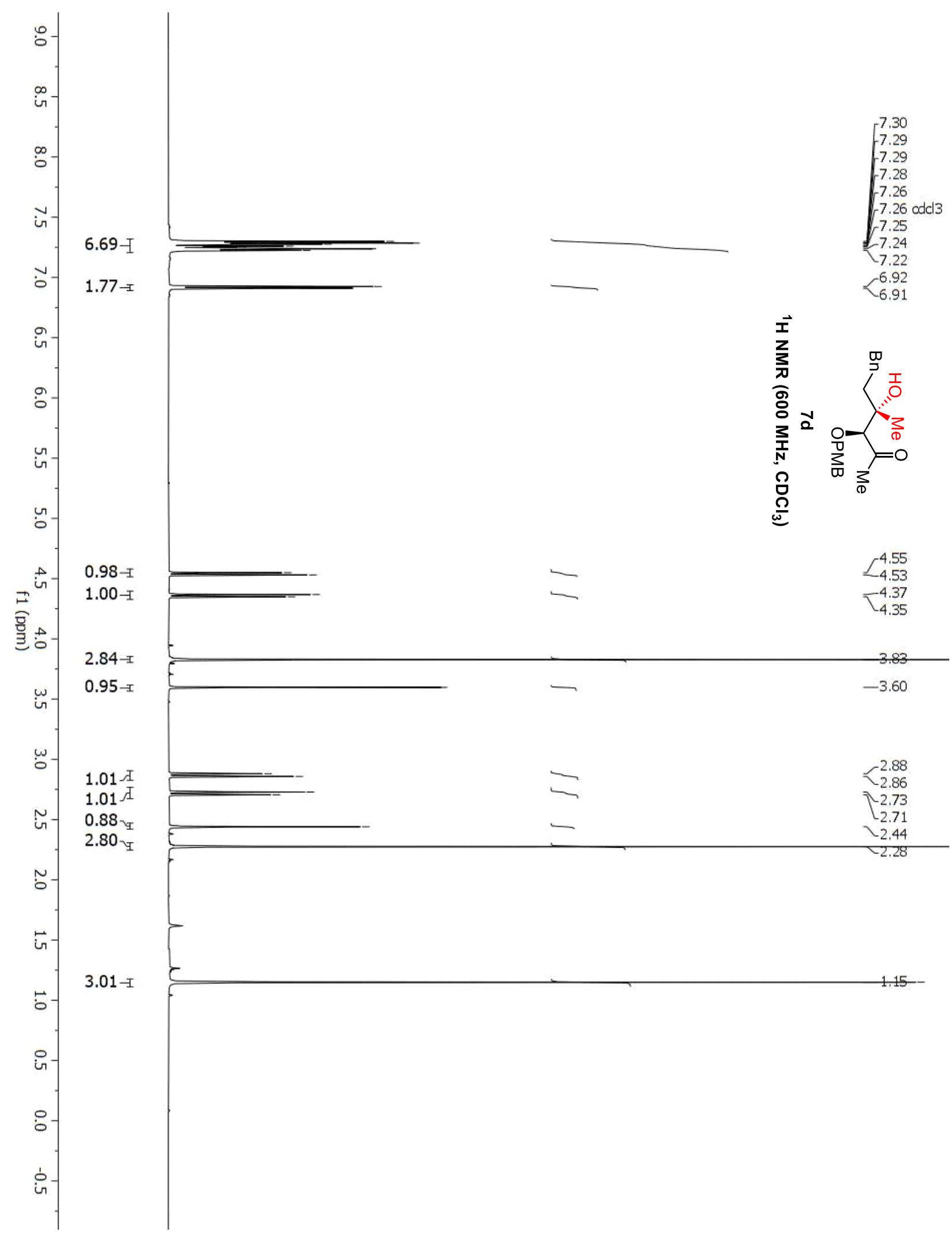




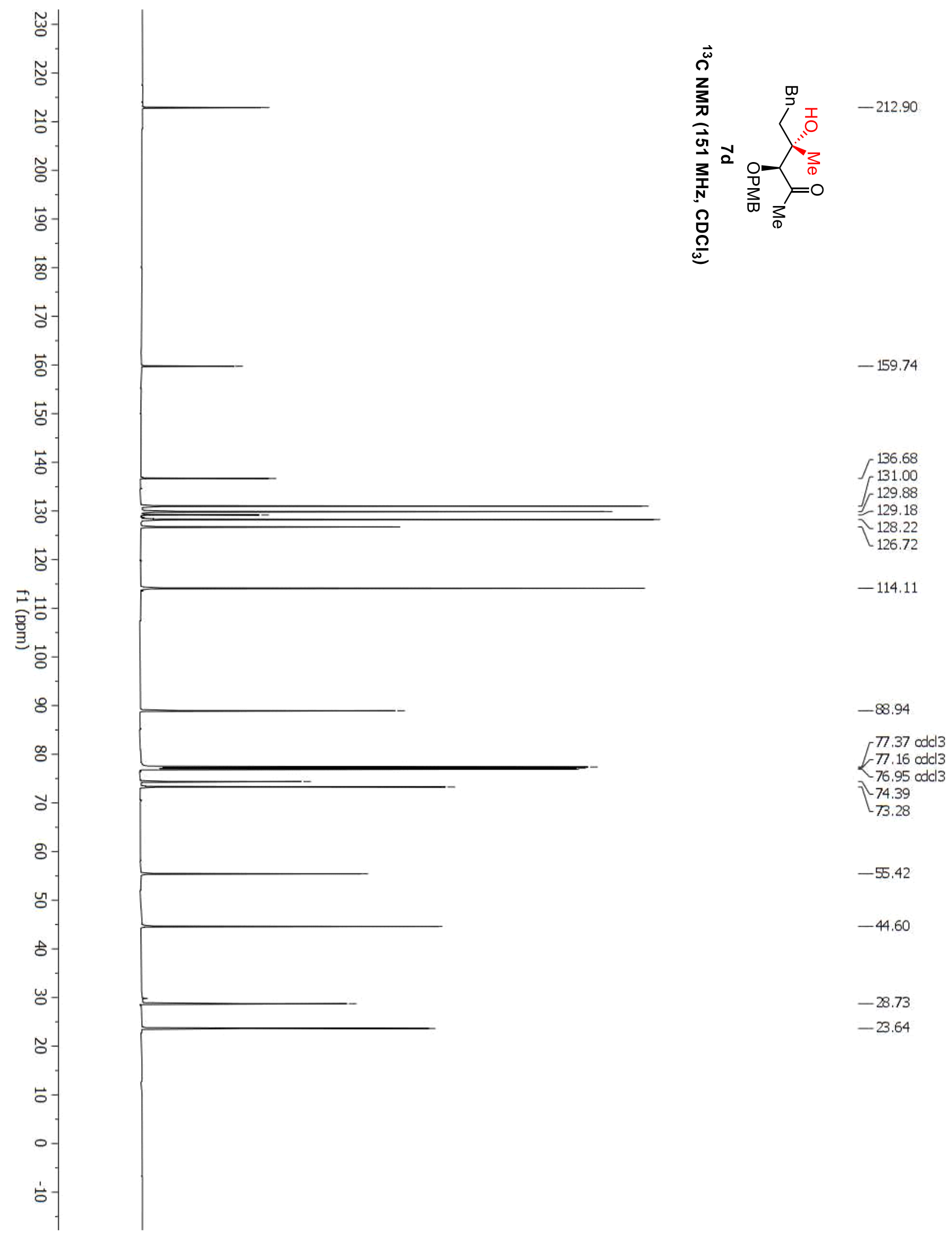




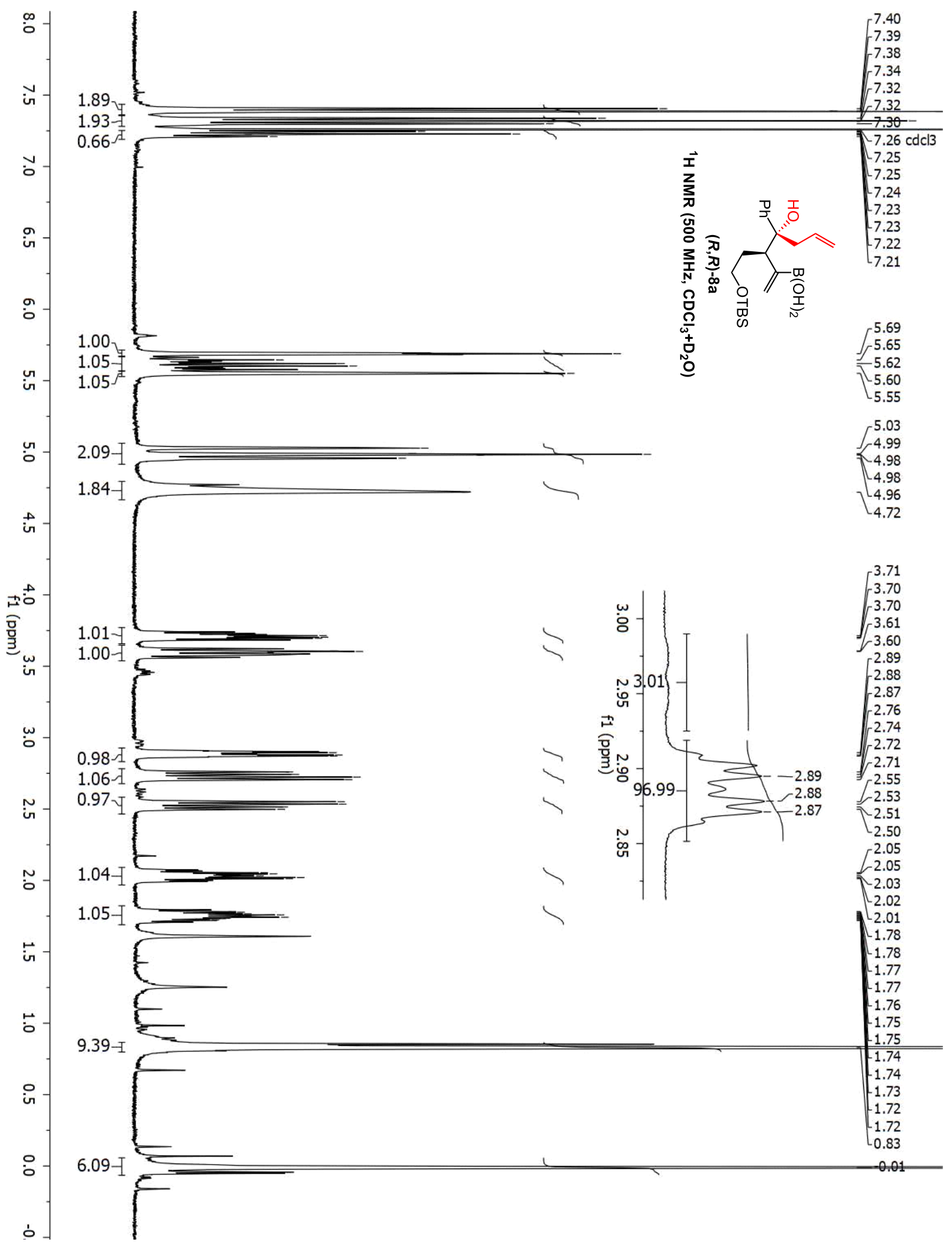




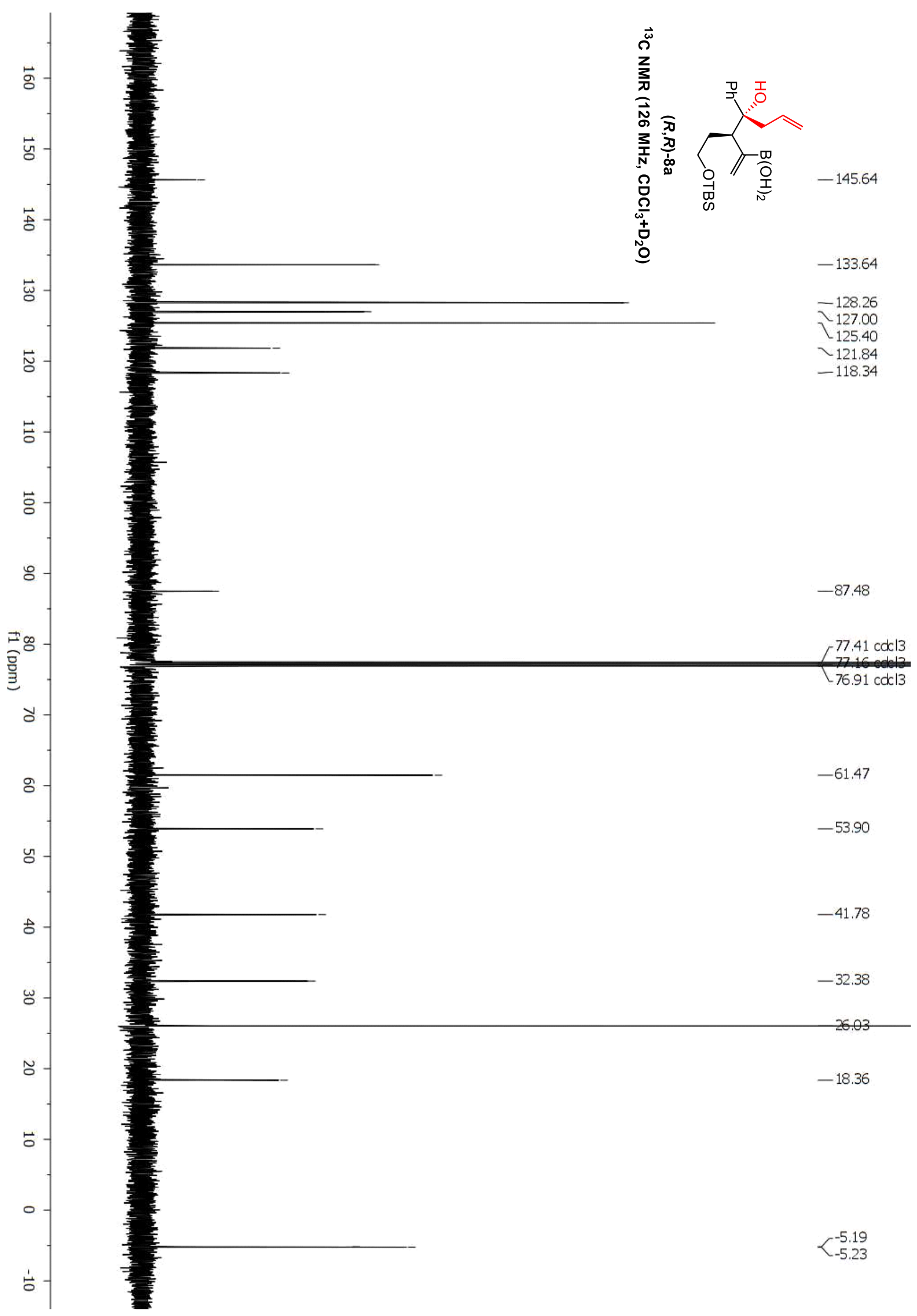


Del Pozo, et al., Supplementary Materials; Page 271

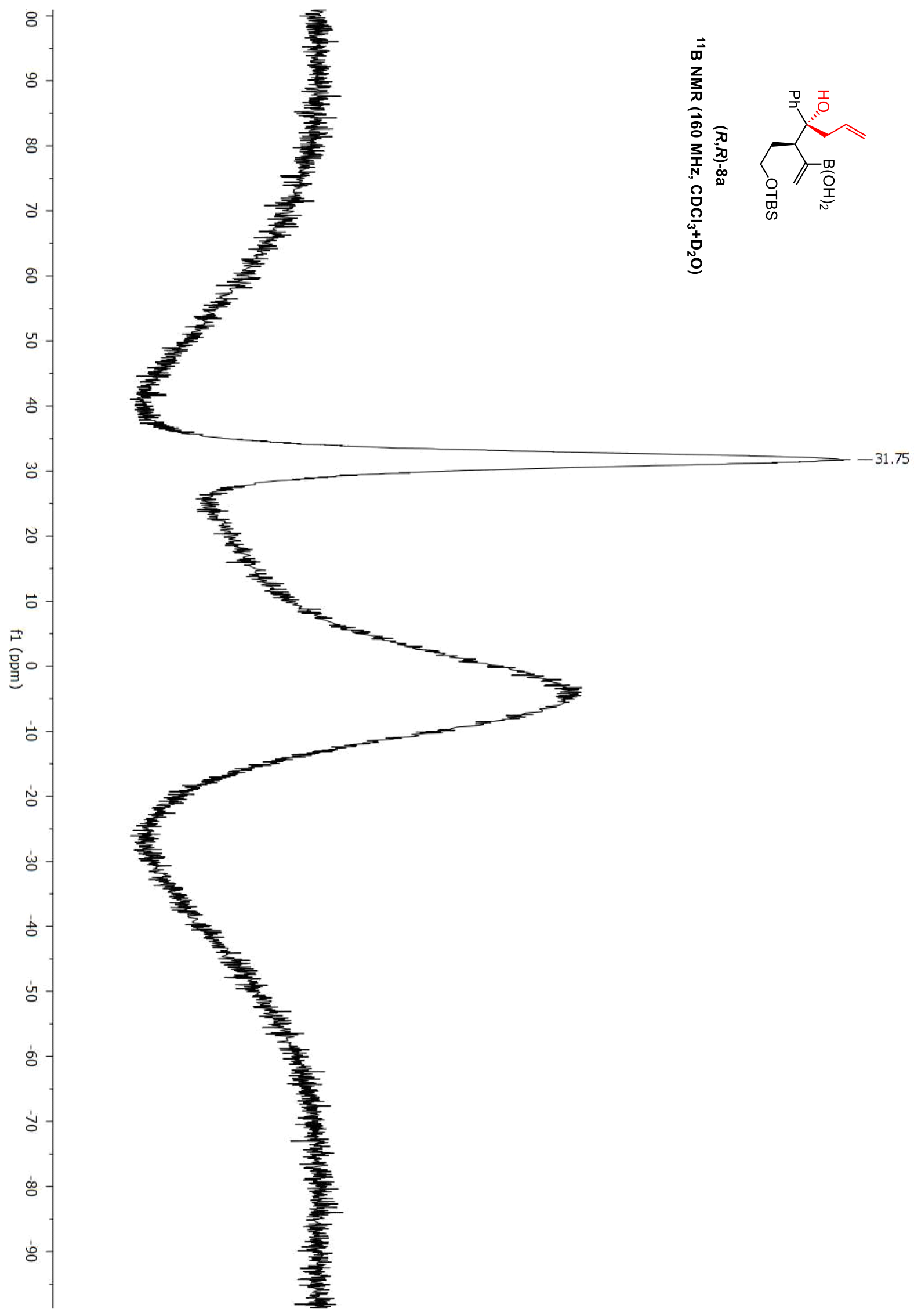




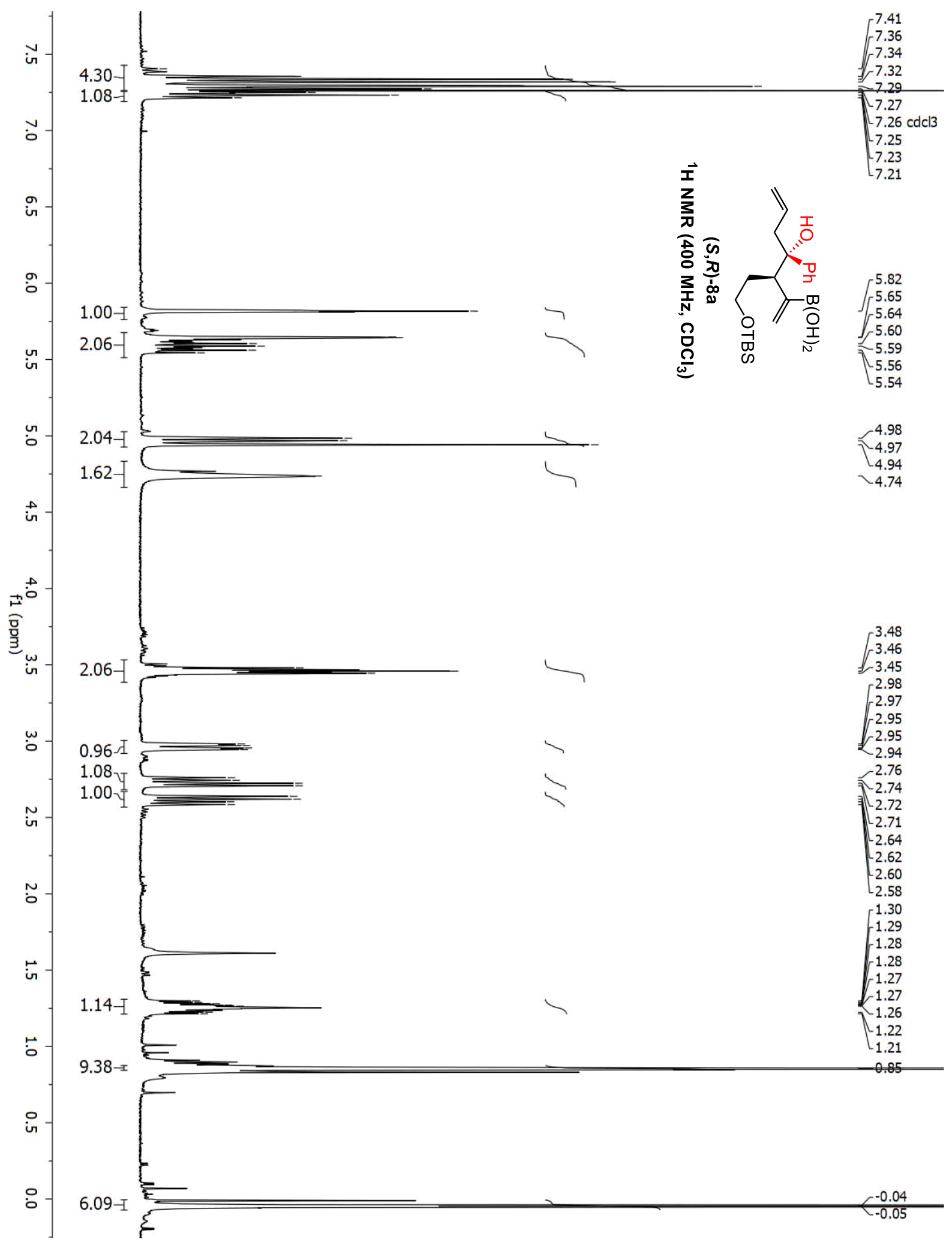




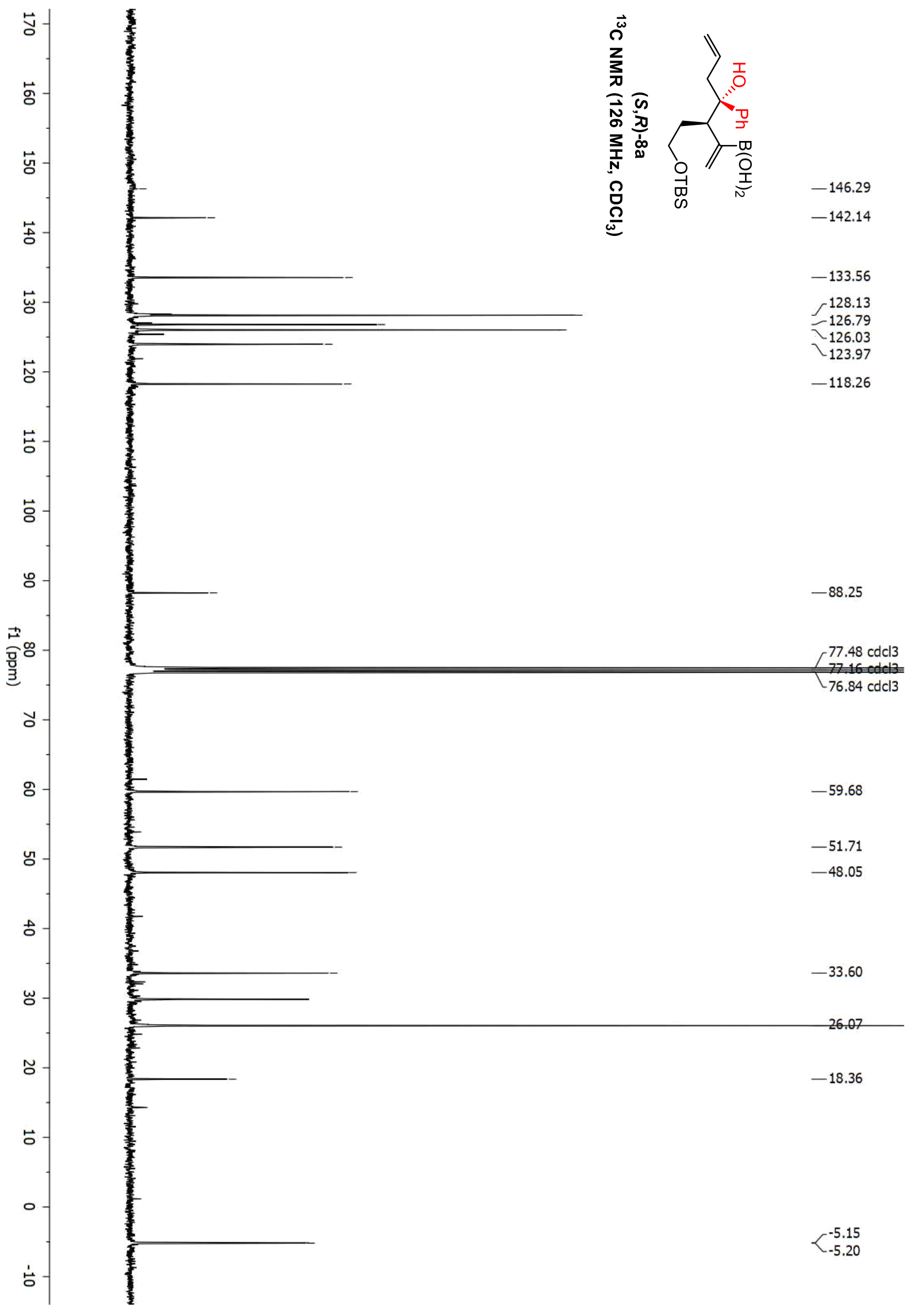



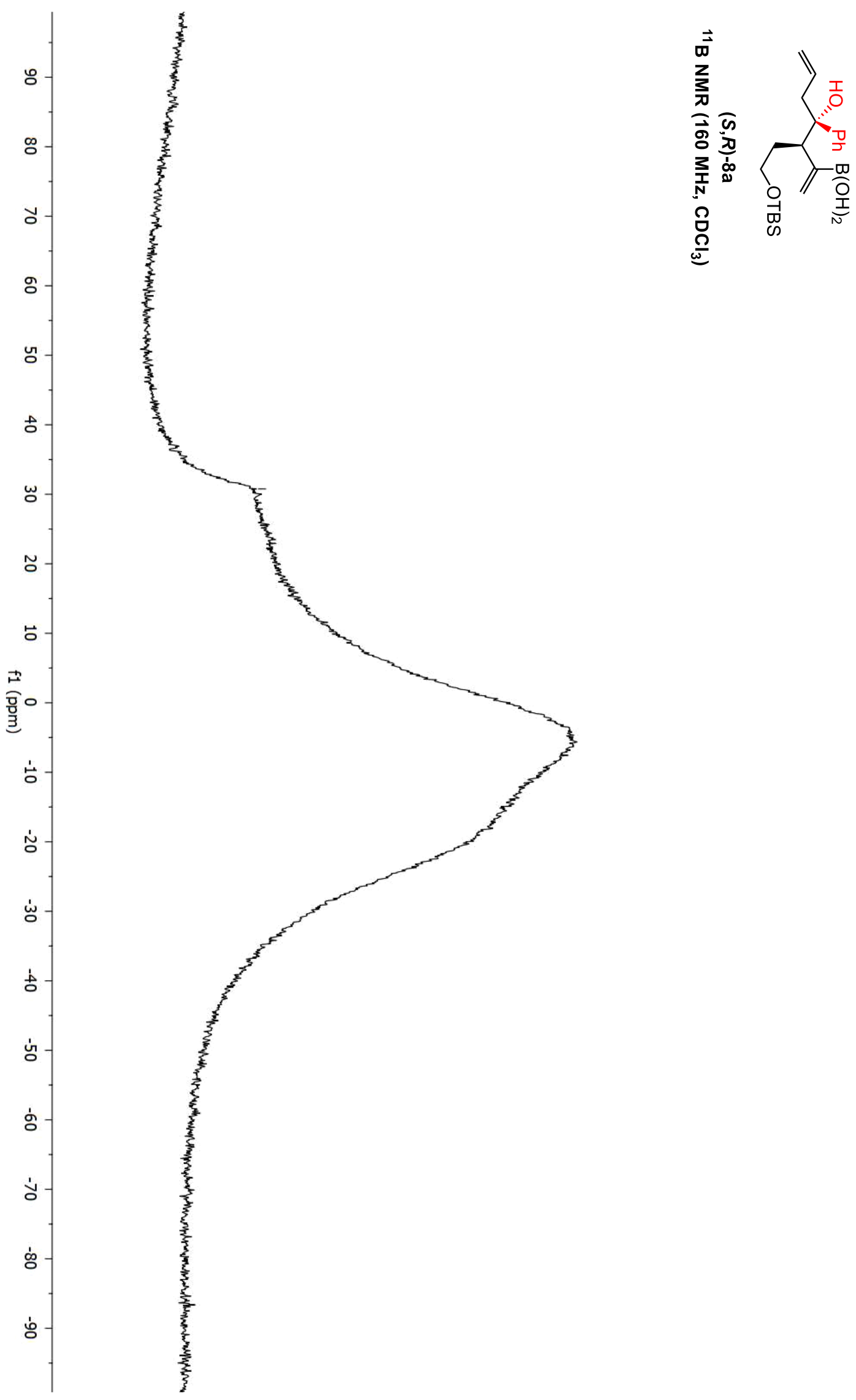


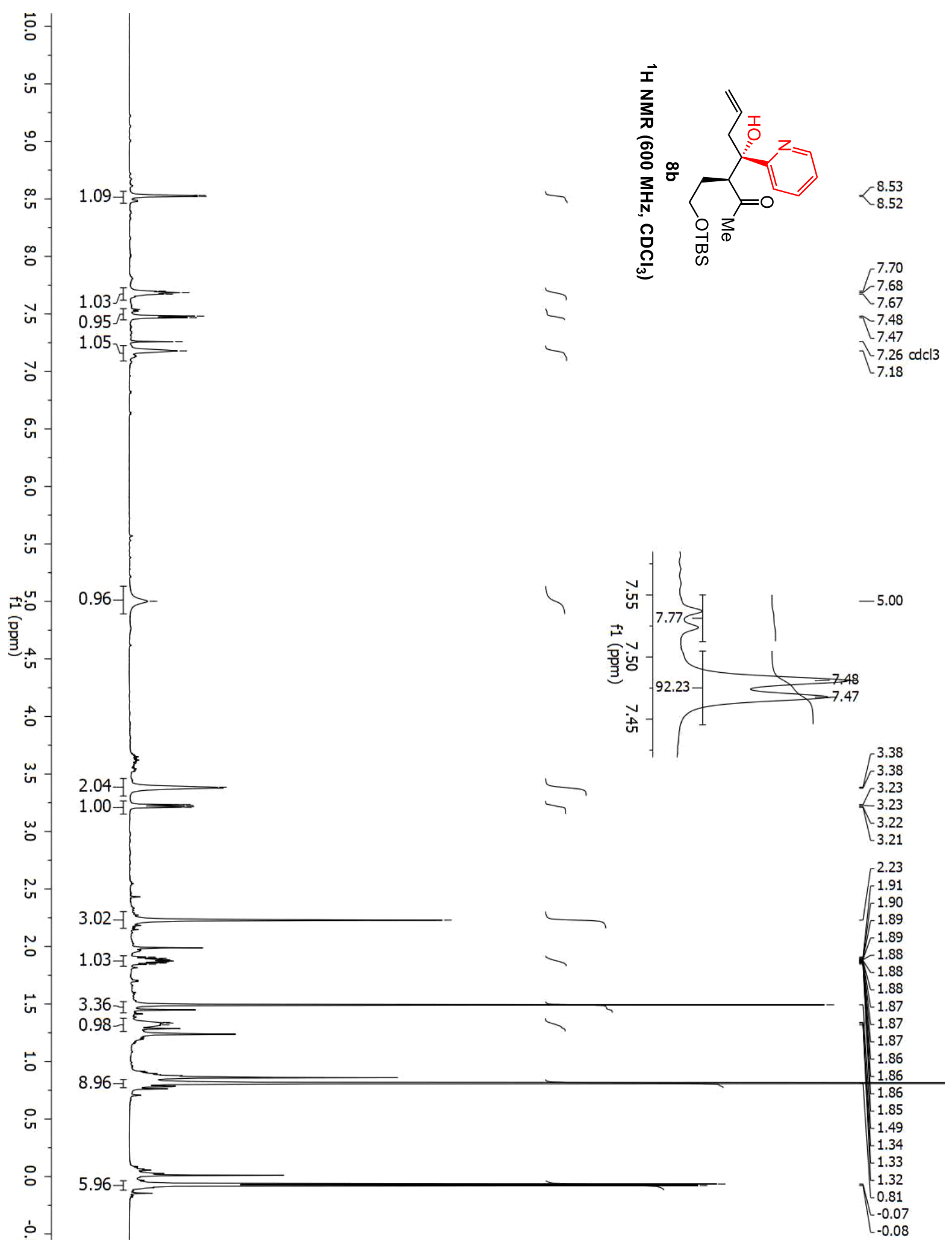




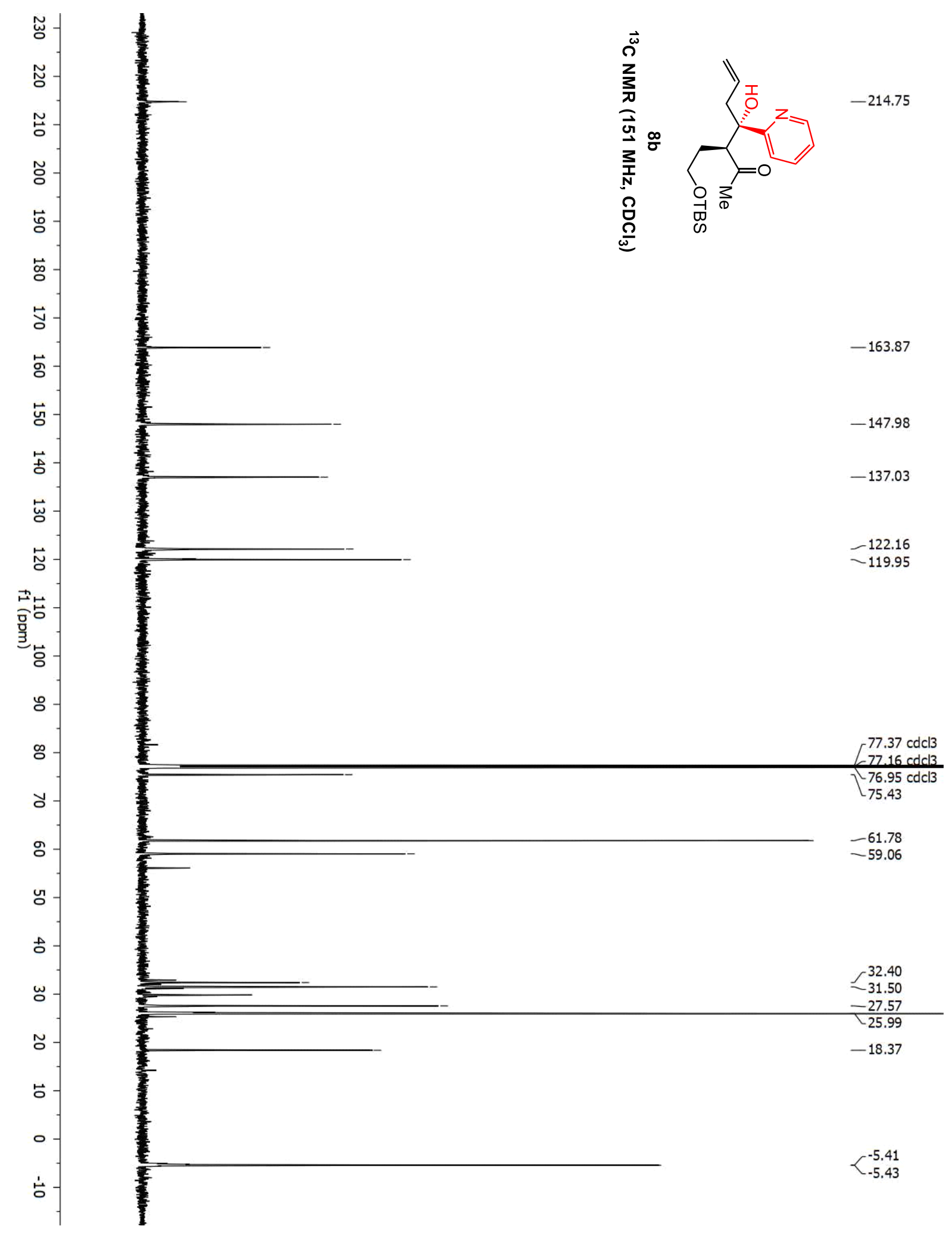




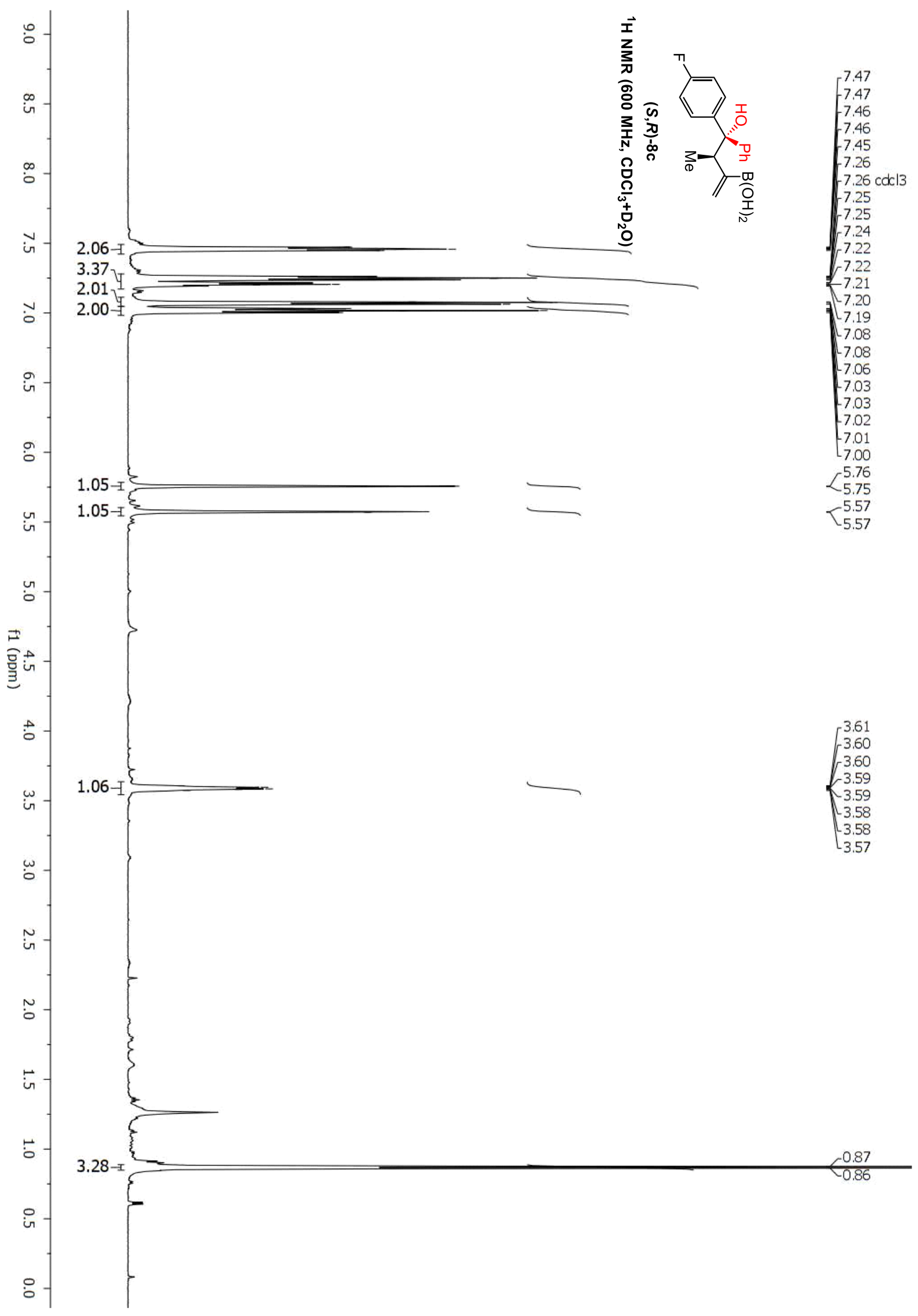




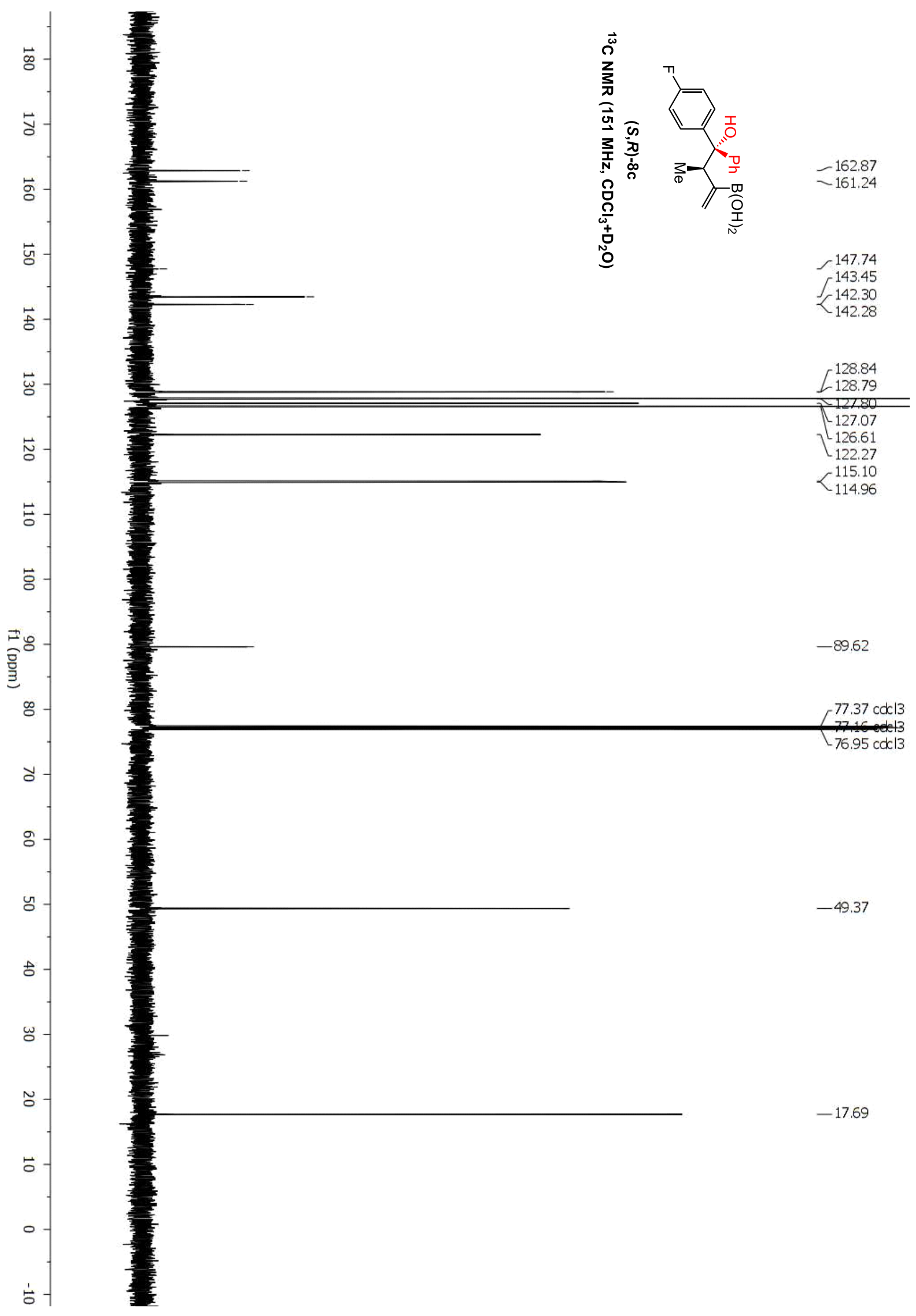


Del Pozo, et al., Supplementary Materials; Page 279

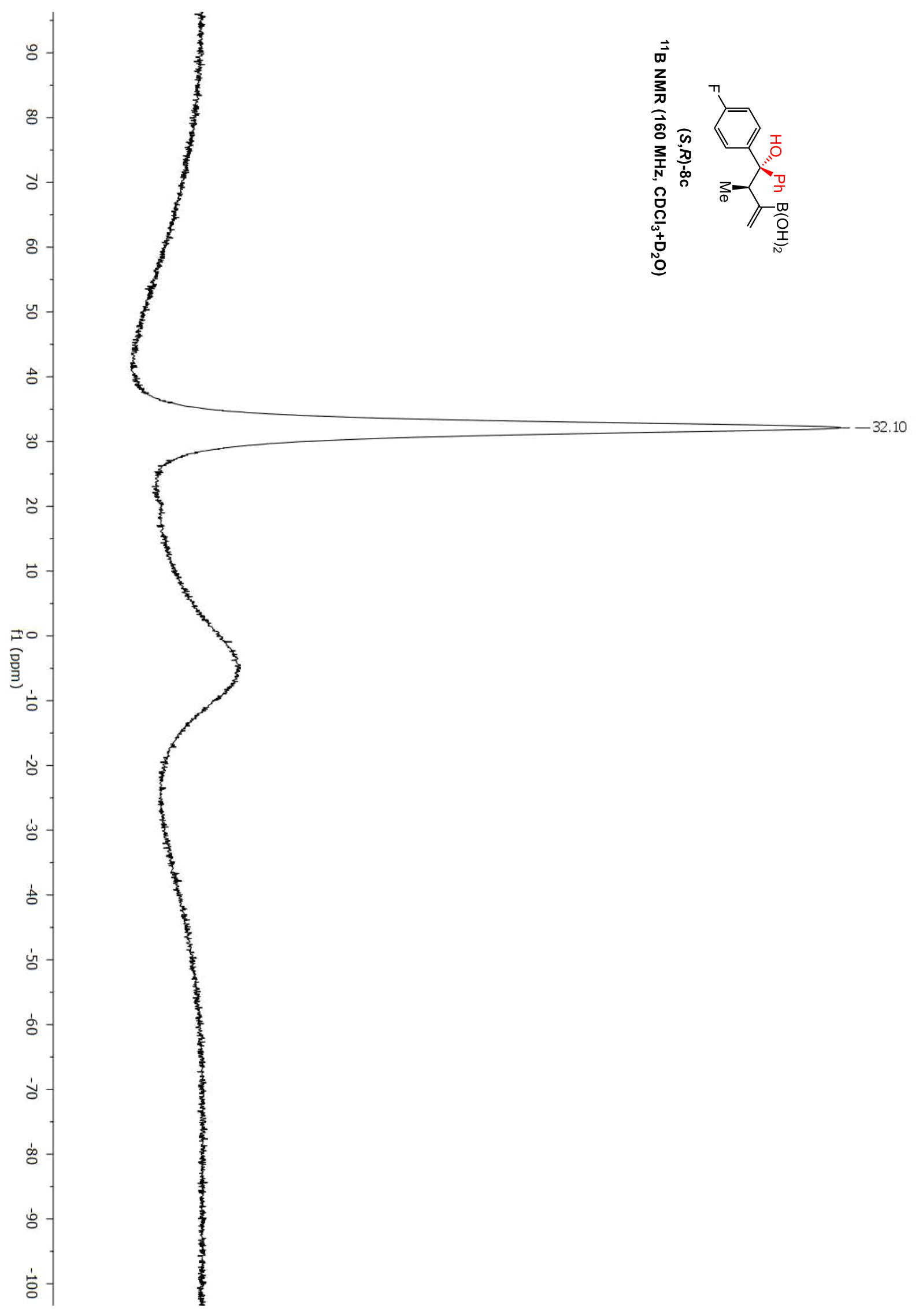




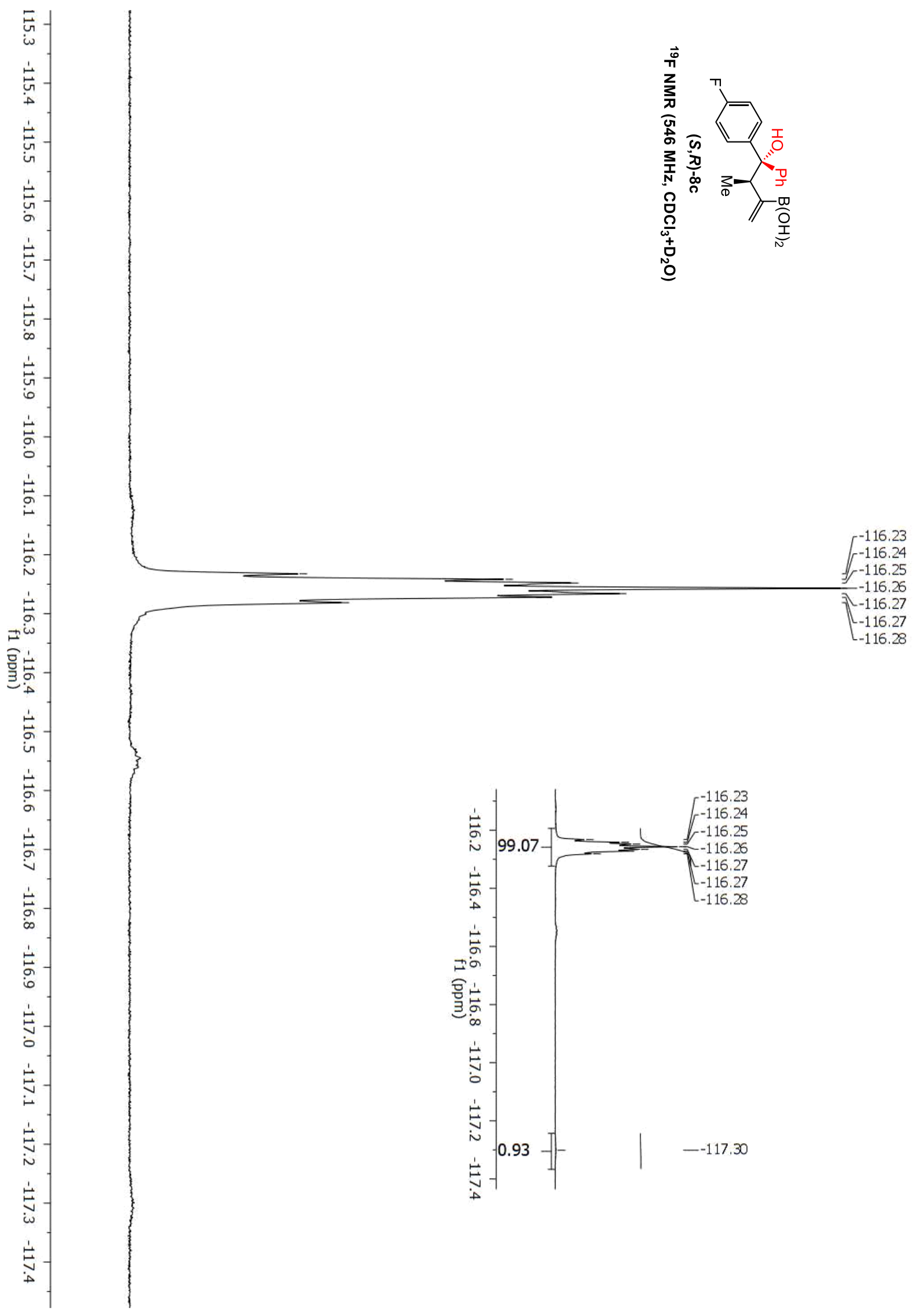




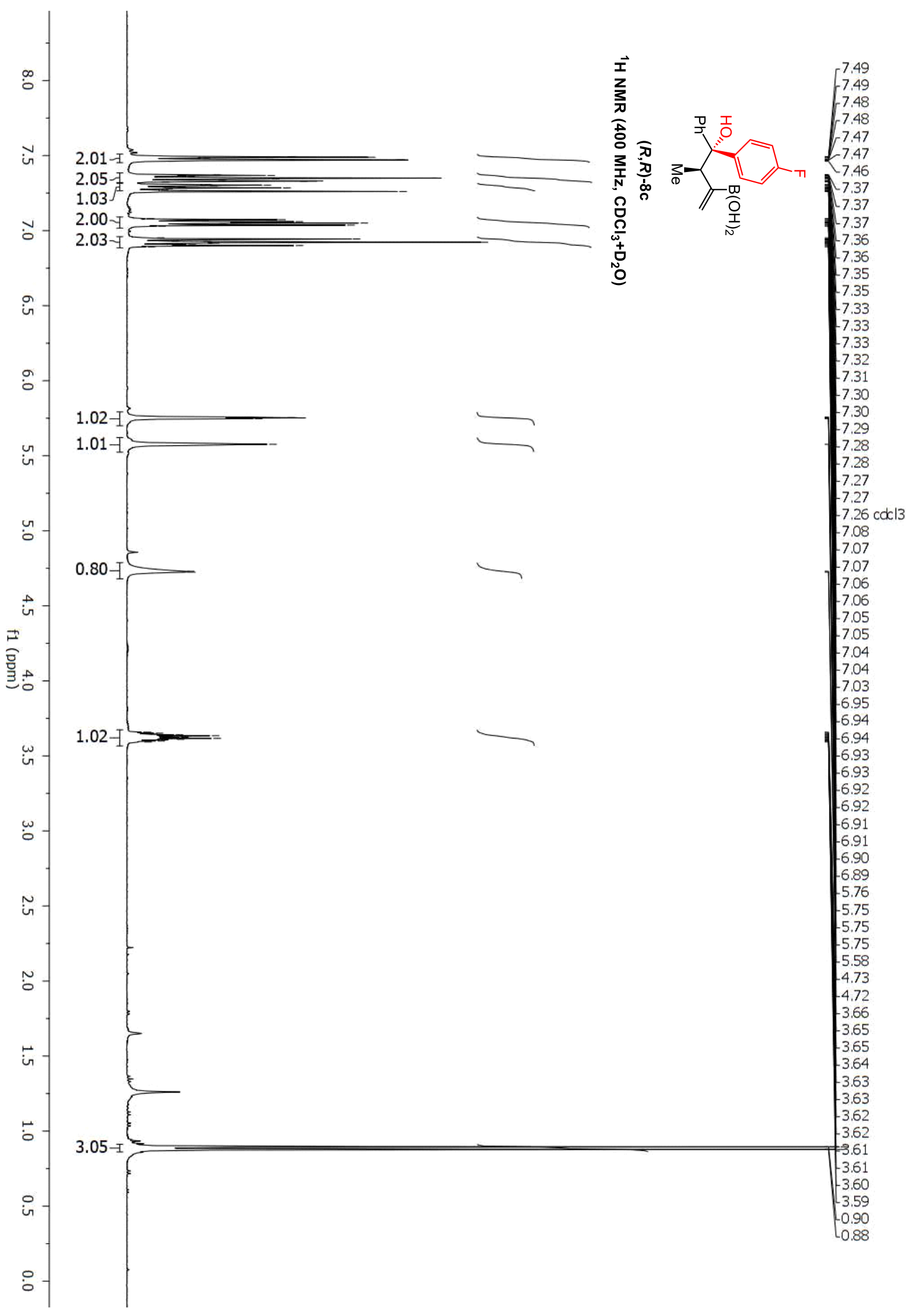




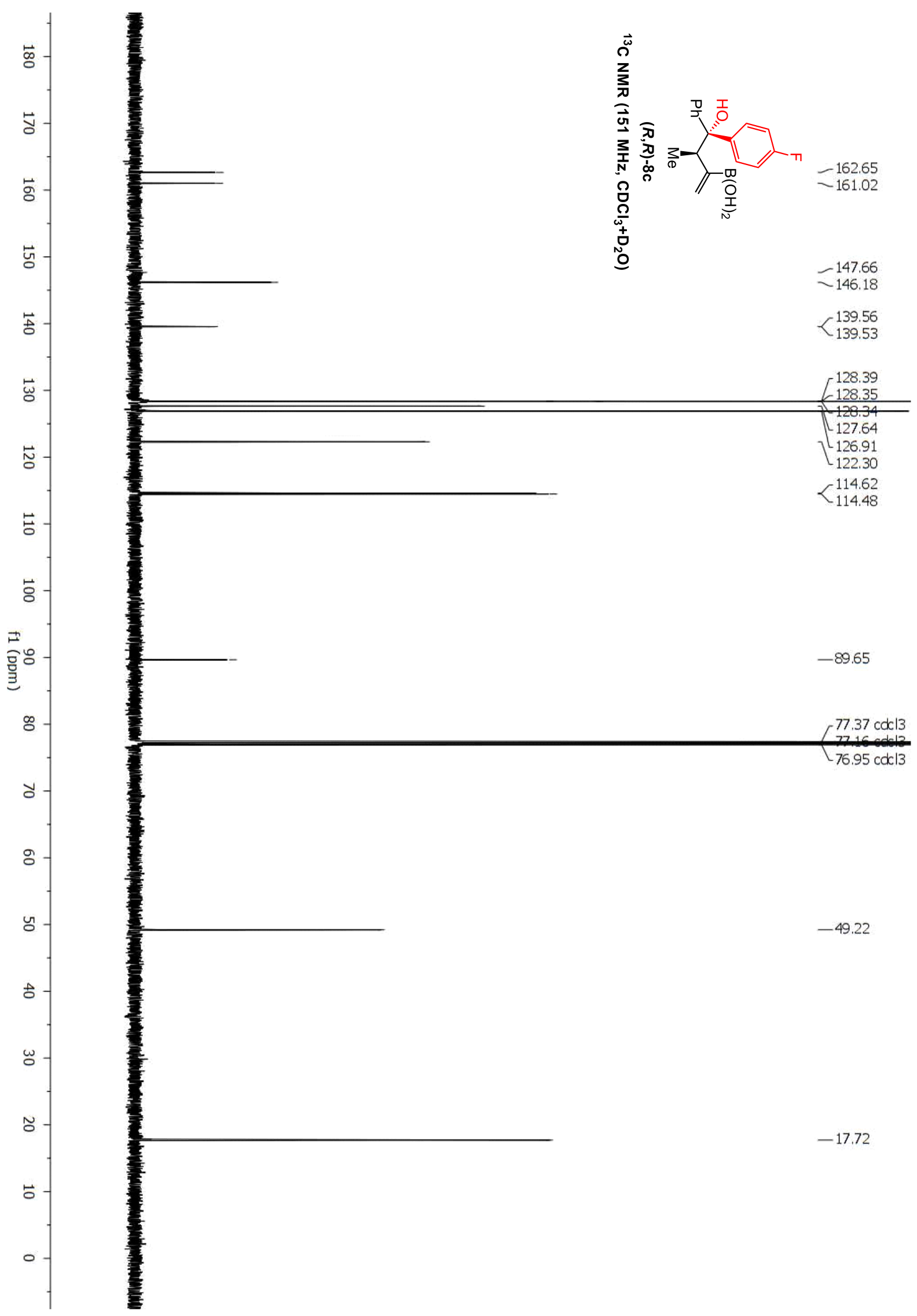


Del Pozo, et al., Supplementary Materials; Page 283

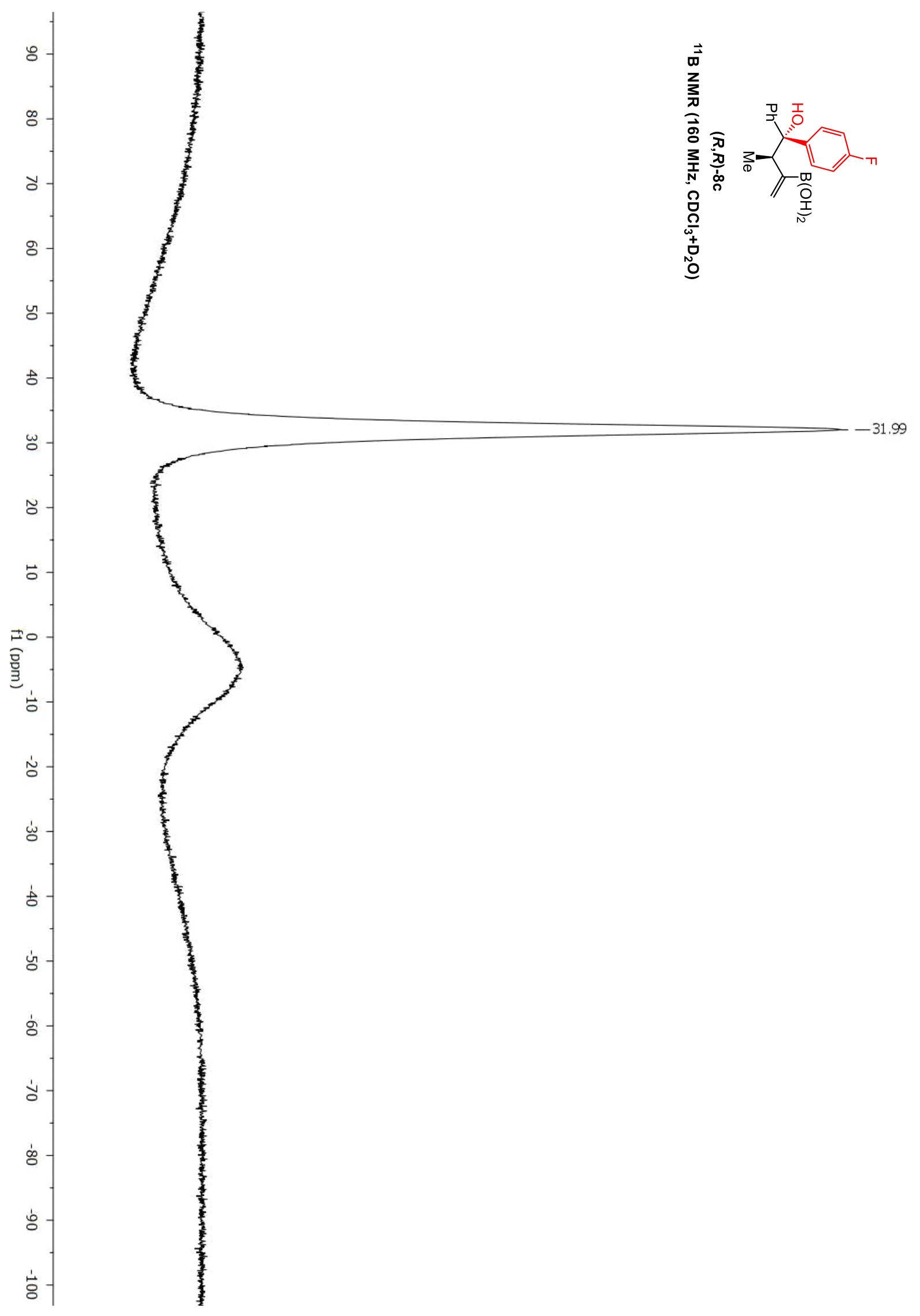




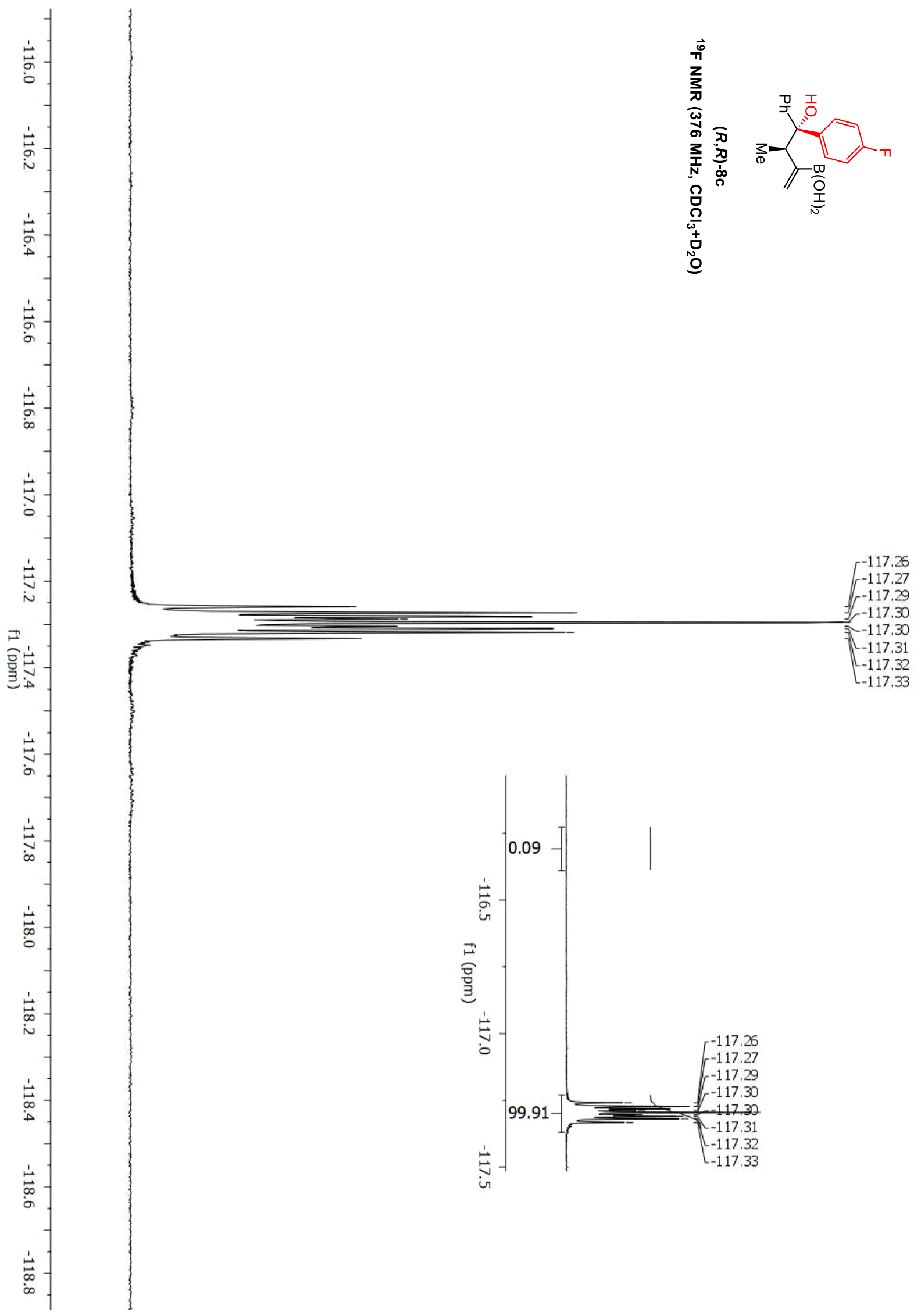




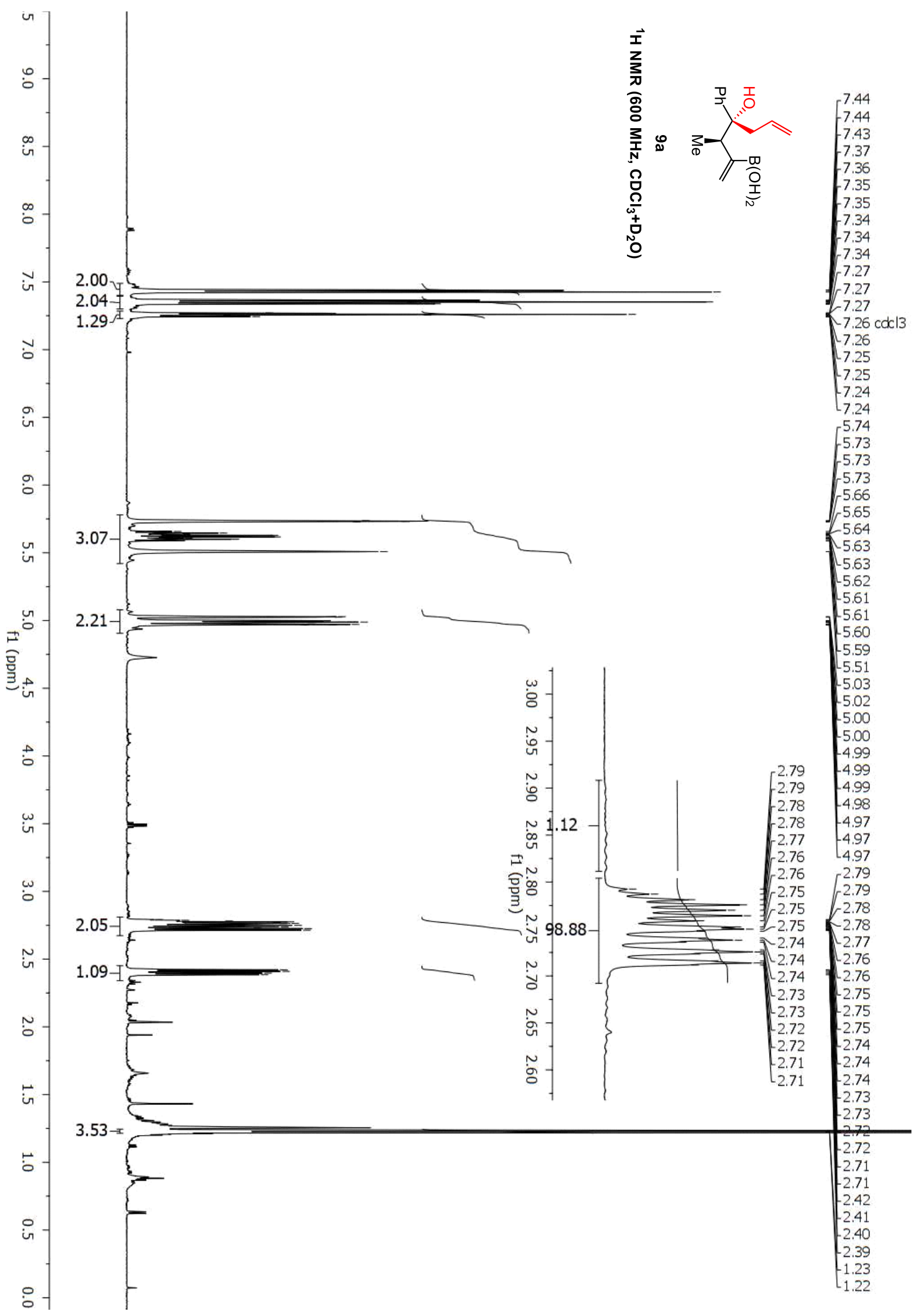




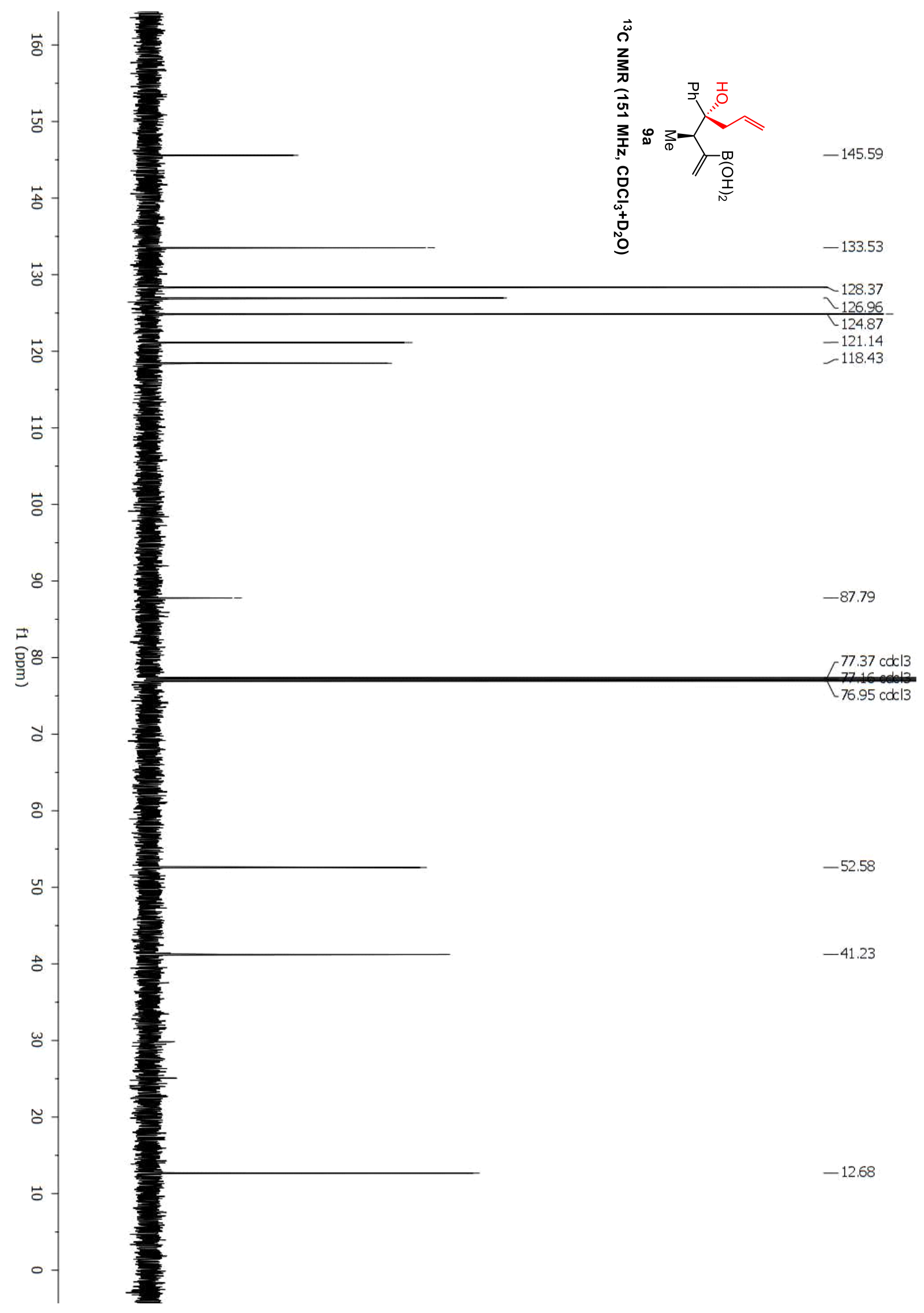


Del Pozo, et al., Supplementary Materials; Page 287

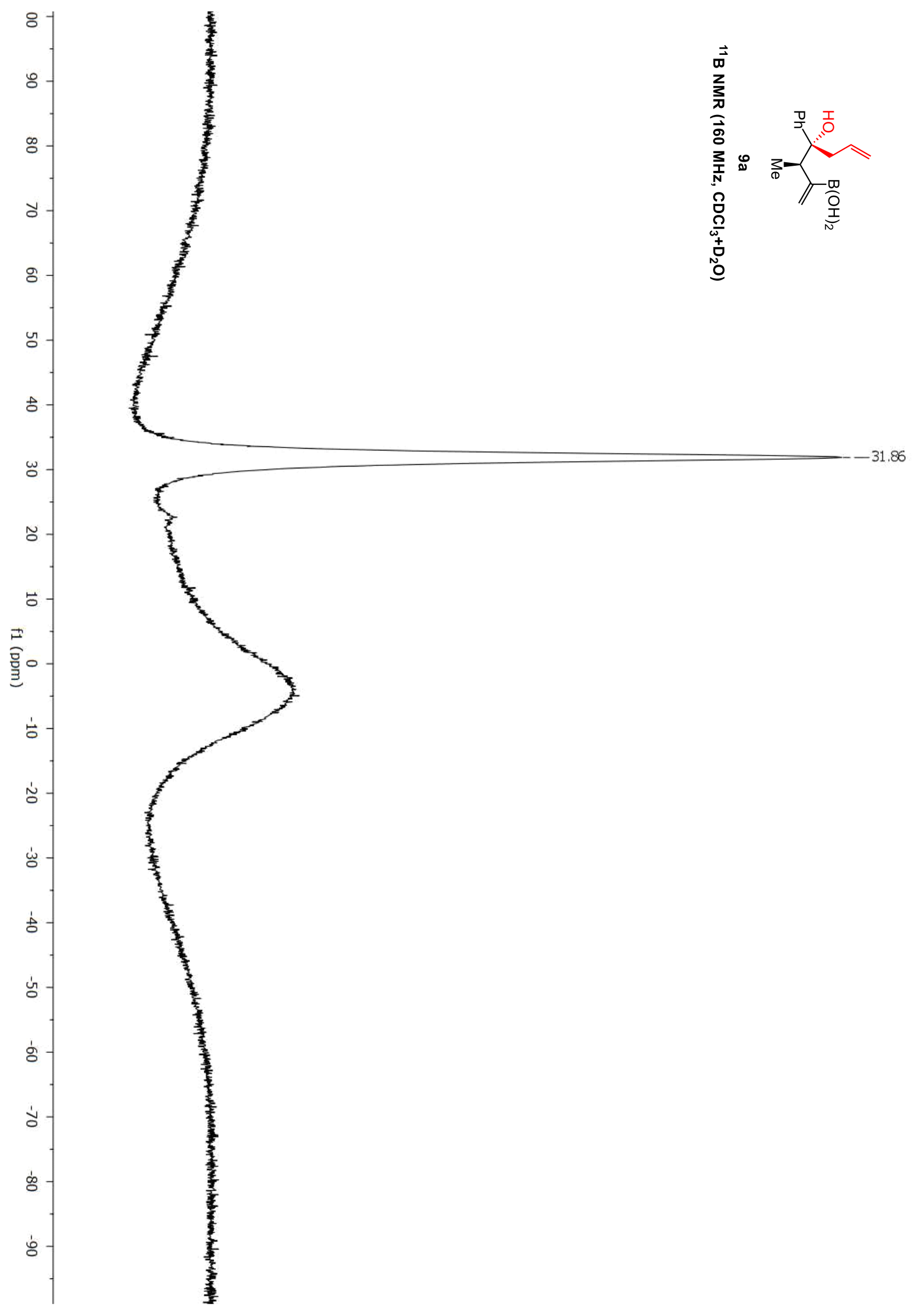




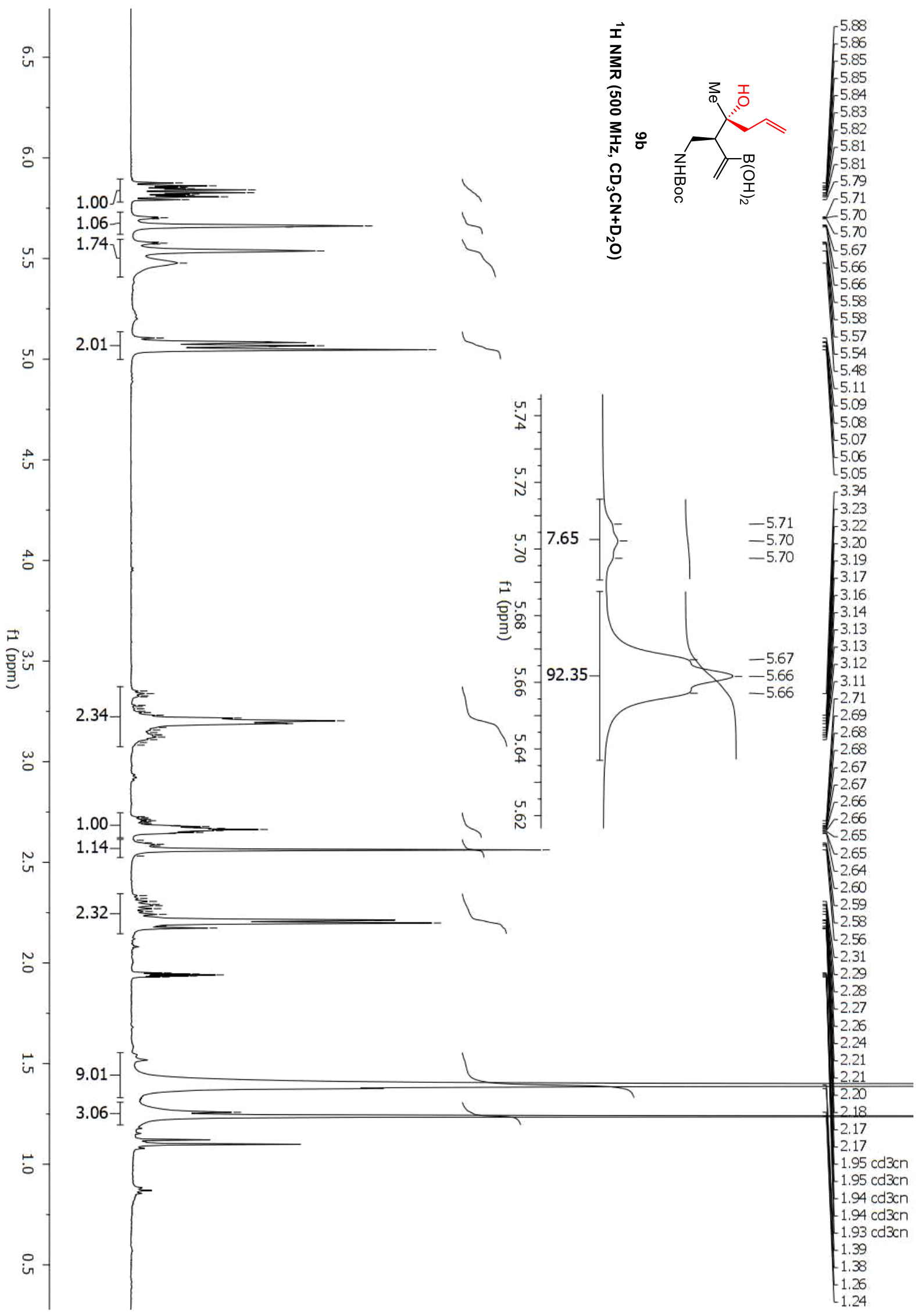




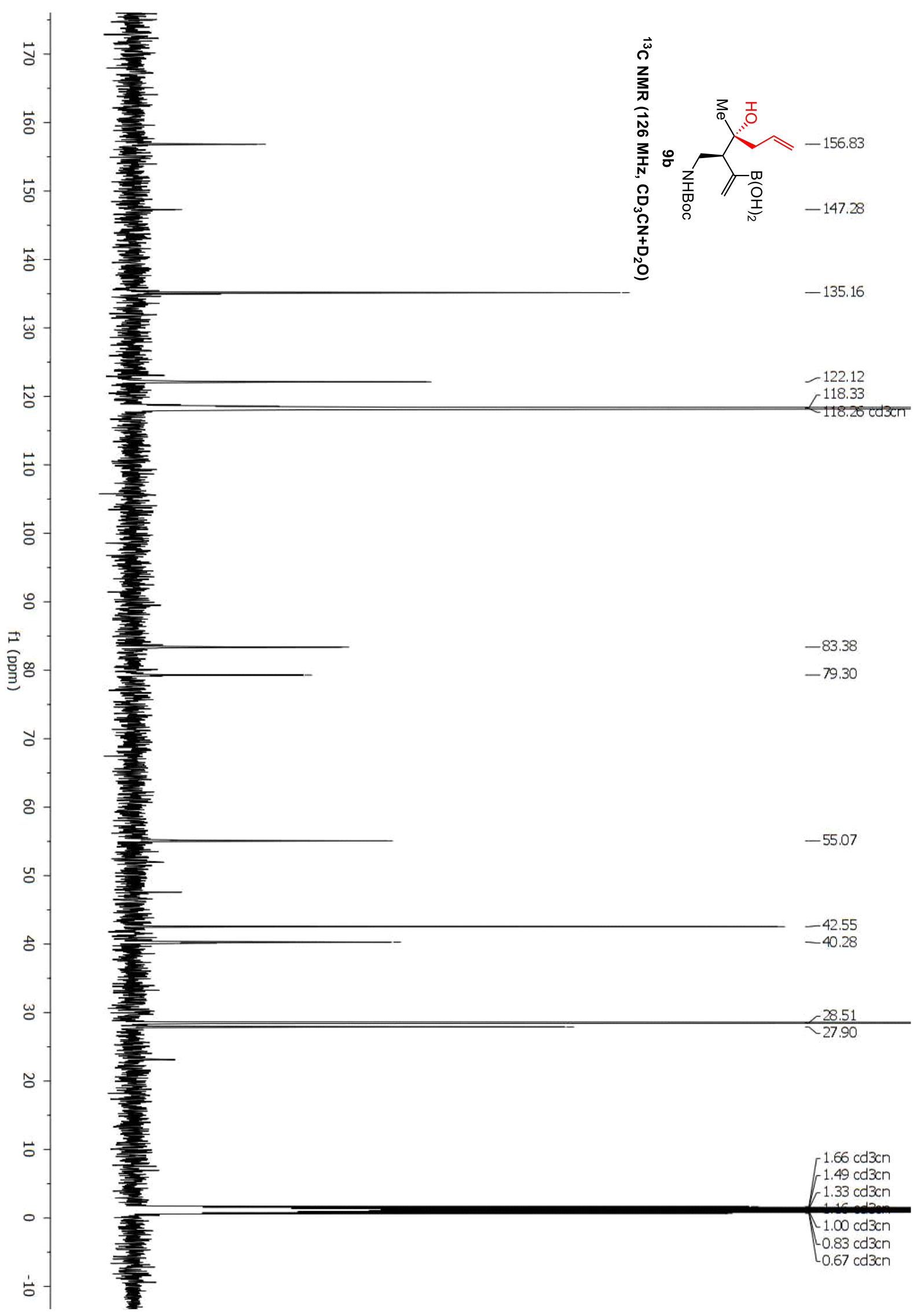




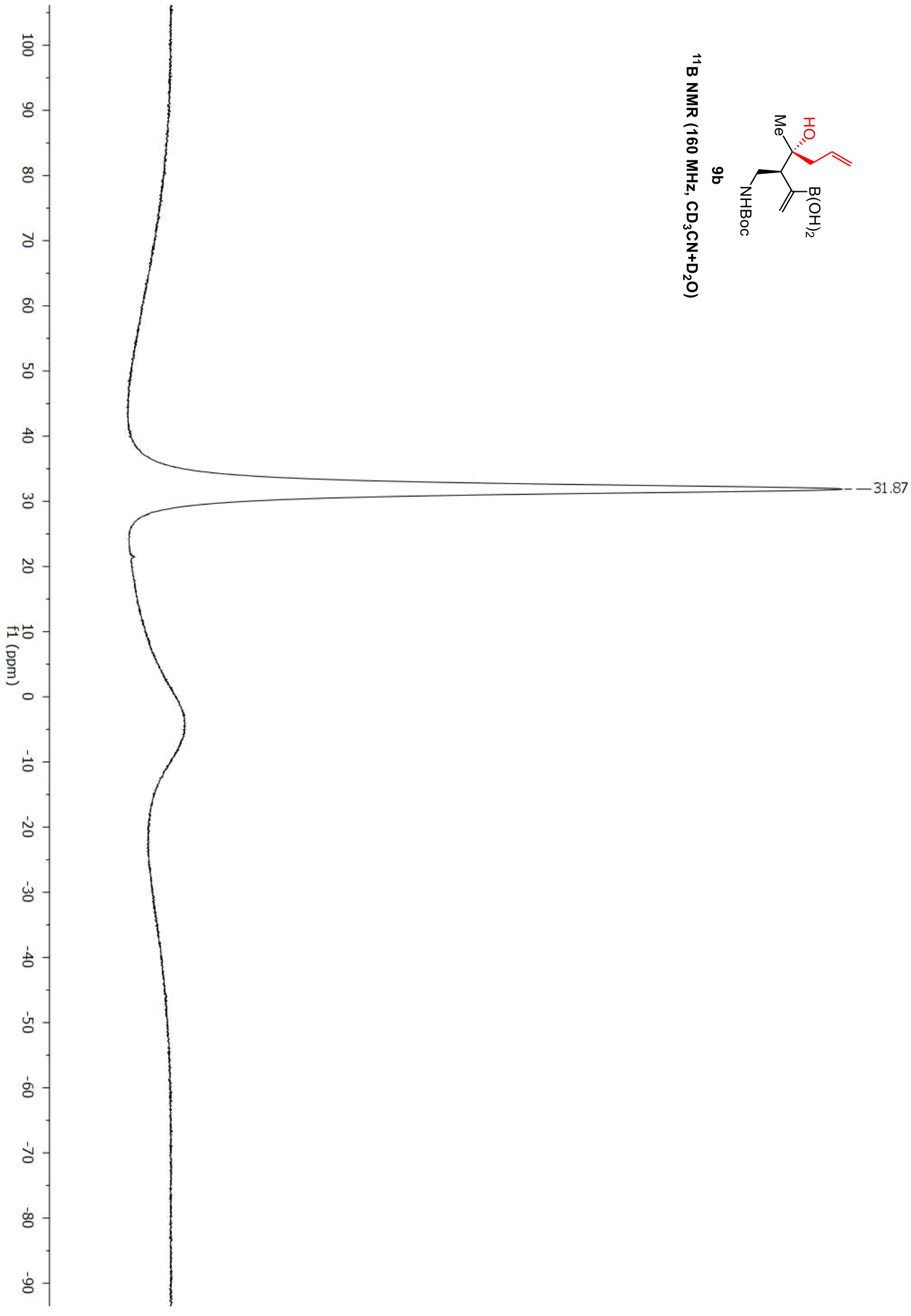




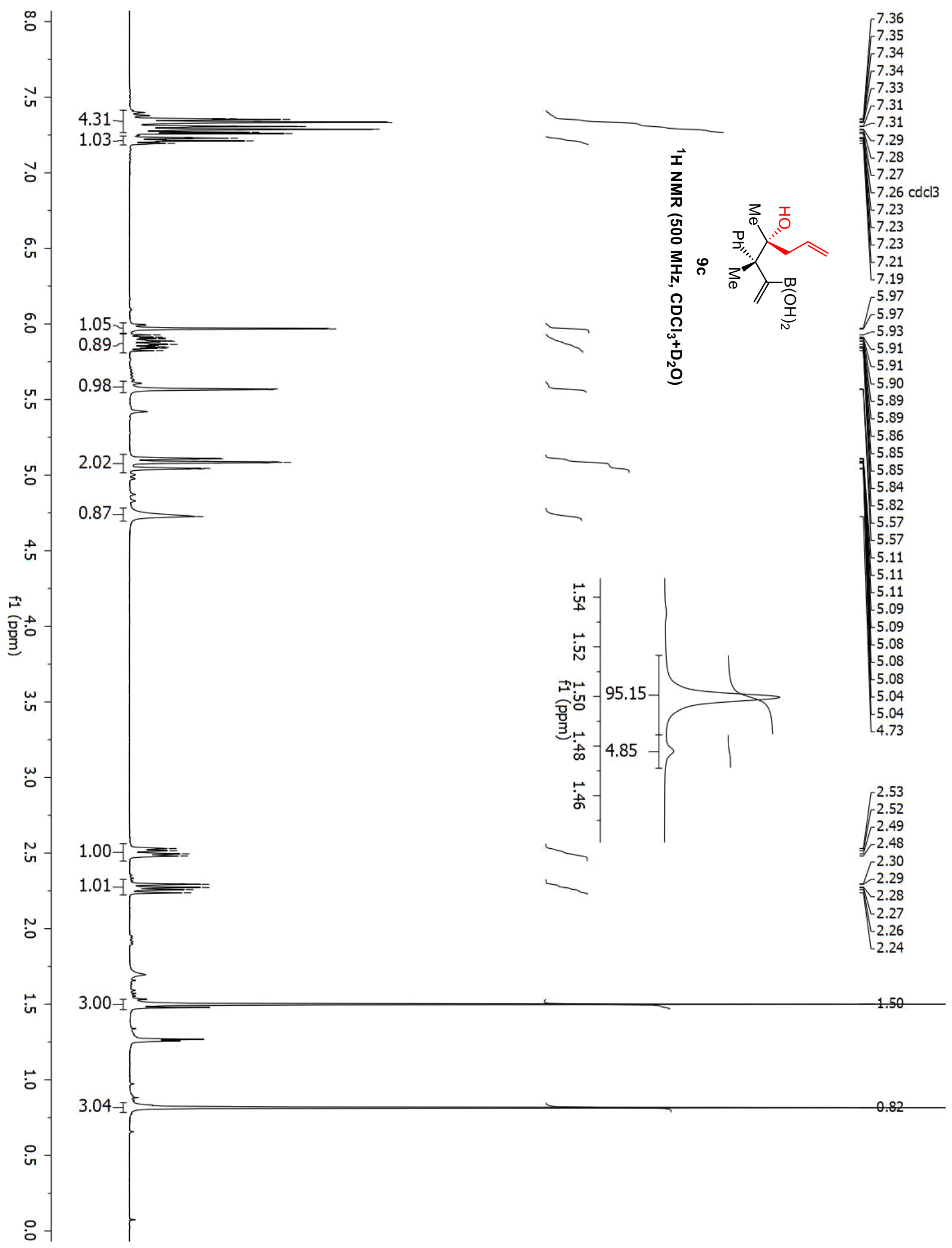




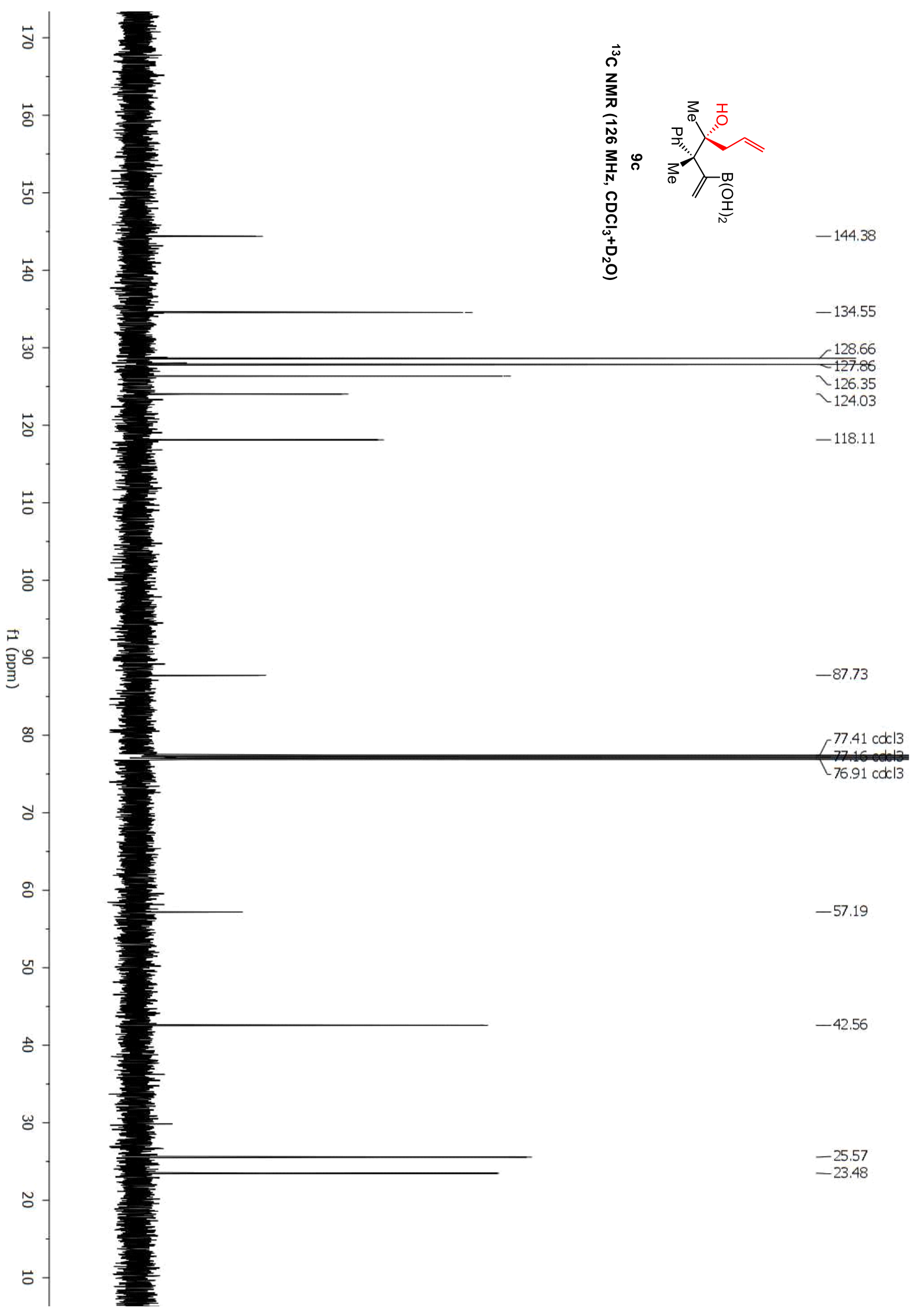


Del Pozo, et al., Supplementary Materials; Page 293

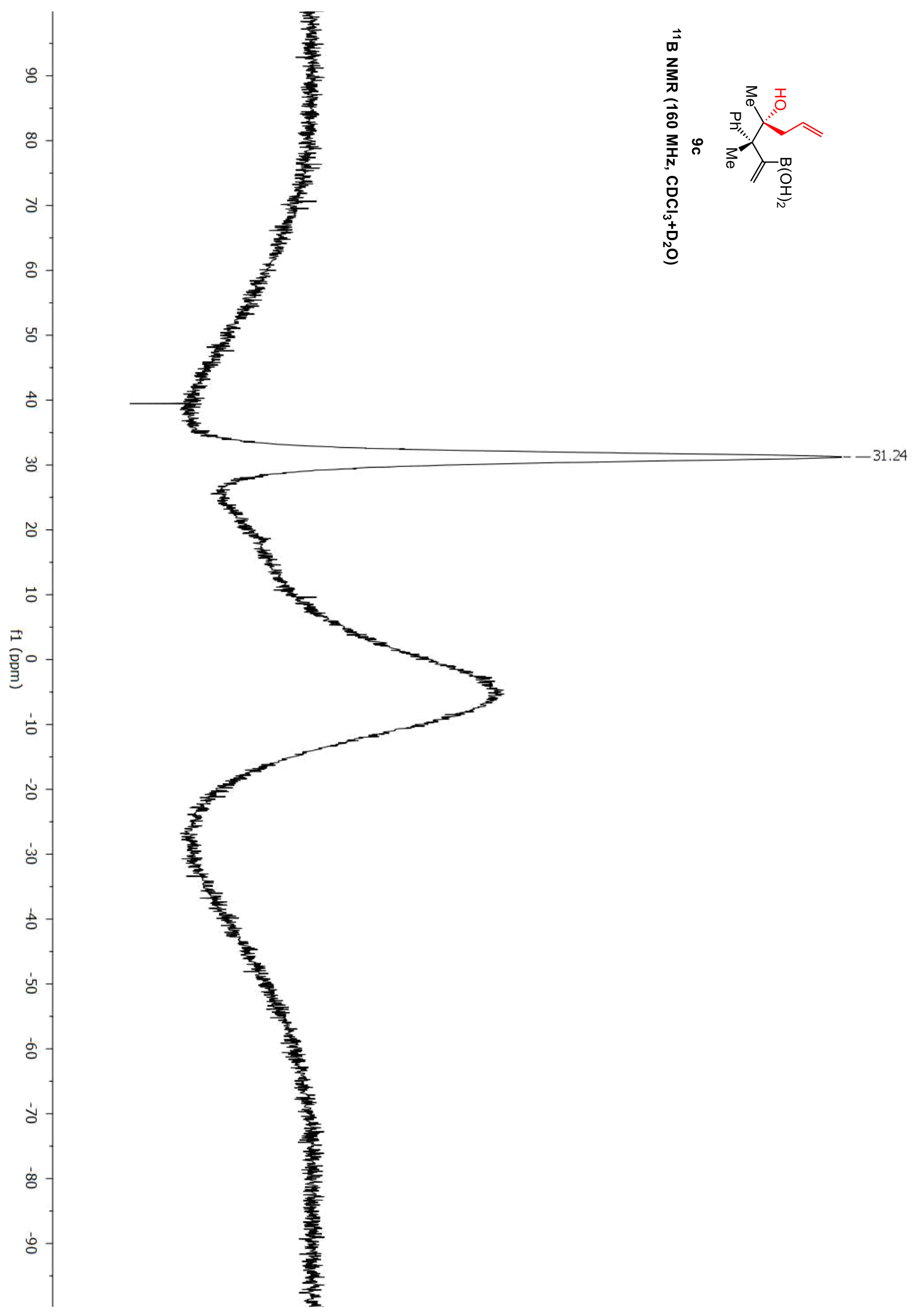




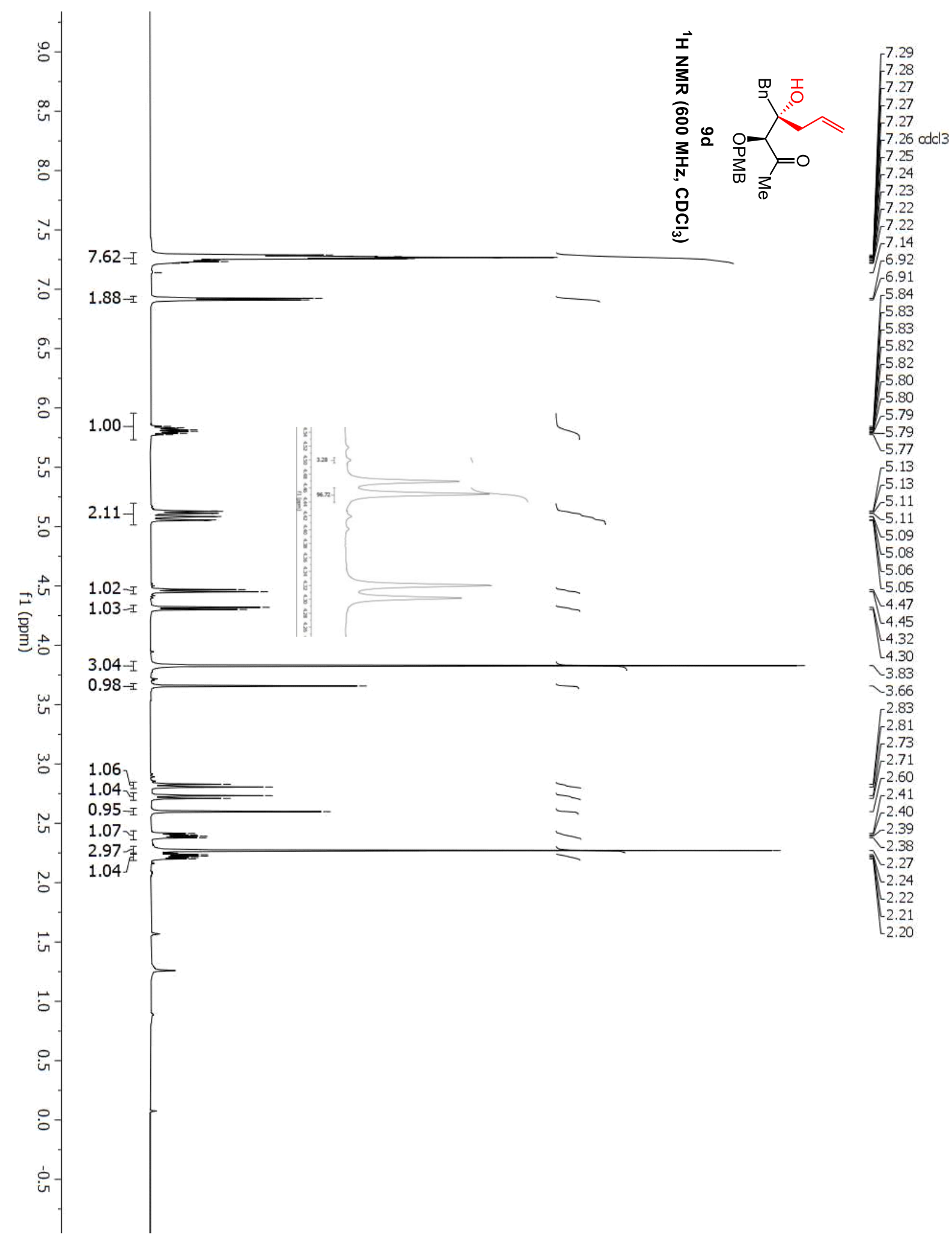




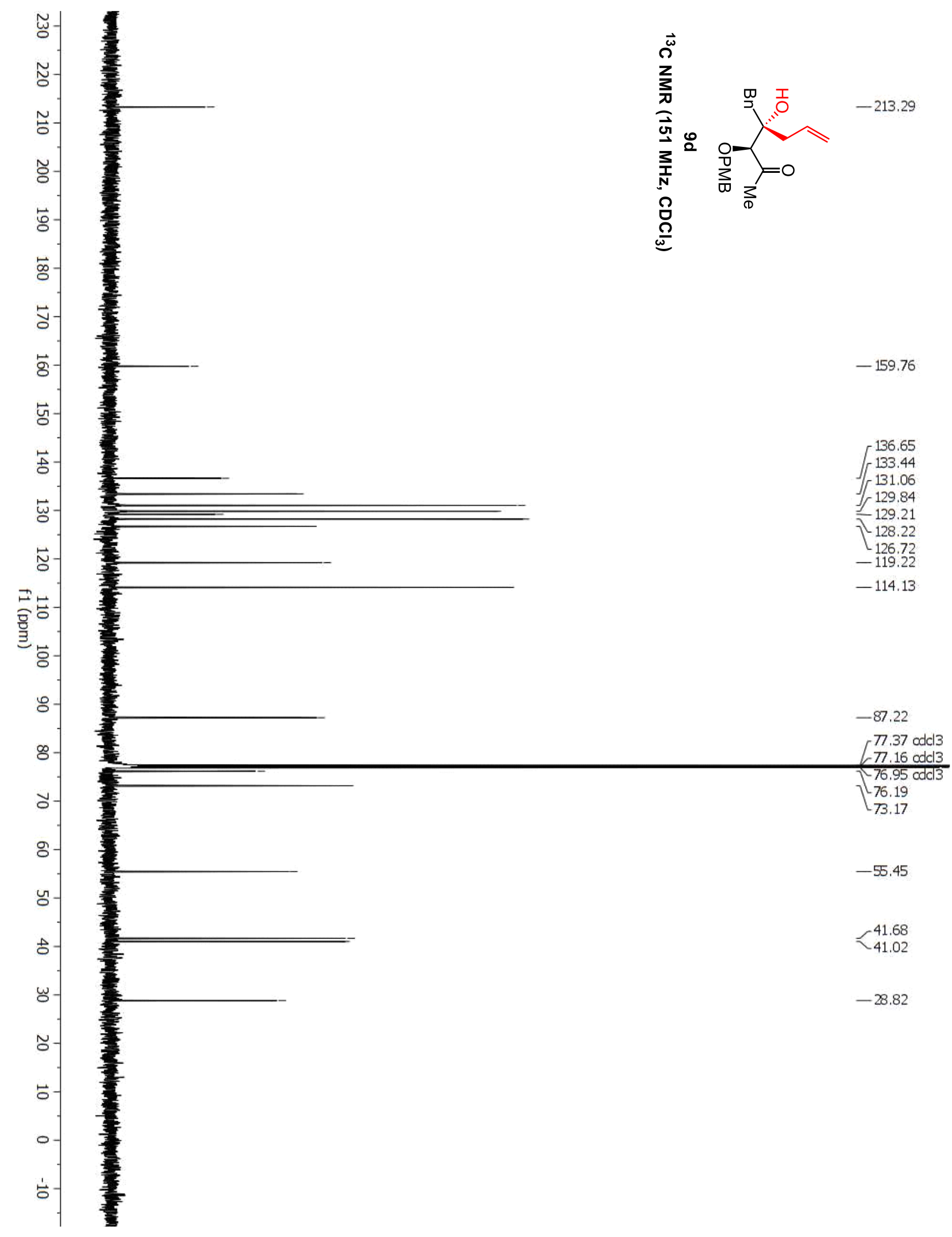




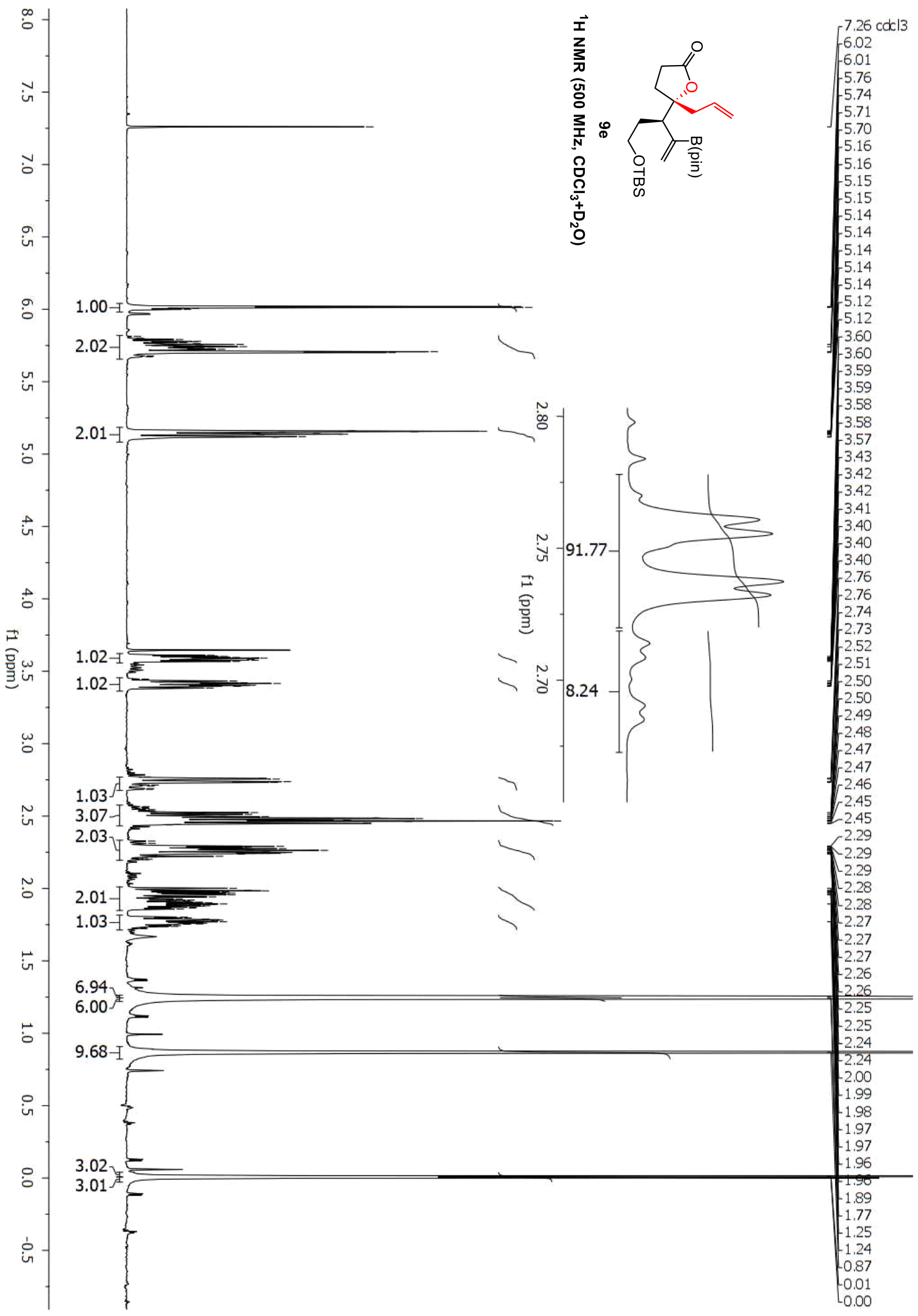




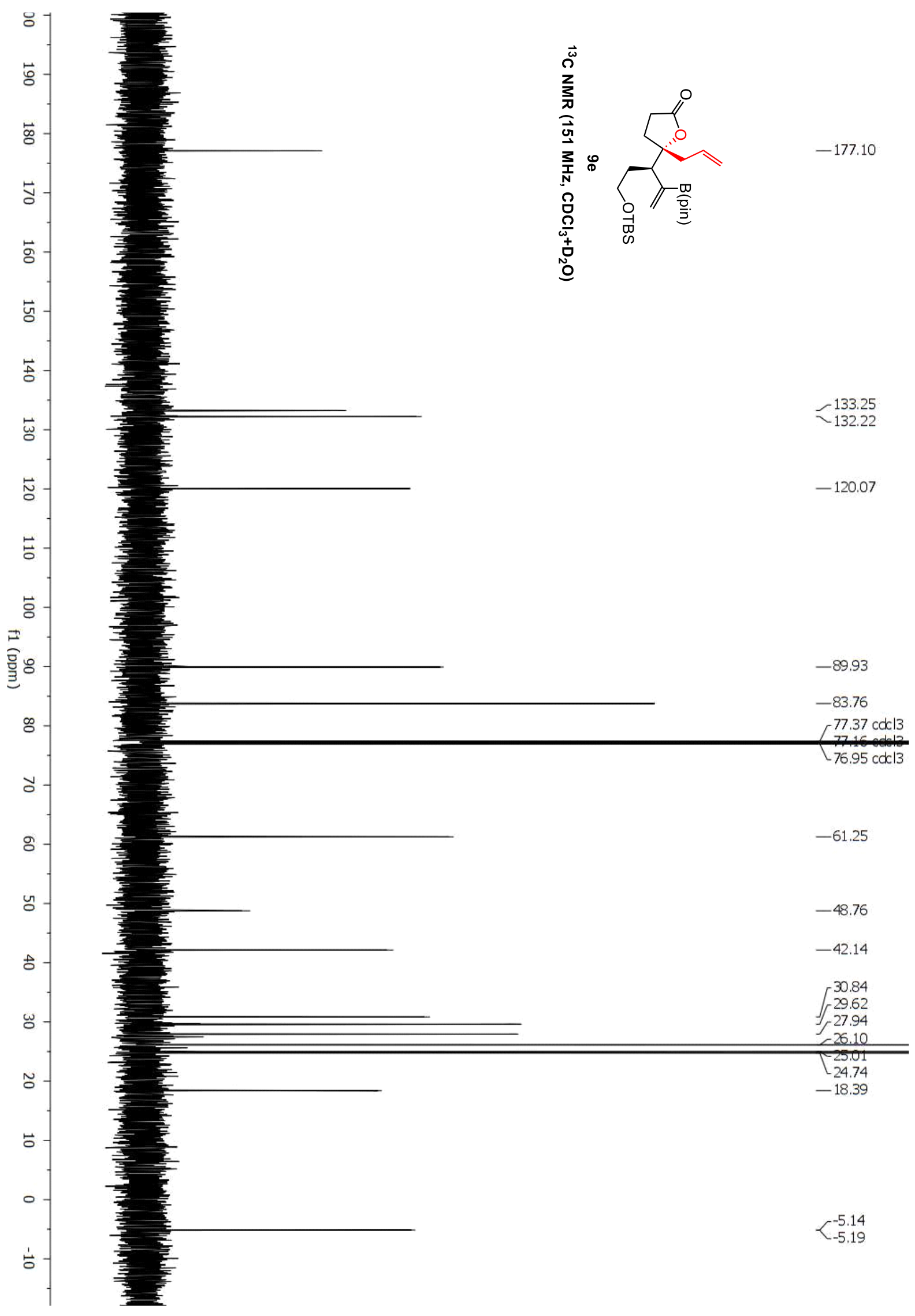




$$
\{
$$




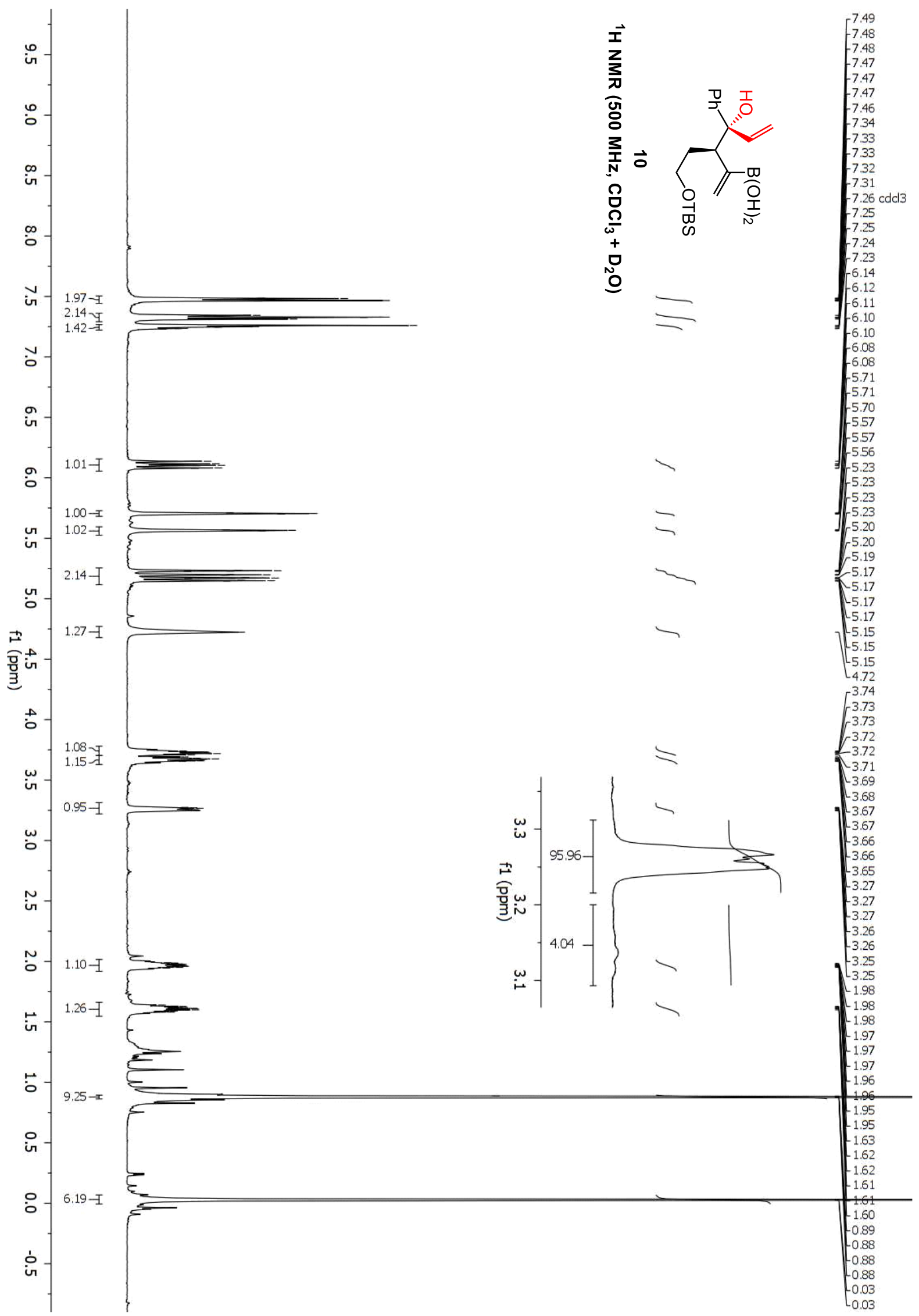




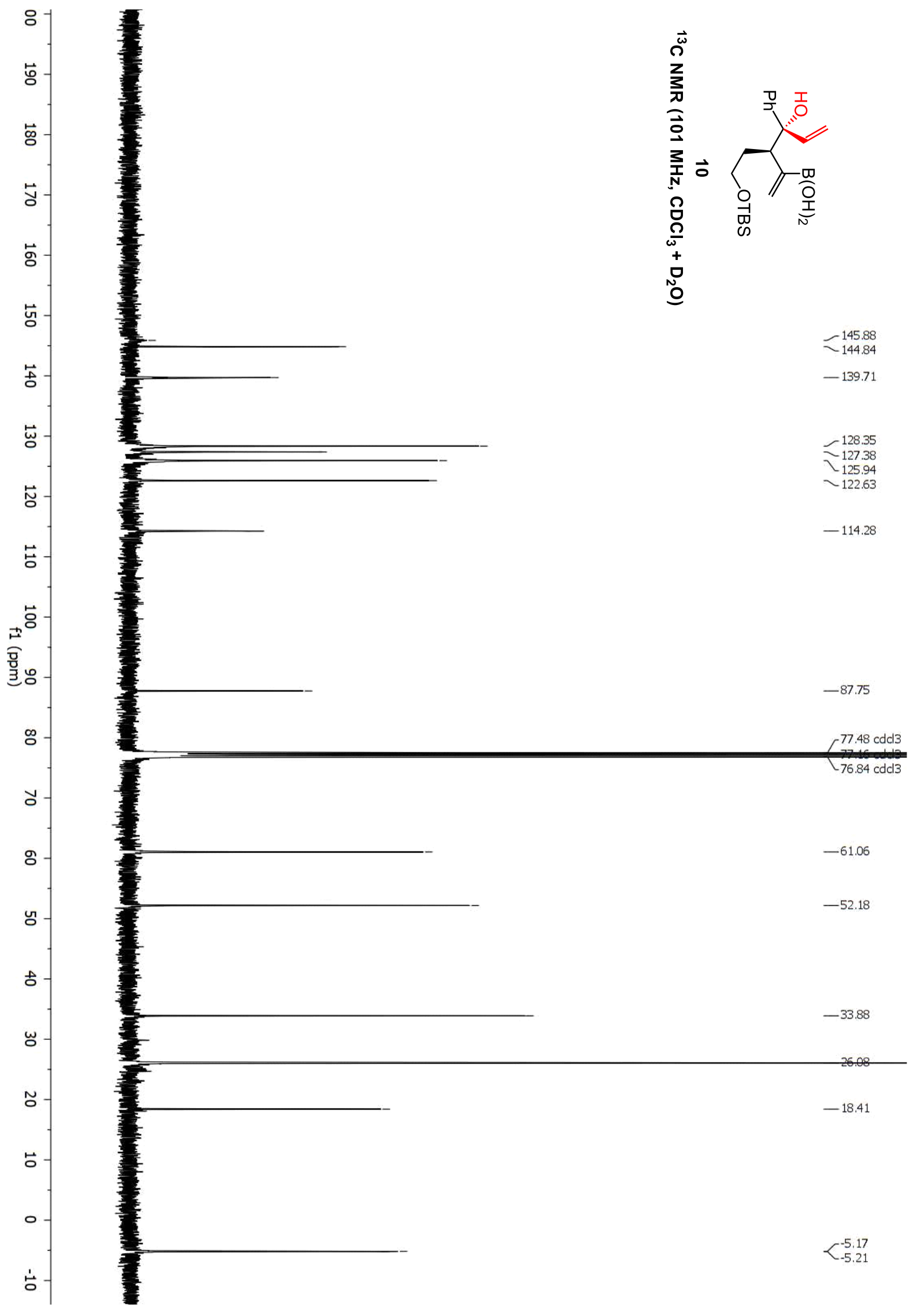


Del Pozo, et al., Supplementary Materials; Page 301

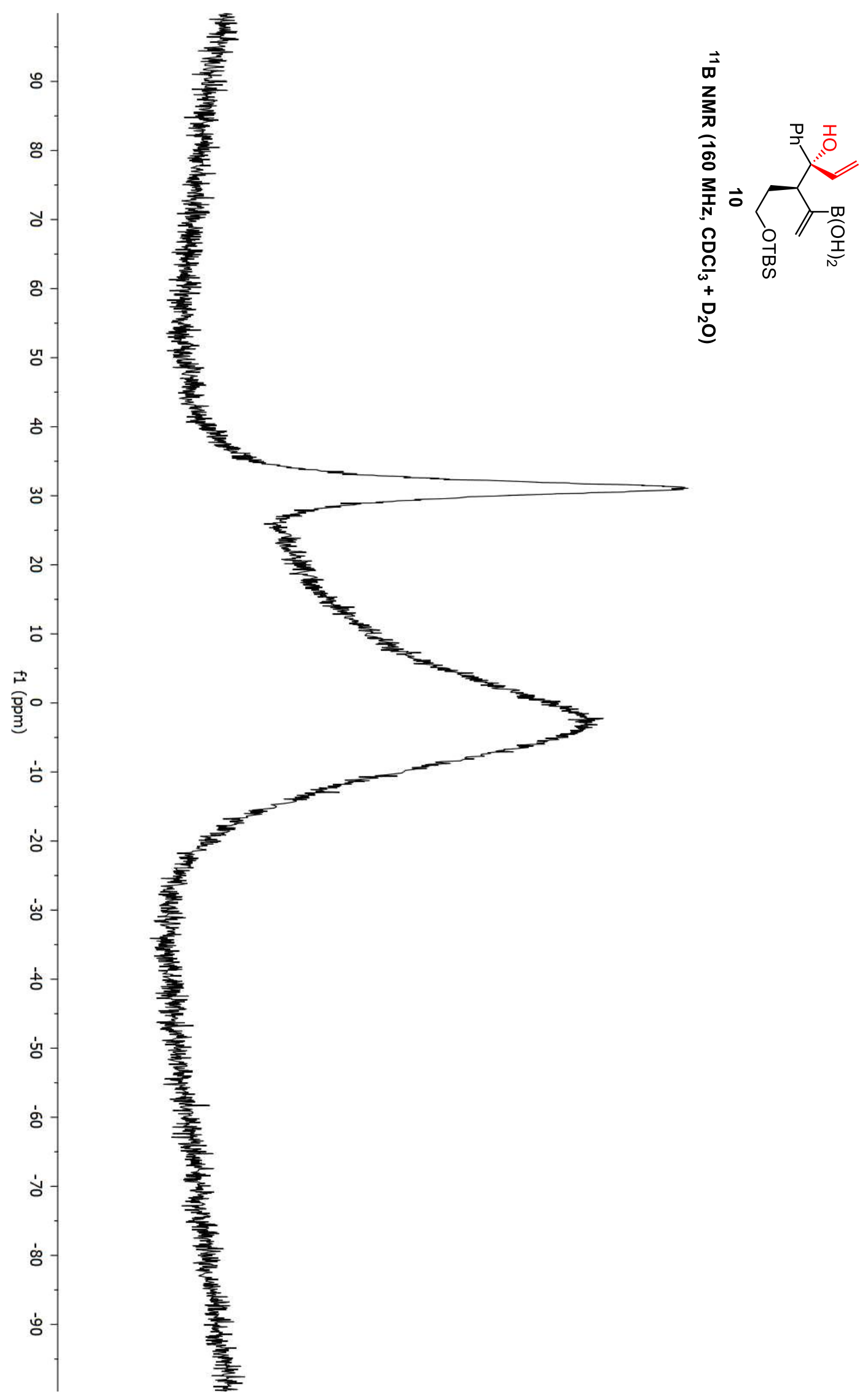

$-31.08$ 


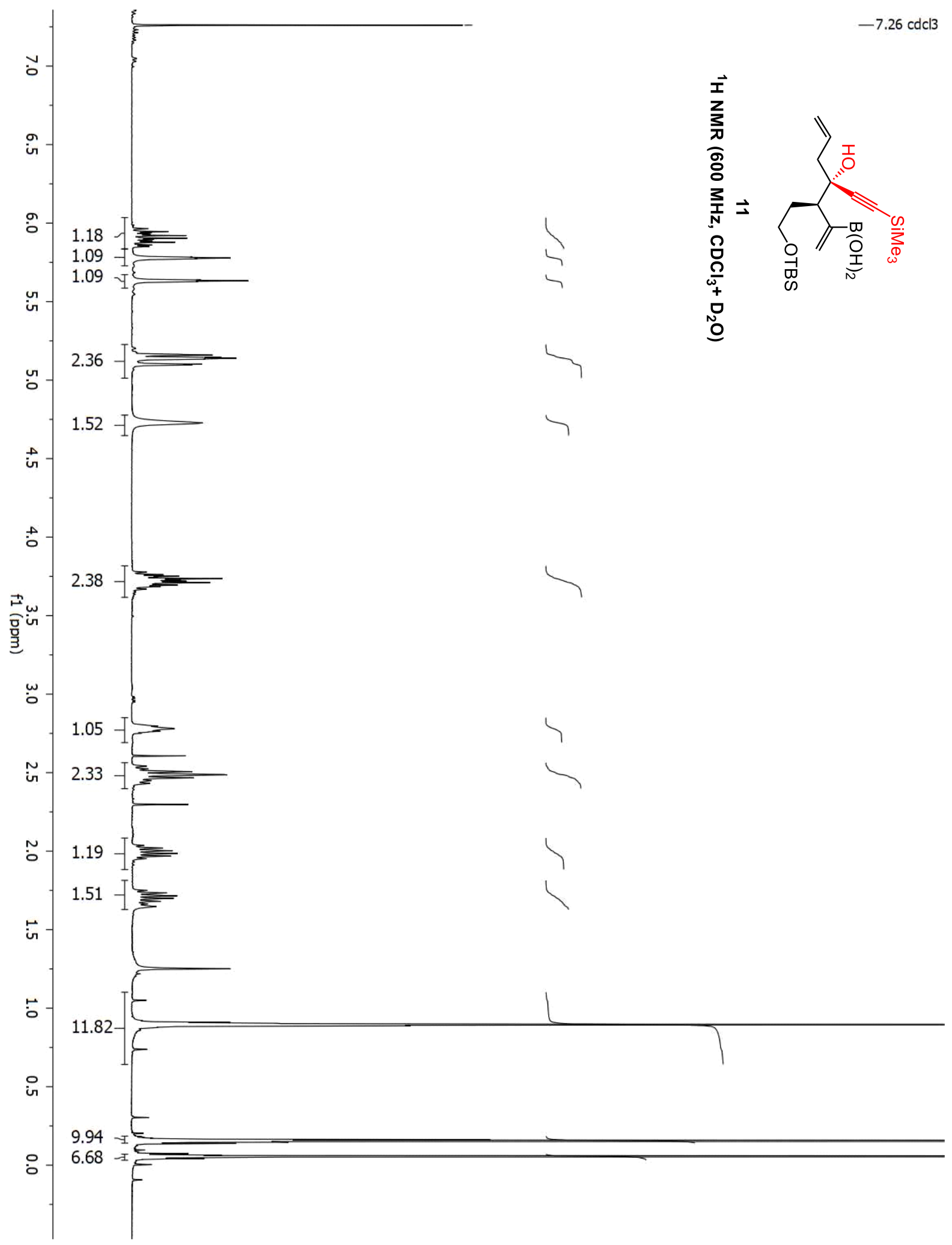




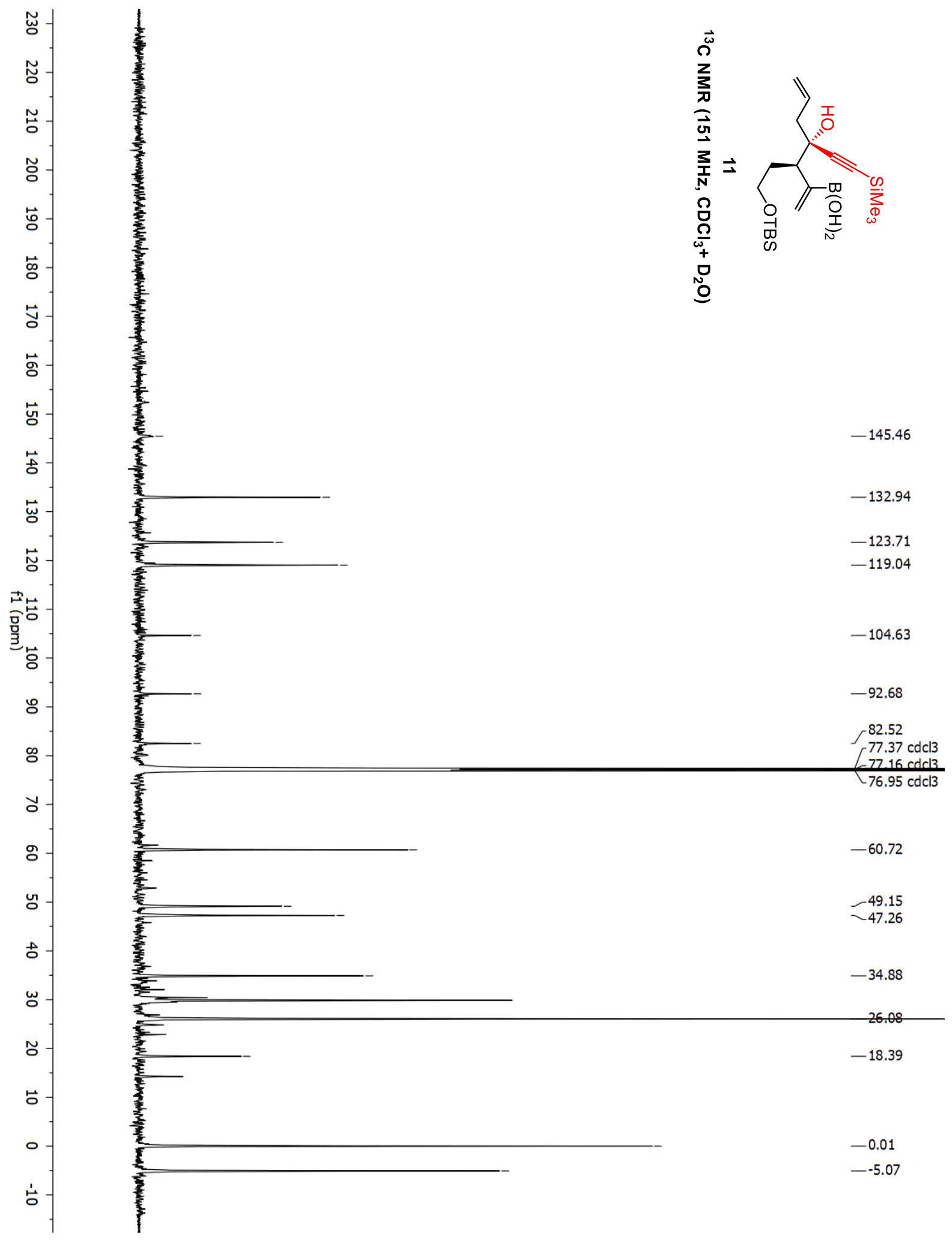


Del Poo, et al., Supplementary Materials; Page 304

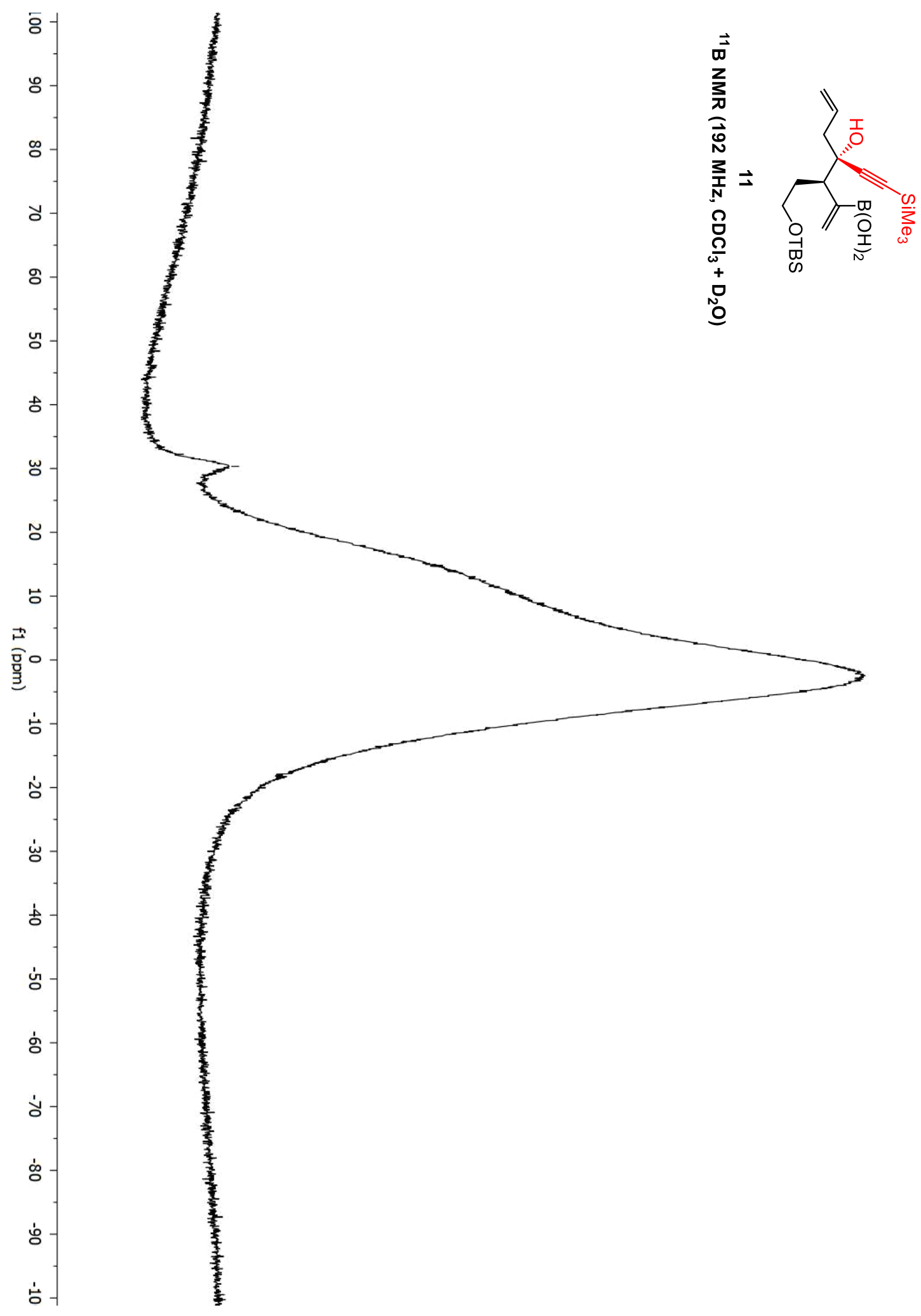

$-30.34$ 


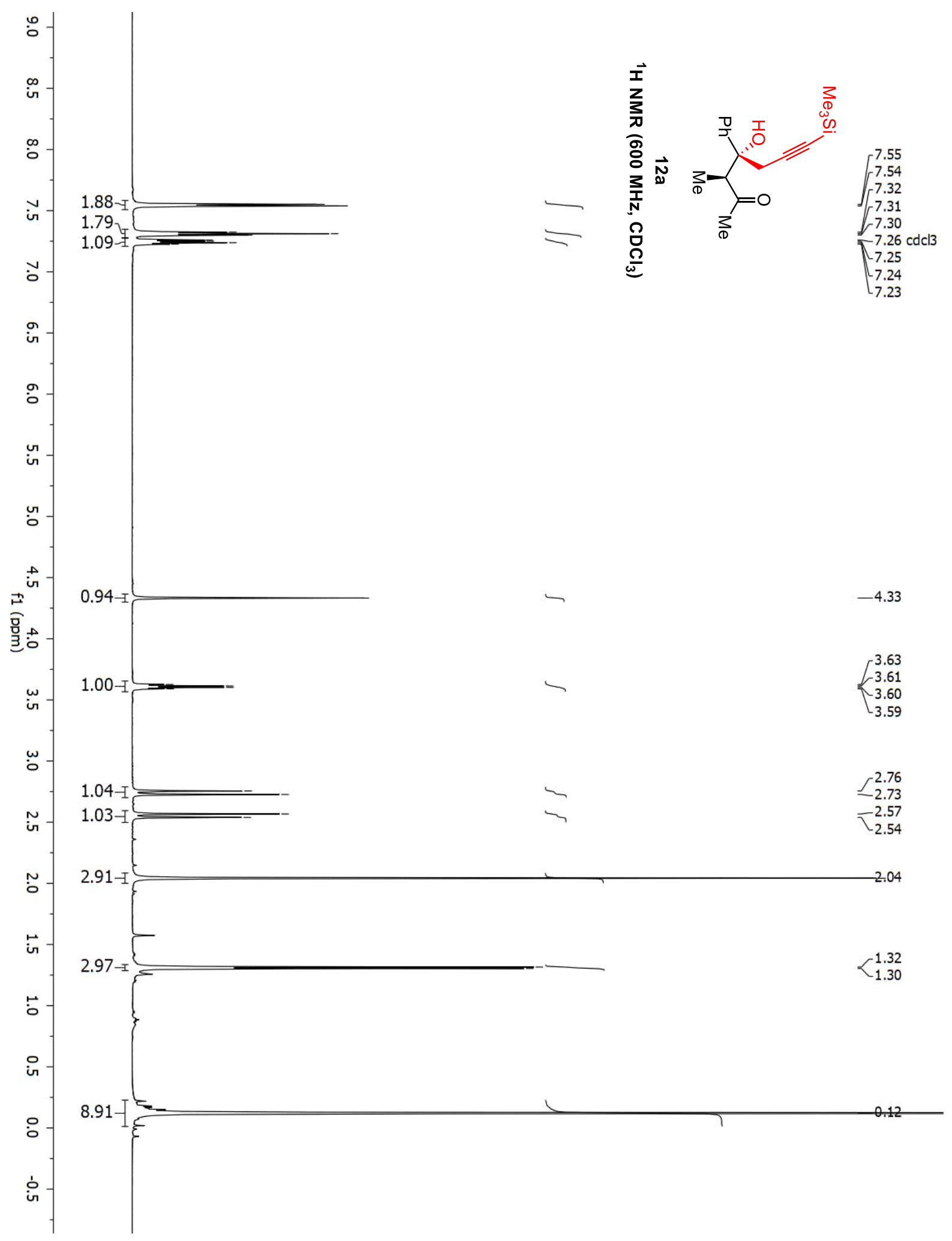




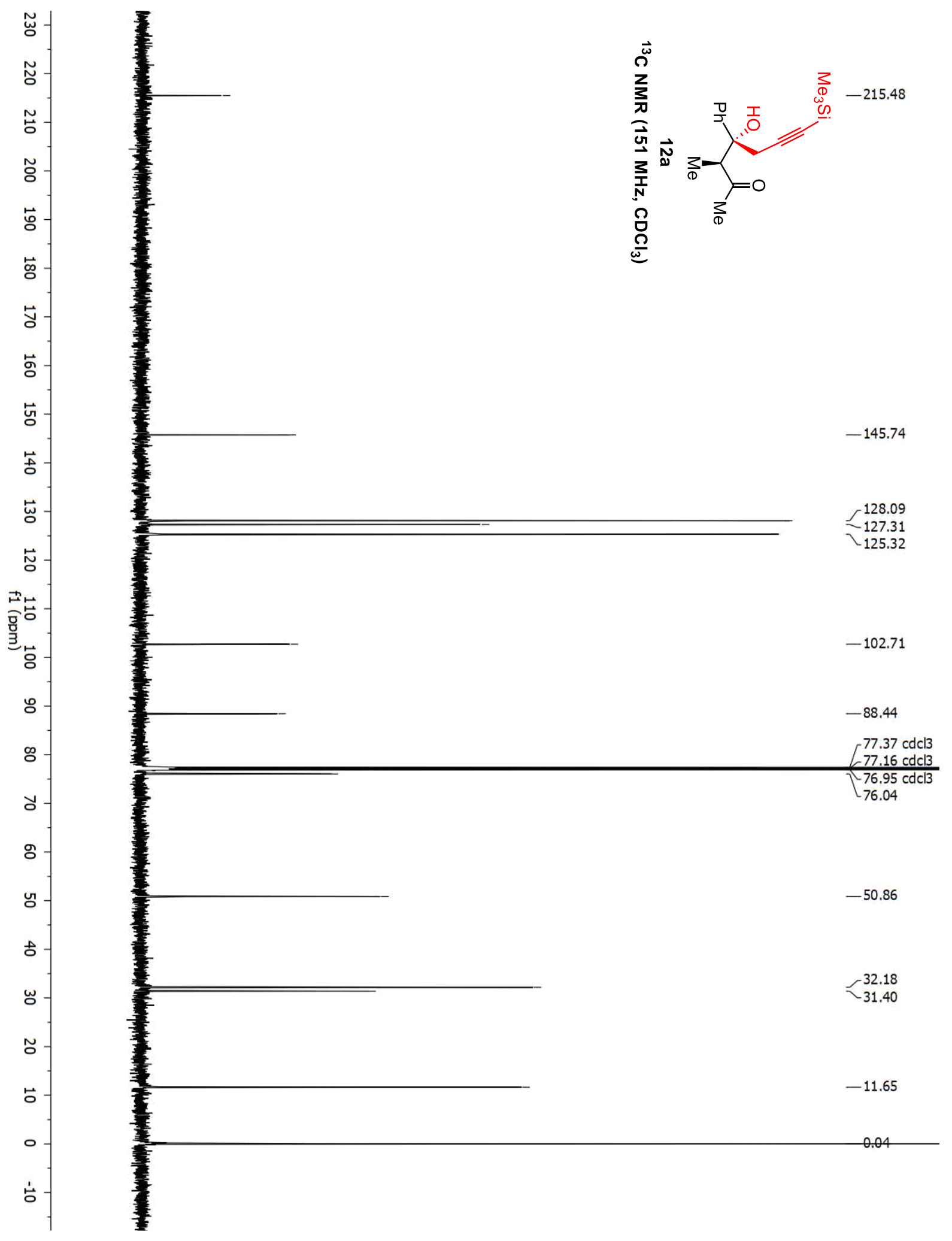




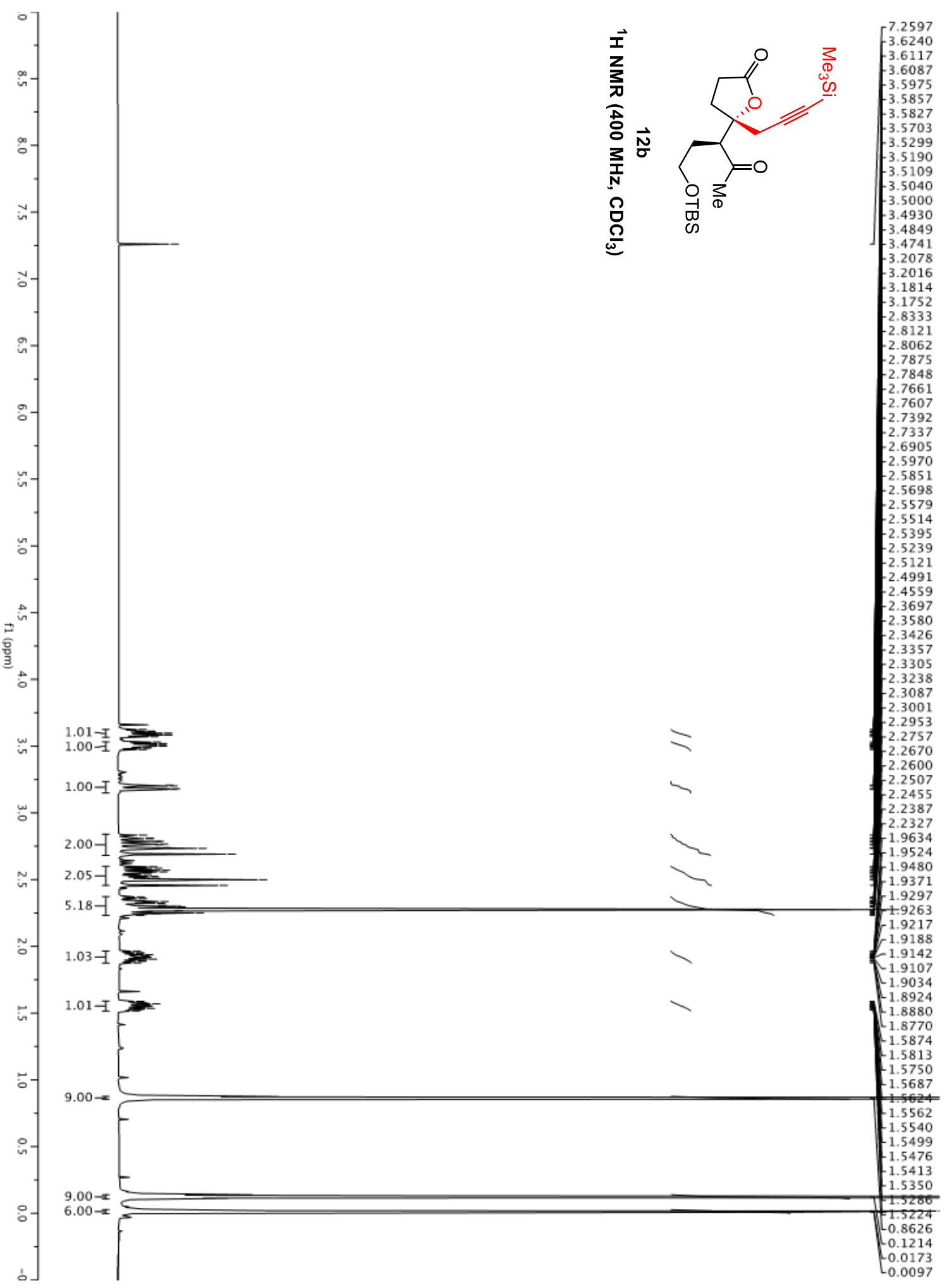


Del Pozo, et al., Supplementary Materials; Page 308

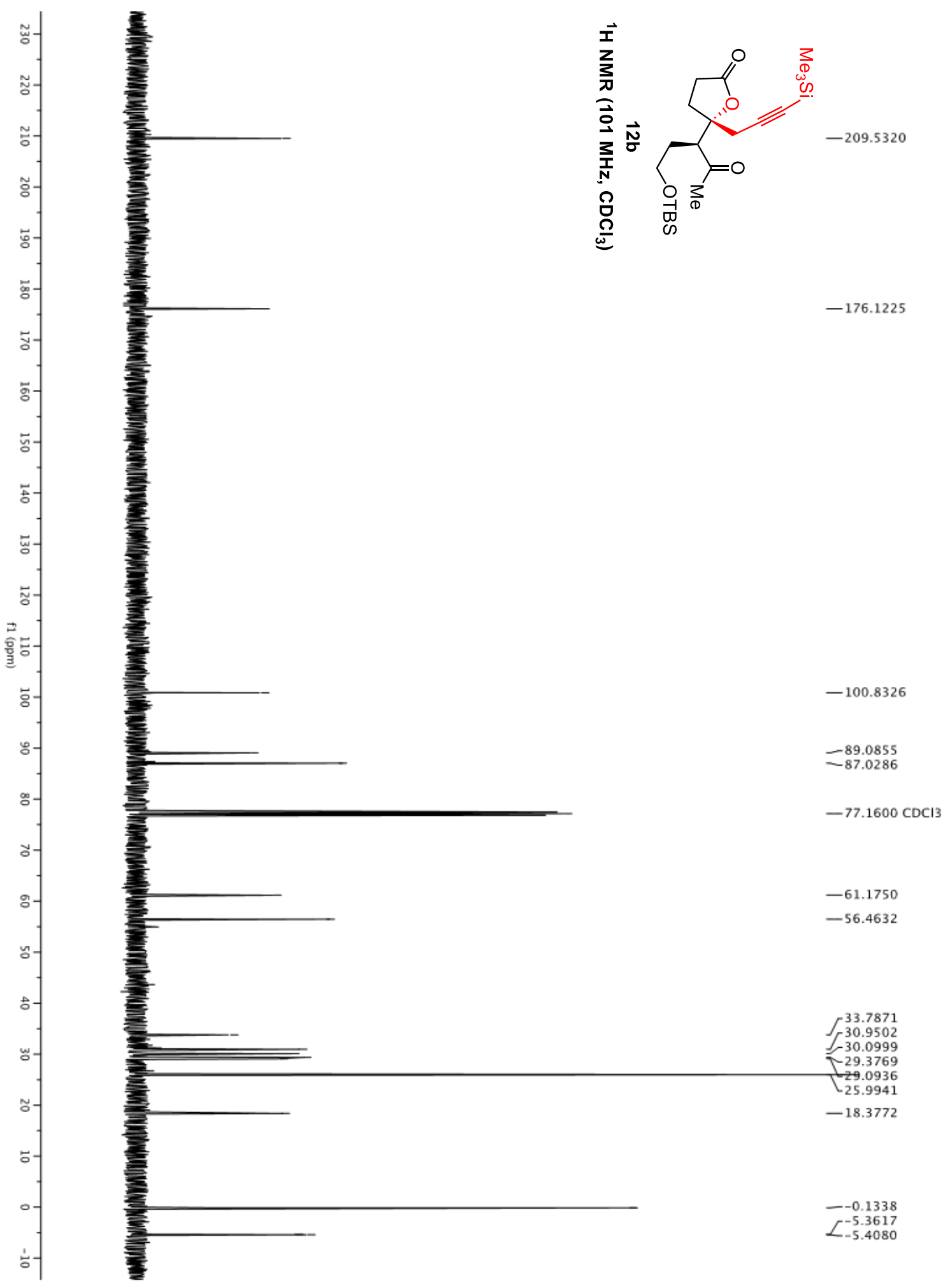




\subsection{Representative functionalizations}

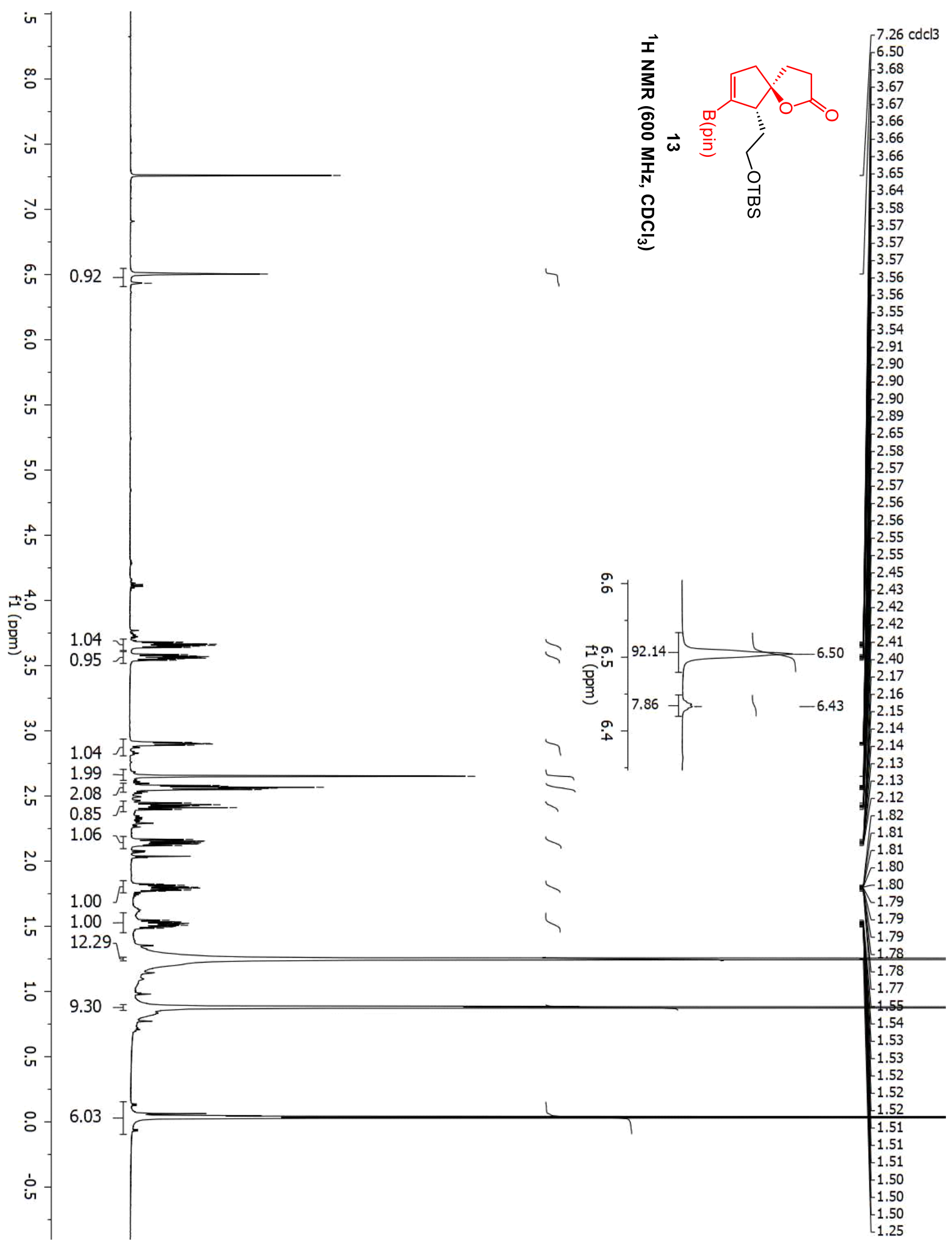




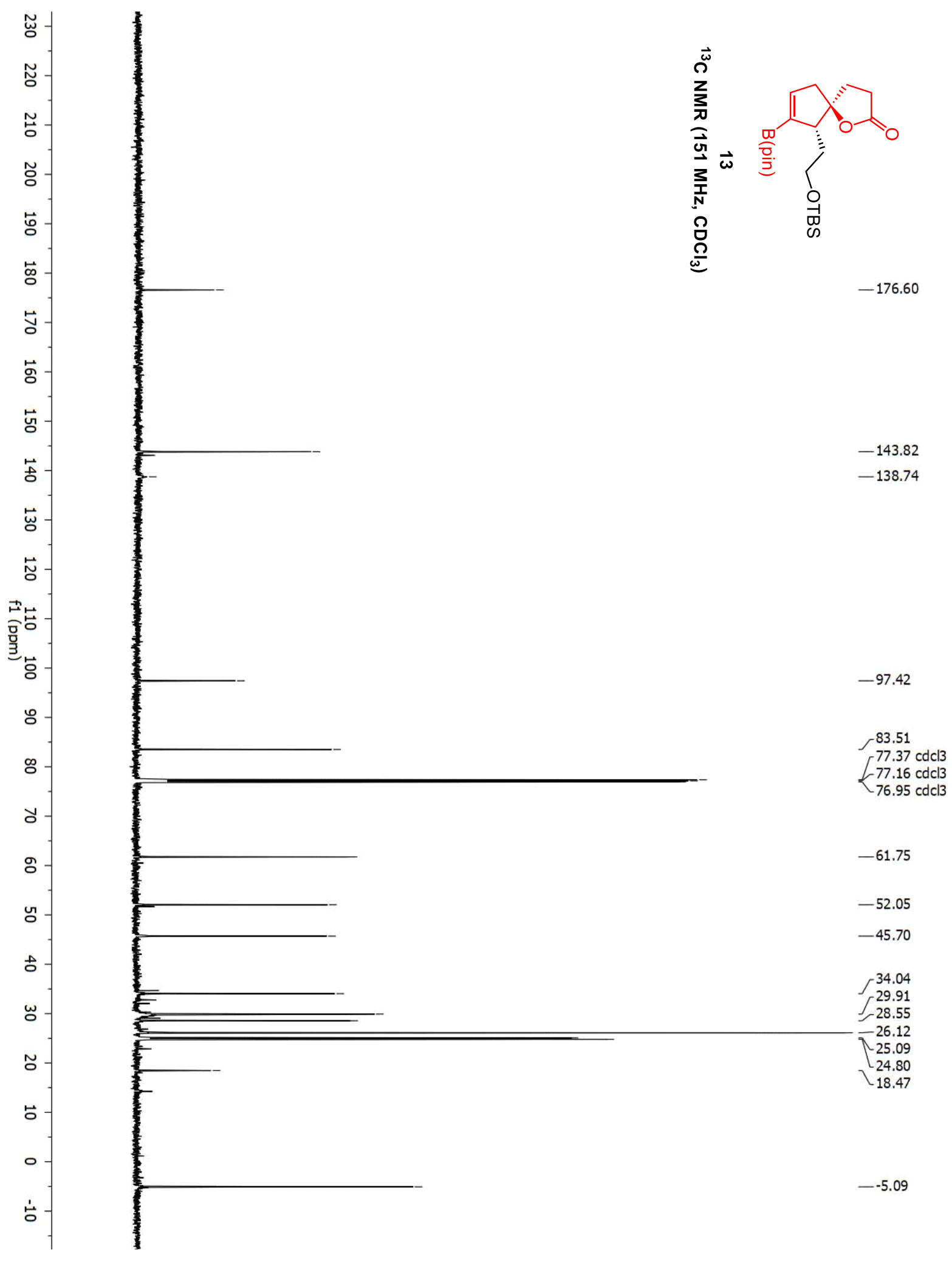



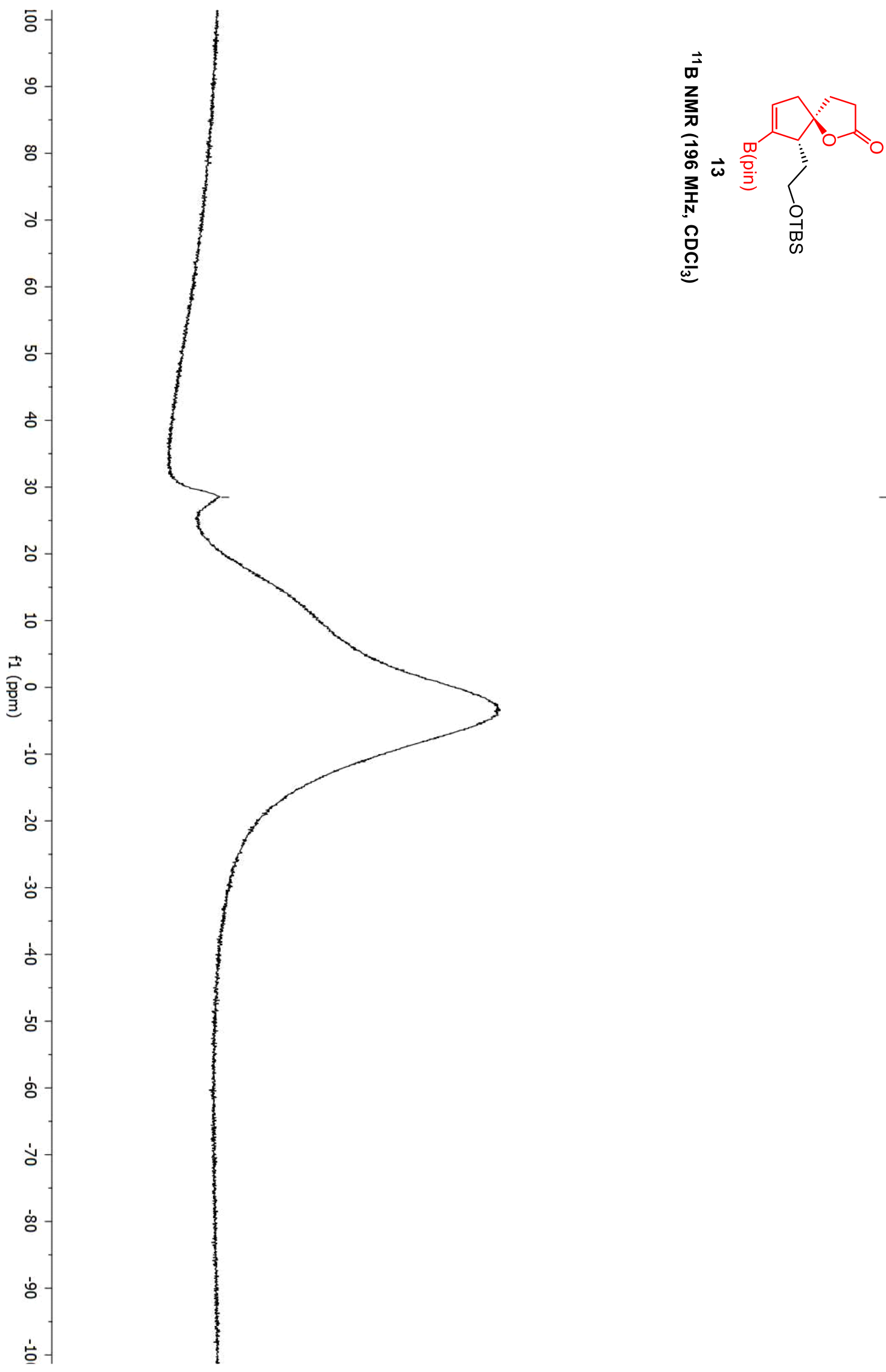


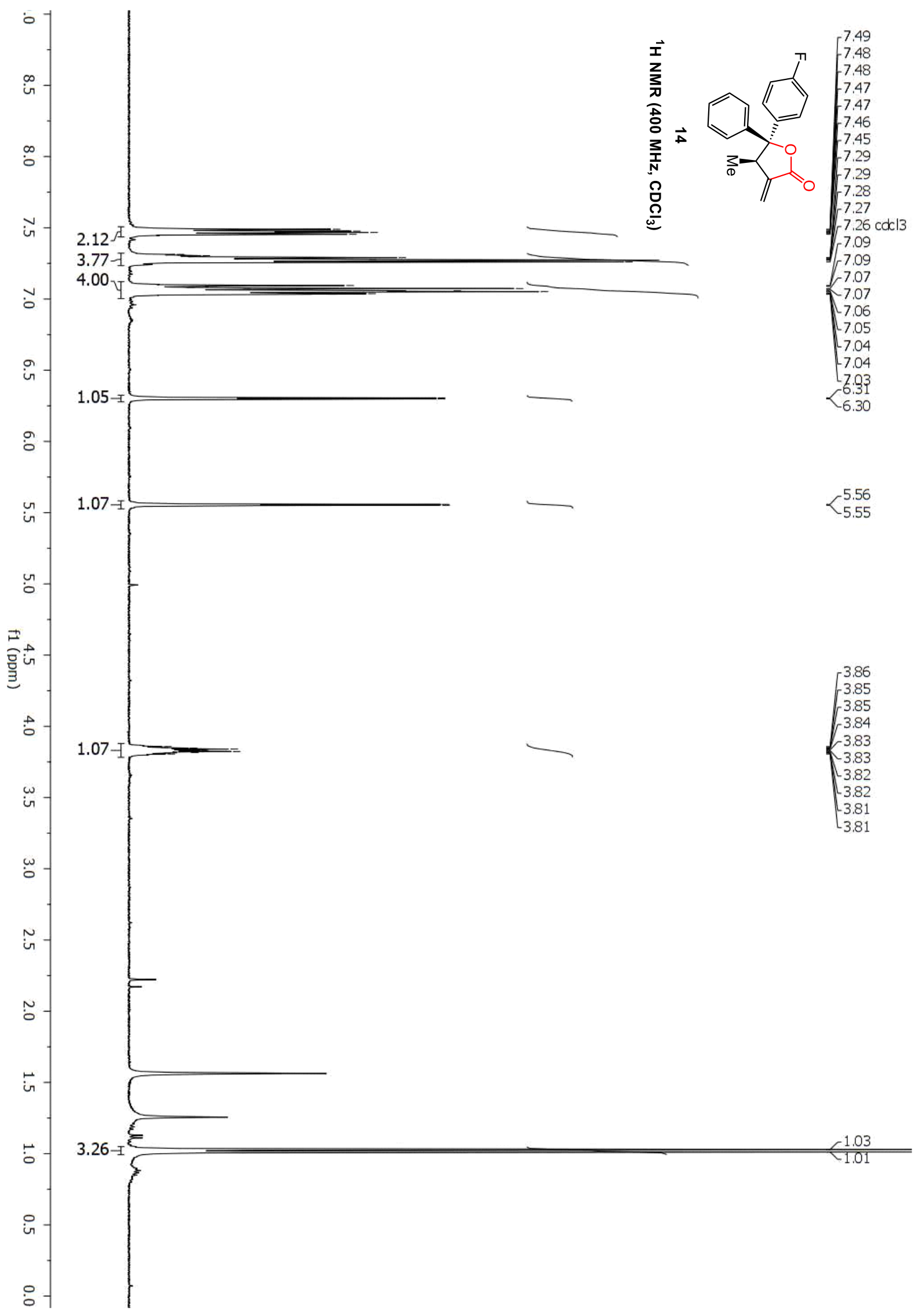




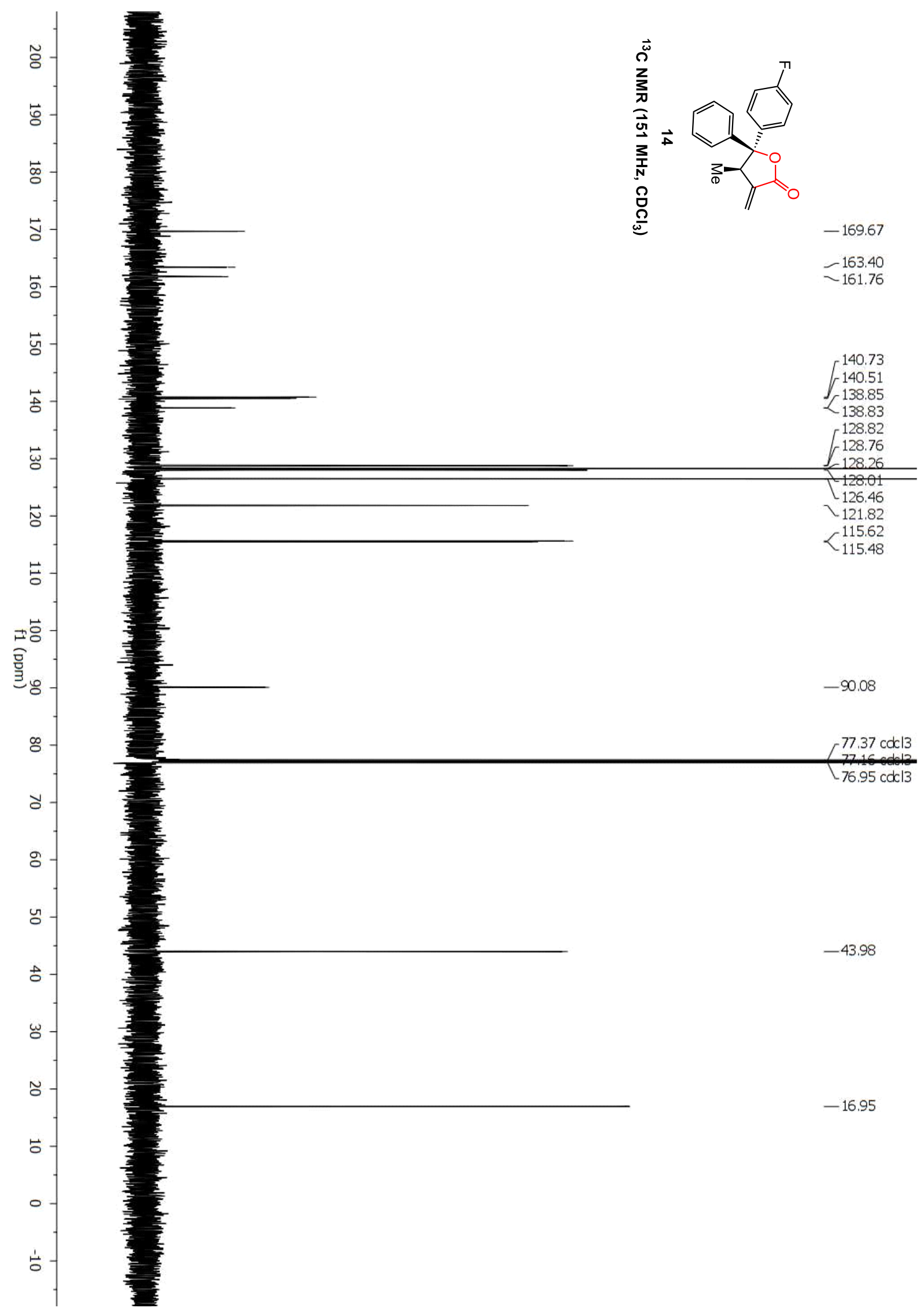




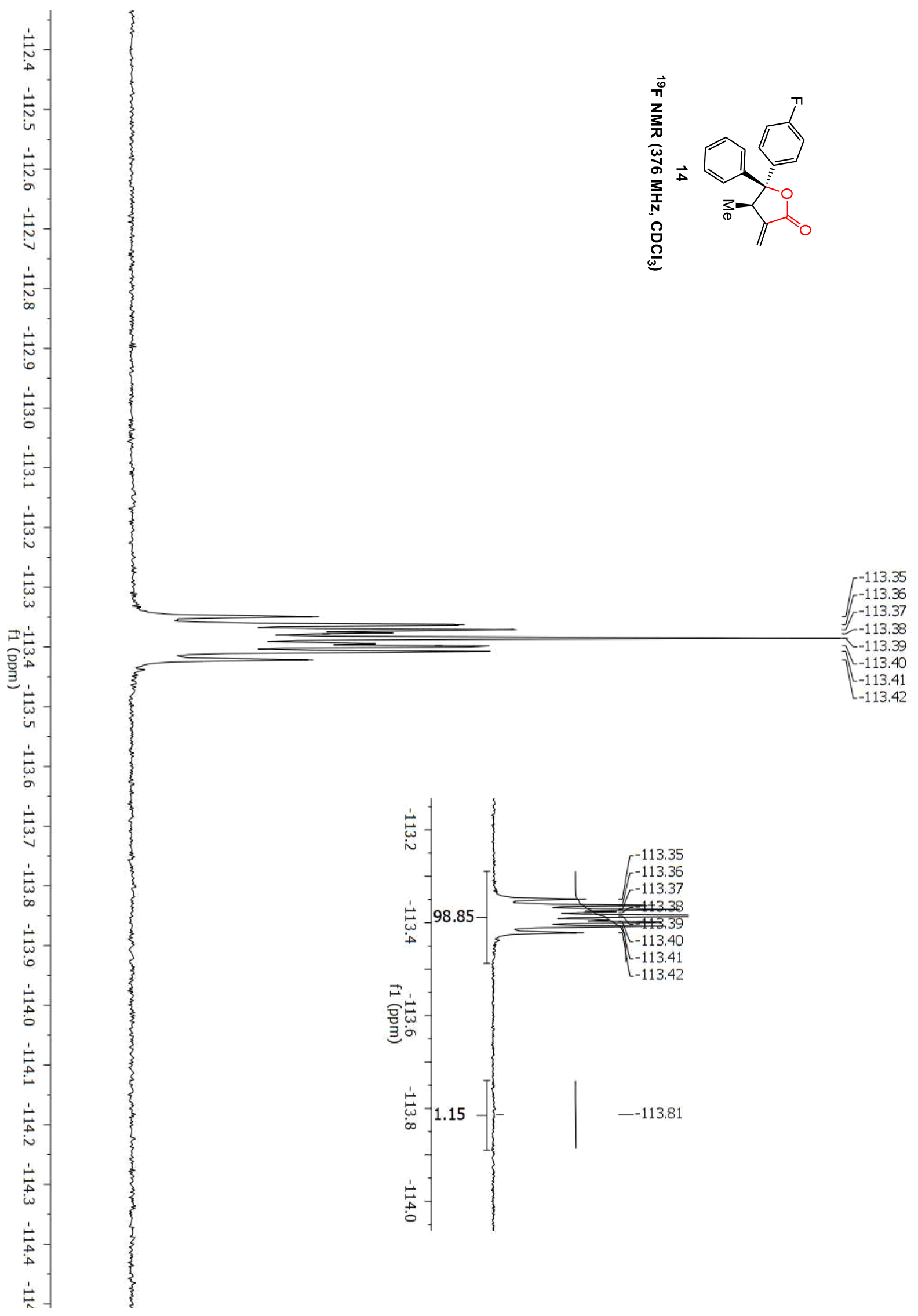




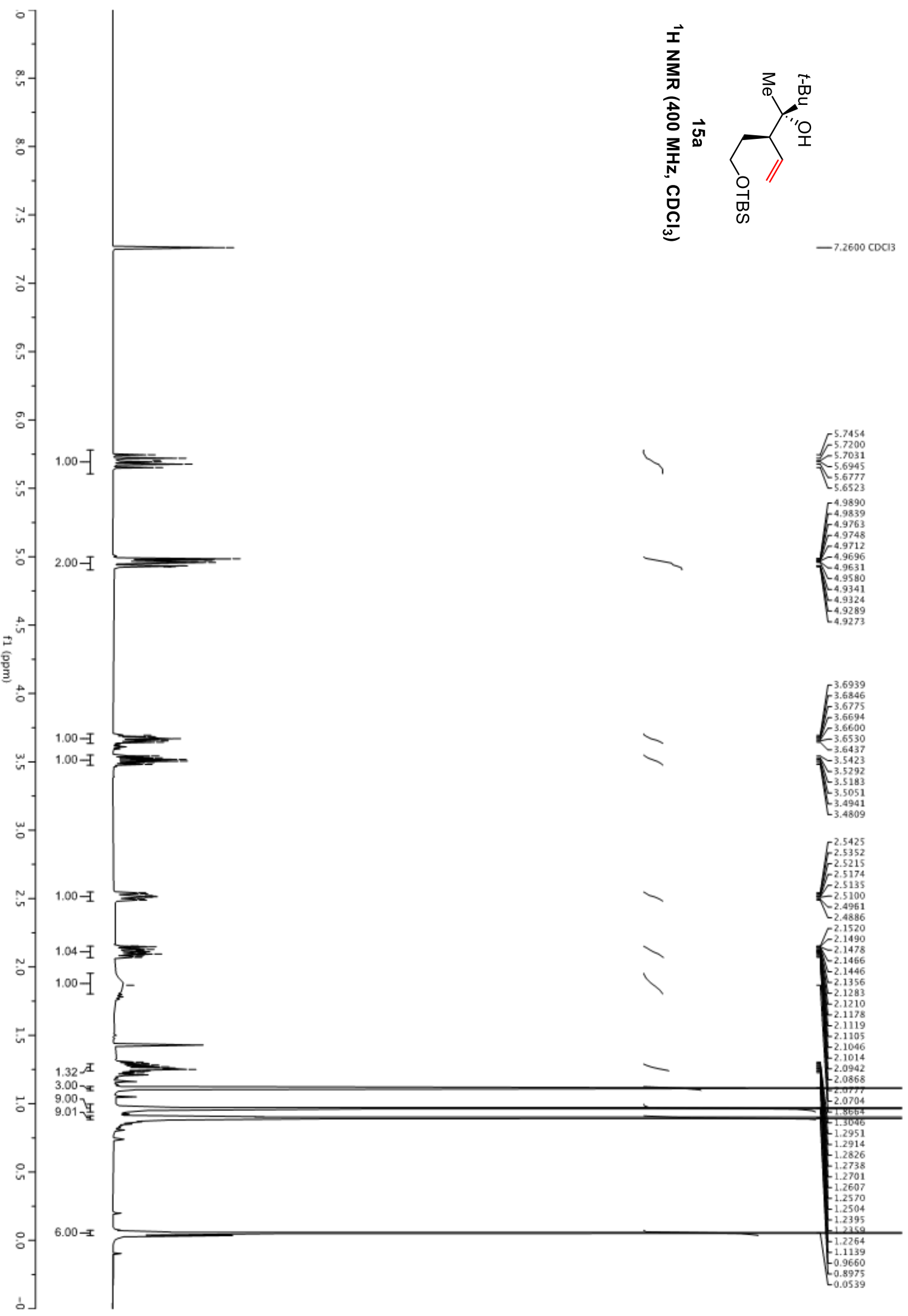


Del Pozo, et al., Supplementary Materials; Page 316

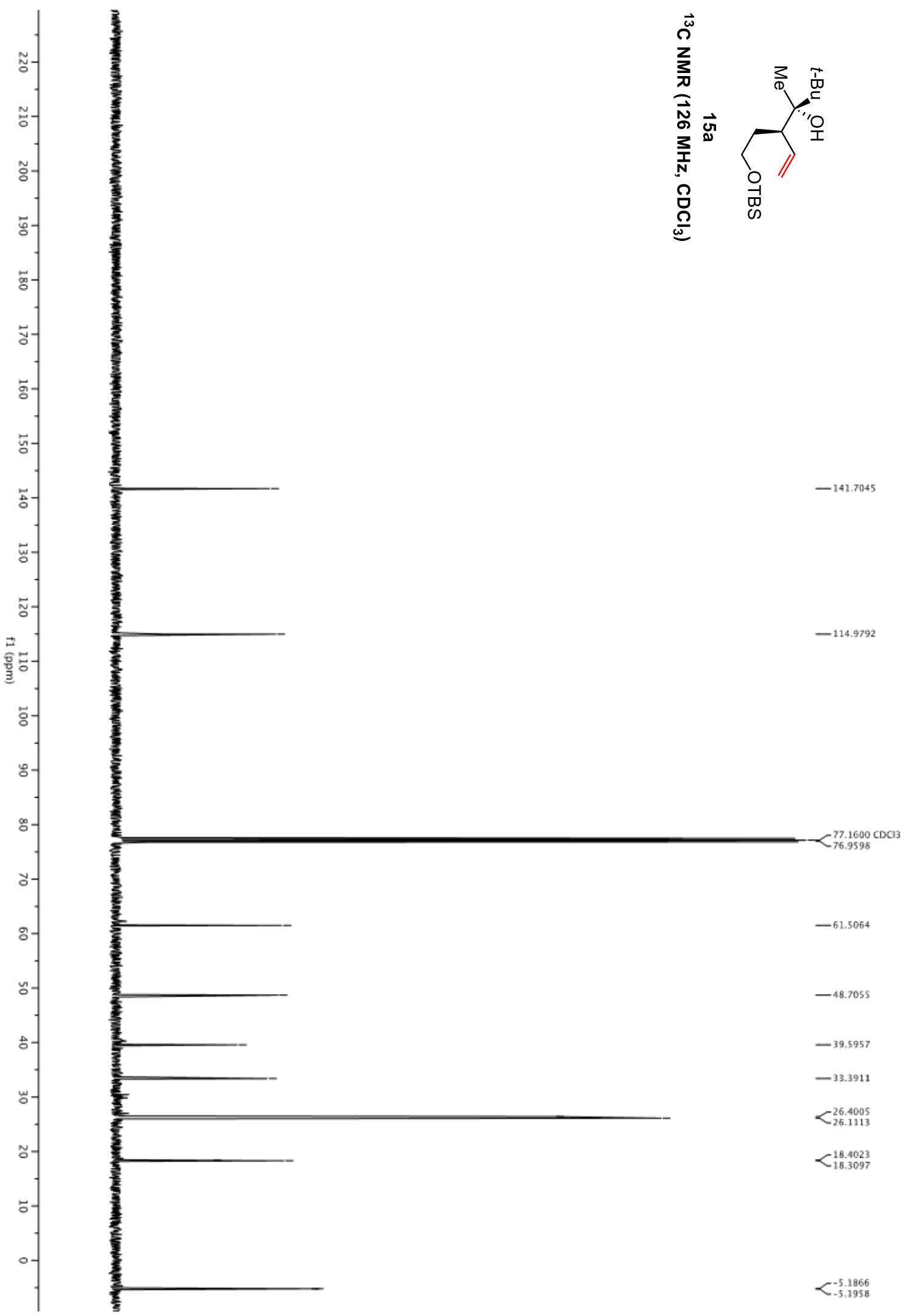




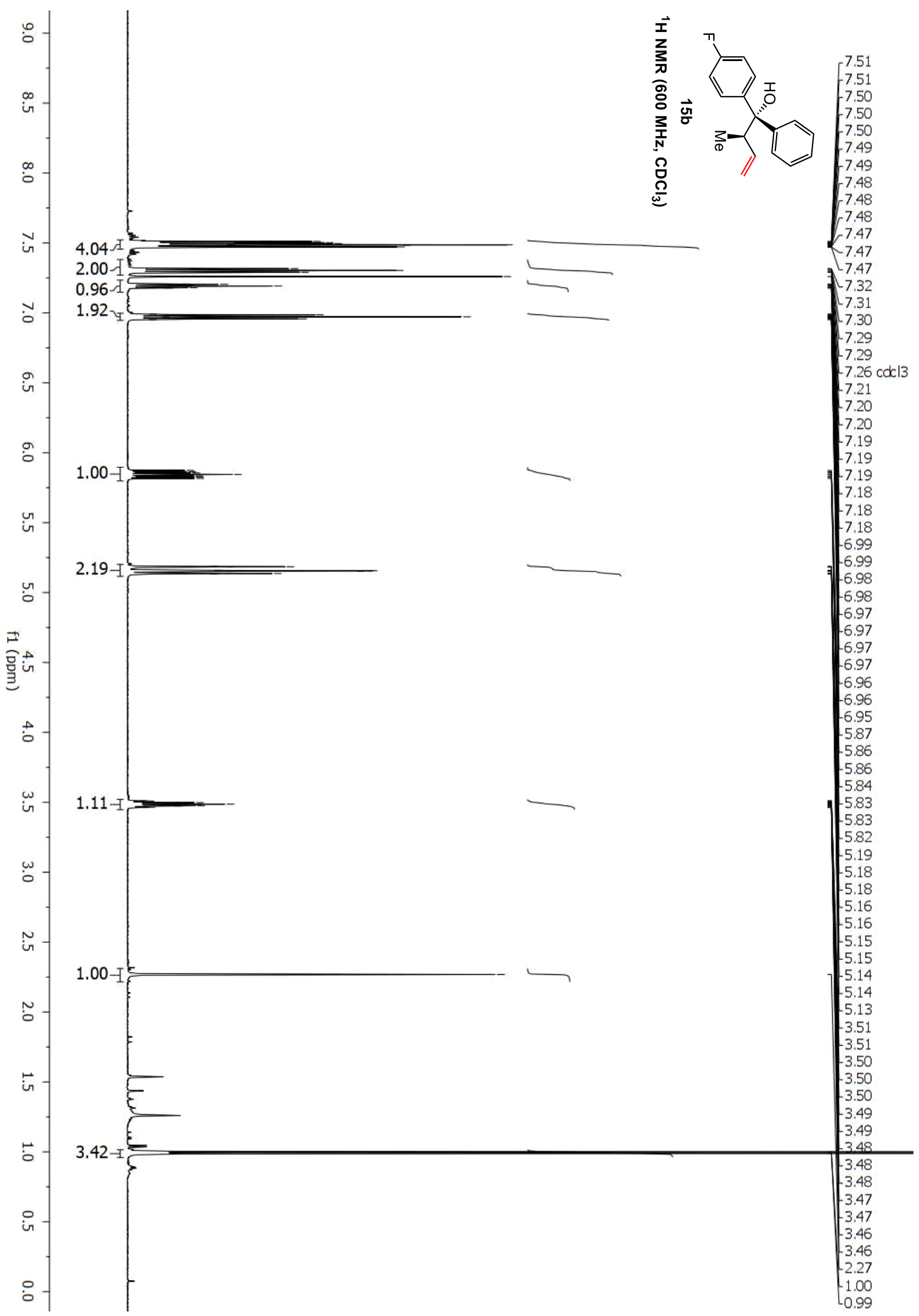




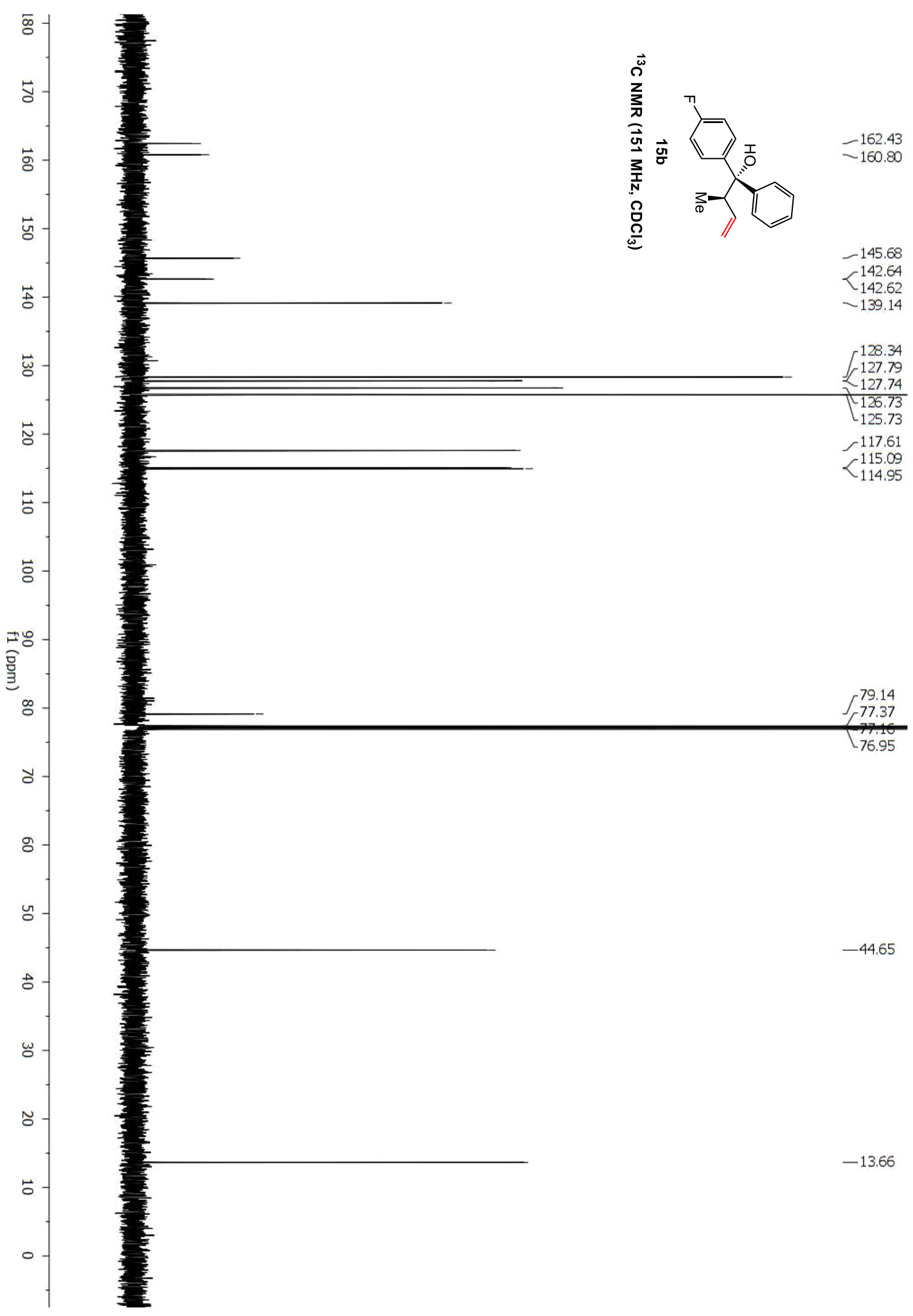




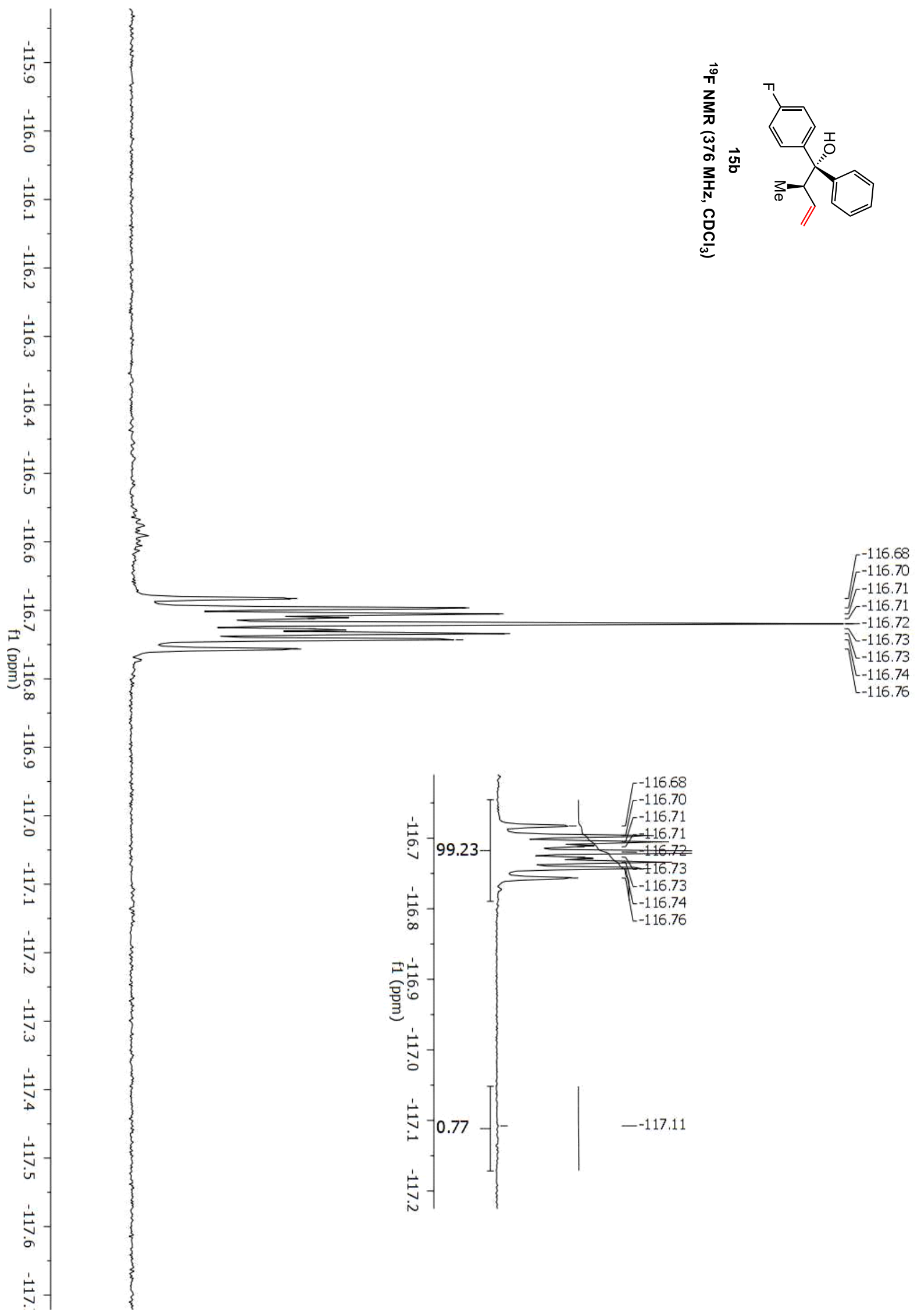




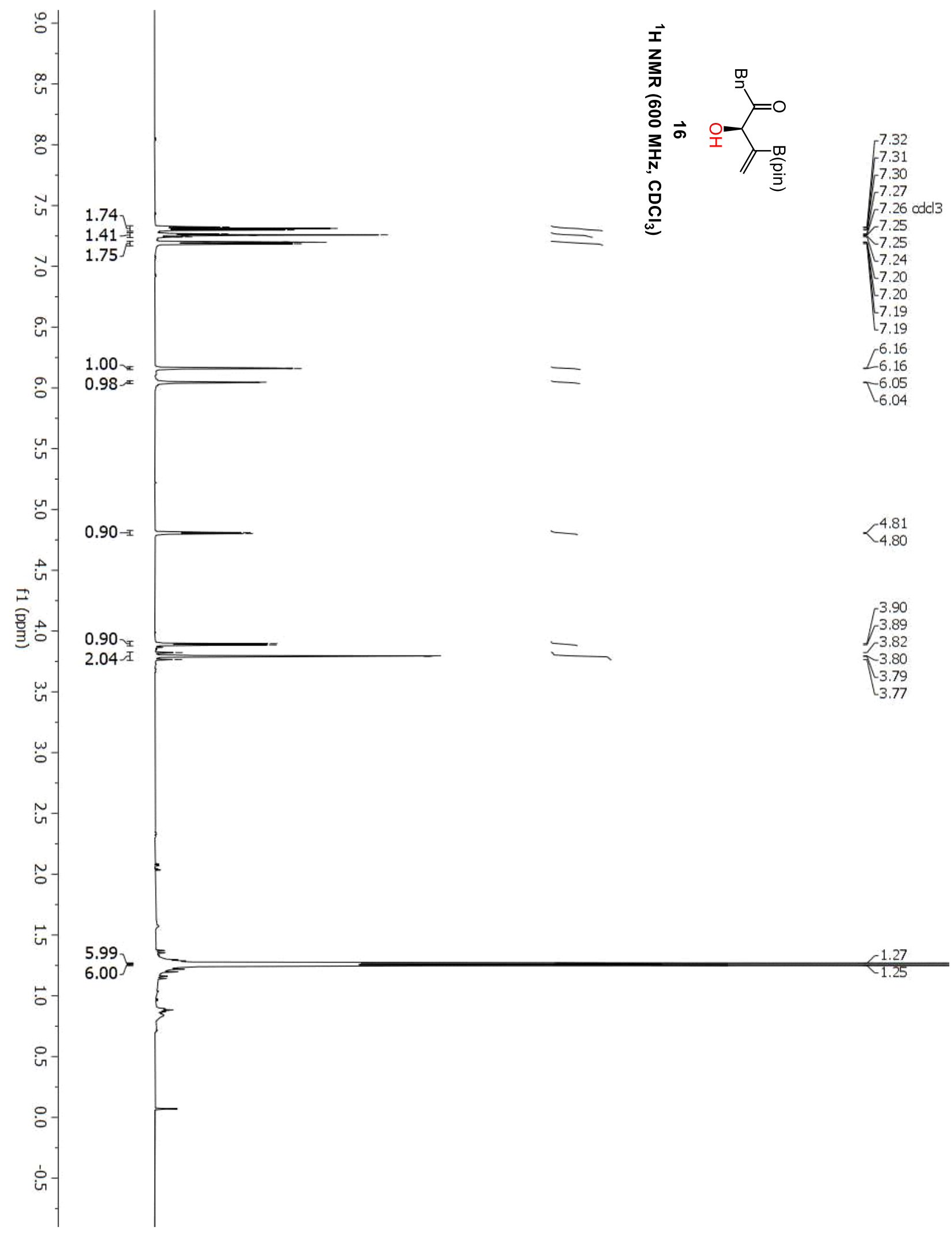




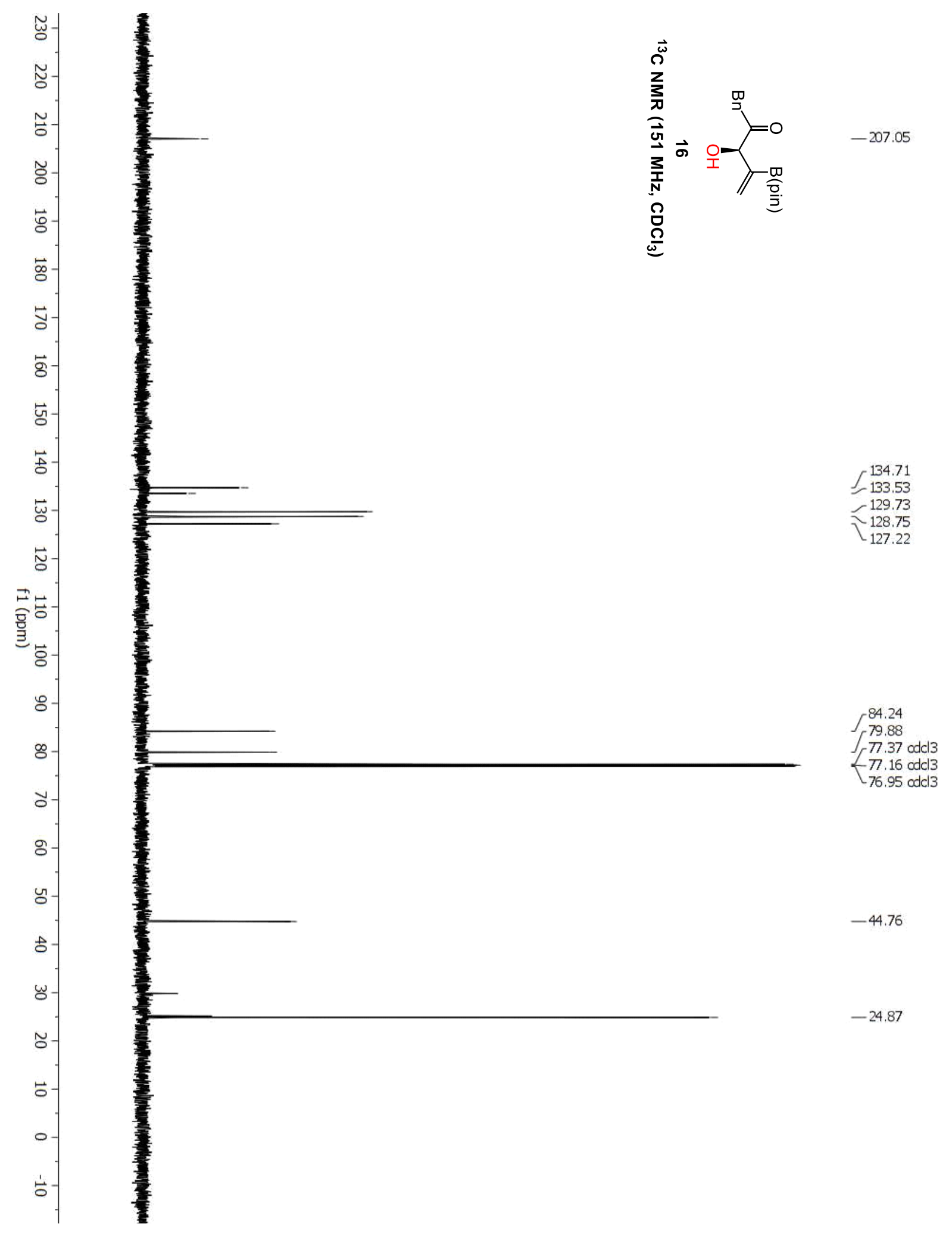



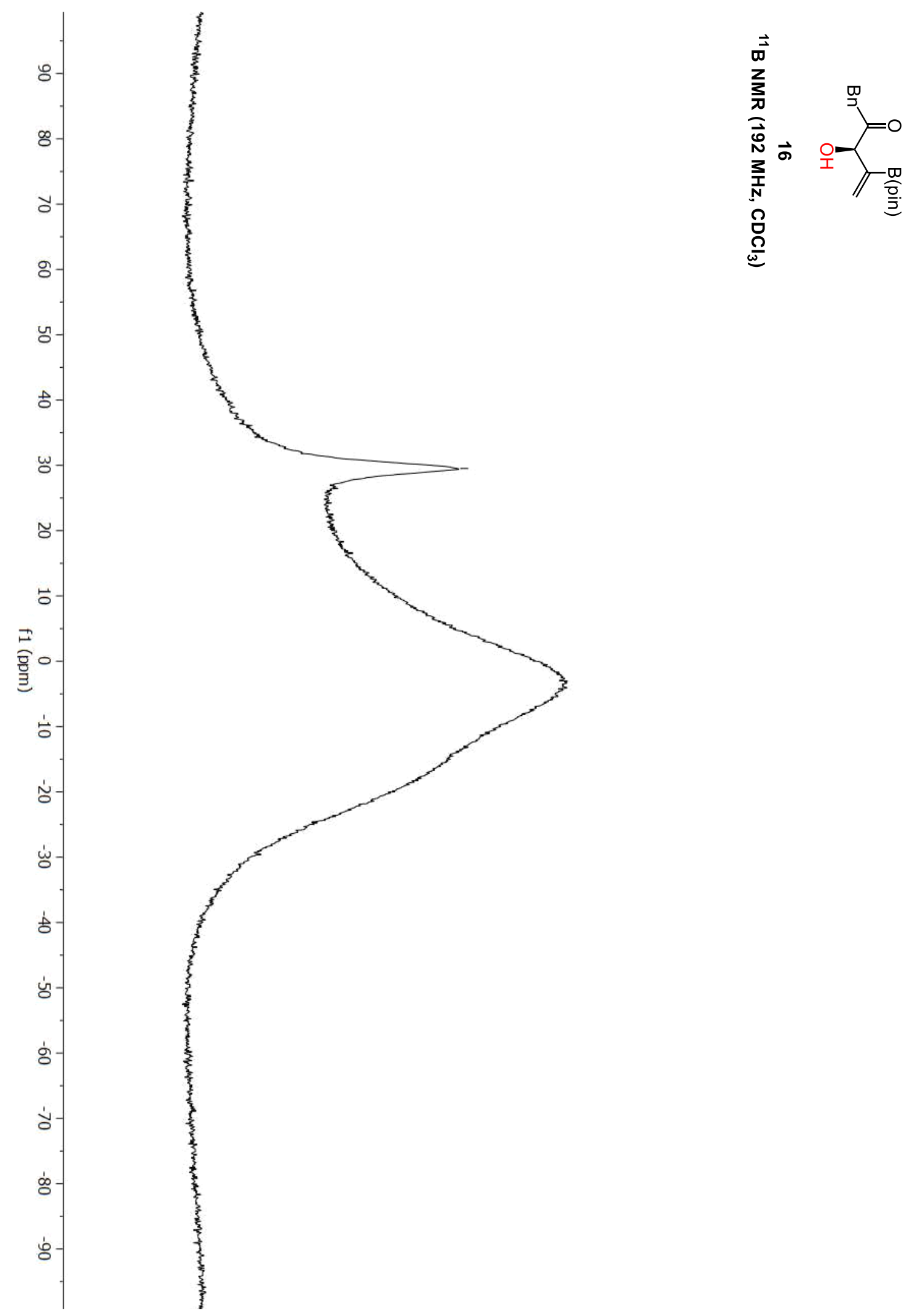


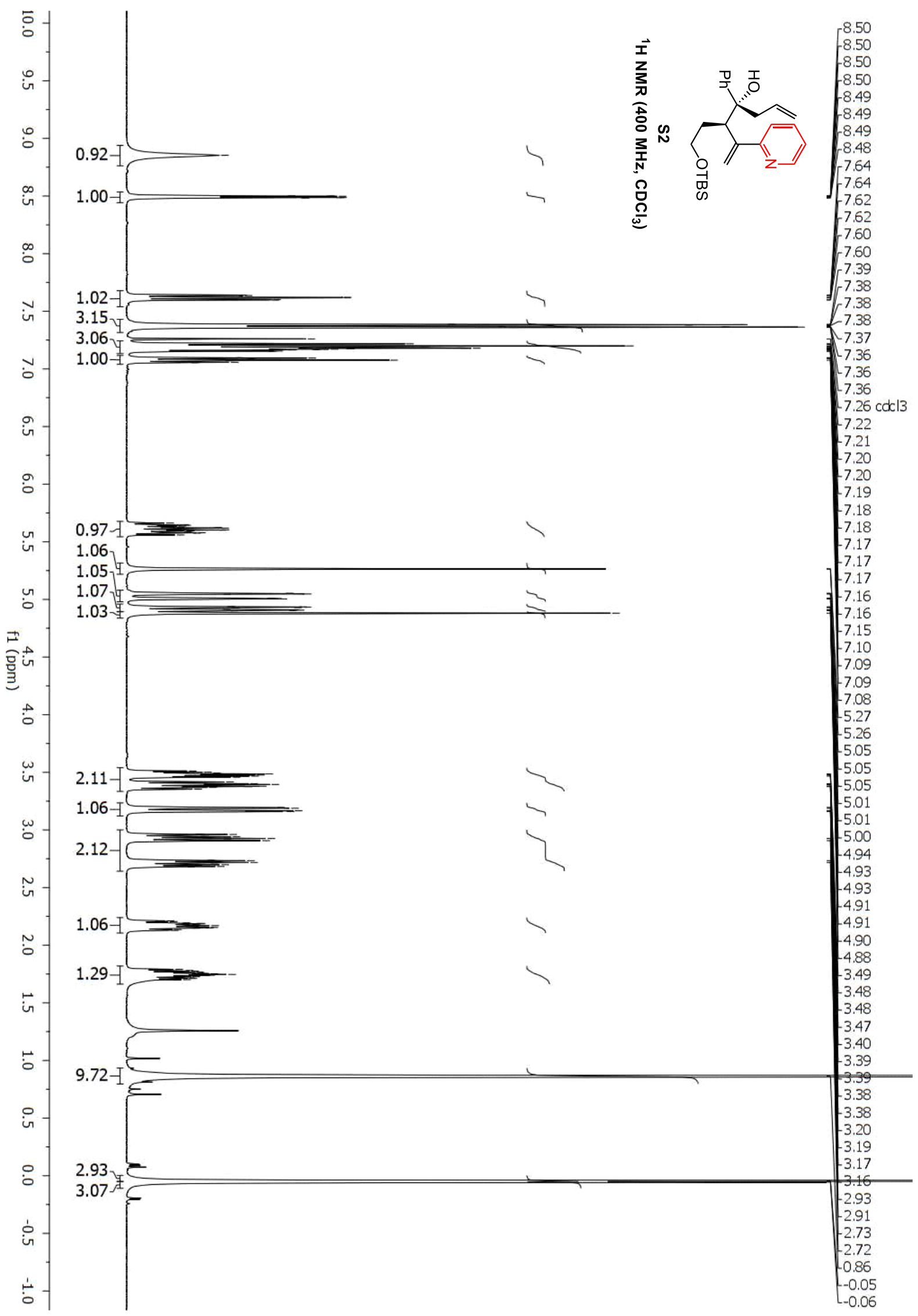




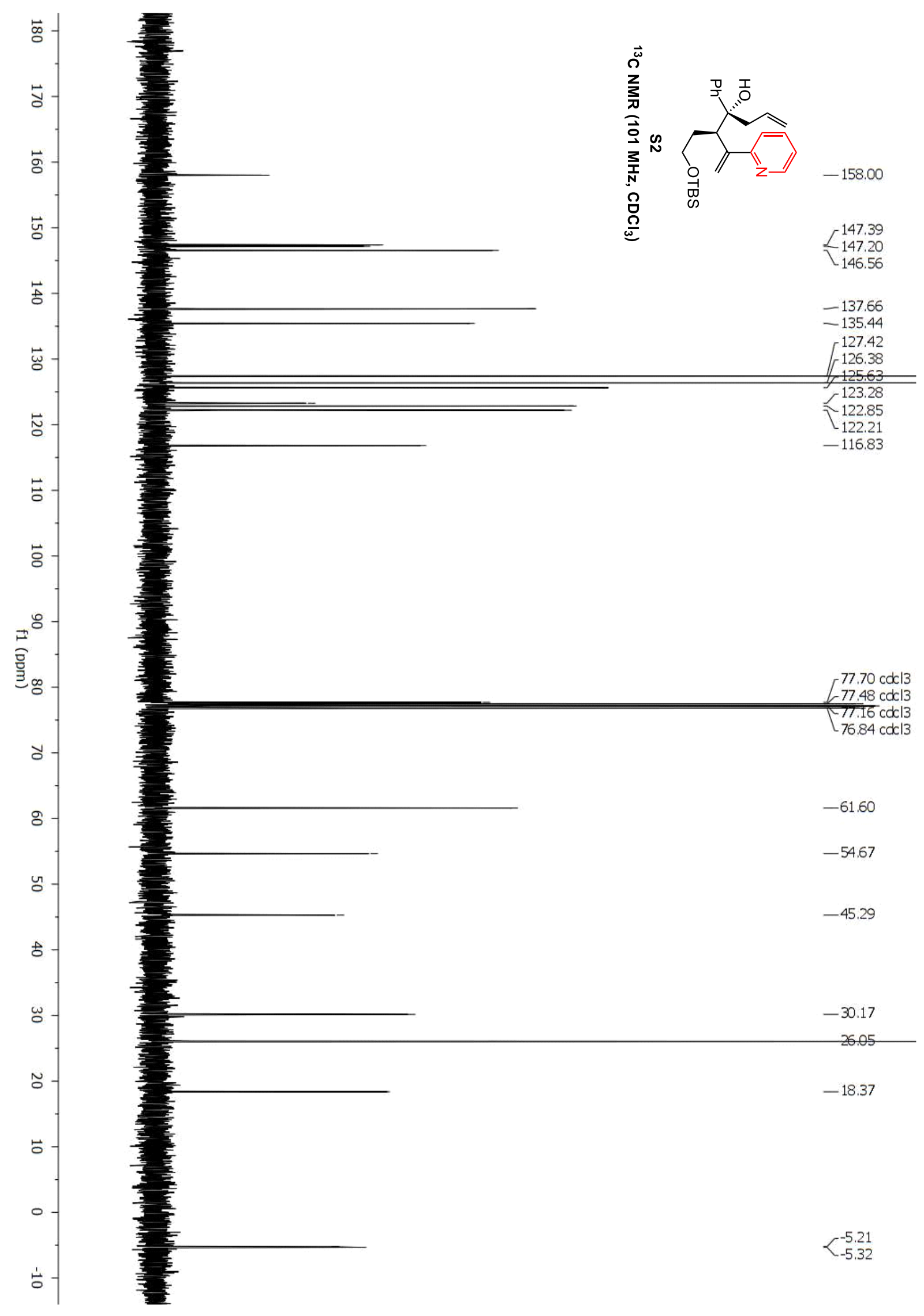




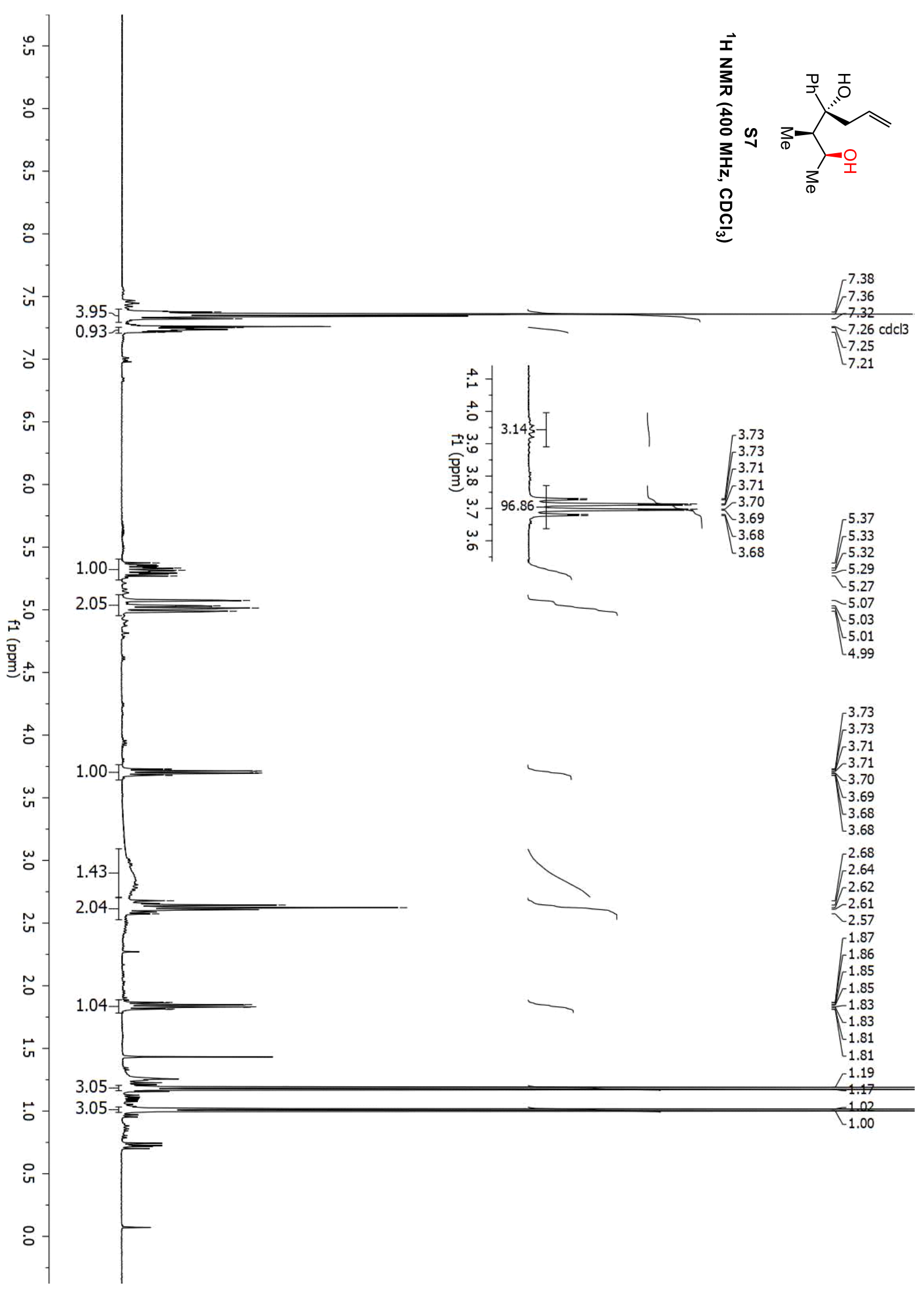




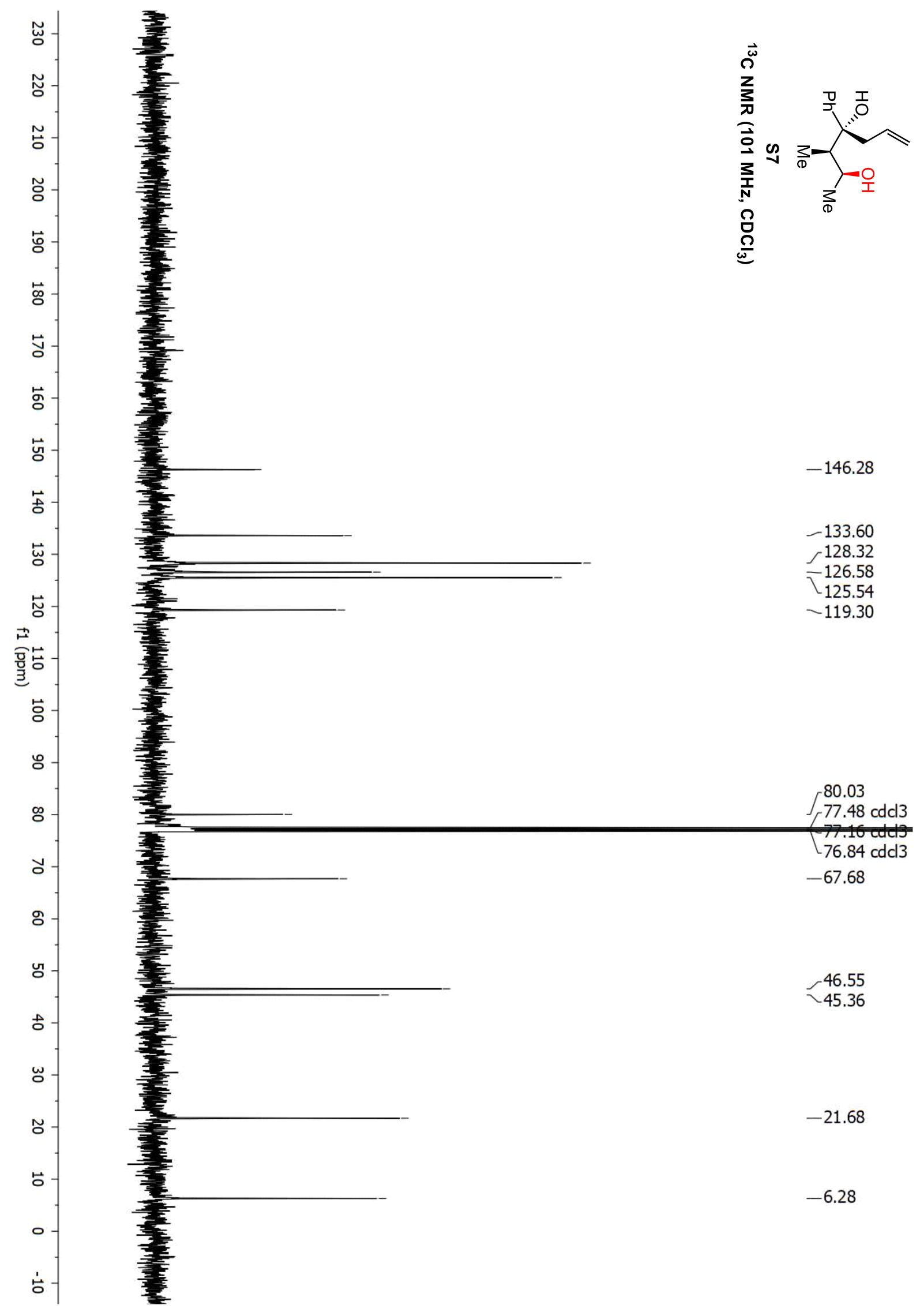




\subsection{Synthesis of the Bicyclic Fragments of (+)-Rubriflordilactone A and B}

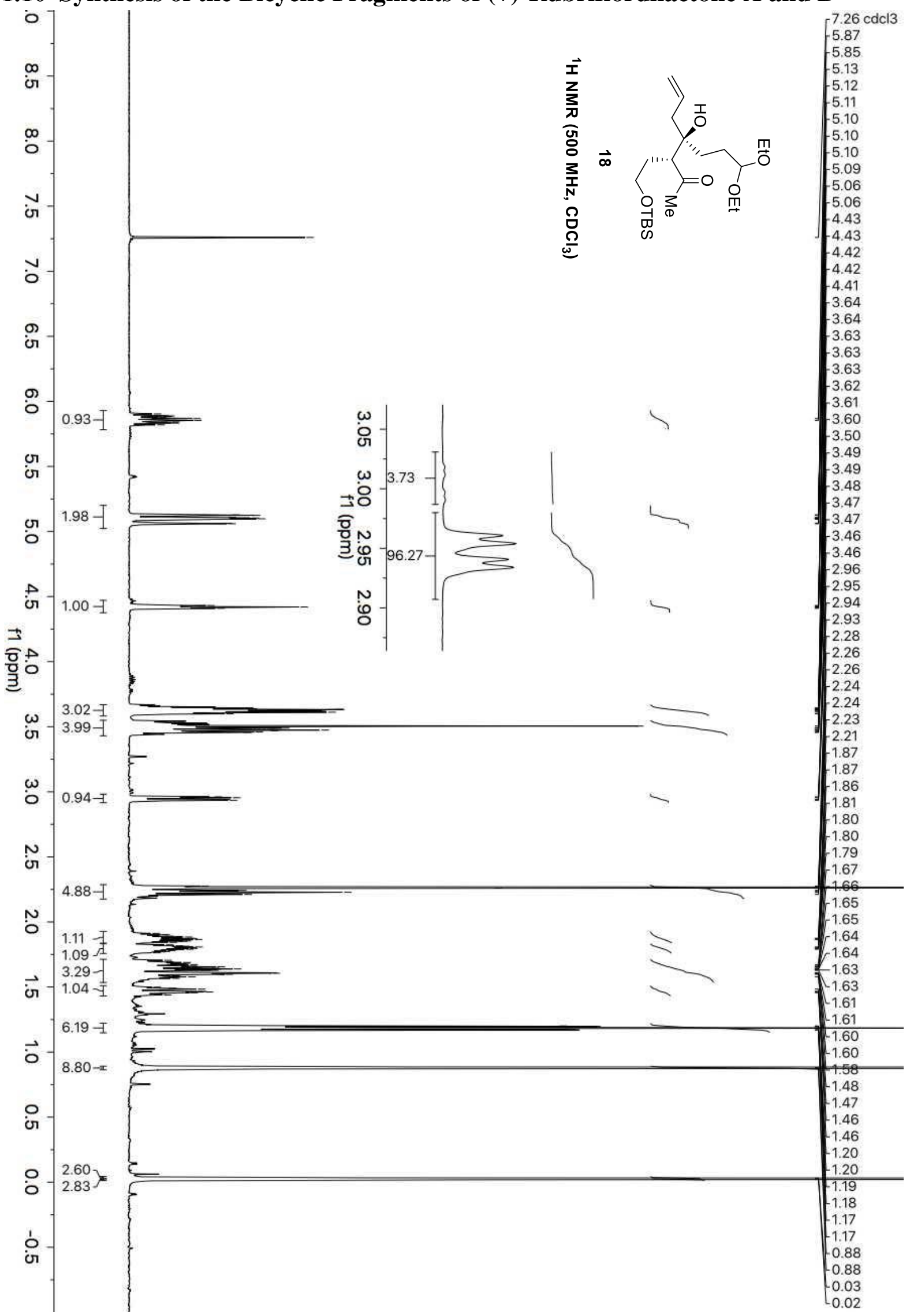




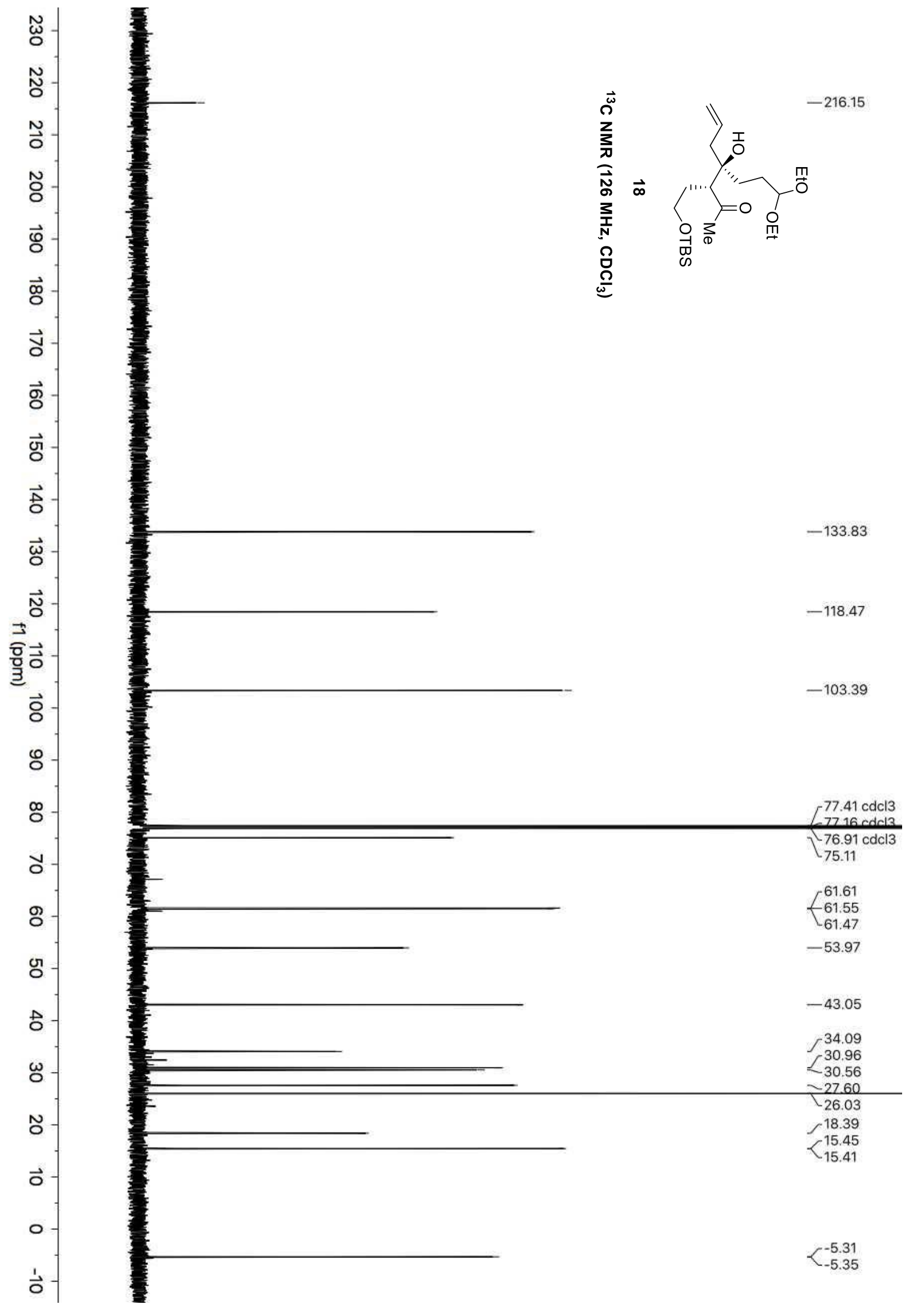




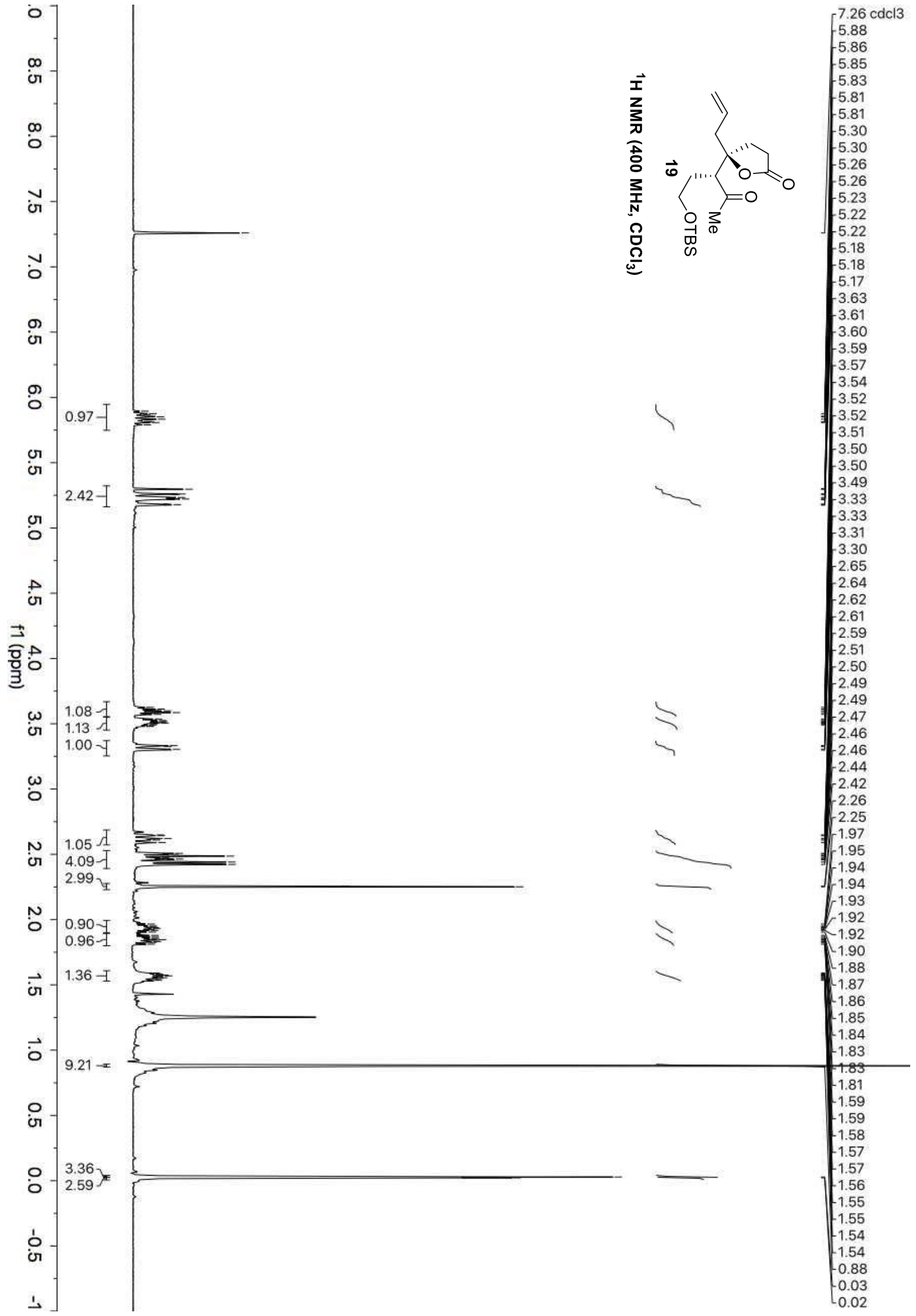




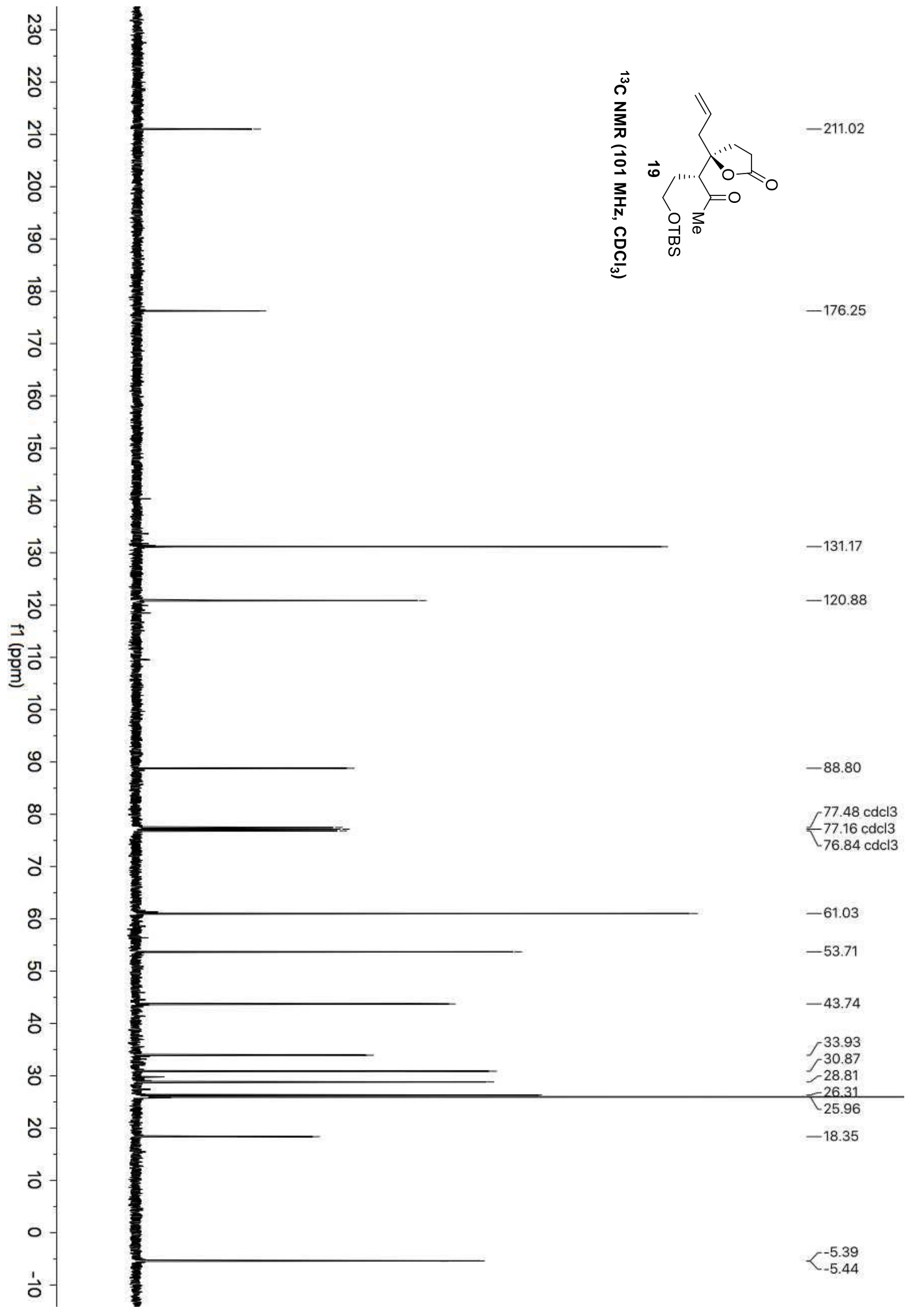




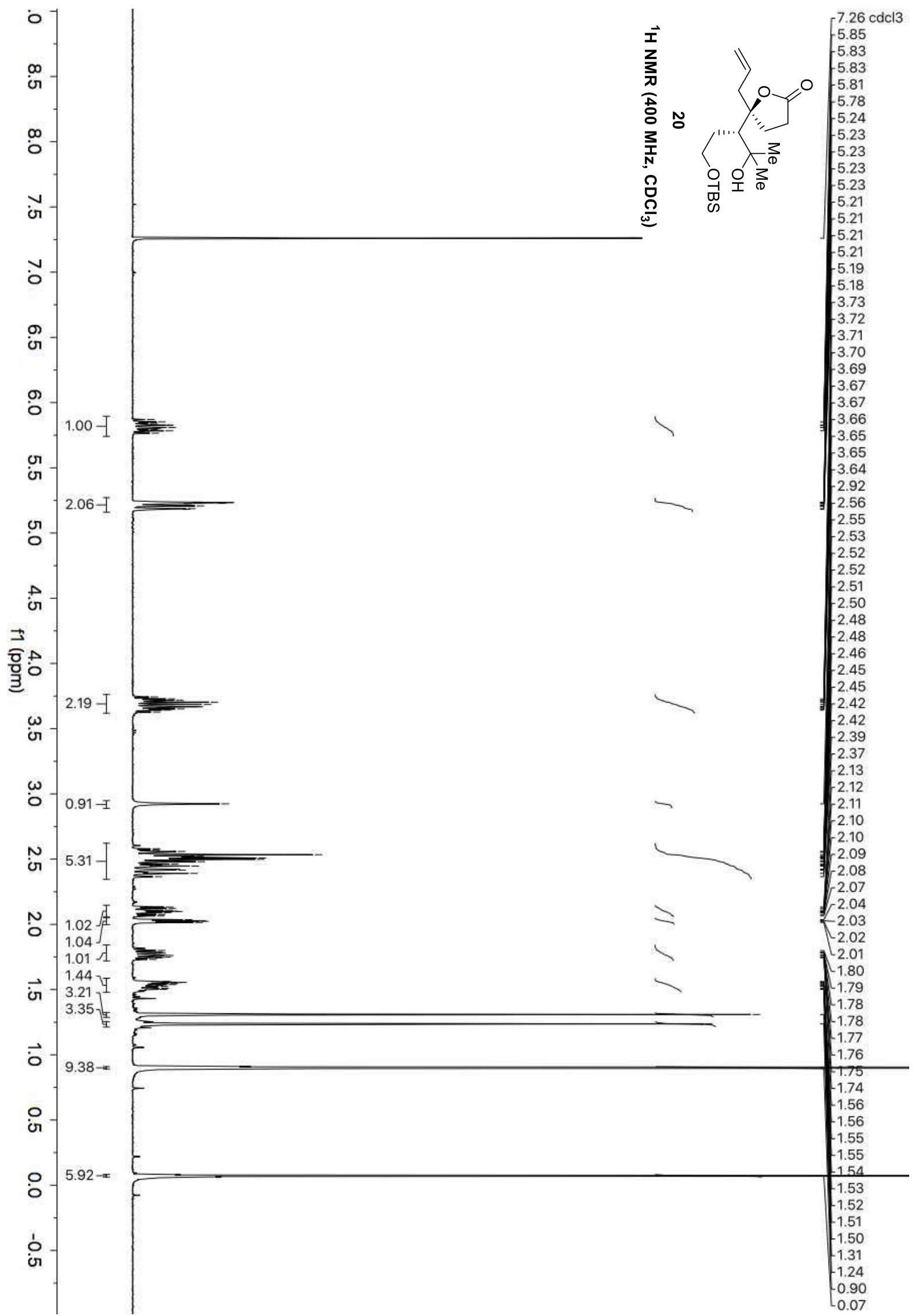




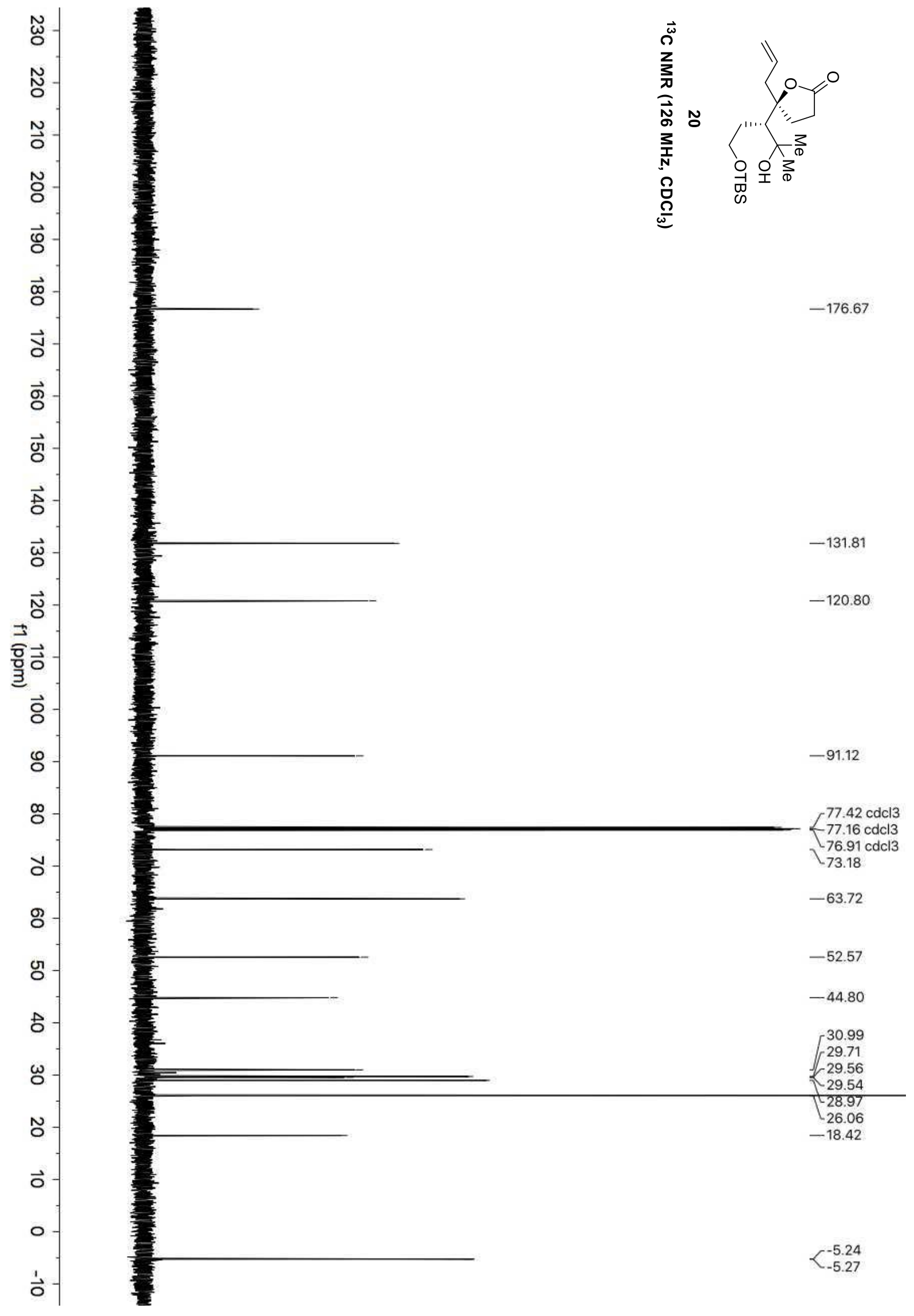




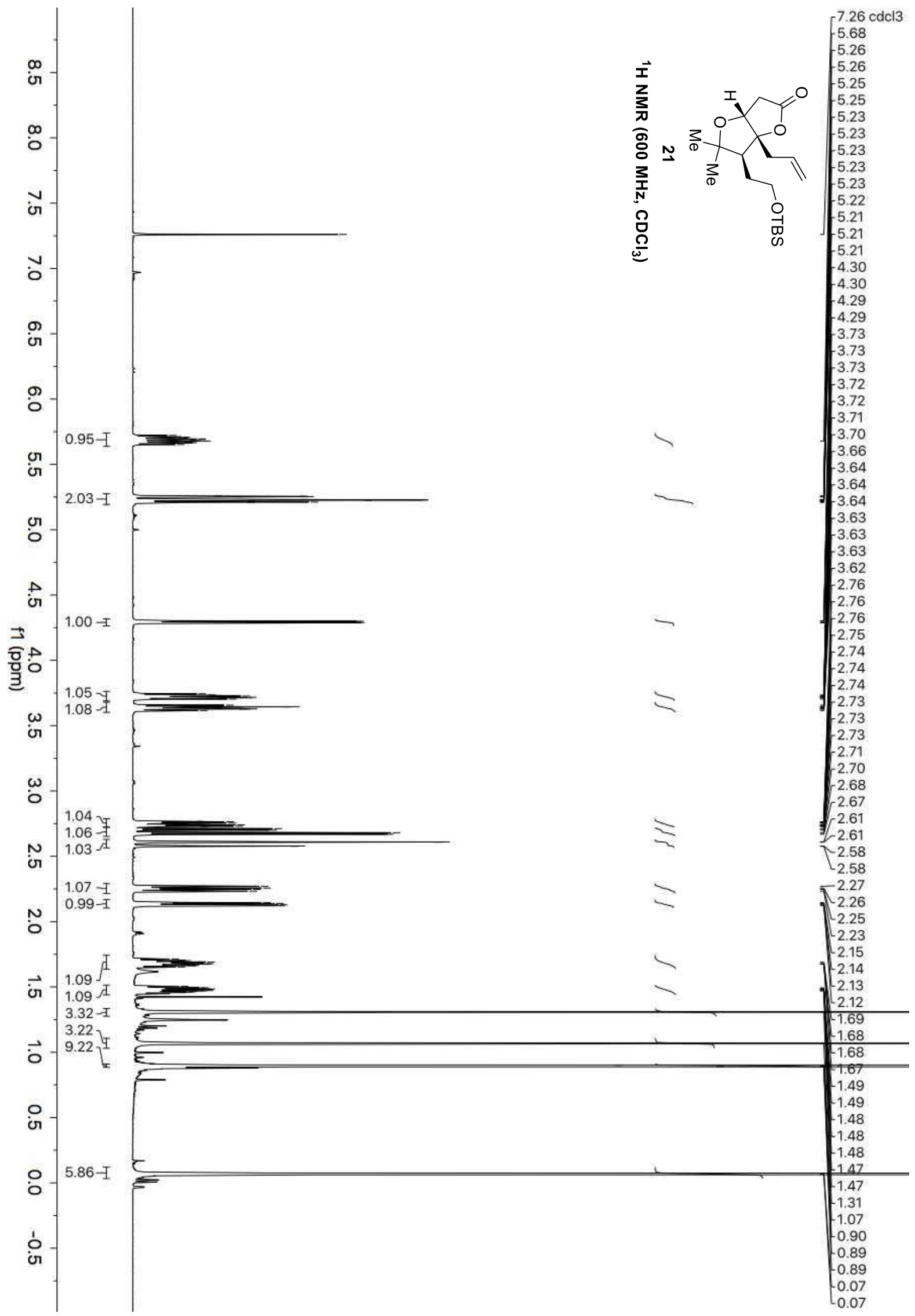




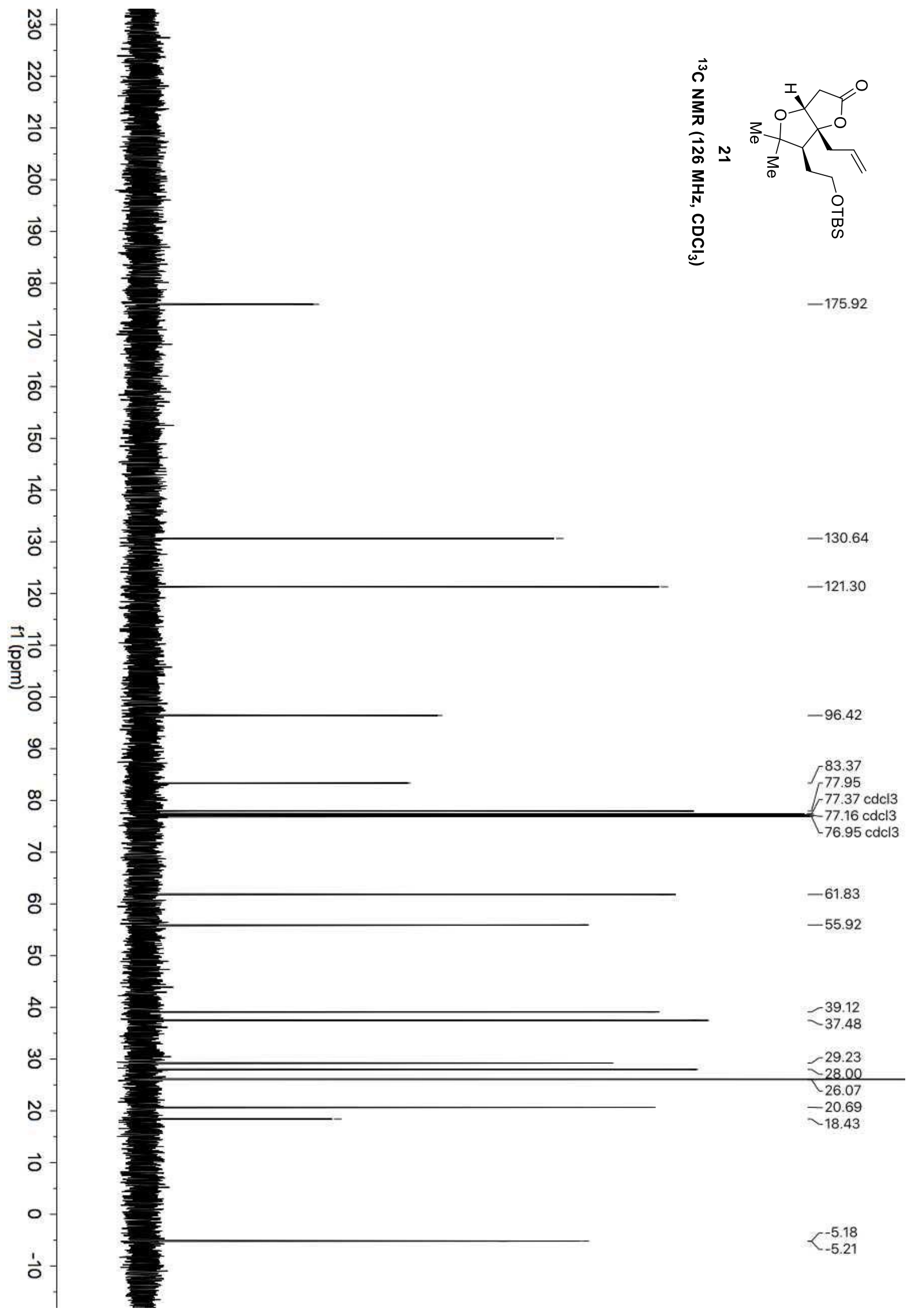




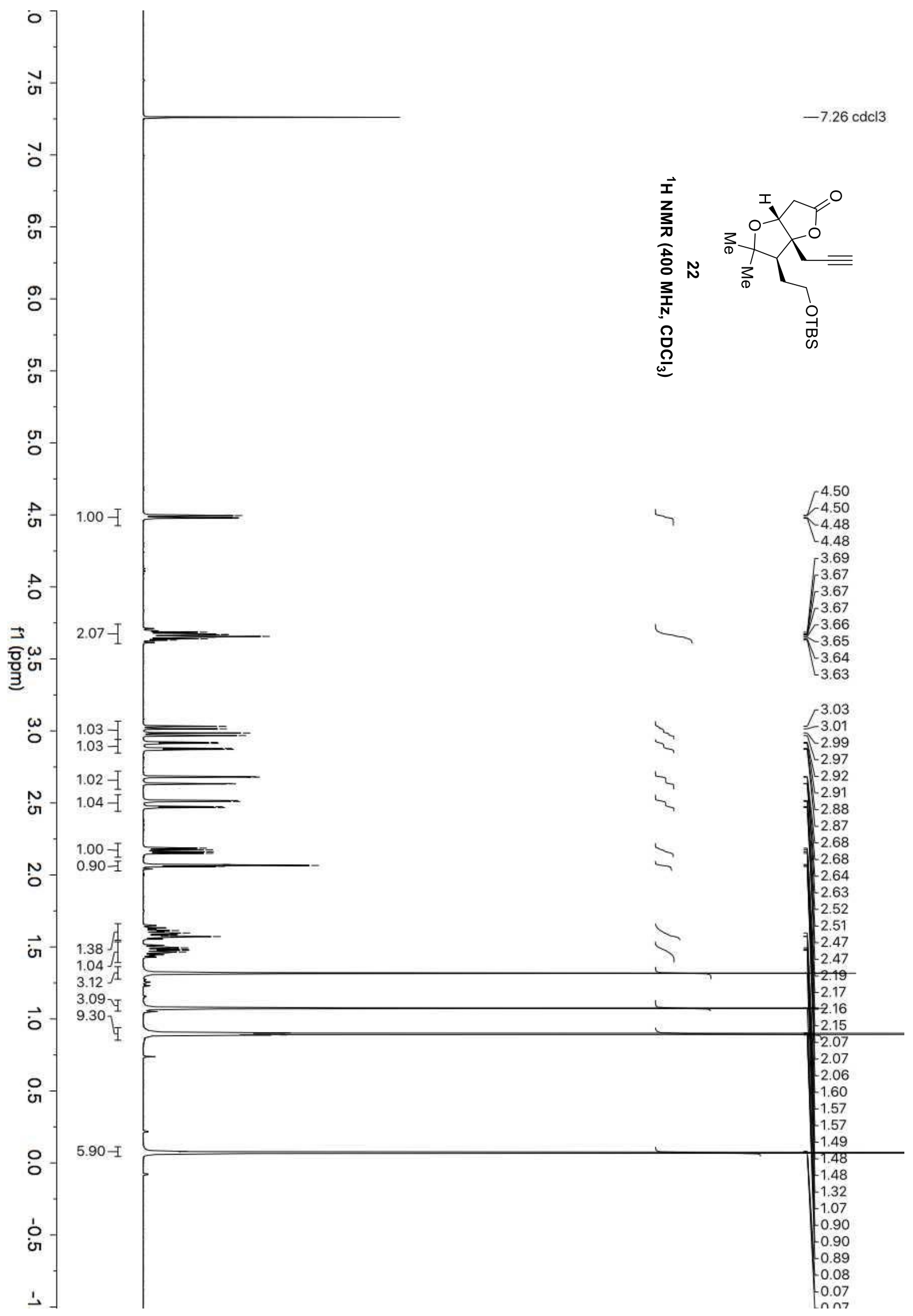




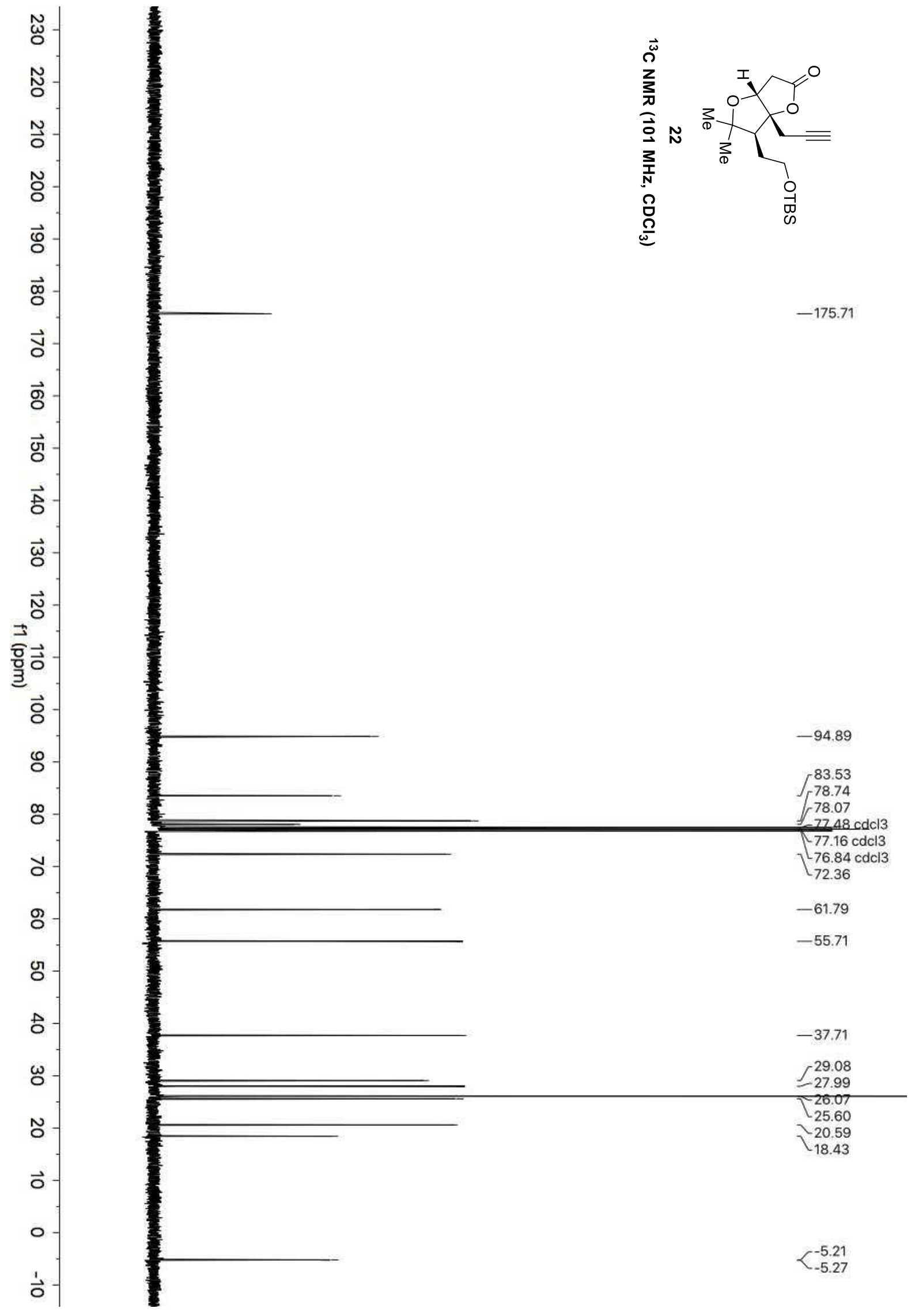




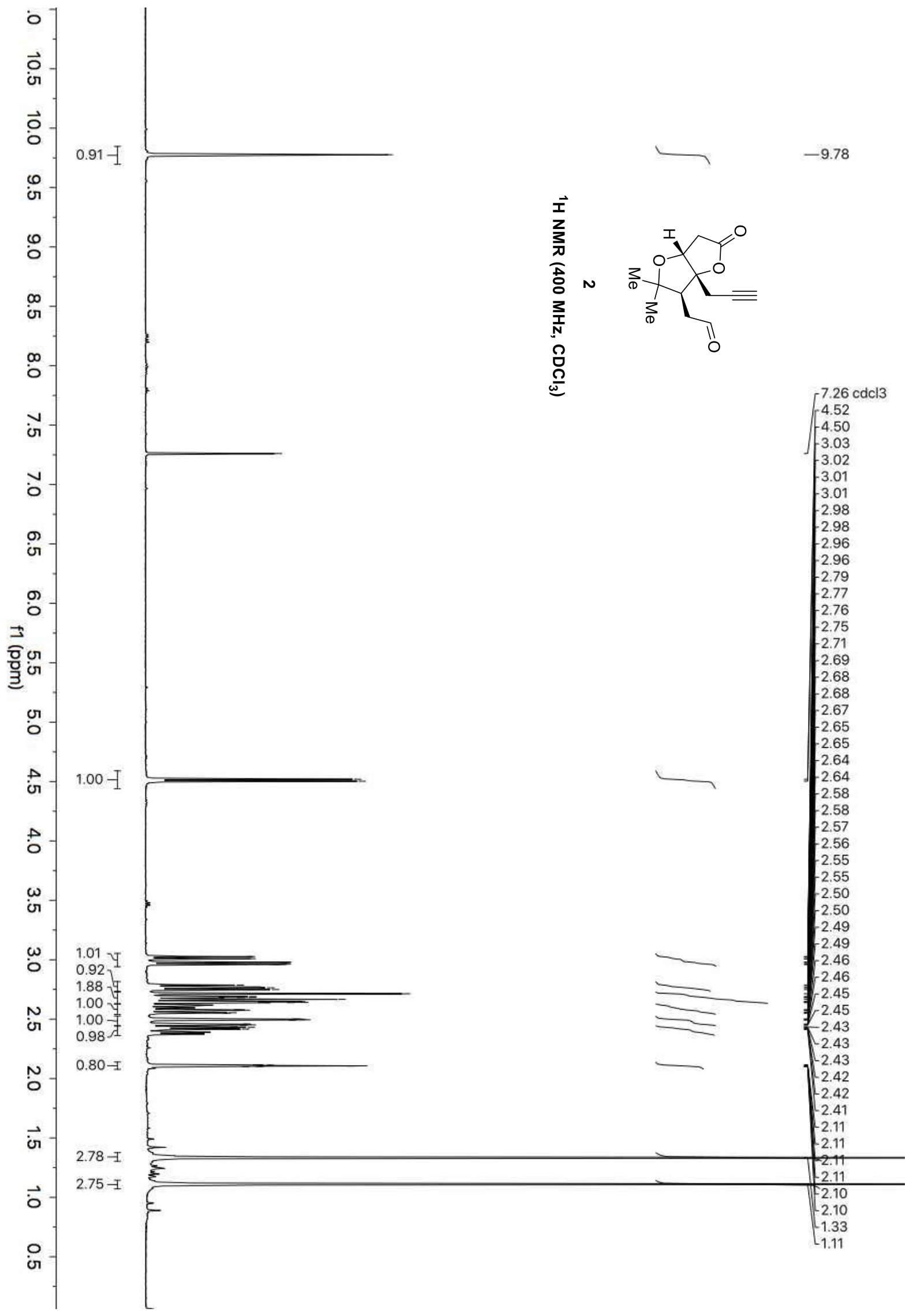




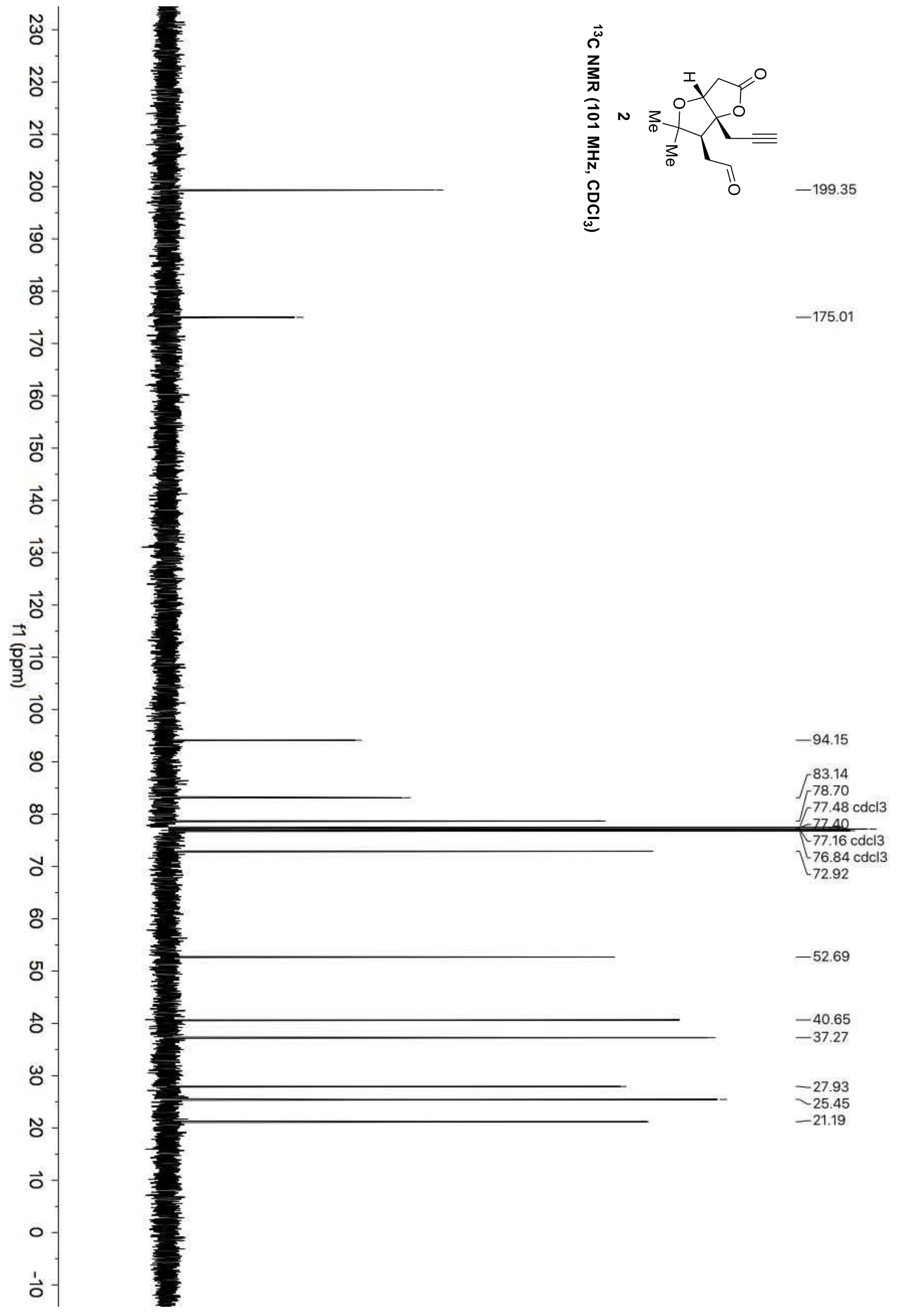




\subsection{Synthesis of bicyclic fragment of 5-epi-rubriflordilactone A and B}

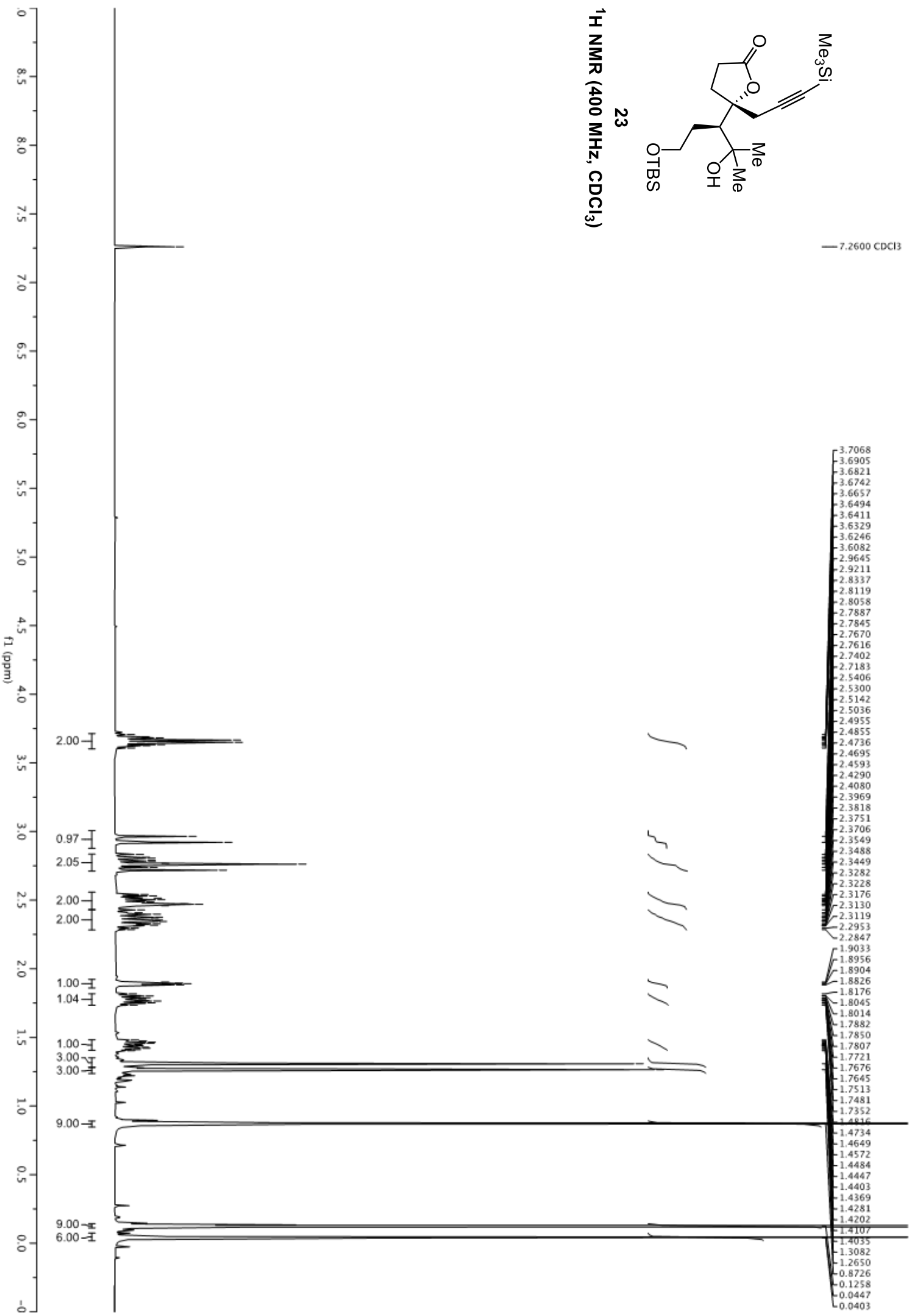




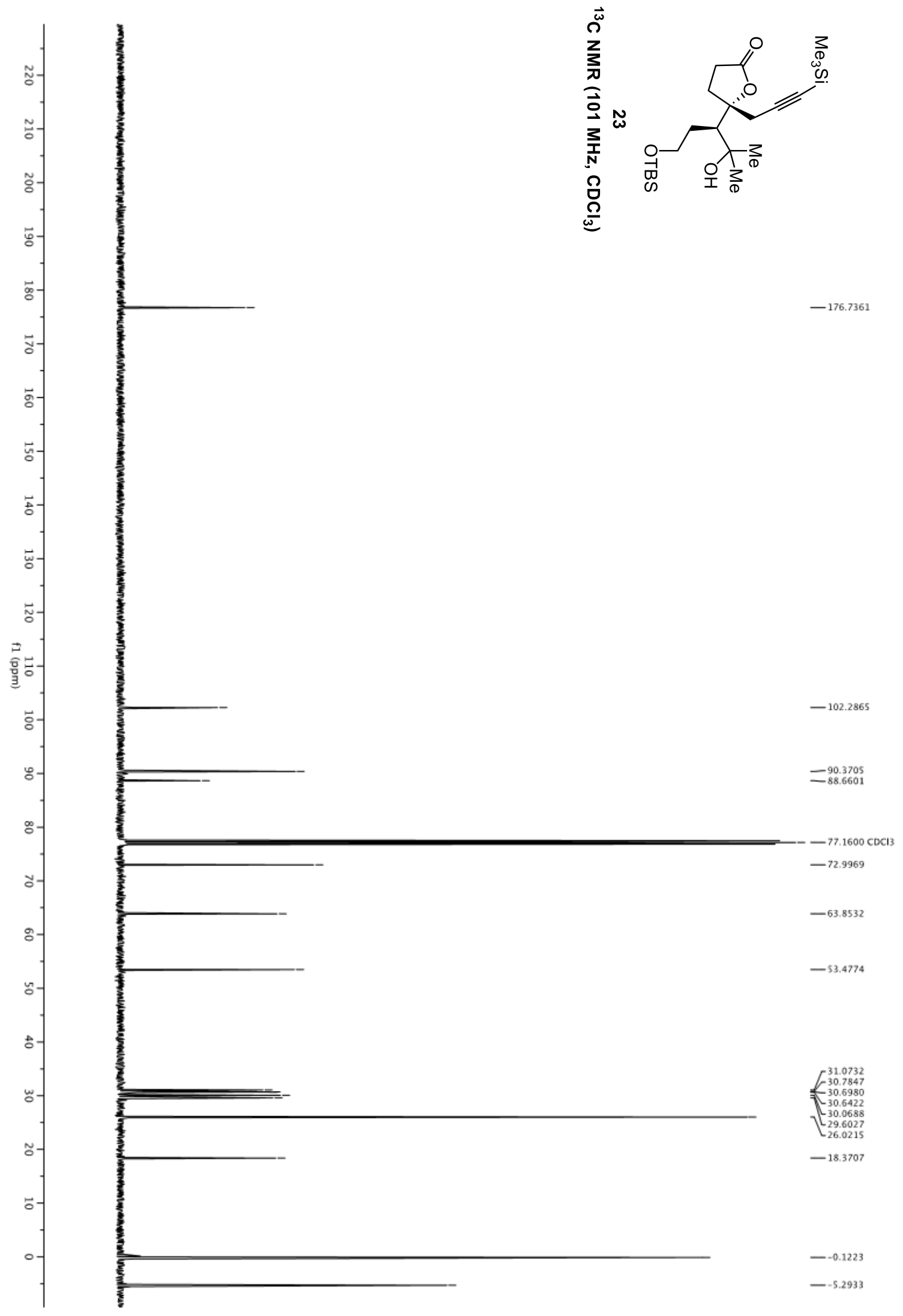




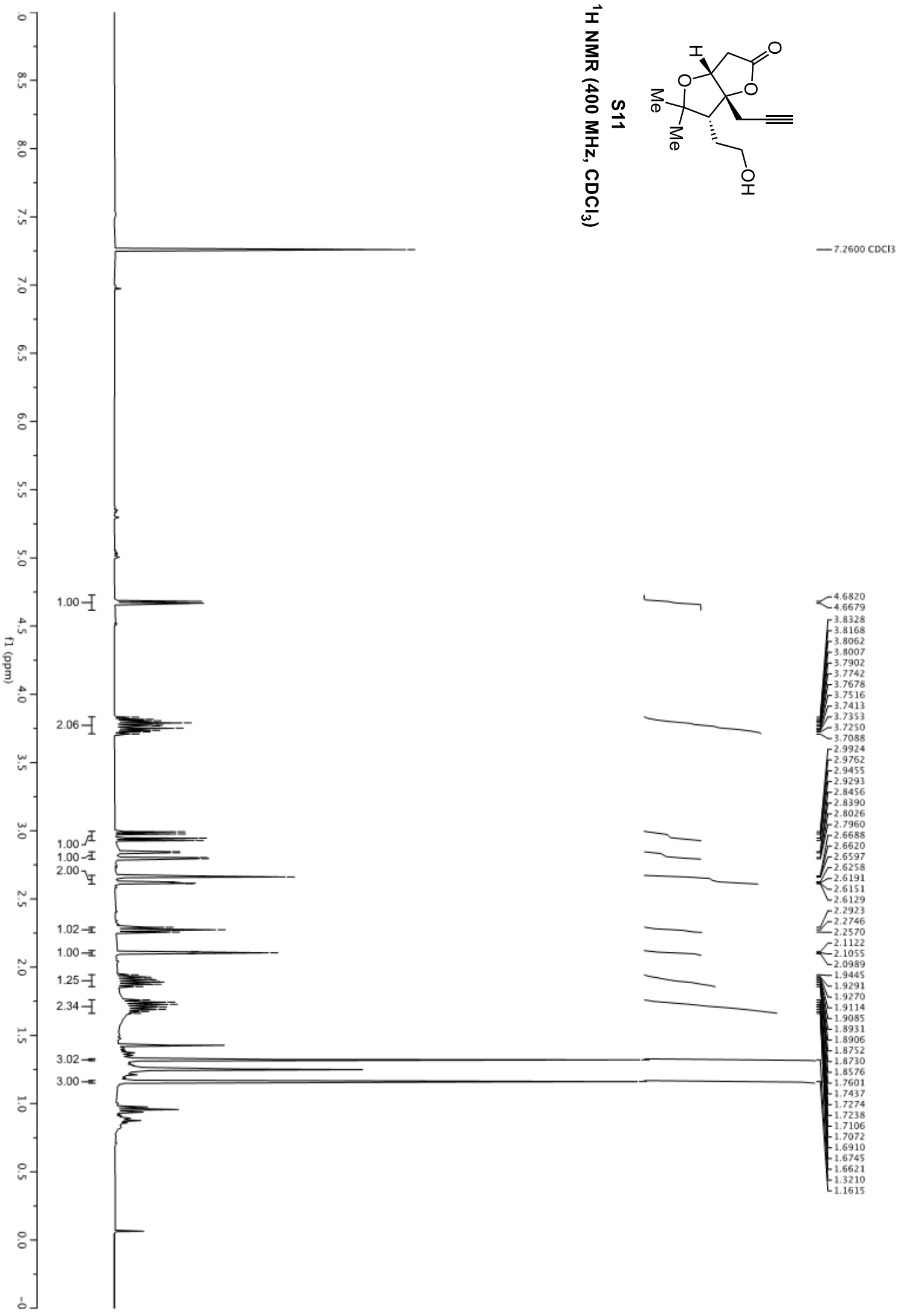




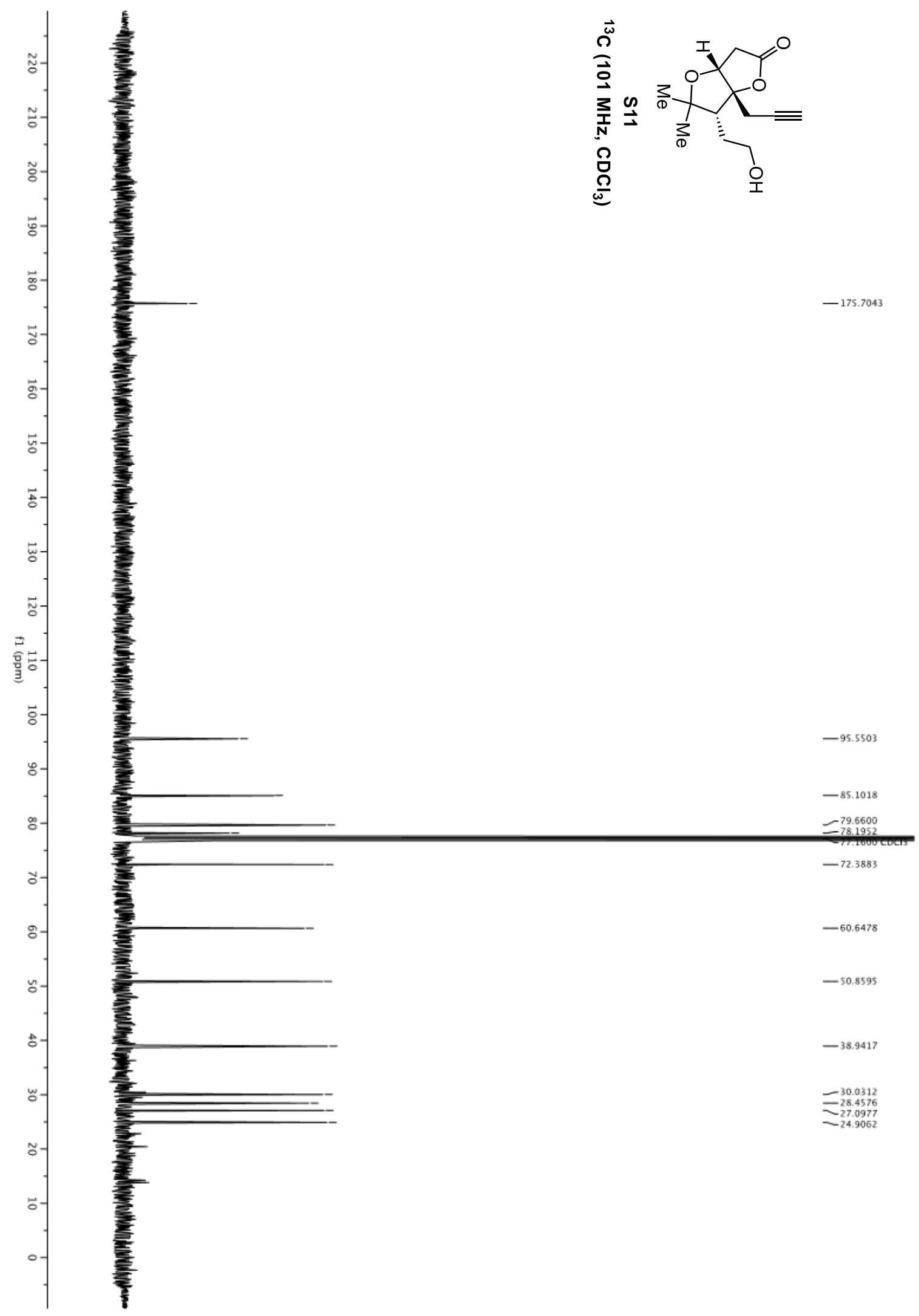




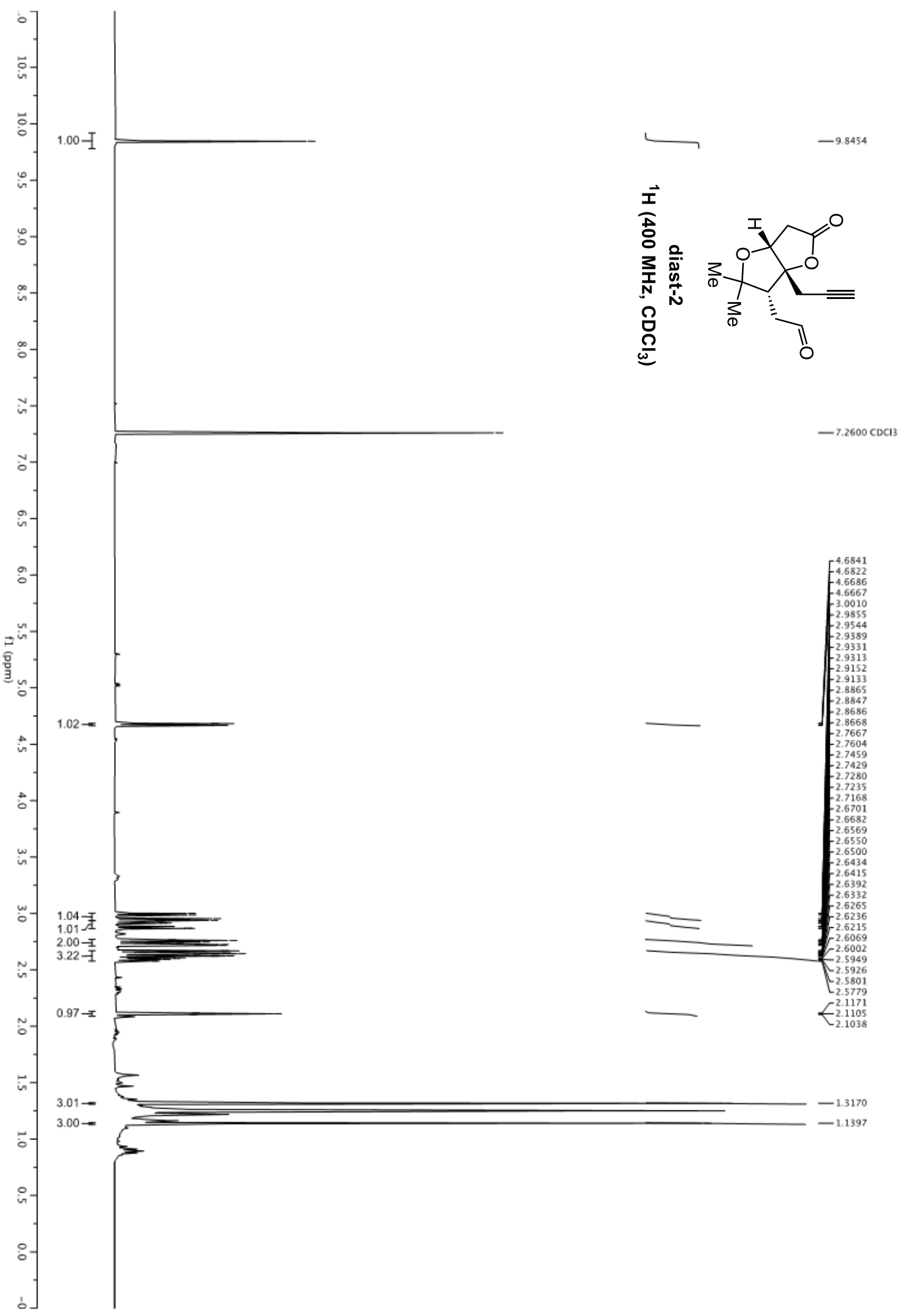


Del Pozo, et al., Supplementary Materials; Page 344

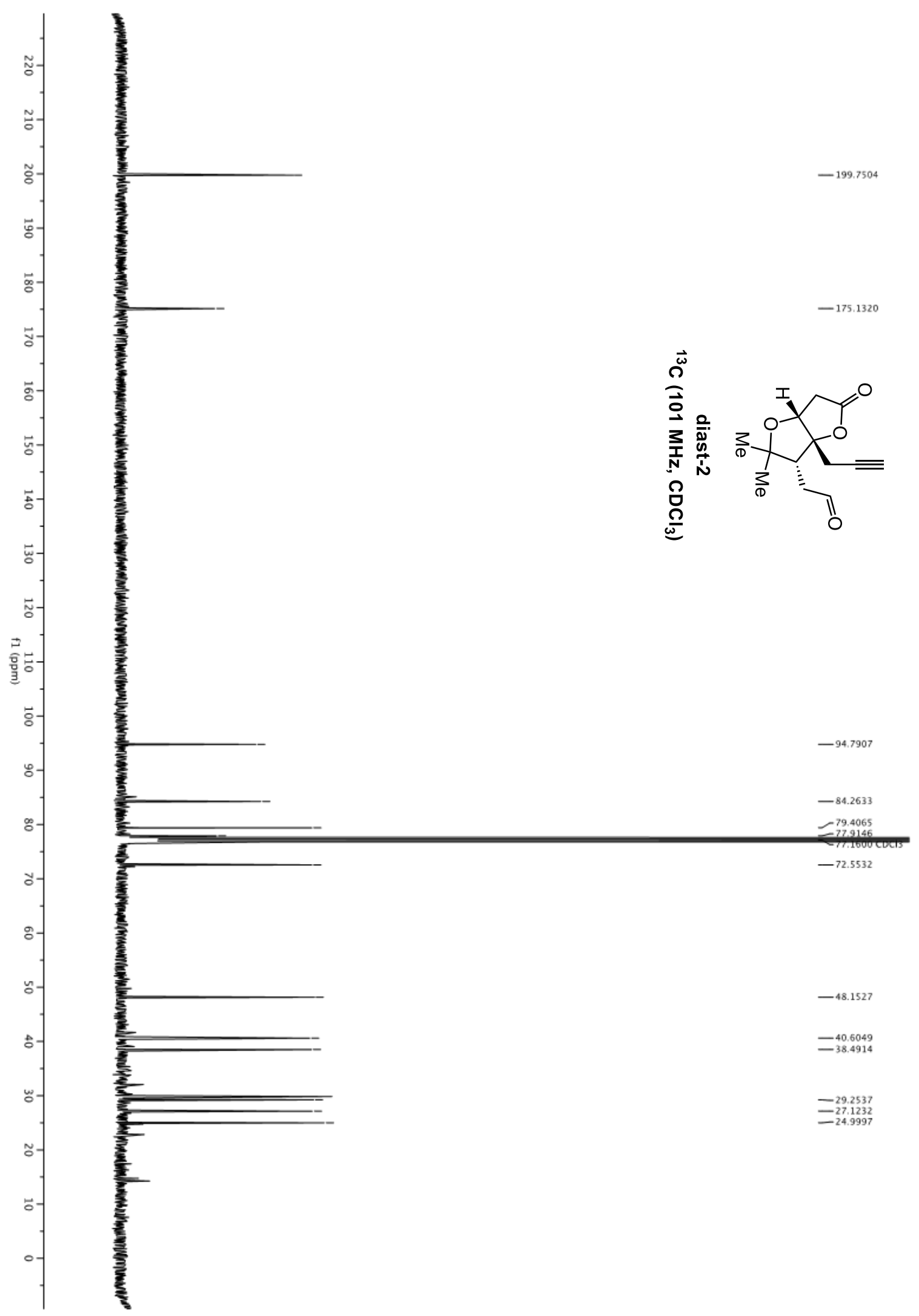




\subsection{Determination of the absolute and relative configuration of products}

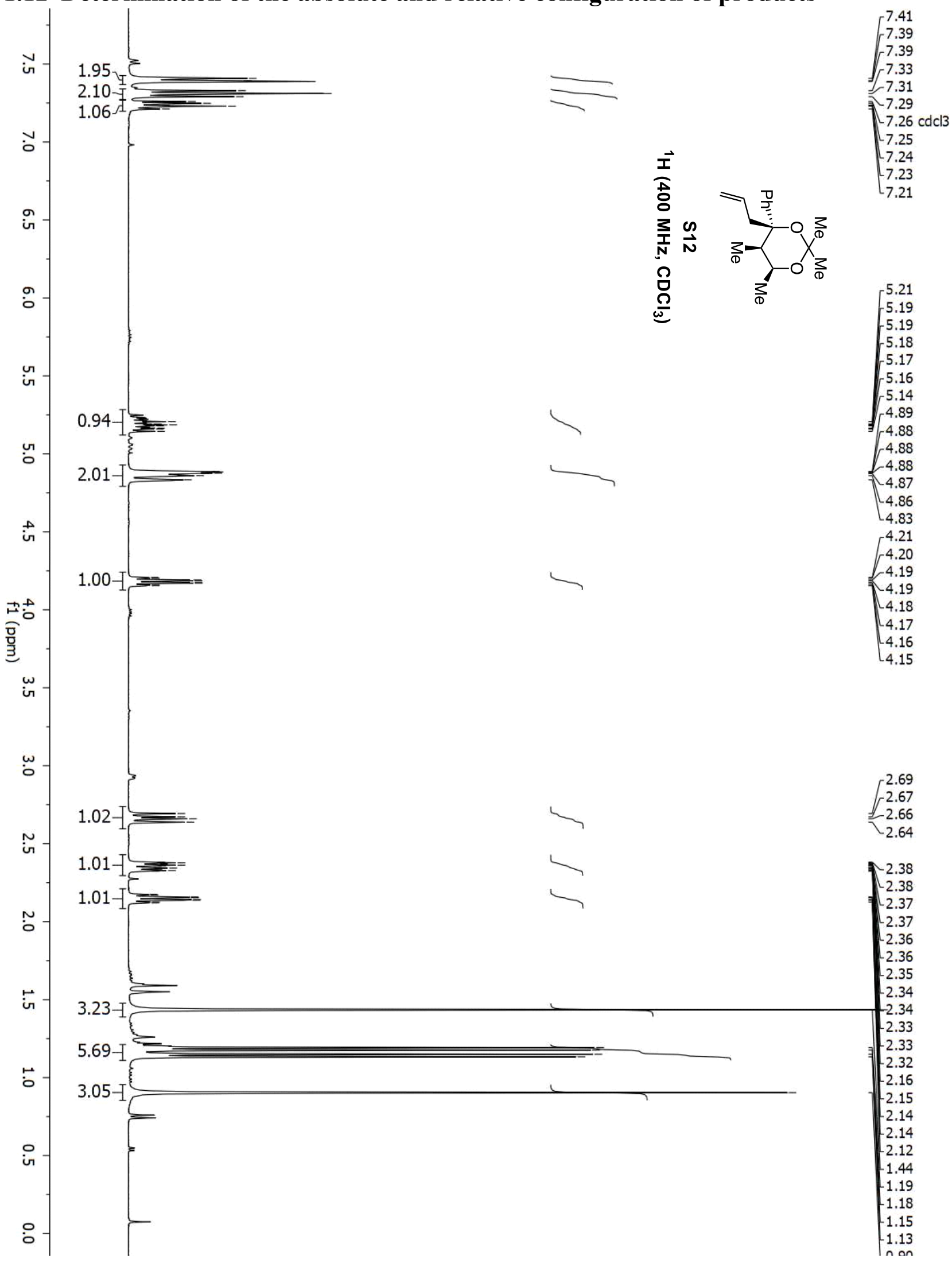




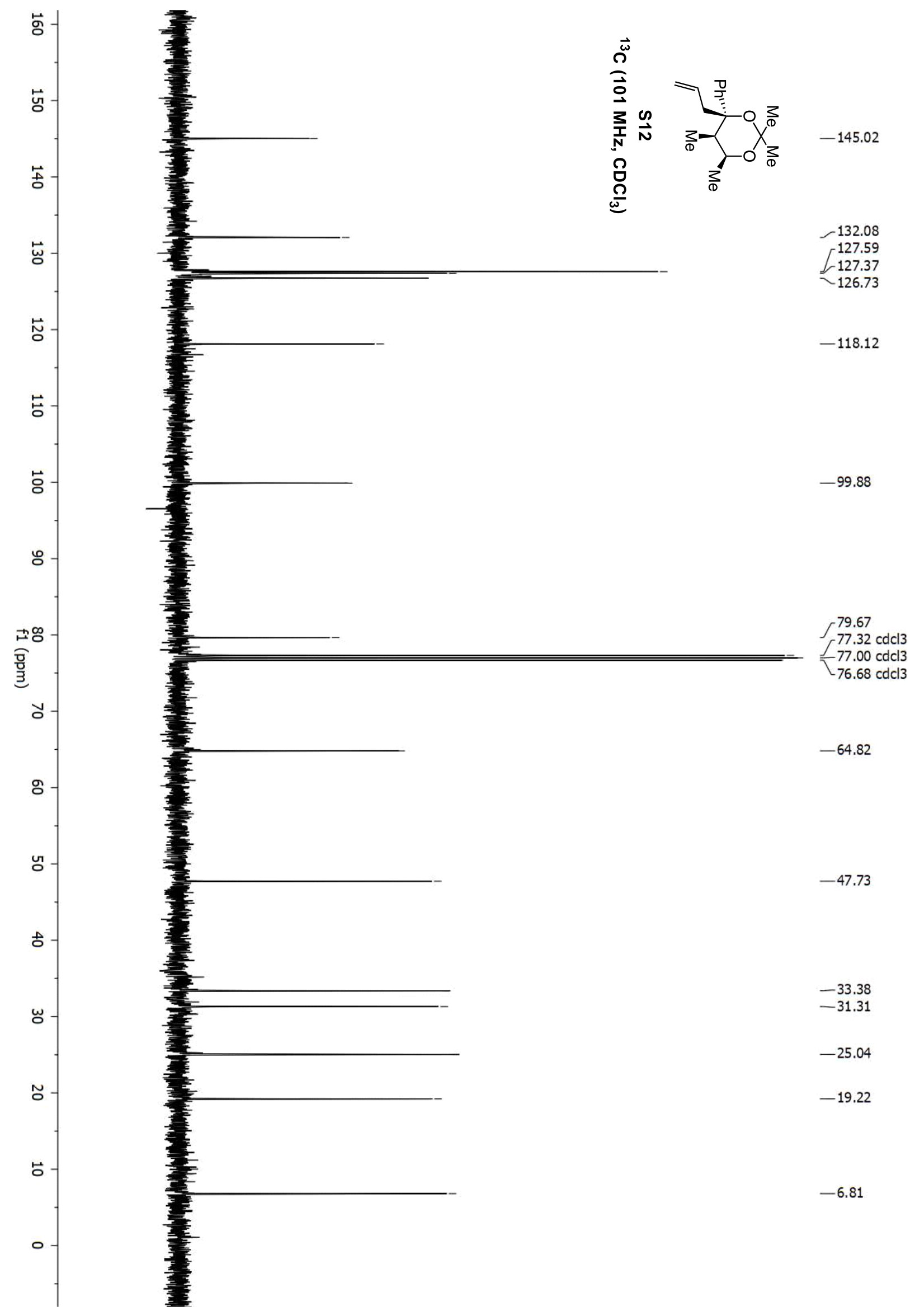

